\title{
SAFETY EVALUATION OF FREEWAY SPEED-CHANGE LANES BASED ON CRASHES AND SIMULATED CONFLICTS
}

\author{
By \\ Lei Qin \\ Master of Applied Science, Beijing Jiaotong University, Beijing, China, 2011 \\ Bachelor of Engineering, Southwest Jiaotong University, Chengdu, China, 2009
}

A thesis presented to Ryerson University

\author{
In partial fulfillment of the \\ requirements for the degree of \\ Master of Applied Science \\ in the Program of \\ Civil Engineering
}

Toronto, Ontario, Canada, 2016

(C) Lei Qin 2016 


\section{Author's Declaration}

I hereby declare that I am the sole author of this thesis. This is a true copy of the thesis, including any required final revisions, as accepted by my examiners.

I authorize Ryerson University to lend this thesis to other institutions or individuals for the purpose of scholarly research.

I further authorize Ryerson University to reproduce this thesis by photocopying or by other means, in total or in part, at the request of other institutions or individuals for the purpose of scholarly research.

I understand that my thesis may be made electronically available to the public. 


\title{
SAFETY EVALUATION OF FREEWAY SPEED-CHANGE LANES BASED ON CRASHES AND SIMULATED CONFLICTS
}

\author{
By \\ Lei Qin \\ Department of Civil Engineering \\ Ryerson University \\ Master of Applied Science, 2016
}

\begin{abstract}
To facilitate the evaluation of the safety performance of freeway merge, diverge, and weave areas, conventional crash-based Safety Performance Functions (SPFs) were developed using generalized linear models (GLM) with a negative binomial (NB) error structure. However, crash-based SPFs may not take into account all factors that contribute to the crashes. The use of simulated conflicts as a surrogate safety measure to predict crashes can address this issue and provide recommendations for the designs and traffic control strategies. This approach was explored by using Surrogate Safety Assessment Model (SSAM) and VISSIM software to generate and analyze conflicts for merge areas on Ontario freeways. Crash-conflict integrated SPFs with different Time to Collision (TTC) thresholds were then developed and compared. Their predictive capabilities were also evaluated. To complement this analysis, the transferability of US crash prediction models to Ontario data was evaluated and the goodness-of-fit of these models was explored.
\end{abstract}




\section{Acknowledgements}

I would like to thank my family and friends for all of their continued support.

I would like to thank my supervisor Dr. Bhagwant Persaud for all the financial and educational support throughout my study.

I would like to thank Mr. Craig Lyon, a consultant on the project on which this thesis is based, for his help throughout the research.

I would like to thank my colleagues Taha Saleem and Shahram Almasizadeh for assisting with the data and other help.

I would like to thank the Ministry of Transportation, Ontario, specifically Mr. Michael Pardo of the Traffic Office, for providing the data.

I would like to thank Dr. Yoassry Elzohairy and Dr. Arnold Yuan for their valuable comments and input as committee members.

The research was supported by grants from the Natural Sciences and Engineering Research Council of Canada and the Ministry of Transportation, Ontario. 


\section{Table of Contents}

Author's Declaration ................................................................................................................................... ii

Abstract.......................................................................................................................................................iii

Acknowledge ments ................................................................................................................................... iv

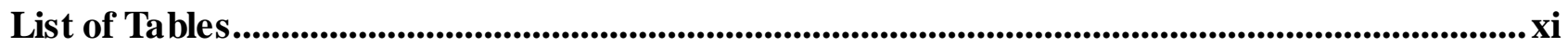

List of Figures............................................................................................................................................... xiv

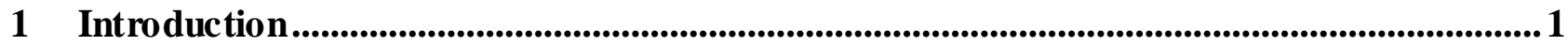

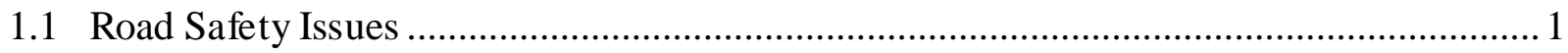

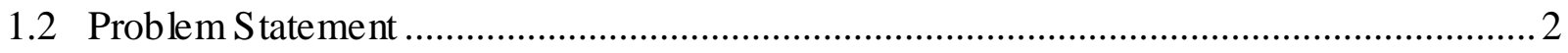

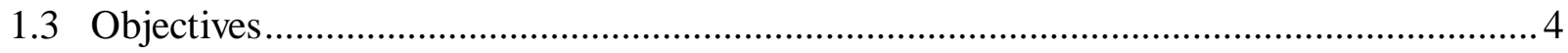

1.4 Organization of Thes is ............................................................................................... 4

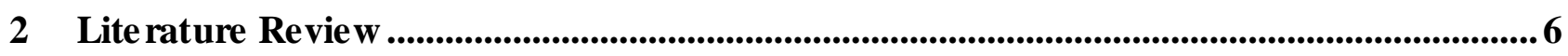

2.1 Crash Prediction Models ........................................................................................... 6

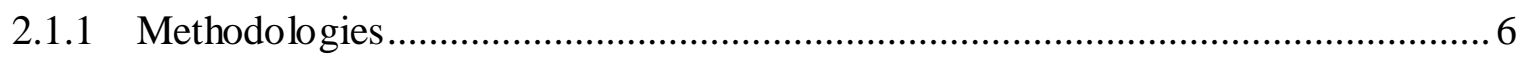

2.1.2 Goodness of Prediction Measures......................................................................... 7

2.1.3 Crash Prediction Models for Freeway Entrance and Exit Ramps............................. 9

2.2 Surrogate Safety Measures.......................................................................................... 11

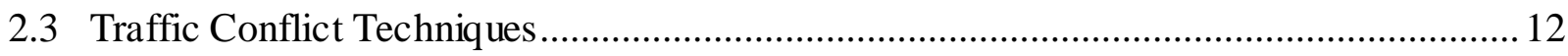

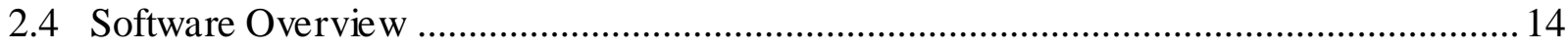

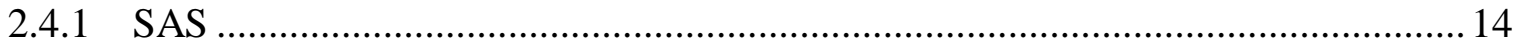

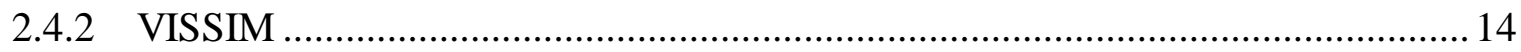

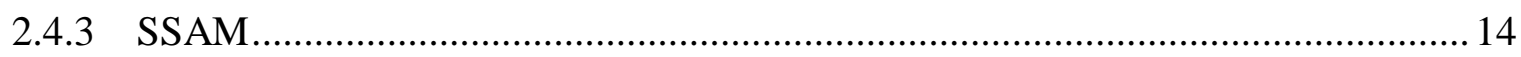

3 Determination of Influence Areas for Analys is ............................................................................ 16

3.1 Definition of Speed-Change Lanes ................................................................................. 16

3.2 Merge and Diverge Influence Areas ………………...................................................... 17 


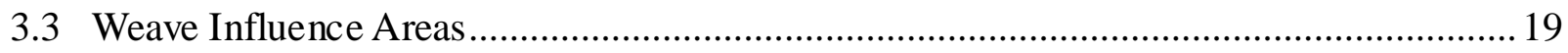

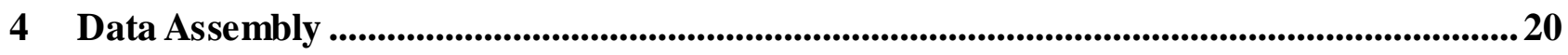

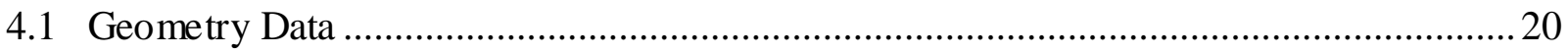

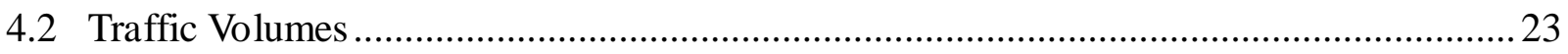

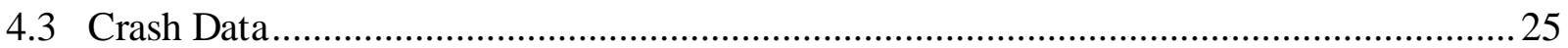

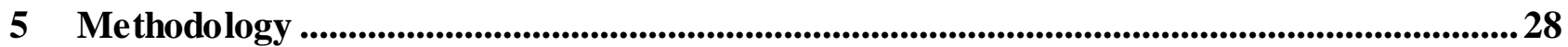

5.1 Develop Crash-based Safety Performance Functions for Speed-Change Lanes ............... 28

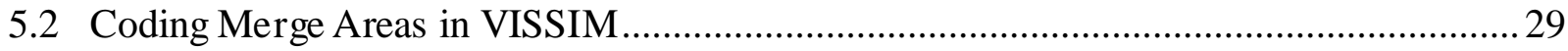

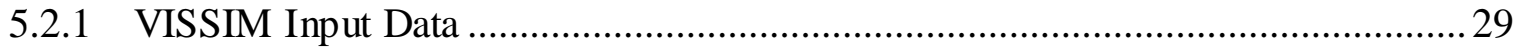

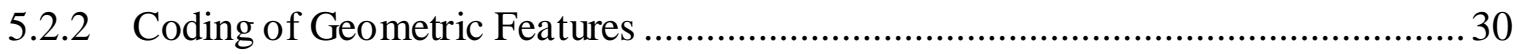

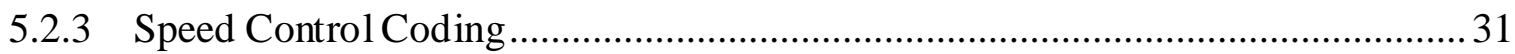

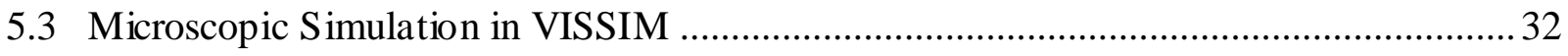

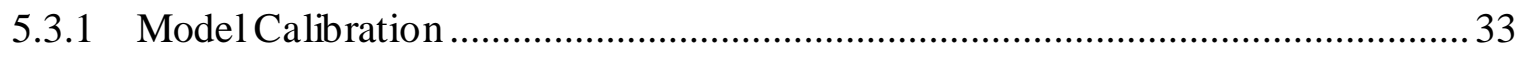

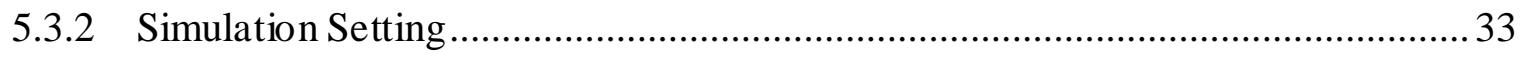

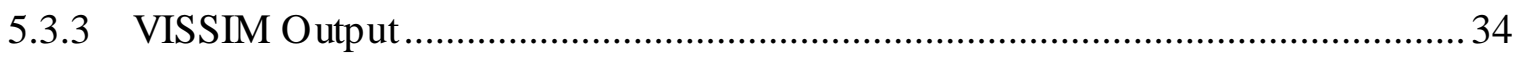

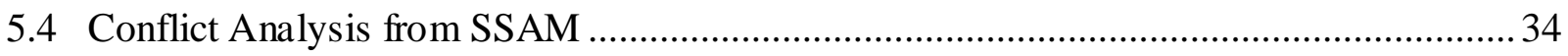

5.5 Development of Conflict-based Safety Performance Functions for Merge Areas............ 36

5.6 Development of Crash-Conflict Integrated Safety Performance Functions for Merge



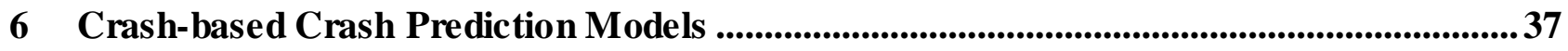

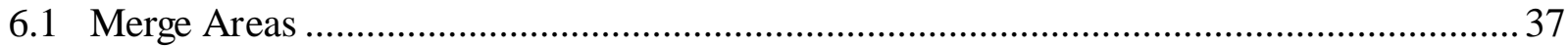

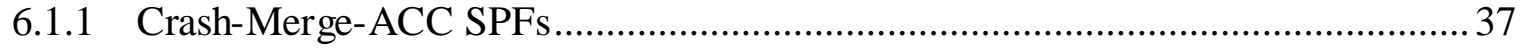

6.1.2 Crash-Merge-1,500 ft. SPFs ................................................................. 40

6.1.3 Model Comparison.............................................................................. 44

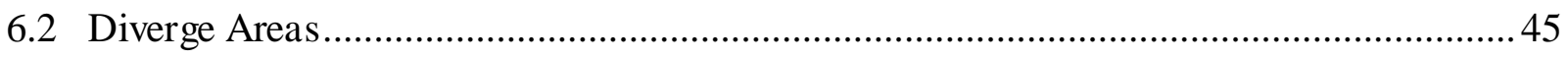

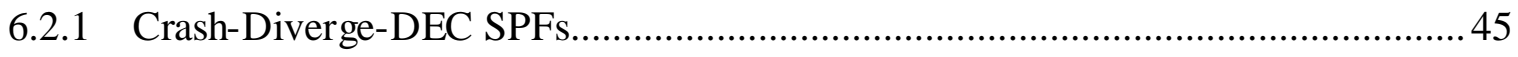




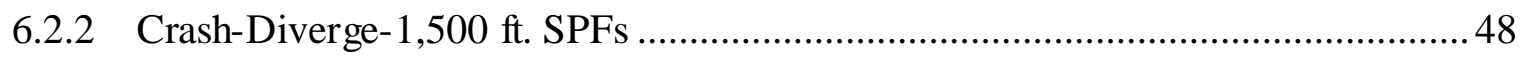

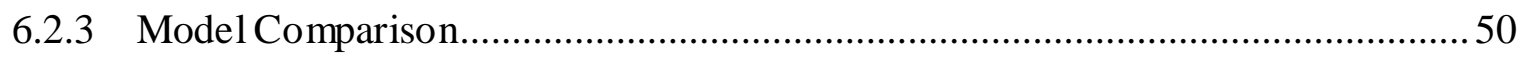

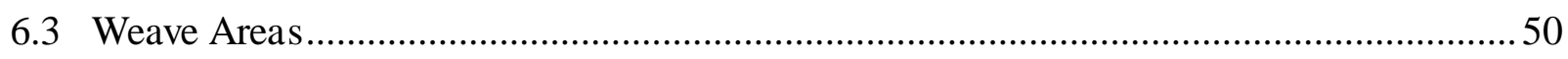

7 Conflict Prediction Models.............................................................................................................5

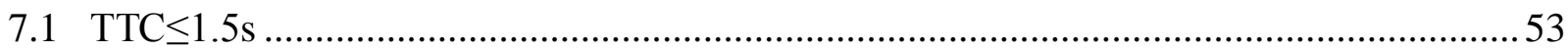



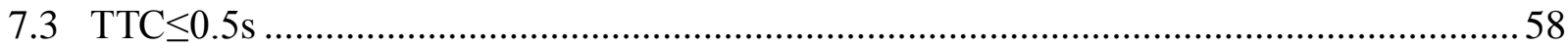

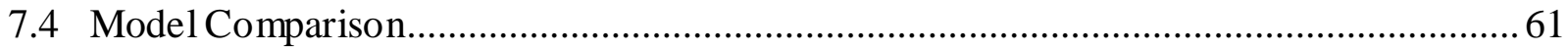

8 Crash-Conflict Integrated Crash Prediction Models ..............................................................62

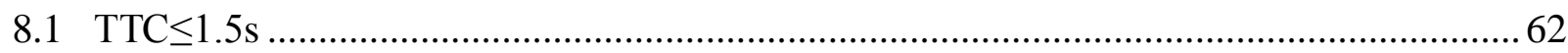

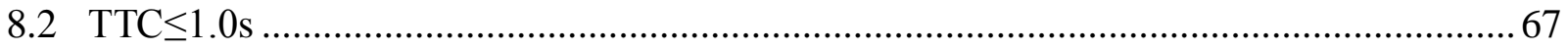

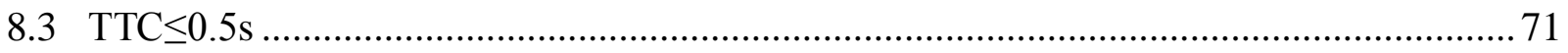

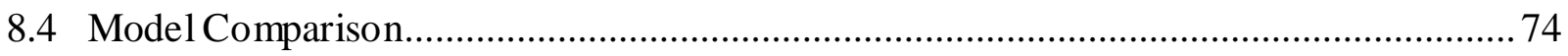

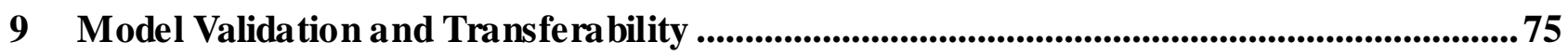

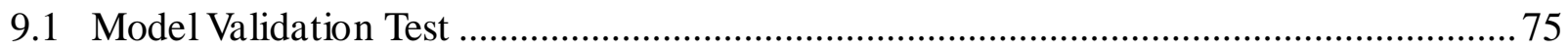

9.2 NCHRP 17-45 Model Transferability Analysis ……………………………………...... 76

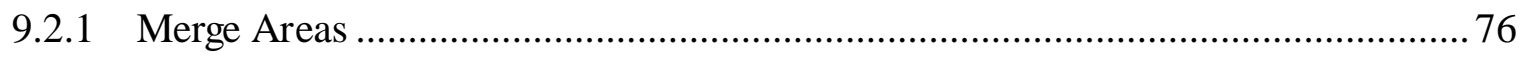

9.2.2 Diverge Areas ............................................................................................... 79

10 Summary and Conclusions................................................................................................................. 82

Appendix A: List of Study Sites ........................................................................................................85

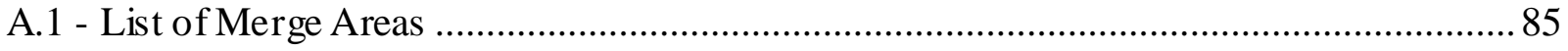

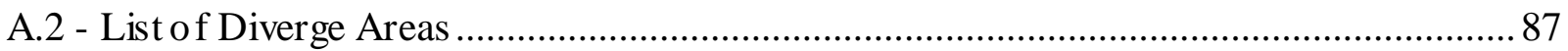

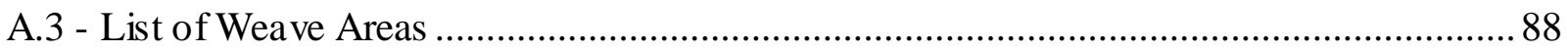

Appendix B: Additional CURE Plots for Crash-based SPFs in Chapter 6 ...................................90



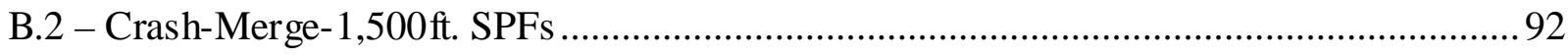




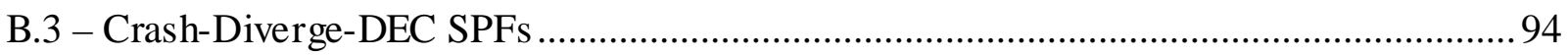

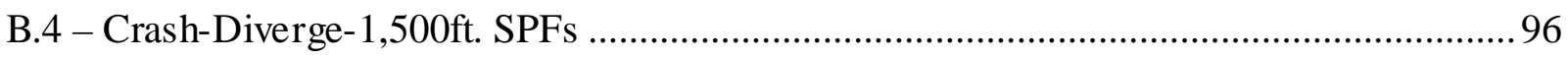

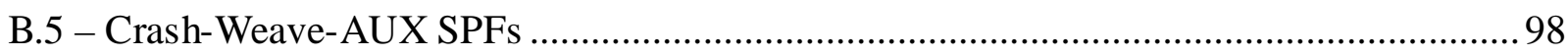

Appendix C: Additional CURE Plots for Conflict-based SPFs in Chapter 7 ............................... 100

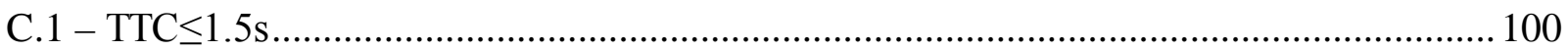

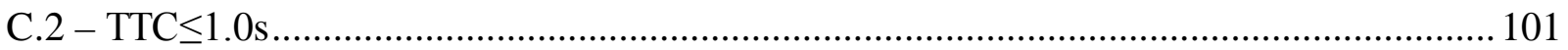

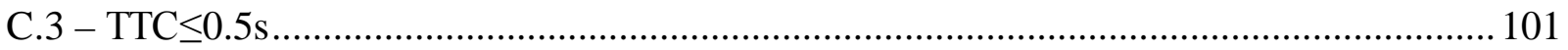

Appendix D: Additional CURE Plots for Crash-Conflict Integrated SPFs in Chapter 8 ........ 102

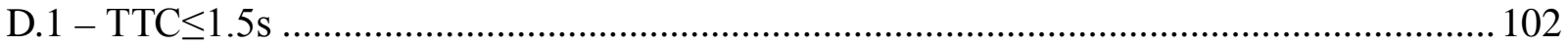

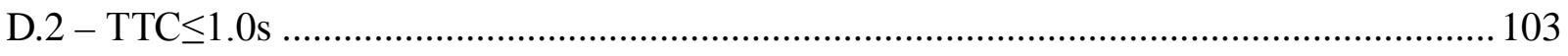

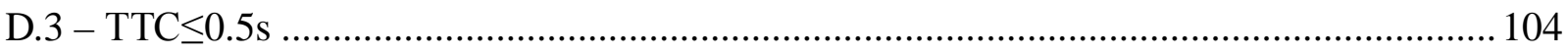

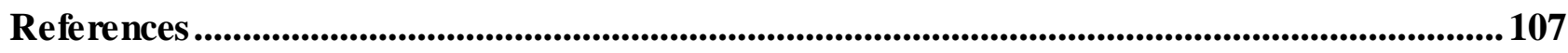




\section{List of Acronyms}






$\begin{array}{ll}\text { MSPE } & \text { Mean Squared Prediction Error } \\ \text { NB } & \text { Negative Binomial } \\ \text { PDO } & \text { Property Damage Only } \\ \text { PET } & \text { Post-encroachment Time } \\ \text { RAADT } & \text { Ramp Annual Average Daily Traffic } \\ \text { RPHV } & \text { Ramp Peak Hour Volumes } \\ \text { SAS } & \text { Statistical Analysis Software } \\ \text { SCL } & \text { Speed-Change Lane } \\ \text { SnglVeh } & \text { Single Vehicle } \\ \text { SPFs } & \text { Safety Performance Functions } \\ \text { SSAM } & \text { Surrogate Safety Assessment Model } \\ \text { TCT } & \text { Traffic Conflict Technique } \\ \text { TTC } & \text { Time to Collision }\end{array}$




\section{List of Tables}

Table 1. Traffic Volume Statistics for 103 Merge Areas ......................................................... 24

Table 2. Traffic Volume Statistics for 78 Diverge Areas.......................................................... 24

Table 3. Traffic Volume Statistics for 22 Weave Areas.......................................................... 25

Table 4. Crash Data Statistics for Merge Areas with Type A Influence Area (ACC+Mainline)... 26

Table 5. Crash Data Statistics for Merge Areas with Type B Influence Area (1,500 ft.) ............. 26

Table 6. Crash Data Statistics for Diverge Areas with Type A Influence Area (DEC+Mainline) 26

Table 7. Crash Data Statistics for Diverge Areas with Type B Influence Area $(1,500$ ft.) .......... 26

Table 8. Crash Data Statistics for Weave Areas (AUX+Mainline) ...........................................2 27

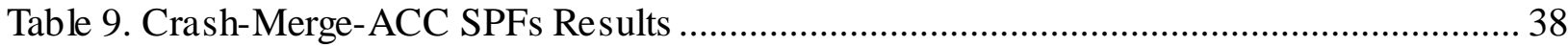

Table 10. Crash-Merge-ACC SPFs Goodness-of-Fit Results .................................................. 39

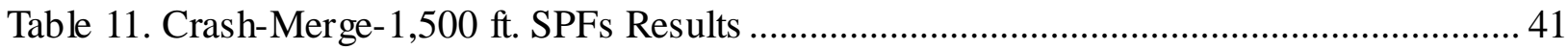

Table 12. Crash-Merge-1,500 ft. SPFs Goodness-of-Fit Results ............................................ 42

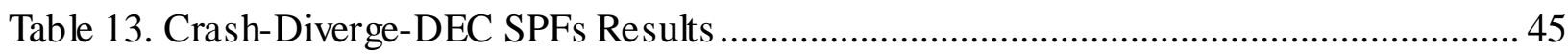

Table 14. Crash-Diverge-DEC SPFs Goodness-of-Fit Results.............................................. 46

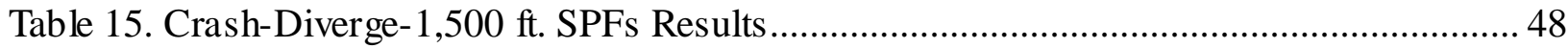

Table 16. Crash-Diverge-1,500 ft. SPFs Goodness-of-Fit Result ............................................ 49

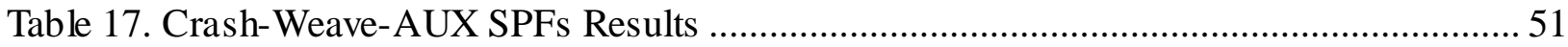

Table 18. Crash-Weave-AUX SPFs Goodness-of-Fit Results ................................................ 52

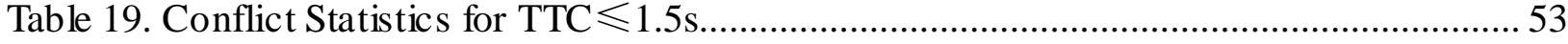

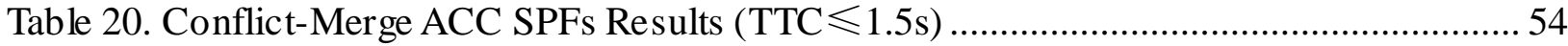

Table 21. Conflict-Merge ACC SPFs Goodness-of-Fit Results (TTC $\leqslant 1.5$ s) ........................... 54

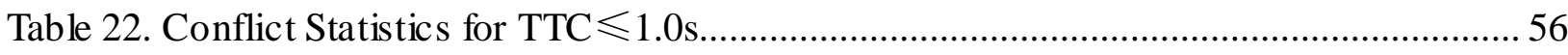

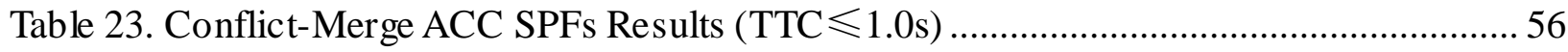

Table 24. Conflict-Merge ACC SPFs Goodness-of-Fit Results (TTC $\leqslant 1.0$ s) .......................... 57 




Table 26. Conflict-Merge ACC SPFs Results (TTC $\leqslant 0.5 \mathrm{~s})$........................................................... 59

Table 27. Conflict-Merge ACC SPFs Goodness-of-Fit Results (TTC $\leqslant 0.5 \mathrm{~s})$................................ 59

Table 28. Crash-Conflict-Merge ACC SPFs Results (TTC $\leqslant 1.5 \mathrm{~s})$............................................... 63

Table 29. Crash-Conflict-Merge ACC SPFs Goodness-of-Fit Results of Total Crashes (TTC $\leqslant$

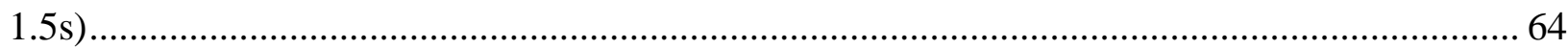

Table 30. Crash-Conflict-Merge ACC SPFs Goodness-of-Fit Results of F\&I Crashes (TTC $\leqslant 1.5 \mathrm{~s}$ ) 64

Table 31. Crash-Conflict-Merge ACC SPFs Goodness-of-Fit Results of PDO Crashes (TTC $\leqslant$

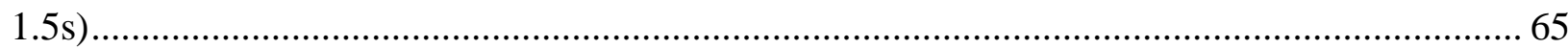

Table 32. Crash-Conflict-Merge ACC SPFs Goodness-of-Fit Results of Single Vehicle Crashes

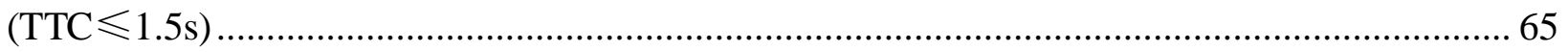

Table 33. Crash-Conflict-Merge ACC SPFs Goodness-of-Fit Results of RearEnd \& SideSwipe

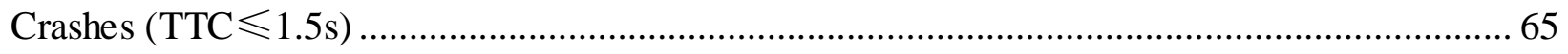

Table 34. Crash-Conflict-Merge ACC SPFs Results (TTC $\leqslant 1.0$ s) ………………………............... 67

Table 35. Crash-Conflict-Merge ACC SPFs Goodness-of-Fit Results of Total Crashes (TTC $\leqslant$

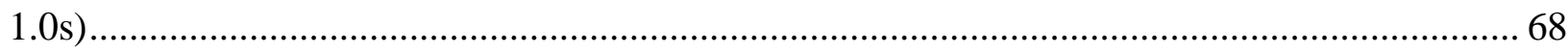

Table 36. Crash-Conflict-Merge ACC SPFs Goodness-of-Fit Results of F\&I Crashes (TTC $\leqslant 1.0 \mathrm{~s}$ ) 68

Table 37. Crash-Conflict-Merge ACC SPFs Goodness-of-Fit Results of PDO Crashes (TTC $\leqslant$ $1.0 \mathrm{~s})$ 69

Table 38. Crash-Conflict-Merge ACC SPFs Goodness-of-Fit Results of Single Vehicle Crashes $(\mathrm{TTC} \leqslant 1.0 \mathrm{~s})$ 69

Table 39. Crash-Conflict-Merge ACC SPFs Goodness-of-Fit Results of RearEnd \& SideSwipe

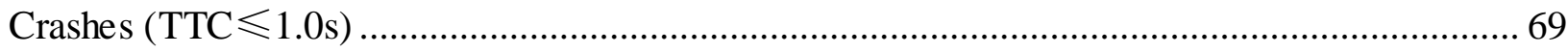

Table 40. Crash-Conflict-Merge ACC SPFs Results (TTC $\leqslant 0.5 \mathrm{~s})$................................................ 71 
Table 41. Crash-Conflict-Merge ACC SPFs Goodness-of-Fit Results of Total Crashes (TTC $\leqslant$

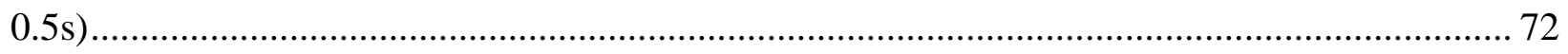

Table 42. Crash-Conflict-Merge ACC SPFs Goodness-of-Fit Results of F\&I Crashes (TTC $\leqslant 0.5 \mathrm{~s}$ ) 72

Table 43. Crash-Conflict-Merge ACC SPFs Goodness-of-Fit Results of PDO Crashes (TTC $\leqslant$

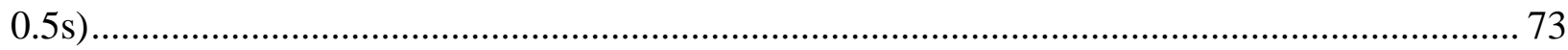

Table 44. Crash-Conflict-Merge ACC SPFs Goodness-of-Fit Results of Single Vehicle Crashes

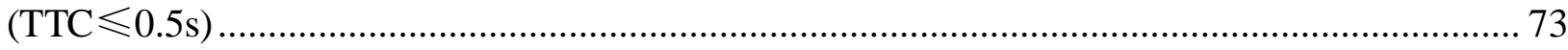

Table 45. Crash-Conflict-Merge ACC SPFs Goodness-of-Fit Results of RearEnd \& SideSwipe

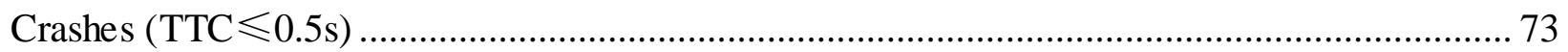

Table 46. Predicted Crashes Comparison with Crash-based SPFs and Crash-Conflict Integrated

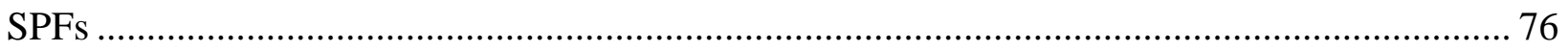

Table 47. Calibration Results for Merge Areas ................................................................. 78

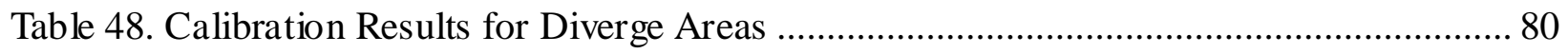

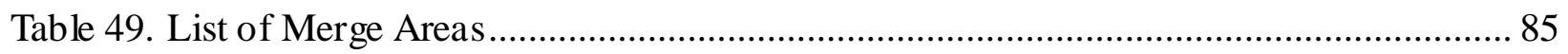

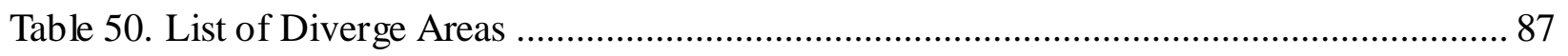

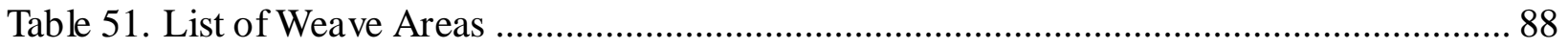




\section{List of Figures}

Figure 1. Fatal and Injury Collisions in Canada from 1994 to 2013 ......................................... 2

Figure 2. SPF Structures of Conventional Method and Surrogate Safety Measures ....................... 5

Figure 3. Example of CURE Plot ……................................................................................. 9

Figure 4. Sa fety Pyramid (a) and Diamond-shaped Severity Hierarchy (b) ................................. 13

Figure 5. SSAM Threshold Angle Diagram (Gettman et al. 2008) ................................................ 15

Figure 6. Parallel and Tapered Acceleration Lane for Merge Areas .............................................. 16

Figure 7. Parallel and Tapered Acceleration Lane for Diverge Areas............................................. 17

Figure 8. Auxiliary Lane for Weave Areas................................................................................ 17

Figure 9. Merge and Diverge Influence Areas for Type A .............................................................. 18

Figure 10. Merge and Diverge Influence Areas for Type B ........................................................... 18

Figure 11. Merge and Diverge Influence Areas for Type C .......................................................... 18

Figure 12. Weave Influence Areas ........................................................................................... 19

Figure 13. Locations of Interchanges Studied (Google Maps, 2016) ............................................ 21

Figure 14. Distribution of Merge, Diverge and Weave Areas......................................................... 21

Figure 15. MTO Interchange Diagram Convention (MTO) ……………………………............ 23

Figure 16. Suggested Coding for a Freeway Merge Area in VISS IM for 400-96-42 .................... 31

Figure 17. VISS IM Coding Example for 400-96-42 ………...................................................... 32

Figure 18. VISSIM Simulation for 400-96-42............................................................................. 34

Figure 19. SSAM Conflict Maps for 400-96-42 with Different Filter Conditions ......................... 35

Figure 20. Crash-Merge-ACC SPFs PDO Crash CURE Plots (good CURE plots) ....................... 39

Figure 21. Crash-Merge-ACC SPFs Rear End Crash CURE Plots (CURE plots with outliers) .. 40

Figure 22. Example of an Interchange with Two Successive on Ramps ....................................... 41

Figure 23. Crash-Merge-1,500 ft. SPFs PDO Crash CURE Plots (good CURE plots) .................. 43

Figure 24. Crash-Merge-1,500 ft. SPFs Rear End Crash CURE Plots (CURE plots with outliers) 
Figure 25. Crash-Diverge-DEC SPFs Side Swipe Crash CURE Plots (good CURE plots) ......... 47 Figure 26. Crash-Diverge-DEC SPFs Rear End Crash CURE Plots (CURE plots with several

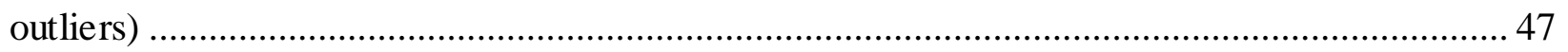

Figure 27. Crash-Diverge-1,500 ft. SPFs F\&I Crash CURE Plots (good CURE plots) .............. 49 Figure 28. Crash-Diverge-1,500 ft. SPFs Rear End Crash CURE Plots (CURE plots with several

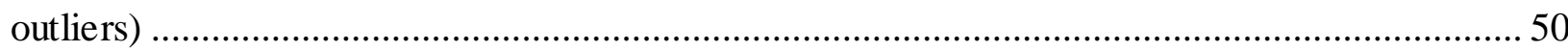

Figure 29. Crash-Weave-AUX SPFs Total Crash CURE Plots (good CURE plots) ................... 52 Figure 30. Conflict-Merge ACC SPFs Lane Change Conflict CURE Plots (TTC $\leqslant 1.5 s$ ) (good

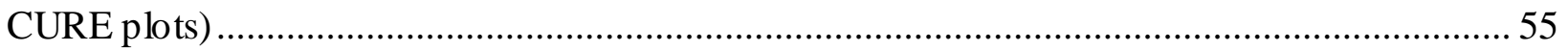

Figure 31. Conflict-Merge ACC SPFs Rear End Conflict CURE Plots (TTC $\leqslant 1.5 s$ ) (CURE plots

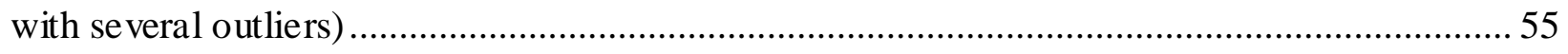
Figure 32. Conflict-Merge ACC SPFs Total Conflict CURE Plots (TTC $\leqslant 1.0$ s) (good CURE

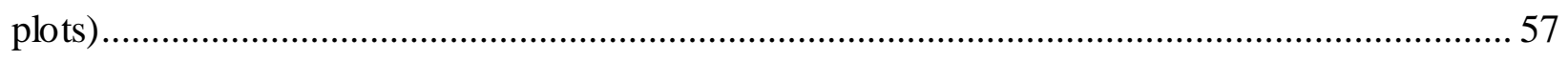
Figure 33. Conflict-Merge ACC SPFs Rear End Conflict CURE Plots (TTC $\leqslant 1.0$ s) (CURE plots

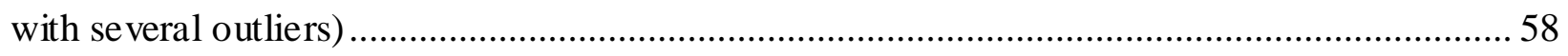
Figure 34. Conflict-Merge ACC SPFs Rear End Conflict CURE Plots (TTC $\leqslant 0.5 \mathrm{~s}$ ) (good CURE

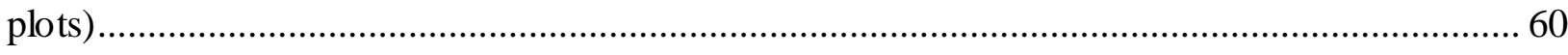
Figure 35. Conflict-Merge ACC SPFs Total Conflict CURE Plots (TTC $\leqslant 0.5 s$ ) (CURE plots with several outliers) 60

Figure 36. Merge ACC Area PDO Crash-Conflict CURE Plots (TTC $\leqslant 1.5 \mathrm{~s})$ (good CURE plots) 66 Figure 37. Merge ACC Area Single Vehicle Crash-Conflict CURE Plots (TTC $\leqslant 1.5 s)$ (CURE

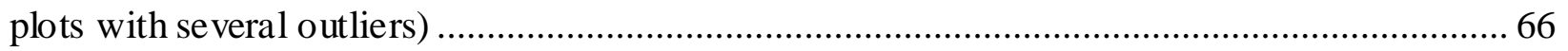
Figure 38. Merge ACC Area F\&I Crash-Conflict CURE Plots (TTC $\leqslant 1.0 s$ ) (good CURE plots) 70 
Figure 39. Merge ACC Area Single Vehicle Crash-Conflict CURE Plots (TTC $\leqslant 1.0 s)$ (CURE

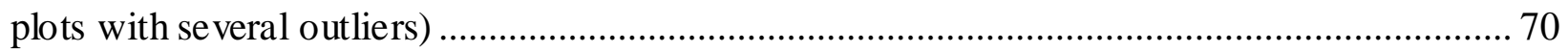
Figure 40. Merge ACC Area Total Crash-Conflict CURE Plots (TTC $\leqslant 0.5 \mathrm{~s}$ ) (CURE plots with

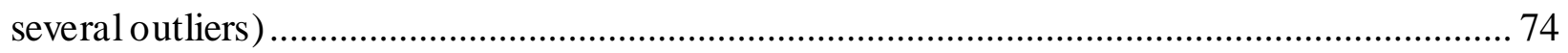

Figure 41. NCHRP-Merge ACC Area F\&I Crash CURE Plots ............................................. 78

Figure 42. NCHRP-Merge ACC Area PDO Crash CURE Plots............................................. 79

Figure 43. NCHRP-Diverge DEC Area F\&I Crash CURE Plots .............................................. 80

Figure 44. NCHRP-Diverge DEC Area PDO Crash CURE Plots .......................................... 81

Figure 45. Crash-Merge-ACC SPFs Total Crash CURE Plots .............................................. 90

Figure 46. Crash-Merge-ACC SPFs F\&I Crash CURE Plots ................................................ 90

Figure 47. Crash-Merge-ACC SPFs Side Swipe Crash CURE Plots ...................................... 91

Figure 48. Crash-Merge-ACC SPFs Single Vehicle Crash CURE Plots ................................. 91

Figure 49. Crash-Merge-1,500 ft. SPFs Total Crash CURE Plots ......................................... 92

Figure 50. Crash-Merge-1,500 ft. SPFs F\&I Crash CURE Plots .......................................... 92

Figure 51. Crash-Merge-1,500 ft. SPFs Side Swipe Crash CURE Plots .................................. 93

Figure 52. Crash-Merge-1,500 ft. SPFs Single Vehicle Crash CURE Plots .............................. 93

Figure 53. Crash-Diverge-DEC SPFs Total Crash CURE Plots ........................................... 94

Figure 54. Crash-Diverge-DEC SPFs F\&I Crash CURE Plots ........................................... 94

Figure 55. Crash-Diverge-DEC SPFs PDO Crash CURE Plots .............................................. 95

Figure 56. Crash-Diverge-DEC SPFs Single Vehicle Crash CURE Plots ................................. 95

Figure 57. Crash-Diverge-1,500 ft. SPFs Total Crash CURE Plots........................................ 96

Figure 58. Crash-Diverge-1,500 ft. SPFs PDO Crash CURE Plots.......................................... 96

Figure 59. Crash-Diverge-1,500 ft. SPFs Side Swipe Crash CURE Plots............................... 97

Figure 60. Crash-Diverge-1,500 ft. SPFs Single Vehicle Crash CURE Plots ........................... 97

Figure 61. Crash-Weave-AUX SPFs F\&I Crash CURE Plots .............................................. 98

Figure 62. Crash-Weave-AUX SPFs PDO Crash CURE Plots ............................................. 98 
Figure 63. Crash-Weave-AUX SPFs Rear End Crash CURE Plots ........................................ 99

Figure 64. Crash-Weave-AUX SPFs Side Swipe Crash CURE Plots ..................................... 99

Figure 65. Crash-Weave-AUX SPFs Single Vehicle Crash CURE Plots ................................. 100

Figure 66. Conflict-Merge ACC SPFs Total Conflict CURE Plots (TTC $\leqslant 1.5 \mathrm{~s})$.................... 100

Figure 67. Conflict-Merge ACC SPFs Lane Change Conflict CURE Plots (TTC $\leqslant 1.0$ s) ......... 101

Figure 68. Conflict-Merge ACC SPFs Lane Change Conflict CURE Plots (TTC $\leqslant 0.5 s$ ) ......... 101

Figure 69. Merge ACC Area Total Crash-Conflict CURE Plots (TTC $\leqslant 1.5 \mathrm{~s})$......................... 102

Figure 70. Merge ACC Area Rear End and Side Swipe Crash-Conflict CURE Plots (TTC $\leqslant 1.5 s$ ) 102

Figure 71. Merge ACC Area F\&I Crash-Conflict CURE Plots (TTC $\leqslant 1.5 \mathrm{~s})$.......................... 103

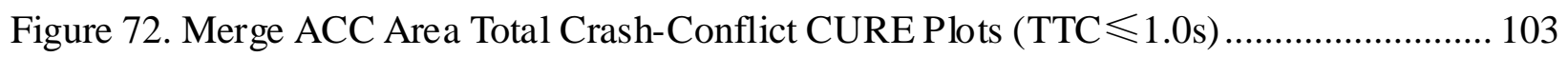

Figure 73. Merge ACC Area PDO Crash-Conflict CURE Plots (TTC $\leqslant 1.0 \mathrm{~s})$......................... 104

Figure 74. Merge ACC Area Rear End and Side Swipe Crash-Conflict CURE Plots (TTC $\leqslant 1.0 s$ ) 104

Figure 75. Merge ACC Area Rear End and Side Swipe Crash-Conflict CURE Plots (TTC $\leqslant 0.5 s$ ) 104

Figure 76. Merge ACC Area F\&I Crash-Conflict CURE Plots (TTC $\leqslant 0.5 \mathrm{~s})$.......................... 105

Figure 77. Merge ACC Area PDO Crash-Conflict CURE Plots (TTC $\leqslant 0.5 s$ ) ......................... 105

Figure 78. Merge ACC Area Single Vehicle Crash-Conflict CURE Plots (TTC $\leqslant 0.5 s$ ) ........... 106 


\section{Introduction}

\subsection{Road Safety Issues}

Transportation problems such as the increased traffic congestion and amount of traffic collisions have become critical global challenges. The fatalities and injuries occurring in motor vehicle collisions lead to high costs for society. The amount of motor vehicle fatalities and serious injuries occurring in Canada from 1994 to 2013 are shown in Figure 1 (Transport Canada 2013). In recent years, although the amount of the two types of collisions went down, the absolute social costs were still significant. According to a report from Transport Canada 2007, the annual social costs of the 613,000 motor vehicle collisions regarding loss of life, medical treatment,

rehabilitation, lost productivity, and property damage was around $\$ 62.7$ billion (4.9\% of Canada’s 2004 Gross Domestic Product). In terms of Ontario, the social cost generated by motor vehicle collisions in 2004 was \$18 billion, in which fatalities made the largest single contribution of \$11 billion (Vodden 2007; Heydari 2012).

Compared with other road facilities, collisions occurring at the freeways are usually more severe, especially for merging, diverging, and weaving movements. High speed and lane change maneuver behaviours can increase the risk of collisions on freeways. Many studies found that the risk of being involved in a collision and the severity of that collision would increase as speed increased (Goldenbeld \& van Schagen 2005; Elvik 2005). Poorly designed ramps with inappropriate speed-change lanes could also result in high frequency of collisions. 
Fatal and Injury Collisions 1994-2013

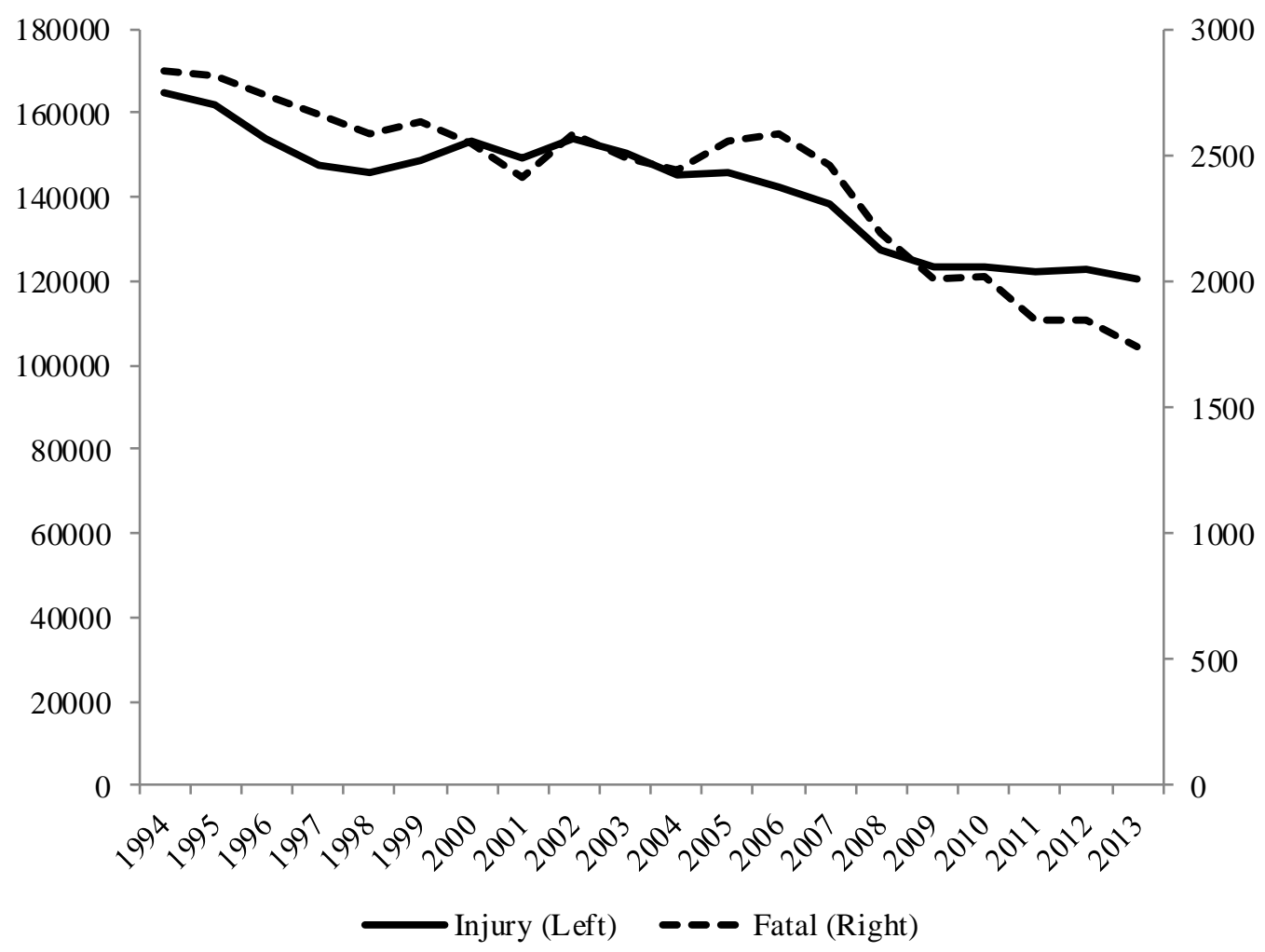

Figure 1. Fatal and Injury Collisions in Canada from 1994 to 2013

\subsection{Problem Statement}

Because merging, diverging, and weaving movements may pose high risk of collisions, authorities are more and more concerned about the safety of the entrance and exit ramps on the freeways. Many attempts have been made to identify the hazardous sites and reduce the crash frequency. One conventional method used by many authorities to identify these sites is carried out by ranking the crash counts or frequency (Persaud 2001). However, earlier studies found that this method of identification of hazardous location is weak, as collisions are random phenomenon and not always consistent over time (Jovanis \& Chang 1986; Miaou \& Lum 1993; Hauer et al. 1988). To address this issue, crash prediction models such as Safety Performance Functions (SPFs) could be used to improve the estimation of the expected crashes (Lyon et al. 
2005; Hauer 2001). The Empirical Bayes (EB) approach using these SPFs can be applied to identify the hazardous locations and evaluate the effectiveness of the countermeasures (Persaud \& Lyon 2007).

Two approaches have been developed for crash prediction modeling. The conventional method is crash-based SPFs. Based on the historical collision data within a certain period, the SPFs can be estimated and used to determine the major causations and relations between collisions with traffic volumes (such as AADT, ADT, and PHV), geometric features (length, lane configuration and ramp configuration), and/or traffic control systems (with or without metering). The second method is Surrogate Safety Measures. Observed or simulated traffic conflicts, rather than historical collision data used in conventional SPFs, can be used as a surrogate safety measure to predict the related crashes. Using simulated conflict data is more advantageous than using collision data for the following reasons: (1) the use of conflict data can capture more factors that may contribute to the collisions occurrence compared with conventional crash-based SPFs; (2) conflicts occur more frequently, thus providing a larger database; (3) using simulated traffic conflicts is more efficient and cost-effective compared with using observed conflicts. In particular, simulated conflicts as a surrogate safety measure are especially useful for the sites with insufficient or limited crash data.

In spite of the importance of crash prediction modeling for freeway merge, diverge, and weave areas, only a few studies have been done. Crash-based SPFs were developed in one study using historical Ontario crash data (Sarhan et al. 2008). However, the sample size was very limited. Using simulated conflicts, only one research paper studied the effect of merging and diverging influence areas (Atamo 2012). However, speed-change lanes were not considered as an independent variable in the SPFs. In sum, the study on the safety effects of speed-change lanes and their correlation with geometric features is lacking, especially for Canadian freeways. 


\subsection{Objectives}

The main purpose of this study is to develop crash prediction models by using crash-based SPFs and simulated conflicts. Accordingly, the research has the following specific objectives:

- Develop SPFs for merge areas with two types of influence areas for 103 sites.

- $\quad$ Develop SPFs for diverge areas with two types of influence areas for 78 sites.

- $\quad$ Develop SPFs for weave areas for 22 sites.

- Identify the relationship between observed crashes and simulated conflicts for 103 merge areas.

- Assess the effect of simulation results with different simulation parameter thresholds.

- $\quad$ Assess the transferability to Ontario data of SPFs estimated with US data.

\subsection{Organization of Thesis}

The thesis is organized into 10 Chapters. Chapter 2 presents a review of methodologies for crash prediction models and surrogate safety measures. An overview of modeling and simulation software is also given in this chapter. Chapter 3 presents and compares the influence areas for merge, diverge, and weave areas with different influence types. Chapter 4 introduces the data collection process for SPFs modeling and VISSIM simulation. Chapter 5 describes the methodologies for developing SPFs and VISSIM simulation process. Chapter 6 proposes models for merge, diverge, and weave areas based on crash-based SPFs. Chapter 7 shows the results of conflict-based SPFs for merging influence areas. Chapter 8 presents the results of crash-conflict integrated SPFs for merging influence areas. Chapter 9 discusses the models transferability by using Ontario data with NCHRP models. Chapter 10 summarizes the major findings in this study and proposes potential contributions for road safety analysis. Figure 2 provides an overall picture by summarizing the SPF development structure for this thesis. 




Figure 2. SPF Structures of Conventional Method and Surrogate Safety Measures 


\section{Literature Review}

The purpose of this chapter is to review the published literature on topics relevant to this research. These are: crash prediction models, surrogate safety measures, the traffic conflict techniques, and microscopic simulation.

\subsection{Crash Prediction Models}

\subsubsection{Methodologies}

Previous studies found that the relationship between expected crashes and traffic volumes is non-linear (Hauer 1997; Persaud et al. 1999; Persaud 2001). Crash prediction models could be developed using multiple variables. For example, crash counts could be fitted by a non-linear function with traffic volumes, geometric and operation characteristics as independent variables.

Crash counts used to be considered as following the Poisson distribution with the assumption that the variance is equal to the mean (Kononov \& Allery 2003; Persaud et al. 1999; etc.). However, it was found that the variance is usually larger than the mean, which means that the crash data are over-dispersed (Hauer 2001; Lord \& Park 2008). The negative binomial (NB) distribution could be used to address the over-dispersion issue and reduce the prediction bias (Mitra \& Washington 2007). In addition, generalized linear models (GLM) with a negative binomial (NB) error structure were recommended for developing safety performance functions (SPFs) for crash prediction. Also, maximum likelihood can be used to estimate the parameter

coefficients (Hauer 2015). Statistical software such as SAS (SAS, 2008) and R-statistical software (R, 2014) are frequently applied to develop SPFs. 
The generalized form of the frequently used crash prediction model is shown in Equation 1 (Persaud et al. 2012):

$$
\text { Crashes }=e^{\alpha} \times \text { Variable }^{\beta_{1}} \times \text { Variable }^{\beta_{2}} \times \ldots \times \text { Years }_{\text {Varion }} \text { 1) }
$$

where

$$
\alpha=\text { Estimated intercept, }
$$$$
\text { Variable1, Variable2, etc. }=\text { Selected explanatory variables, }
$$$$
\beta_{1}, \beta_{2} \text {, etc. = Estimated coefficients for the selected explanatory variables, }
$$
and Years $=$ Number of years of crash data.

\subsubsection{Goodness of Prediction Measures}

Once the parameters in each model are estimated, their statistical significance should be validated by goodness-of-fit (GOF) measures. To assess the overall performance of the model, MPB, MAD, MSPE, MSE (See below.), and the negative binomial over-dispersion parameter, $k$, have been used (Oh et al. 2003). For each variable in the models, the p-values and Cumulative Residual (CURE) plots (Hauer \& Bamfo 1997) can be applied to determine the model performance at 95\% confidence level. These measures are described below.

- $\quad$ P-value - P-value is widely used to determine the significance of the modeling results. The p-value is the probability of finding the observed results when the null hypothesis $\left(\mathrm{H}_{0}\right)$ of a studied question is true. A small p-value $(\leq 0.05)$ indicates strong evidence against the null hypothesis, so it is rejected.

- Mean prediction bias (MPB) - The mathematical average of the difference between predicted and observed crash frequency of all samples, as shown in Equation 2, where $n$ is the validation data sample size, and $\hat{Y}$ is the fitted value of $Y$. A positive value indicates the model over predicts the collisions. 


$$
M P B=\frac{\sum_{i=1}^{n}\left(\hat{Y}_{i}-Y_{i}\right)}{n}
$$

- Mean absolute deviation (MAD) - The mathematical average of the absolute difference between predicted and observed crash frequency, shown in Equation 3. A value close to zero indicates that the model predicts the observed value well.

$$
M A D=\frac{\sum_{i=1}^{n}\left|\hat{Y}_{i}-Y_{i}\right|}{n}
$$

- Mean squared prediction error (MSPE) - The mathematical average of the squared differences between predicted and observed crash frequency, shown in Equation 4, where $n_{2}$ is the validation data sample size.

$$
M S P E=\frac{\sum_{i=1}^{n}\left(\hat{Y}_{i}-Y_{i}\right)^{2}}{n_{2}}
$$

- Mean squared error (MSE) - The sum of squared differences between predicted and observed crash frequency, and divided by the difference between the sample size and the amount of model variables, shown in Equation 5, where $n_{1}$ is the estimation data sample size, and $p$ is the number of degrees of freedom.

$$
M S E=\frac{\sum_{i=1}^{n}\left(\hat{Y}_{i}-Y_{i}\right)^{2}}{n_{1}-p}
$$

- Over-dispersion parameter (k) - A smaller over-dispersion parameter value identifies a model that better captures the over-dispersion in the data. Crash data tend to be over-dispersed, thus a generalized linear models (GLM) with a negative binomial (NB) error structure is applied. 
- CURE plots - Plots of cumulative residuals (the difference between the number of observed and predicted crashes) against each variable in the model. The CURE Plot gives the 95\% confidence of upper and lower limits with cumulative residuals in increasing order. It also indicates the goodness-of-fit of the model by evaluating each covariate (Hauer \& Bamfo 1997). Large vertical drops in the CURE plot are indicative of large residuals or possible outliers. Long up or down runs correspond to the regions of consistent over and underestimation (Hauer 2015). Figure 3 shows an example of CURE plot for a model with no prediction biases.

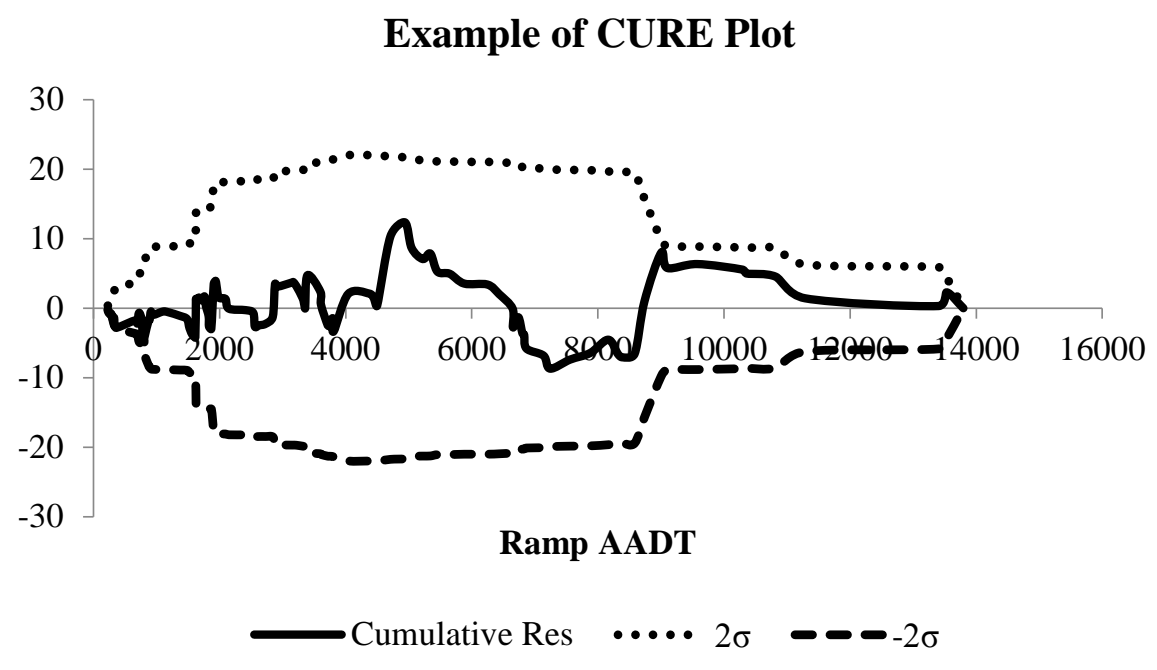

Figure 3. Example of CURE Plot

\subsubsection{Crash Prediction Models for Freeway Entrance and Exit Ramps}

Bauer and Harwood (1998) collected 3-year crash data from 192 acceleration lanes and 276 deceleration lanes in Washington. The initial attempt only identified the speed-change lanes as the influence areas. They found that crash frequency increased with increasing acceleration lane length. After combining the entire ramps and their adjacent speed-change lanes, the combined crash frequency decreased with increasing length of speed-change lanes. The models also indicated that exit ramps have $65 \%$ more crashes compared with entrance ramps. 
Bared et al. (1999) collected 3-year crash data from 276 exit ramps and 192 entrance ramps in Washington, and SPFs for acceleration and deceleration lane lengths were developed. Variables such as freeway AADT, ramp AADT, area types, ramp types, ramp configuration, length of ramps, and speed-change lanes were considered. The model showed that by increasing the length of speed-change lanes, the collision frequency would be reduced.

Sarhan et al. (2008) selected 5-year crash data from 26 interchanges on a freeway in Canada. Speed-change lanes and adjacent freeway segments were considered as influence areas. SPFs were developed for 41 acceleration lanes, 21 deceleration lanes and 34 weaving segments. The number of crashes decreased with increasing length of speed-change lanes. The models also indicated that there were more collisions associated with acceleration lanes compared to deceleration lanes.

Moon and Hummer (2009) collected 3-year crash data for 158 ramps with 33 left-side ramps on freeways in North Carolina. 1,500 ft. from the ramp gore was used as the influence area to collect crashes related to speed-change lanes. The prediction models indicated that the left-side on or off ramps had 1.7 to 2.5 times more total crashes than the right-side ramps.

Zhao (2009) collected 3-year crash data from deceleration lanes and a distance up to 1,000 ft. upstream. Cameras were used to collect vehicle conflicts by the observation method with 4 left-side off-ramps on freeways in Florida. The study found that the left-side off-ramps had 1.8 times more total crashes compared with the right-side off-ramps.

Atamo (2012) gathered 3-year crash data for 21 interchanges with 42 merging and 42 diverging areas in Colorado. 3,000 ft. around the gore was considered as an influence area for each site. VISSIM and SSAM software packages were used to generate and analyze the simulated conflicts. 
Crash perdition models for both merge and diverge areas were developed with crash-conflict integrated models. The study found that off-ramps with higher speeds were more likely to have higher crash frequency.

Lyon et al. (2013) selected 5-year crash data to develop the SPFs for merge zones. Merge zones were categorized as isolated (385 sites), non-isolated (69 sites) and weave (74 sites) with different influence types in Colorado. For non-isolated and weave zones, collisions were collected from speed-change lanes and adjacent mainline. For isolated on-ramps, 1,500 ft. influence area was applied for crash data collection. Estimated traffic volumes on lane 1 and lane 2 were also considered instead of the entire directional freeway AADT. However the results indicated that the entire freeway AADT was a better predictor in the developed SPFs.

\subsection{Surrogate Safety Measures}

Crash counts are random and infrequent, and crash rates are generally specified on a yearly basis. Besides, it is time-consuming and cost-ineffective to collect crash data and it is also a significant challenge to predict the crashes for sites with low crash rates. Thus, assessing the safety of traffic facilities without waiting for a statistically significant "random" or "large" number of crashes to actually occur is of great importance. Several surrogate safety measures have been proposed as safety indicators. The following list provides several examples (Gettman et al. 2008; El-Basyouny 2006; Tarko et al. 2009):

- Delay

- Travel Time

- Approach speed

- Queue length

- Percentage of stopped vehicles

- Accepted gaps 
- Headways

- $\quad$ Shock-waves

- Stop-bar encroachments

- Red-light violations

- Percentage of left turns

- $\quad$ Speed distribution

- Deceleration distribution

- Traffic conflict technique

Compared to crashes, the abovementioned measures could be observed with higher frequency. Thus, they could be a better predictor of safety for the sites with insufficient or limited crash data. The most frequently used measure is the traffic conflict technique (TCT).

\subsection{Traffic Conflict Techniques}

Traffic conflict techniques were first developed and applied by Perkins and Harris (1967). They studied the conflict characteristics at intersections and the relationship with various types of intersection collisions using field observations without any technical equipment.

Hydén defined a traffic conflict as any potential crash situation where two road users take evasive actions to avoid collision. Time to collision (TTC) and speed were used to determine the conflict severity in his study (Hydén 1987). Figure 4 shows the relation between severity and frequency of crashes and conflicts (Hydén 1987; Svensson 1998). 

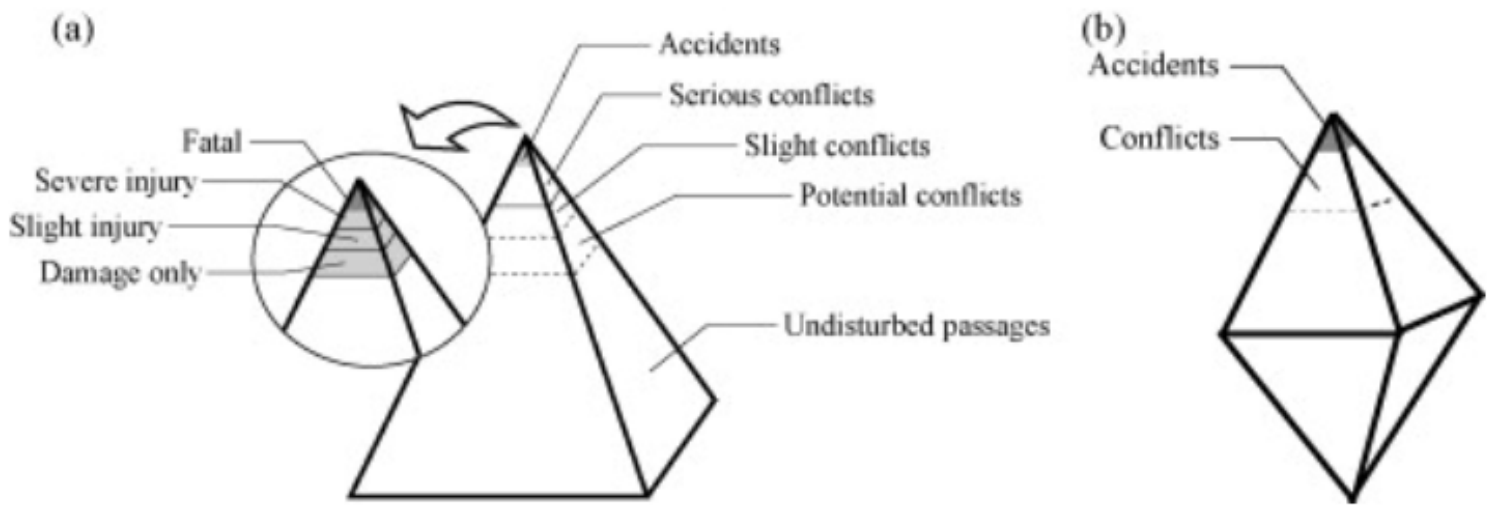

Figure 4. Safety Pyramid (a) and Diamond-shaped Severity Hierarchy (b) (Hydén 1987; Svensson 1998)

The traditional method to collect conflict data is by direct observation in the field or by cameras. However, only trained observers could identify serious conflicts based on time to collision and speed, and it is time-consuming and costly. Microscopic simulation models offer a solution and could be used to support the evaluations of various traffic engineering alternatives, especially for unbuilt facilities or proposed strategies. Microscopic simulation software including AIMSUN, Paramics, TEXAS, and VISSIM are compatible with SSAM to generate conflicts.

Some of the most frequently used safety indications including time to collision, post-encroachment time, time gap, time headway, and initial deceleration rate has been discussed by Saleem (2012) and Caliendo \& Guida (2012). Briefly, these are:

- Time to collision (TTC): expected time for two vehicles to crash if they remain at their present speed and on the same trajectory (Hayward 1971).

- Post-encroachment time (PET): the time between the first vehicle last occupied a position and the second vehicle subsequently arrived at the same location (Allen et al. 1978).

- Time gap: the time interval between the first passing vehicle and the next arriving vehicle (Gordon et al. 1996).

- Time headway $(\mathrm{H})$ : the time between the front of the lead vehicle passing a certain point and the front of the following vehicle passing the same spot (Evans 1991). 
- Initial deceleration rate (DR): the deceleration action of the subject vehicle to avoid a collision (Cooper \& Ferguson 1976).

\subsection{Software Overview}

The software packages used in this study includes SAS, VISSIM, and SSAM.

\subsubsection{SAS}

SAS (Statistical Analysis Software) is developed by SAS Institute for advanced analytics, multivariate analysis, business intelligence, data management, and predictive analytics (SAS, 2008). It is important in road safety modeling since it is an efficient and convenient tool to develop SPFs by estimating the coefficients and p-values for each variable in the models. In this study, SAS Enterprise 6.1 was used for predicting SPFs.

\subsubsection{VISSIM}

VISSIM is a world's leading microscopic traffic simulation software developed by the PTV Group. This software offers flexibility to allow users to model geometries with any level of complexity with many alternative attributes for driver and vehicle characteristics (PTV 2011). In this study, VISSIM 5.40 was used to code the merge junctions and generate vehicle trajectory files.

\subsubsection{SSAM}

SSAM (Surrogate Safety Assessment Model) is designed to perform analysis of vehicle trajectory files generated by microscopic traffic simulation models. This software can compute the number of conflicts with different types and filter the results according to user's criteria in order to remove any irrelevant results (Pu \& Joshi 2008). It classifies the conflicts into four types 
including rear-end, lane change, crossing, and unclassified conflicts based on the absolute value of the conflict angle as shown in Figure 5 (Gettman et al. 2008).

- Crossing Conflict: conflict angle larger than 85 degrees

- Rear-End Conflict: conflict angle less than 30 degrees

- Lane Change Conflict: conflict angle between 30 and 85 degrees

- Unclassified: unknown conflict angle

In this study, SSAM 2.1.6 was used to analyze the trajectory files and generate and filter the specific conflicts with different types in order to remove any irrelevant results.

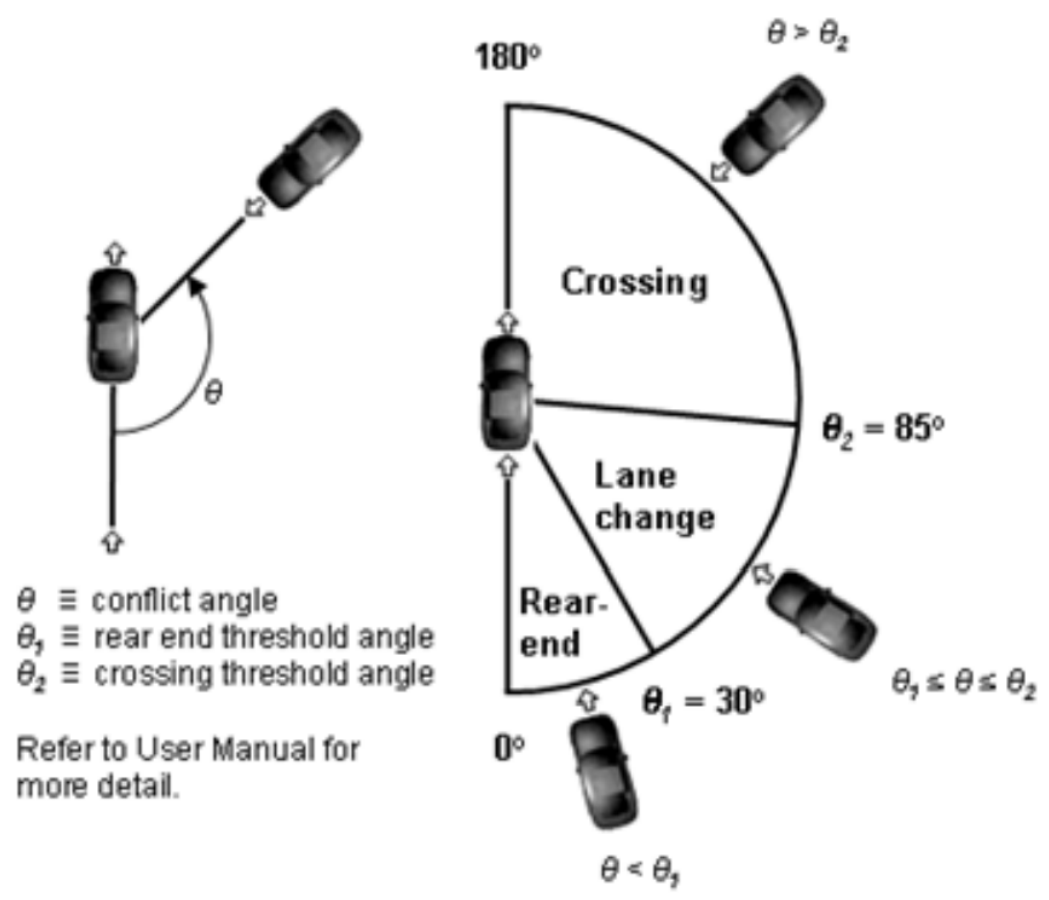

Figure 5. SSAM Threshold Angle Diagram (Gettman et al. 2008) 


\section{Determination of Influence Areas for Analysis}

The influence areas for merge, diverge, and weave sites are very important, because variations exist in the collision numbers collected from different types of influence areas. For developing the SPFs based on historical crash data, each type of influence area was evaluated and compared.

\subsection{Definition of Speed-Change Lanes}

The definition of speed-change lanes will influence their measured lengths. American Association of State Highway and Transportation Officials (AASHTO) and Highway Capacity Manual (HCM) have different definitions (AASHTO 2001; Bared et al. 1999). The definitions for lengths of the acceleration lane (ACC), deceleration lane (DEC), and the auxiliary lane (AUX) in HCM are introduced below (HCM 2010).

Acceleration lane(s) is (are) a paved non-continuous lane(s) including tapered areas to allow vehicles on the ramps to accelerate when merging into freeway mainline. Figure 6 shows two types of acceleration lane(s) for parallel and tapered conditions.
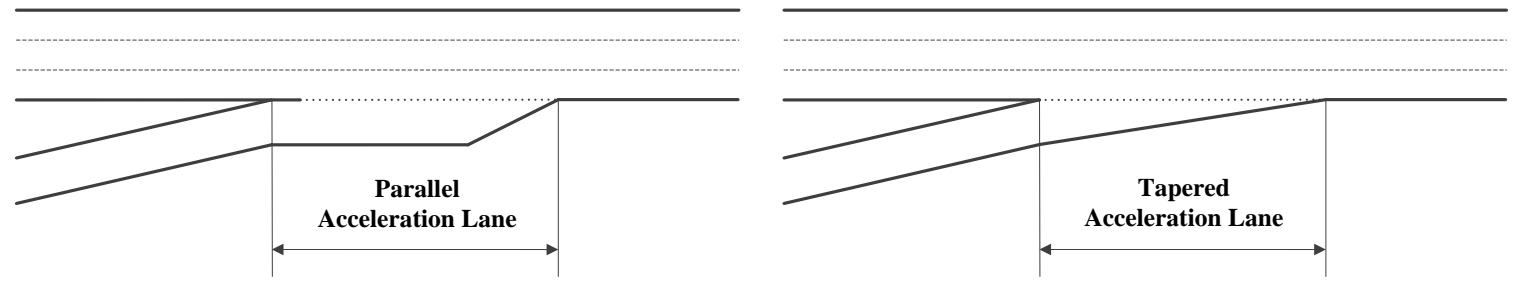

Figure 6. Parallel and Tapered Acceleration Lane for Merge Areas

Deceleration lane(s) is (are) a paved non-continuous lane(s) including tapered areas to allow vehicles leaving the freeway mainline to decelerate. Figure 7 shows two types of deceleration lane(s) for parallel and tapered conditions. 

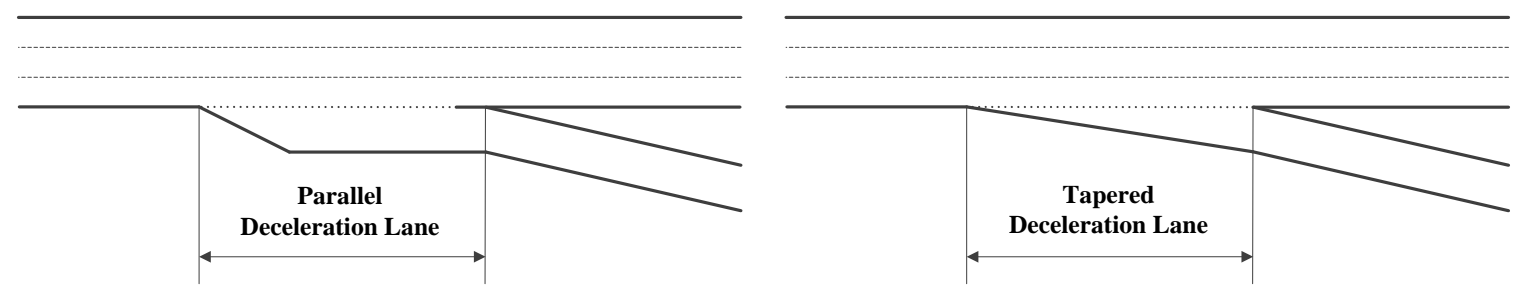

Figure 7. Parallel and Tapered Acceleration Lane for Diverge Areas

Auxiliary lane(s) is (are) a additional lane(s) on the freeway to connect successive on-ramp and off-ramp. Figure 8 shows the length of the auxiliary lane.

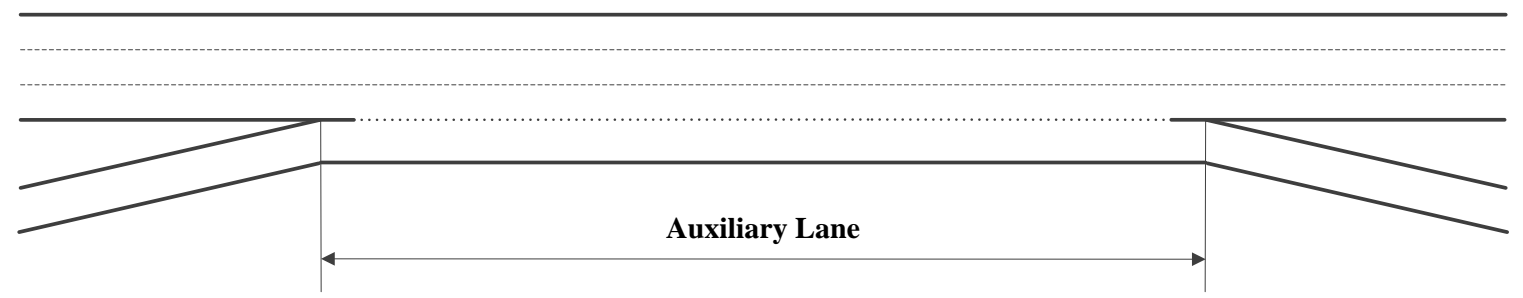

Figure 8. Auxiliary Lane for Weave Areas

\subsection{Merge and Diverge Influence Areas}

When evaluating the safety performance for merge areas, the influence areas can be determined in several ways. Most studies collected crashes which occurred at the speed-change lanes and adjacent freeway segments (Cirillo 1970; Sarhan et al. 2008). Zhao (2009) and Moon and Hummer (2009) gathered crashes on speed-change lanes and freeway segments for a distance up to $1,000 \mathrm{ft}$. and 1,500 ft. from the ramp gore, respectively. Bauer and Harwood (1998) modeled crash data by combining ramps and speed-change lanes. Atamo (2012) used a distance of 1,500 $\mathrm{ft}$. on either side of the gore (total 3,000 ft.) as the influence areas. However, in Atamo's study, the 3,000 ft. influence area was problematic when there was an adjacent on or off ramp, which might lead to overlaps between those two ramps. Also, it was hard to capture the relationship between crashes and the lengths of speed-change lanes. Thus, only Type A and Type B were applied as the influence areas in this study as shown below. 
For type A, the crashes were collected from the speed-change lanes and adjacent freeway mainline. The influence areas for both merge and diverge areas are shown in Figure 9.
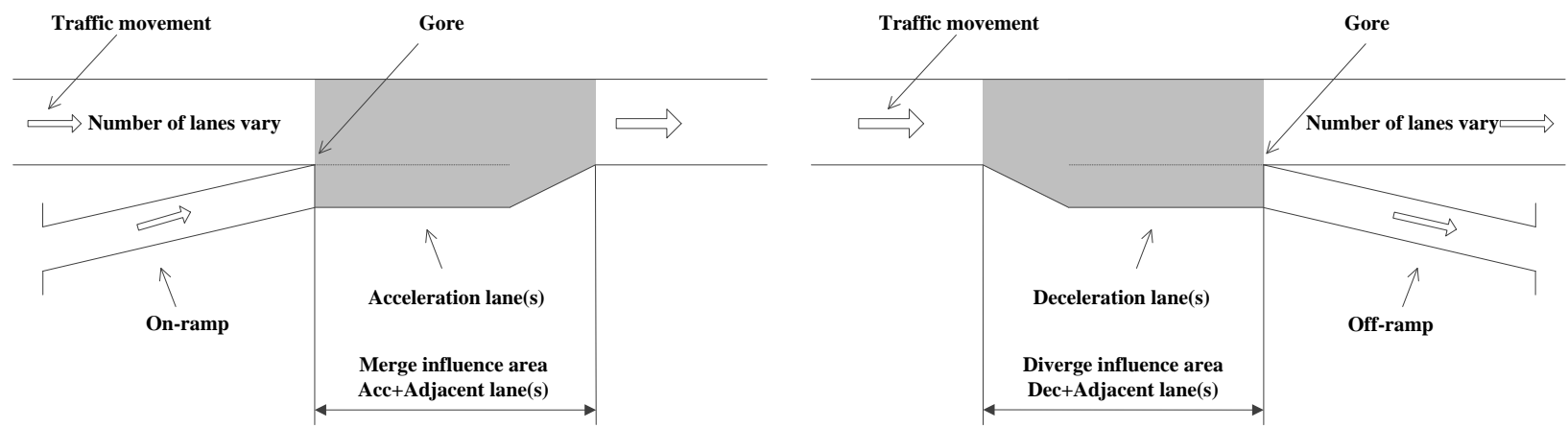

Figure 9. Merge and Diverge Influence Areas for Type A

For type B, the crashes were gathered from $1,500 \mathrm{ft}$. from the gore to the end of the taper. The influence areas for both merge and diverge areas are shown in Figure 10.
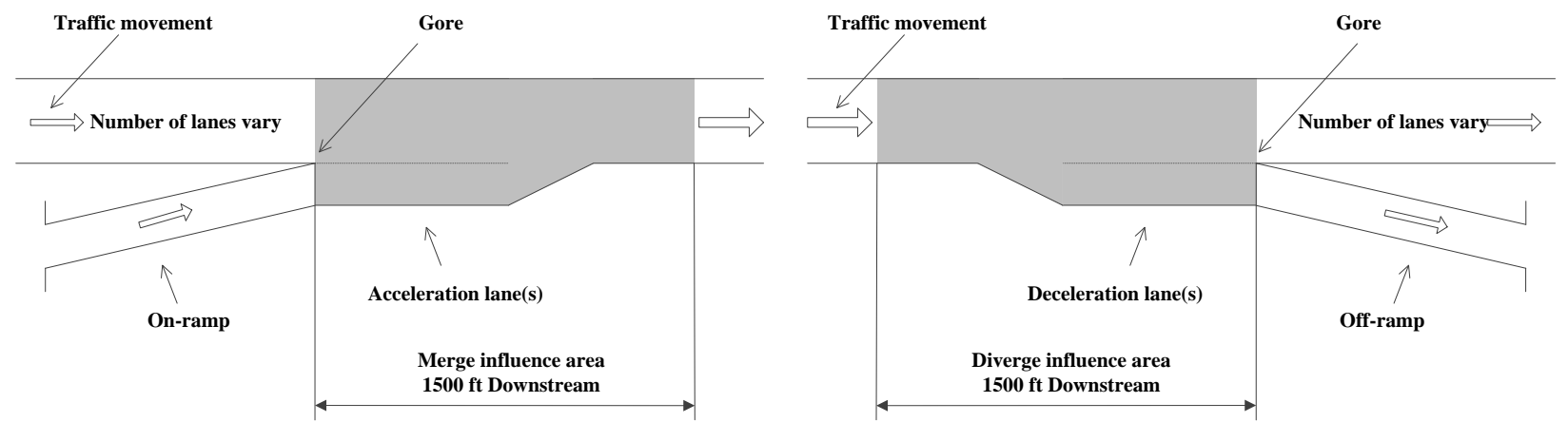

Figure 10. Merge and Diverge Influence Areas for Type B

For type C, the crashes were gathered from 3,000 ft. around the gore with 1,500 ft. on each side. The influence areas for both merge and diverge areas are shown in Figure 11.
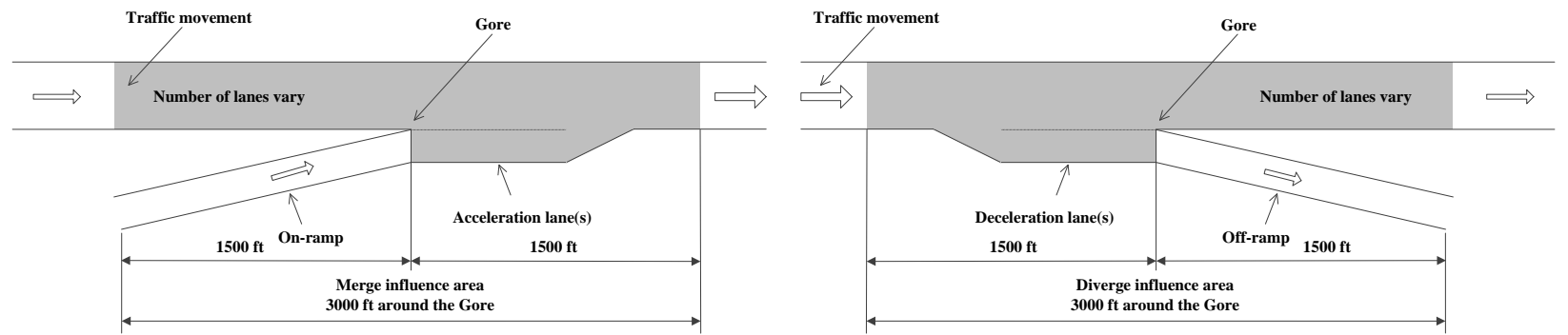

Figure 11. Merge and Diverge Influence Areas for Type C 


\subsection{Weave Influence Areas}

A weaving section has maneuvers for both merging and diverging vehicles, so during peak hours, there could be increased risk of getting involved in rear-end collisions (Bonneson et al. 2012). The influence areas for weaving sections usually cover all freeway lanes between two adjacent gores, as shown in Figure 12.

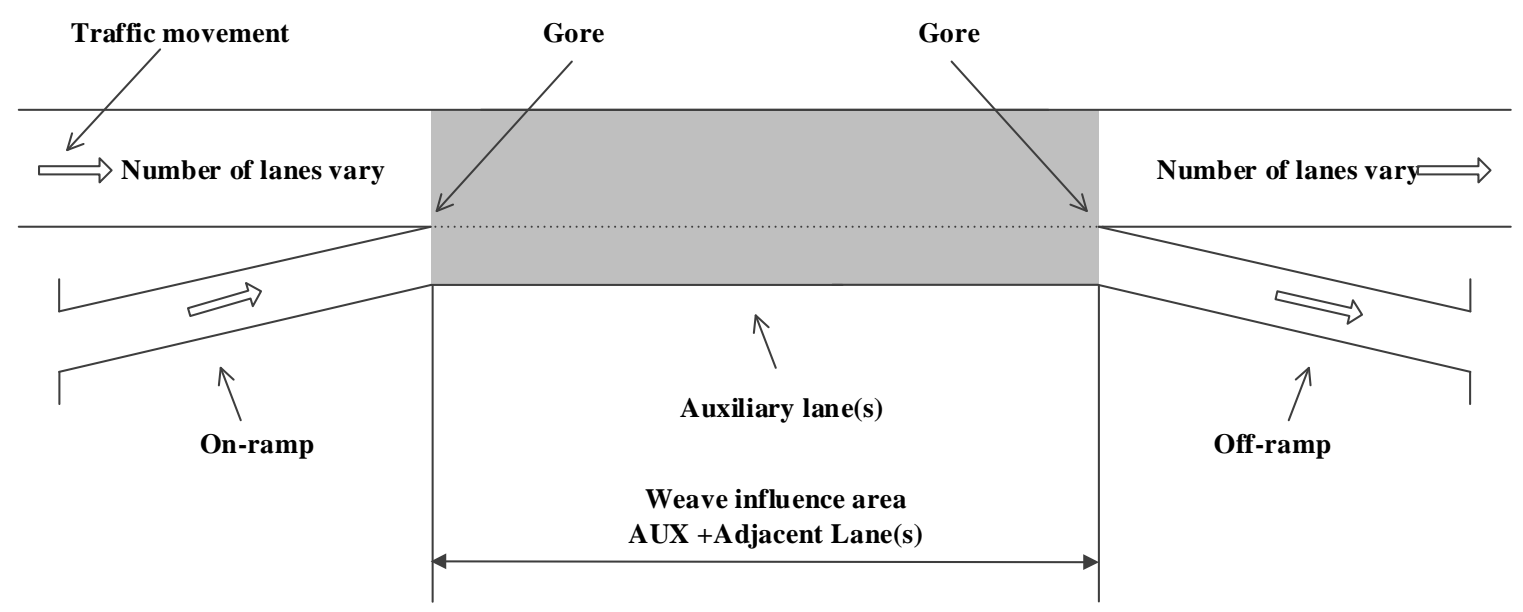

Figure 12. Weave Influence Areas 


\section{Data Assembly}

To develop a suitable database for developing crash prediction models for freeway ramps, data consisting of the geometry features, traffic volumes, and crashes on both freeways and ramps from different resources were collected.

\subsection{Geometry Data}

For the geometry data part, 67 interchanges were selected in the Greater Toronto Area, Ontario. Interchanges were selected from the QEW freeway and Highways 400, 401, 402, 404, and 410. Also, in order to avoid highly congested situations, only freeway-to-arterial interchanges away from downtown areas were selected. Conventional acceleration, deceleration and auxiliary lanes were considered, while left-side and metered ramps were excluded in this study. Figure 13 shows the locations of studied interchanges on Google Maps. In addition, the distribution for the merge, diverge, and weave areas on different freeways is shown in Figure 14. Full lists of the specific locations are provided in Appendices A, B and C. 


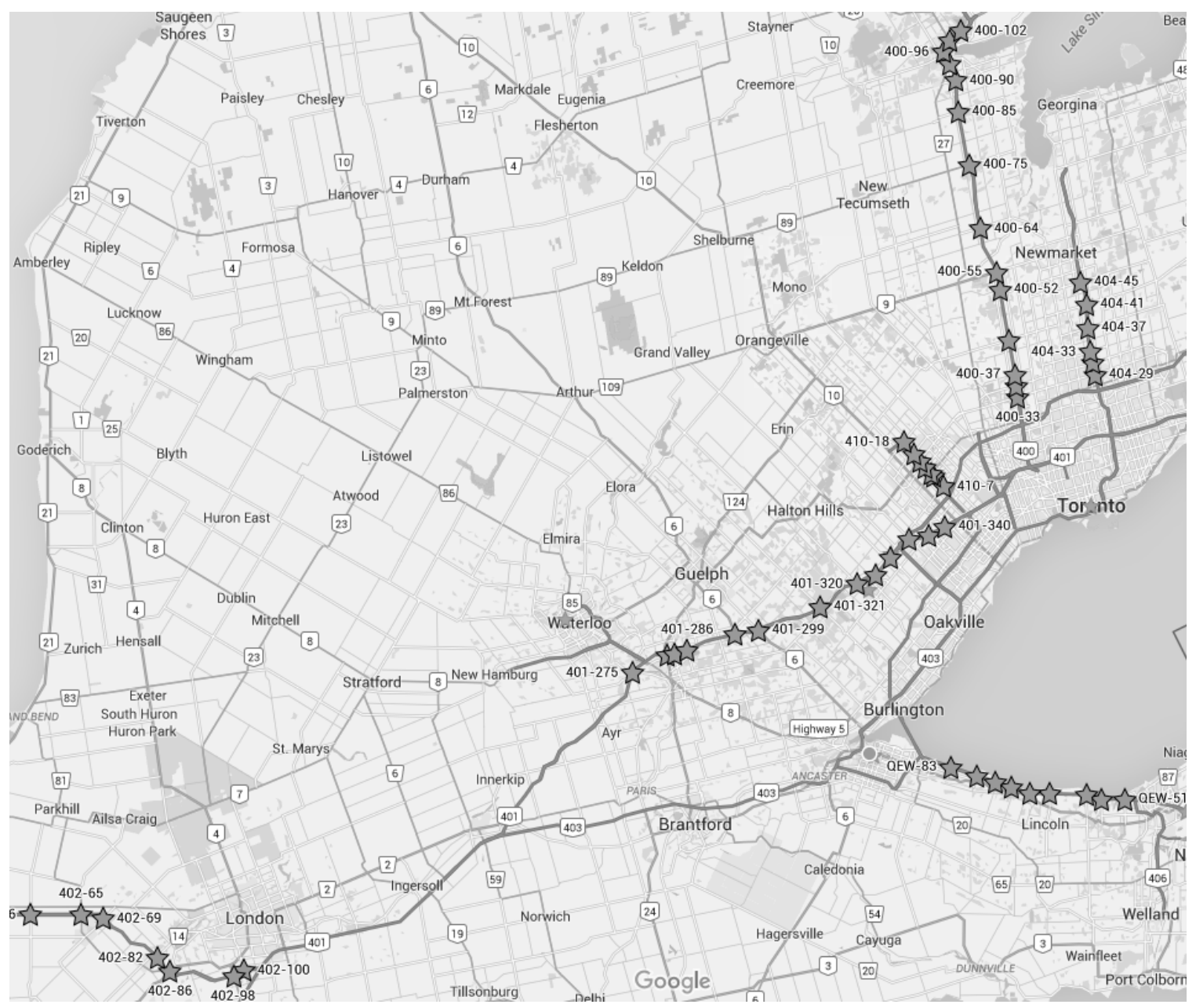

Figure 13. Locations of Interchanges Studied (Google Maps, 2016)

\section{Distribution of Merge, Diverge, and Weave Areas}

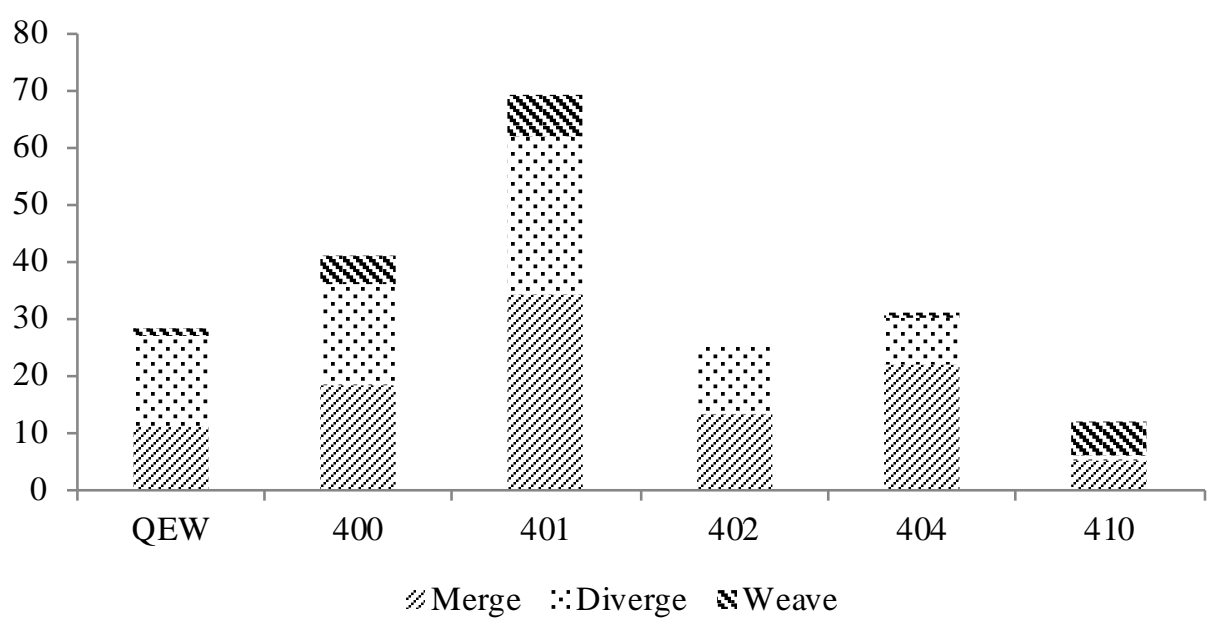

Figure 14. Distribution of Merge, Diverge and Weave Areas 
Using Google Maps, Google Earth Pro, and MTO iCorridor system, the following geometric information was collected:

- Interchange ID, locations, Linear Highway Referencing System (LHRS)

- Ramp ID, configuration, type

- $\quad$ Merge vs diverge area

- Taper vs parallel ramp

- Length of the acceleration lane from gore to the end of taper in meters

- Length of the deceleration lane from beginning of taper to the gore in meters

- Length of the auxiliary lane in meters

- Offset ranges of 1,500 ft. (around $500 \mathrm{~m}$ due to the offset is $200 \mathrm{~m}$ based) influence areas for merge and diverge junctions

- Offset ranges of speed-change lane influence areas

- Distance between successive ramps

- Number of lanes on mainline

- Number of lanes on ramps

- $\quad$ Posted speed limit

Interchange IDs were queried from Google Maps. However, the ramp IDs needed to be identified according to the direction and configuration of the ramps. As shown in Figure 15, an Ontario ramp ID is a unique two-digit number. The first number indicates the origin direction, and the second number shows the direction of the destination. For example, the ramp ID for the ramp from Eastbound to North \& Southbound is 51 . 


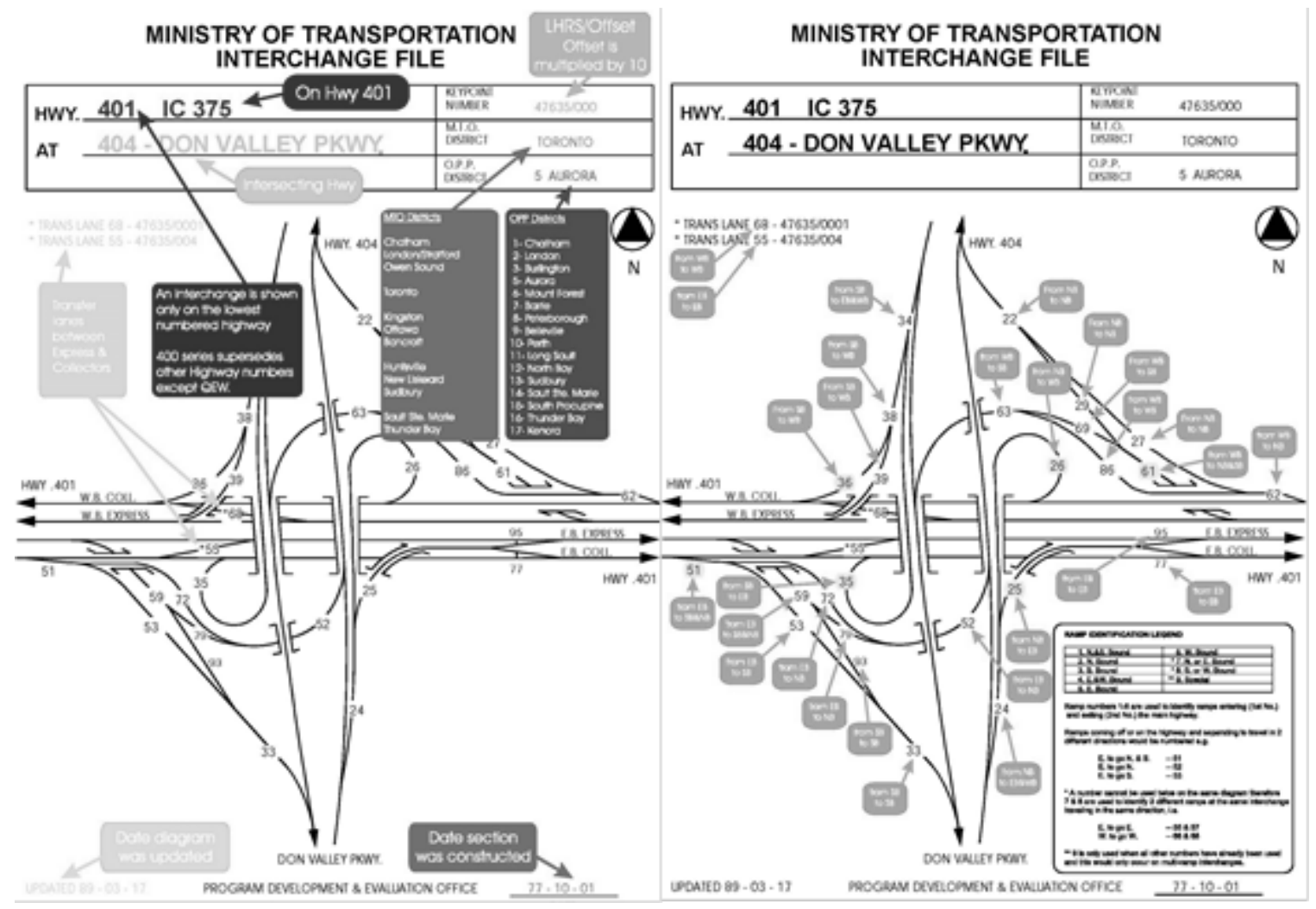

Figure 15. MTO Interchange Diagram Convention (MTO)

\subsection{Traffic Volumes}

Both freeway traffic volumes and ramp traffic volumes were used for this study. Sources are as follows:

- Data from MTO iCorridor System

o Directional freeway annual average daily traffic (FAADT) from the year 2010 (latest data)

o Directional freeway hourly volumes for 7 a.m. as Peak Hour Volume (FPHV)

o Freeway heavy vehicle percentage (FHV\%)

- MTO provided Data
o Ramp ID
o Ramp AADT (RAADT) from 2010 (latest data)
o Environment 


\section{o Ramp type \\ o Ramp length}

- Estimated data
o Ramp PHV (RPHV) (estimated by proportion of FPHV and FAADT)
o Ramp HV\% (RHV\%) (same as FHV\%)

For merge areas, data of 103 acceleration lanes were collected. Table 1 summarizes the AADT and the acceleration lane data for these sites.

Table 1. Traffic Volume Statistics for 103 Merge Areas

\begin{tabular}{|c|c|c|c|c|c|c|c|}
\hline Variables & FAADT & RAADT & ACC Lane & FPHV & RPHV & FHV\% & RHV\% \\
\hline Sum & 4596350 & 414011 & 34934 & 367708 & 33121 & 1544 & 1544 \\
\hline Maximum & 87400 & 13797 & 460 & 6992 & 1104 & 38 & 38 \\
\hline Minimum & 8350 & 226 & 195 & 668 & 18 & 4 & 4 \\
\hline Mean & 44624.76 & 4019.52 & 339.17 & 3569.98 & 321.56 & 14.99 & 14.99 \\
\hline
\end{tabular}

For diverge areas, data of 78 deceleration lanes were collected. However, since the simulation for diverge area was not applied in this study, peak hour volumes and heavy vehicle data were not collected. Table 2 summarizes the AADT and the deceleration lane data for these sites.

Table 2. Traffic Volume Statistics for 78 Diverge Areas

\begin{tabular}{|c|c|c|c|}
\hline Variables & FAADT & RAADT & DEC Lane \\
\hline Sum & 3357600 & 449865 & 20704 \\
\hline Maximum & 80100 & 25199 & 545 \\
\hline Minimum & 8900 & 212 & 112 \\
\hline Mean & 43046.15 & 5767.49 & 265.44 \\
\hline
\end{tabular}

For weave areas, the data of 22 auxiliary lanes were collected. Similarly, only the freeway AADT and auxiliary lane lengths were collected. Table 3 summarizes the AADT and auxiliary lane data 
for these sites.

Table 3. Traffic Volume Statistics for 22 Weave Areas

\begin{tabular}{|c|c|c|}
\hline Variables & FAADT & AUX Lane \\
\hline Sum & 1395500 & 12926 \\
\hline Maximum & 87400 & 954 \\
\hline Minimum & 36400 & 234 \\
\hline Mean & 63431.82 & 587.54 \\
\hline
\end{tabular}

\subsection{Crash Data}

Crash data from 2009 to 2013 was used, and the raw data were queried from MTO Accident Information System. Key parameters listed in the raw data include:

- MFYR: year

- HWY_NAME; highway name

- CLASAC: classification including Total, Fatal and Injury (F\&I), Property Damage Only (PDO) collisions

- INTIMP: initial impact type including Rear End, Side Swipe, Single Motor Vehicle collisions

- DIRTRA: initial direction of traffic

- REFERENCE_NO: reference number of collision locations

- OFFSET: offset of the collision locations

- $\quad$ RAMPNO: ramp ID

In order to collect accurate collision counts in a large dataset, an Excel tool was developed to collect the information related to each merge, diverge, and weave influence areas.

For merge areas, the crash data statistics for influence areas of type A and type B are shown in Table 4 and Table 5 . 
Table 4. Crash Data Statistics for Merge Areas with Type A Influence Area (ACC+Mainline)

\begin{tabular}{|c|c|c|c|c|c|c|}
\hline Crashes & Total & F\&I & PDO & Rear End & Side Swipe & Single Vehicle \\
\hline Sum & 1229 & 225 & 1004 & 450 & 225 & 541 \\
\hline Maximum & 63 & 13 & 60 & 37 & 13 & 46 \\
\hline Minimum & 0 & 0 & 0 & 0 & 0 & 0 \\
\hline Mean & 11.93 & 2.18 & 9.75 & 4.37 & 2.18 & 5.25 \\
\hline Percentage & $100.00 \%$ & $18.31 \%$ & $81.69 \%$ & $36.62 \%$ & $18.31 \%$ & $44.02 \%$ \\
\hline
\end{tabular}

Table 5. Crash Data Statistics for Merge Areas with Type B Influence Area (1,500 ft.)

\begin{tabular}{|c|c|c|c|c|c|c|}
\hline Crashes & Total & F\&I & PDO & Rear End & Side Swipe & Single Vehicle \\
\hline Sum & 1598 & 290 & 1308 & 598 & 296 & 687 \\
\hline Maximum & 135 & 15 & 121 & 74 & 24 & 48 \\
\hline Minimum & 0 & 0 & 0 & 0 & 0 & 0 \\
\hline Mean & 15.51 & 2.82 & 12.70 & 5.81 & 2.87 & 6.67 \\
\hline Percentage & $100.00 \%$ & $18.15 \%$ & $81.85 \%$ & $37.42 \%$ & $18.52 \%$ & $42.99 \%$ \\
\hline
\end{tabular}

For diverge areas, the crash data statistics for influence areas of type A and type B are shown in Table 6 and Table 7.

Table 6. Crash Data Statistics for Diverge Areas with Type A Influence Area (DEC+Mainline)

\begin{tabular}{|c|c|c|c|c|c|c|}
\hline Crashes & Total & F\&I & PDO & Rear End & Side Swipe & Single Vehicle \\
\hline Sum & 843 & 141 & 702 & 268 & 164 & 403 \\
\hline Maximum & 44 & 8 & 36 & 19 & 11 & 24 \\
\hline Minimum & 0 & 0 & 0 & 0 & 0 & 0 \\
\hline Mean & 10.81 & 1.81 & 9.00 & 3.44 & 2.10 & 5.17 \\
\hline Percentage & $100.00 \%$ & $16.73 \%$ & $83.27 \%$ & $31.79 \%$ & $19.45 \%$ & $47.81 \%$ \\
\hline
\end{tabular}

Table 7. Crash Data Statistics for Diverge Areas with Type B Influence Area (1,500 ft.)

\begin{tabular}{|c|c|c|c|c|c|c|}
\hline Crashes & Total & F\&I & PDO & Rear End & Side Swipe & Single Vehicle \\
\hline Sum & 1082 & 182 & 900 & 308 & 216 & 547 \\
\hline Maximum & 59 & 8 & 51 & 32 & 11 & 25 \\
\hline Minimum & 1 & 0 & 1 & 0 & 0 & 0 \\
\hline Mean & 13.87 & 2.33 & 11.54 & 3.95 & 2.77 & 7.01 \\
\hline Percentage & $100.00 \%$ & $16.82 \%$ & $83.18 \%$ & $28.47 \%$ & $19.96 \%$ & $50.55 \%$ \\
\hline
\end{tabular}


For weave areas, the crash data statistics for the auxiliary lane and adjacent freeway segments are shown in Table 8.

Table 8. Crash Data Statistics for Weave Areas (AUX+Mainline)

\begin{tabular}{|c|c|c|c|c|c|c|}
\hline Crashes & Total & F\&I & PDO & Rear End & Side Swipe & Single Vehicle \\
\hline Sum & 316 & 75 & 241 & 119 & 79 & 114 \\
\hline Maximum & 40 & 10 & 32 & 19 & 10 & 10 \\
\hline Minimum & 2 & 0 & 1 & 0 & 0 & 1 \\
\hline Mean & 14.36 & 3.41 & 10.95 & 5.41 & 3.59 & 5.18 \\
\hline Percentage & $100.00 \%$ & $23.73 \%$ & $76.27 \%$ & $37.66 \%$ & $25.00 \%$ & $36.08 \%$ \\
\hline
\end{tabular}




\section{Methodology}

This chapter describes the key methodologies used in this study. The methodologies pertain to developing crash-based SPFs, microscopic simulation process, conflict analysis, developing conflict-based SPFs, and crash-conflict integrated SPFs.

\subsection{Develop Crash-based Safety Performance Functions for Speed-Change Lanes}

Geometry features, traffic volumes, and crash data were collected and used to develop the SPFs for different speed-change lane influence areas including merge, diverge, and weave sites.

For the merge areas, the data of 103 acceleration lanes were collected to develop the crash prediction models for different influence areas and collision types. Two types of influence areas, Type A (acceleration lane and adjacent freeway mainline) and Type B (1,500 ft. downstream from the gore to the end of the taper), were evaluated and compared. Similarly, the data of 78 deceleration lanes were collected to develop the SPFs for the diverge areas. The influence areas for both Type A and Type B were also evaluated. For weave areas, collision counts were collected on the auxiliary lane and adjacent freeway mainline.

The generalized linear model (GLM) with a negative binomial (NB) error structure was used to predict the crashes. SAS was used to generate model coefficients, over-dispersion parameters, and p-values. Once the models were developed, the goodness-of-fit was evaluated including P-values, MPB, MAD, MSPE, MSE, k, and CURE plots as introduced earlier. 


\subsection{Coding Merge Areas in VISSIM}

To validate that the conflicts can be considered as a surrogate measure to predict crashes for speed-change lane influence areas, merge areas were coded as an example. In some studies, it was suggested to code the transportation facilities in the Synchro microsimulation software (Saleem 2012; Lorion 2014), then export Synchro csv files into VISSIM for further analysis. However, error files were generated after importing the csv files to VISSIM. Thus, all the merge junctions were coded in VISSIM directly.

The collected data were used to model the geometric features and traffic volumes for the speed-change lane influence areas. Since the crash prediction models for merge influence areas were statistically significant, only the merge junctions were coded and simulated for further analysis.

\subsubsection{VISSIM Input Data}

The geometric data of merge areas were collected through Google Maps and Google Earth Pro. The traffic data and crash data were collected from MTO as described before. The following list indicates the input data for coding merge areas in VISSIM:

- $\quad$ Ramp location, ID

- Ramp configuration, type

- Length of acceleration lane

- $\quad$ Ramp length

- Number of lanes on mainline and ramps

- Lane width of mainline and ramps

- FPHV: freeway peak hour volumes

- $\quad$ RPHV: ramp peak hour volumes 
- HV\%: heavy vehicle percentage for freeway and ramps

- Desired speed for freeway mainline: $100 \mathrm{~km} / \mathrm{h}$ for cars and $80 \mathrm{~km} / \mathrm{h}$ for HV

- Desired speed for ramps: $40-60 \mathrm{~km} / \mathrm{h}$

- Ramp and mainline gradients are assumed to be $0 \%$

\subsubsection{Coding of Geometric Features}

For coding the geometry features, links were created to capture the through movements and general curvatures of a corridor with similar geometries. Connectors are used to join two areas with single or multiple links.

VISSIM 5.40-03 User Manual suggests using the method shown in Figure 16 to code the links and connectors for merge ramps, because this ensures the best vehicle behaviour when implementing merging and weaving sections in VISSIM. In addition, to avoid unrealistic lane changes from the mainline to the acceleration lane, the "Lane Change" distance in the connector dialog box should always be larger than the length of the acceleration lane. 


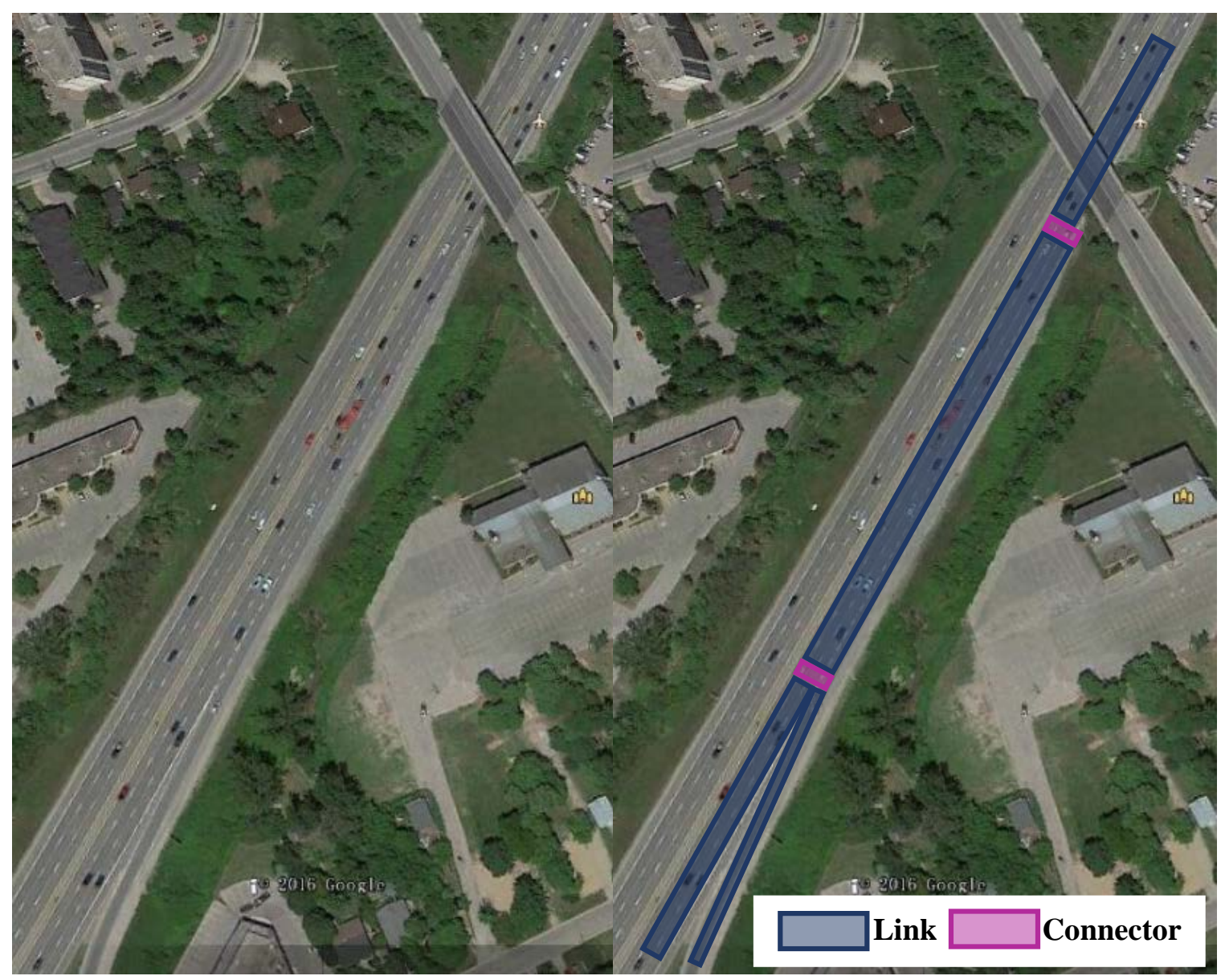

Figure 16. Suggested Coding for a Freeway Merge Area in VISSIM for 400-96-42

\subsubsection{Speed Control Coding}

To control the speed of vehicles in VISSIM, one method is to use the "vehicle composition" to determine the speed of each type of vehicle on the network. Another way is to apply "desired speed decisions" or "reduced speed area" to control the speed of vehicles on the links or in the areas which have a significant speed change due to posted speed limits, geometric changes, topography changes, or facility changes.

In this study, the speed of merging vehicles was controlled to get the best simulation results. The desired speed decision was applied in two areas. One area was at the midpoint of the acceleration 
lane, and the other area was at the end of the acceleration lane. The first spot speed at the midpoint of the acceleration lane was set with $70 \mathrm{~km} / \mathrm{h}$ for cars and $60 \mathrm{~km} / \mathrm{h}$ for heavy vehicles. The second spot speed at the end of the acceleration lane was set with $100 \mathrm{~km} / \mathrm{h}$ for cars and 80 $\mathrm{km} / \mathrm{h}$ for heavy vehicles.

Figure 17 shows an example of geometric features and speed coding results for ramp 42 on interchange 96 at freeway 400 (400-96-42).

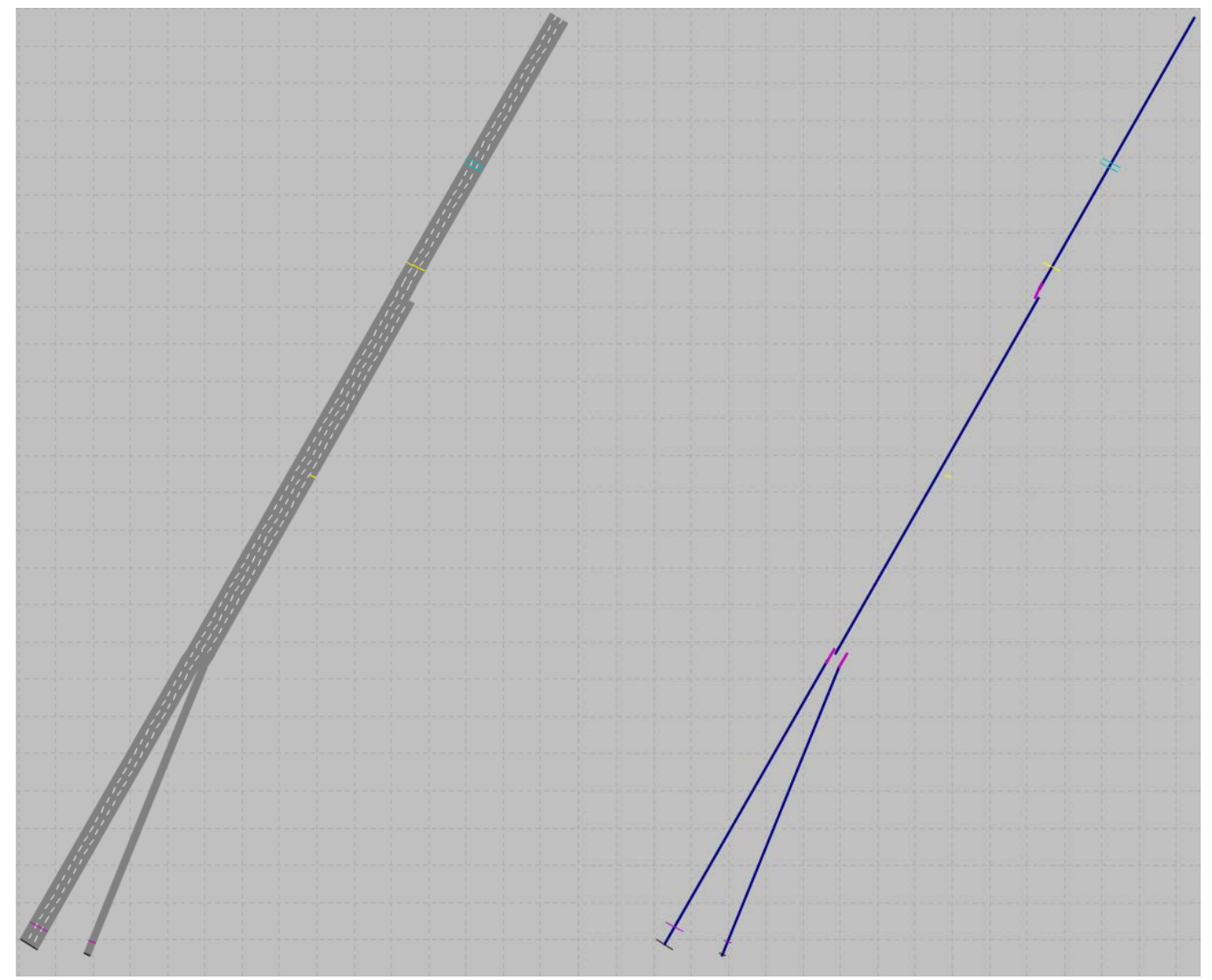

Figure 17. VISSIM Coding Example for 400-96-42

\subsection{Microscopic Simulation in VISSIM}

To further analyze the conflicts in SSAM, the coded merge areas should be simulated to generate vehicle trajectory files. 


\subsubsection{Model Calibration}

The driving behaviour for freeway links and connectors was based on the Wiedemann 99 model as suggested in the VISSIM 5.40-03 User Manual. The available lane changing parameters were the same for both freeway and arterial links, and they were applied on the same link type based on the car following model. Default parameters were used in this study for car following and lane change behaviour in the Wiedemann 99 model.

\subsubsection{Simulation Setting}

The simulations for 103 merging areas were conducted by VISSIM 5.40 using the following settings:

- Traffic regulations: Right-side Traffic

- Simulation Period: 3,600 Simulation seconds representing the peak hour

- Simulation resolution: 5 Time steps(s)/Sim.sec.

- $\quad$ Simulation speed: maximum

- $\quad$ Random Seed: 10

- $\quad$ Starting random seed: 1

- $\quad$ Random seed increment: 1

- Number of simulation runs: 10 runs

The simulation process was observed to ensure that the traffic behaviour and the coding method were correct. Figure 18 shows the simulation process of ramp 42 on interchange 96 at freeway 400. Merging behaviour could be observed clearly in this image as well. 


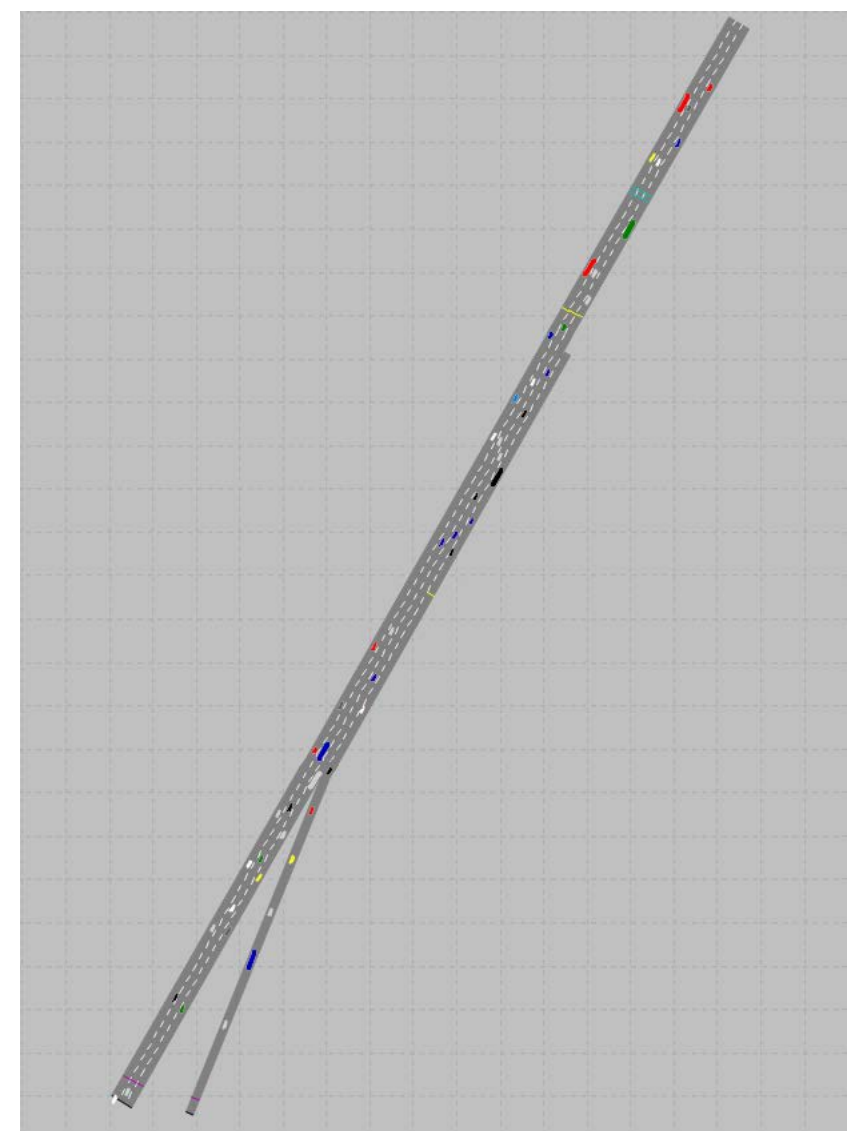

Figure 18. VISSIM Simulation for 400-96-42

\subsubsection{VISSIM Output}

The export configuration in VISSIM can generate SSAM Trajectory files. For each simulation run, one vehicle trajectory file was generated.

\subsection{Conflict Analysis from SSAM}

Trajectory files from VISSIM were imported into SSAM in order to estimate conflicts. After 10 runs of simulation, 10 trajectory files were generated for conflict analysis for one merge area. For merge areas, the major conflict types include total, rear-end, and lane change conflicts. The conflicts used for the crash-conflict integrated models were the average results of 10 simulation runs. 
Once the SSAM analysis process was complete, the conflict results could be filtered by different surrogate thresholds: conflict types, trajectory files, and dedicated areas. The conflicts were filtered using three steps.

- Step 1: Remove the conflicts with time to collision (TTC) and post-encroachment time (PET) values equal to zero. Zero values indicate errors in the simulation (Saleem 2012; Lorion 2014).

- Step 2: Filter the conflicts on the acceleration lane and adjacent mainline. When analyzing the crash-conflict integrated models, the influence areas for crashes and conflicts should be the same.

- Step 3: Filter TTC with different thresholds of 1.5, 1, and 0.5 seconds. For different TTC values, we can analyze the sensitivities of the models by conflict severity.

Figure 19 shows the SS AM conflict maps for ramp 42 located on interchange 96 of highway 400 (400-96-42) with different filters. The first map is the original output of conflicts without any filters. The second map is created by filtering the conflict using step 1 and 2 mentioned above. Since the maximum value for TTC is 1.5 in SSAM, TTC $\leq 1.5$ is already filtered in this map. The other two maps are of TTC $\leq 1.0$ and $\mathrm{TTC} \leq 0.5$.

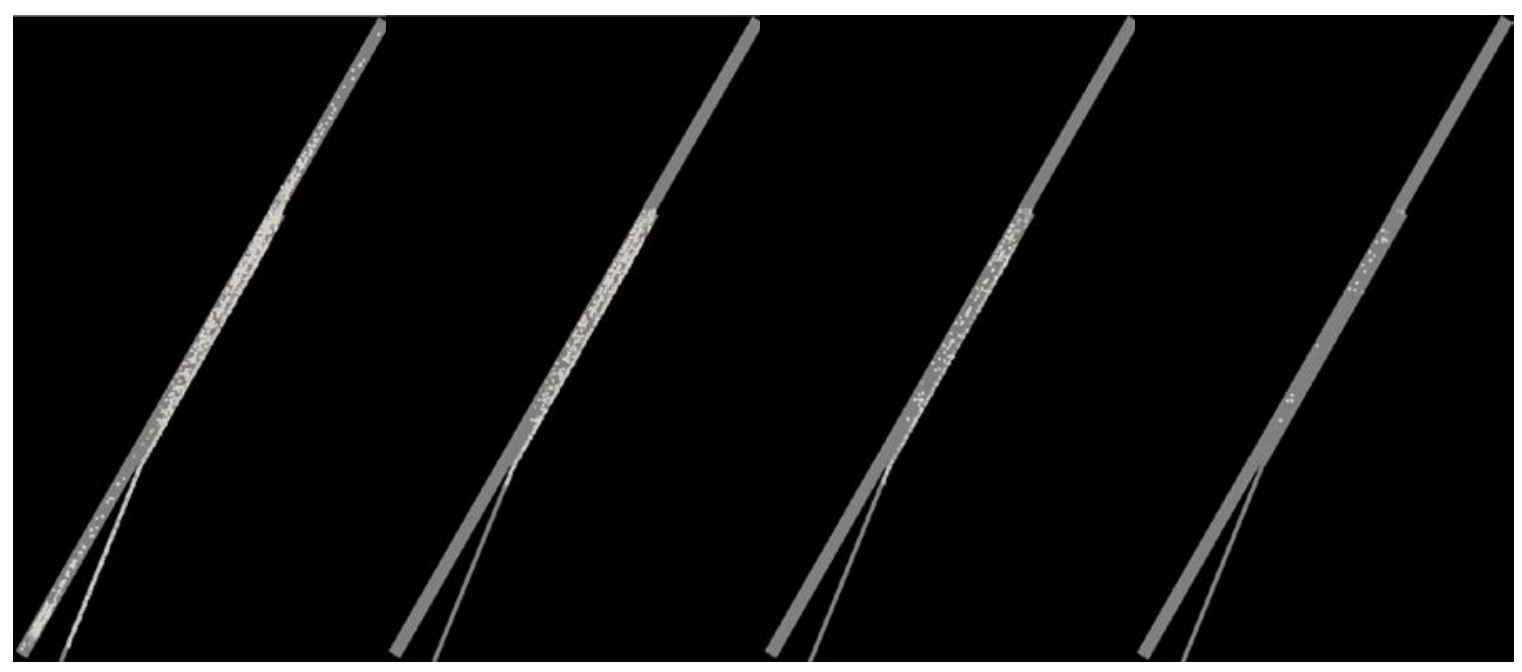

Figure 19. SSAM Conflict Maps for 400-96-42 with Different Filter Conditions 


\subsection{Development of Conflict-based Safety Performance Functions for Merge Areas}

For conflict-based SPFs, the independent variables in this model are different from crash-based SPFs, since the input of VISSIM is peak hour volumes (PHV) for freeways and on-ramps. In addition, the predicted variables are conflict types; thus there is no offset in the model for the parameter "years". Similarly, the crash-based SPFs and the conflict-based SPFs were also developed by SAS with the generalized linear models (GLM) with a negative binomial (NB) error structure. The goodness-of-fit was determined by evaluating P-values, MPB, MAD, MSPE, MSE, $\mathrm{k}$, and CURE plots for these models.

\subsection{Development of Crash-Conflict Integrated Safety Performance Functions for Merge Areas}

The purpose of developing the crash-conflict integrated SPFs is to find the relationship between conflict types and crash types, and to validate the conflicts as a surrogate safety measure for predicting crashes. For crash-conflict integrated SPFs, the average conflict counts of 10 simulation runs for each conflict type were used as an independent variable. The dependent variables were frequency of various crash types. Besides, the number of years is an offset parameter in the models so that the models estimate crashes per year. Similar to crash-based SPFs and conflict-based SPFs, the crash-conflict integrated SPFs were developed by SAS with the generalized linear model (GLM) with a negative binomial (NB) error structure. The goodness-of-fit was determined by evaluating P-values, MPB, MAD, MSPE, MSE, k, and CURE plots for these models. 


\section{Crash-based Crash Prediction Models}

This chapter mainly discusses the SPFs estimated for speed-change lanes by using conventional crash-based prediction models. In addition, the goodness-of-fit for each model was evaluated. The models developed in this chapter are listed as following:

- Crash-Merge-ACC SPFs (crash-based SPFs for merge areas with acceleration lane and adjacent mainline as influence areas)

- Crash-Merge-1,500 ft. SPFs (crash-based SPFs for merge areas with 1,500 ft. as influence areas)

- Crash-Diverge-DEC SPFs (crash-based SPFs for diverge areas with deceleration lane and adjacent mainline as influence areas)

- Crash-Diverge-1,500 ft. SPFs (crash-based SPFs for diverge areas with 1,500 ft. as influence areas)

- Crash-Weave-AUX SPFs (crash-based SPFs for weave areas with auxiliary lane and adjacent mainline as influence areas)

\subsection{Merge Areas}

To develop the SPFs for merge areas, data of 103 sites were collected. Two types of influence areas were evaluated and compared. In addition to the freeway and ramp AADT, the length of the acceleration lane was also considered as an independent variable in the models.

\subsubsection{Crash-Merge-ACC SPFs}

One advantage of these models is that no overlap areas exist between successive ramps, and this could reduce the bias in the models. The collision counts for Crash-Merge-ACC SPFs were collected from the acceleration lane and adjacent mainline. The influence area of each site varies 
according to the length of the acceleration lane. Since the collisions were collected from areas with different lengths, increasing the length could result in an increase in the collision numbers. However, the purpose of increasing the length of the acceleration lane is to reduce the collision counts. Thus, there is a dilemma in evaluating the effectiveness of the acceleration lane.

The model format for the Crash-Merge-ACC SPFs shown in Equation 6 has three independent variables: FAADT (freeway AADT), RAADT (ramp AADT), and ACC length (length of acceleration lane). Table 9 presents the coefficients and p-values for each model.

$$
\frac{\text { Crashes }}{\text { year }}=F A A D T^{\beta_{1}} \times R A A D T^{\beta_{2}} \times e^{\left(\alpha+\beta_{3} A C C L \text { ength }\right)}
$$

Table 9. Crash-Merge-ACC SPFs Results

\begin{tabular}{|c|c|c|c|c|c|c|c|c|c|}
\hline \multirow{2}{*}{ Crash Type } & \multicolumn{2}{|c|}{$\alpha$} & \multicolumn{2}{|c|}{$\beta_{1}$} & \multicolumn{2}{|c|}{$\beta_{2}$} & \multicolumn{2}{|c|}{$\beta_{3}$} & \multirow{2}{*}{$\mathrm{k}$} \\
\hline & Est & $\mathrm{P}>$ ChiSq & Est & $\mathrm{P}>$ ChiSq & Est & $\mathrm{P}>$ ChiSq & Est & $\mathrm{P}>$ ChiSq & \\
\hline Total & -6.1951 & 0.0001 & 0.4495 & 0.0043 & 0.4032 & $<.0001$ & -0.0031 & 0.0131 & 0.4748 \\
\hline F\&I & -10.3012 & $<.0001$ & 0.6822 & 0.0036 & 0.3792 & 0.0029 & -0.0028 & 0.0858 & 0.3919 \\
\hline PDO & -6.1559 & 0.0004 & 0.4367 & 0.0091 & 0.3957 & 0.0001 & -0.0033 & 0.0132 & 0.5275 \\
\hline Rear End & -17.0047 & $<.0001$ & 1.2354 & $<.0001$ & 0.5702 & $<.0001$ & -0.0036 & 0.0672 & 0.8501 \\
\hline Side Swipe & -10.6168 & $<.0001$ & 0.8400 & 0.0004 & 0.2449 & 0.0385 & -0.0037 & 0.0120 & 0.3021 \\
\hline Single Vehicle & -1.8167 & 0.2967 & 0.0277 & 0.8701 & 0.3447 & 0.0008 & -0.0037 & 0.0041 & 0.4603 \\
\hline
\end{tabular}

According to the p-values, the Crash-Merge-ACC models for Total, F\&I, PDO, Rear End and Side Swipe collisions have significant coefficients $(\mathrm{p}<0.05)$ except the SPF for single vehicle collisions. Because the coefficients for ACC length are negative, the estimated collisions will be reduced with increasing the length of the acceleration lane, despite the fact that exposure is increased.

The goodness-of-fit results are shown in Table 10. The CURE plots for FAADT, RAADT, ACC Length, and predicted crashes were evaluated separately for each crash type, and examples of 
good and poor CURE plots are presented in Figure 20 and Figure 21. The MPB, MAD, MES, and MSPE values are close to zero, indicating that the models fit the observed data reasonably well. The CURE plots are generally satisfactory but do identify some outliers in the models especially for the variable of freeway AADT in some models.

Table 10. Crash-Merge-ACC SPFs Goodness-of-Fit Results

\begin{tabular}{|c|c|c|c|c|c|c|}
\hline Crash Type & Total & F\&I & PDO & Rear End & Side Swipe & Single Vehicle \\
\hline Avg. Observed. Crashes/Year/Site & 0.0232 & 0.0042 & 0.0189 & 0.0085 & 0.0042 & 0.0102 \\
\hline MPB & -0.0044 & 0.0071 & -0.2310 & -0.0978 & -0.0220 & -0.0632 \\
\hline MPB/Year/Site & -0.0009 & 0.0014 & -0.0462 & -0.0196 & -0.0044 & -0.0126 \\
\hline MAD & 0.0044 & 0.0071 & 0.2310 & 0.0978 & 0.0220 & 0.0632 \\
\hline MAD/Year/Site & 0.0009 & 0.0014 & 0.0462 & 0.0196 & 0.0044 & 0.0126 \\
\hline MSPE & 114.1938 & 5.0309 & 85.1141 & 36.5214 & 4.3885 & 27.4070 \\
\hline MSPE/Year $^{2} /$ Site & 4.5678 & 0.2012 & 3.4046 & 1.4609 & 0.1755 & 1.0963 \\
\hline MSE/Site & 117.6197 & 5.1818 & 87.6676 & 37.6170 & 4.5202 & 28.2292 \\
\hline MSE/Year ${ }^{2} /$ Site & 4.7048 & 0.2073 & 3.5067 & 1.5047 & 0.1808 & 1.1292 \\
\hline
\end{tabular}

PDO Crash - FAADT CURE Plot

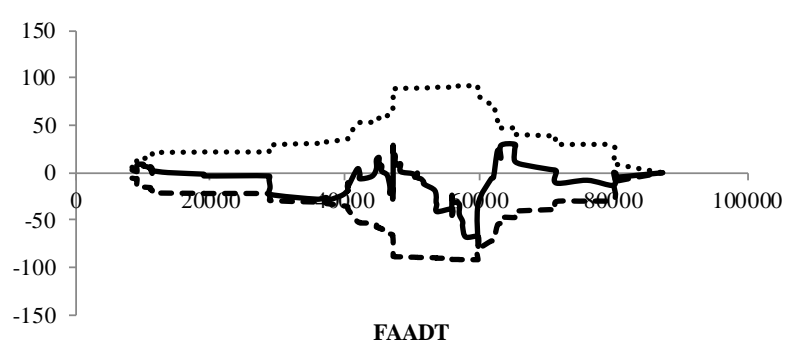

C Cumulative Res $\cdots \cdots \cdot 2 \sigma \quad-\quad--2 \sigma$

PDO Crash - ACC Length CURE Plot

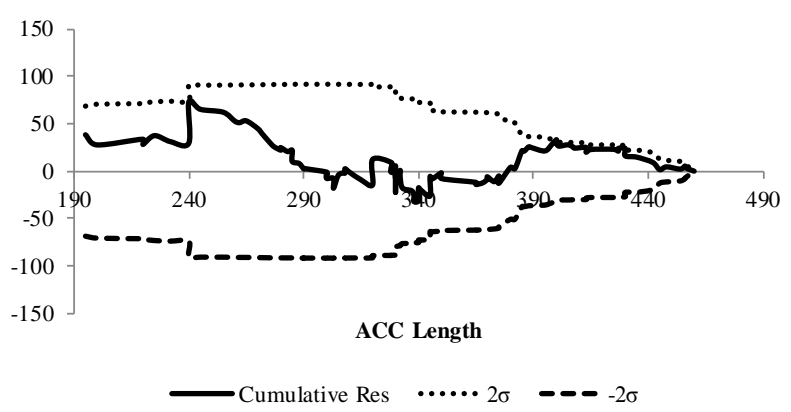

PDO Crash - RAADT CURE Plot

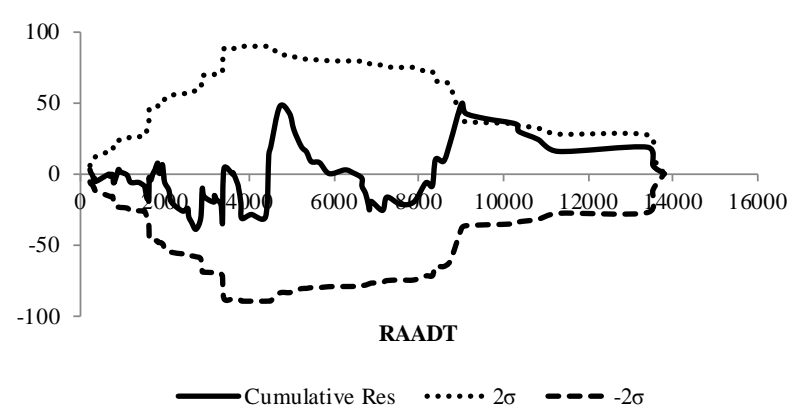

PDO Crash - Predicted PDO Crash CURE Plot

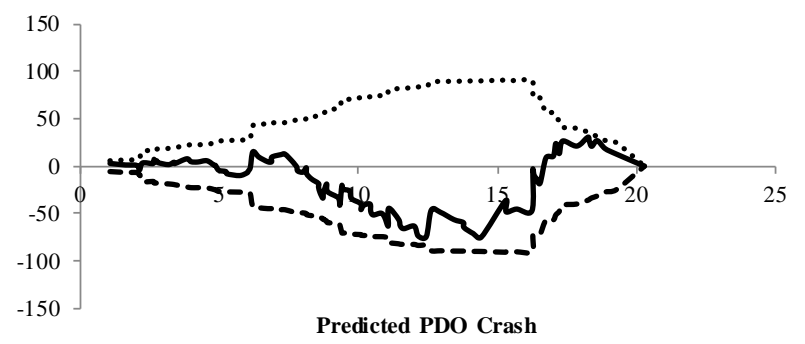

Figure 20. Crash-Merge-ACC SPFs PDO Crash CURE Plots (good CURE plots) 

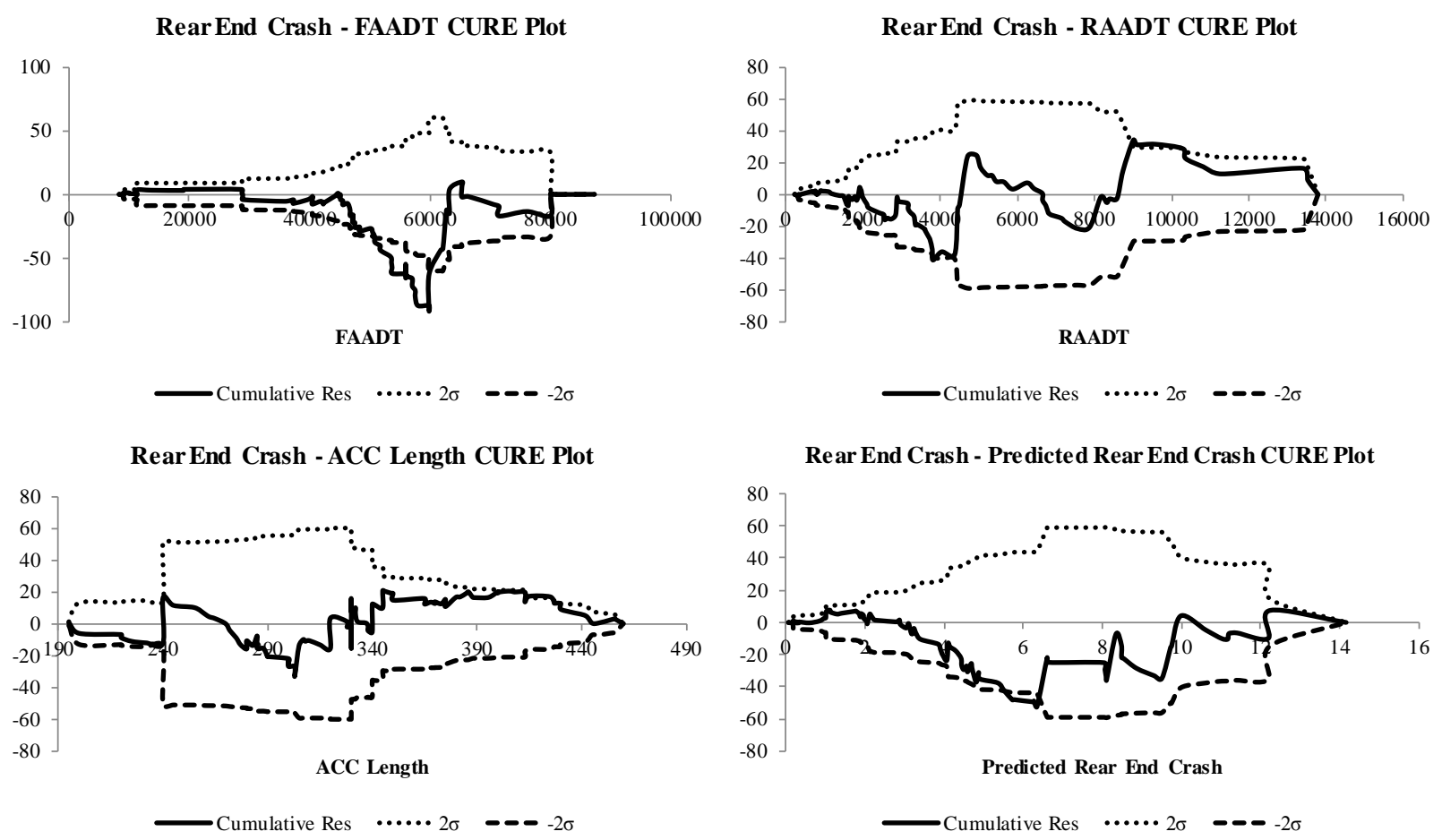

Figure 21. Crash-Merge-ACC SPFs Rear End Crash CURE Plots (CURE plots with outliers)

\subsubsection{Crash-Merge-1,500 ft. SPFs}

The collisions for Crash-Merge-1,500 ft. SPFs were collected from the 1,500 ft. section from the gore to the end of the taper. The influence area of each site is a fixed area with the same length on the freeways. Since the length of each site is the same, the comparison and evaluation the effectiveness of the acceleration lane is more reliable. However, for this type of influence area, there might be minor overlaps between adjacent ramps and the collisions would be double counted when developing the SPFs. In this case, bias would be introduced in the models. However, for some of the interchanges in Ontario with two successive on ramps shown in Figure 22 , the space between those two ramps is usually less than $1,500 \mathrm{ft}$; thus it is not feasible to eliminate the ramps with overlaps. 


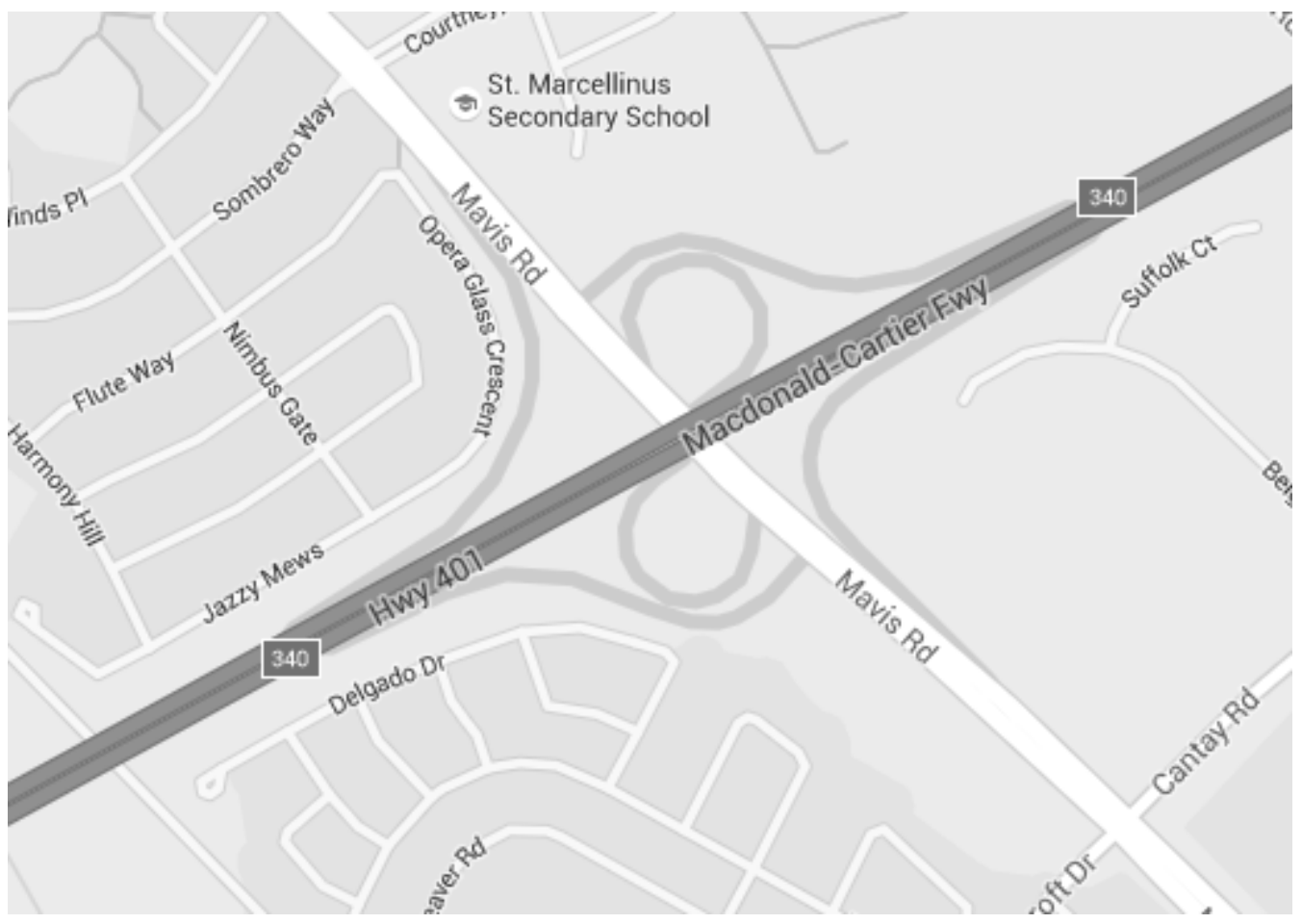

Figure 22. Example of an Interchange with Two Successive on Ramps

The model format of Crash-Merge-1,500 ft. SPFs shown in Equation 7 is the same as that of the Crash-Merge-ACC SPFs. Table 11 presents the coefficients and p-values for each model.

$$
\frac{\text { Crashes }}{\text { year }}=F A A D T^{\beta_{1}} \times R A A D T^{\beta_{2}} \times e^{\left(\alpha+\beta_{3} A C C L \text { ength }\right)}
$$

Table 11. Crash-Merge-1,500 ft. SPFs Results

\begin{tabular}{|c|c|c|c|c|c|c|c|c|c|}
\hline \multirow{2}{*}{ Crash Type } & \multicolumn{2}{|c|}{$\alpha$} & \multicolumn{2}{|c|}{$\beta_{1}$} & \multicolumn{2}{|c|}{$\beta_{2}$} & \multicolumn{2}{|c|}{$\beta_{3}$} \\
\cline { 2 - 11 } & Est & P>ChiSq & Est & P>ChiSq & Est & P>ChiSq & Est & P >ChiSq & $\mathrm{k}$ \\
\hline Total & -5.7854 & 0.0005 & 0.5801 & 0.0002 & 0.2474 & 0.0094 & -0.0040 & 0.0026 & 0.5494 \\
\hline F\&I & -10.1430 & $<.0001$ & 0.8408 & 0.0001 & 0.2006 & 0.0791 & -0.0033 & 0.0356 & 0.4279 \\
\hline PDO & -5.6620 & 0.0014 & 0.5490 & 0.0010 & 0.2551 & 0.0116 & -0.0041 & 0.0026 & 0.6059 \\
\hline Rear End & -15.1888 & $<.0001$ & 1.2729 & $<.0001$ & 0.4350 & 0.0018 & -0.0062 & 0.0016 & 0.9446 \\
\hline Side Swipe & -10.6625 & $<.0001$ & 1.0424 & $<.0001$ & 0.0436 & 0.7156 & -0.0044 & 0.0064 & 0.5344 \\
\hline Single Vehicle & -1.8556 & 0.3003 & 0.1545 & 0.3621 & 0.2094 & 0.0388 & -0.0036 & 0.0072 & 0.5588 \\
\hline
\end{tabular}

According to the p-values, the Crash-Merge-1,500 ft. models for Total, F\&I, PDO, and Rear End 
collisions have significant coefficients $(\mathrm{p}<0.05)$, except for the SPF for single vehicle collisions. Similar to the Crash-Merge-ACC SPFs, the coefficients for ACC length are negative despite the fact that the exposure is increased.

The goodness-of-fit results are shown in Table 12. The CURE plots for FAADT, RAADT, ACC Length, and predicted crashes were evaluated separately for each crash type, and examples of good and poor CURE plots are presented in Figure 23 and Figure 24. The MPB, MAD, MES, and MSPE values are close to zero, indicating that the models fit the observed data well. The CURE plots are reasonable but do identify some outliers in the models for freeway AADT in F\&I, rear-end, and single vehicle collision models.

Table 12. Crash-Merge-1,500 ft. SPFs Goodness-of-Fit Results

\begin{tabular}{|c|c|c|c|c|c|c|}
\hline Crash Type & Total & F\&I & PDO & Rear End & Side Swipe & Single Vehicle \\
\hline Avg. Observed. Crashes/Year/Site & 0.0301 & 0.0055 & 0.0247 & 0.0113 & 0.0056 & 0.0130 \\
\hline MPB & -0.3895 & -0.0563 & -0.0723 & -0.2657 & -0.0479 & -0.0684 \\
\hline MPB/Year/Site & -0.0779 & -0.0113 & -0.0145 & -0.0531 & -0.0096 & -0.0137 \\
\hline MAD & 0.3895 & 0.0563 & 0.0723 & 0.2657 & 0.0479 & 0.0684 \\
\hline MAD/Year/Site & 0.0779 & 0.0113 & 0.0145 & 0.0531 & 0.0096 & 0.0137 \\
\hline MSPE & 441.2821 & 14.2300 & 317.7532 & 144.2743 & 17.8285 & 61.2116 \\
\hline MSPE/Year ${ }^{2} /$ Site & 17.6513 & 0.5692 & 12.7101 & 5.7710 & 0.7131 & 2.4485 \\
\hline MSE & 454.5206 & 14.6569 & 327.2858 & 148.6025 & 18.3634 & 63.0479 \\
\hline MSE/Year ${ }^{2} /$ Site & 18.1808 & 0.5863 & 13.0914 & 5.9441 & 0.7345 & 2.5219 \\
\hline
\end{tabular}


PDO Crash - FAADT CURE Plot

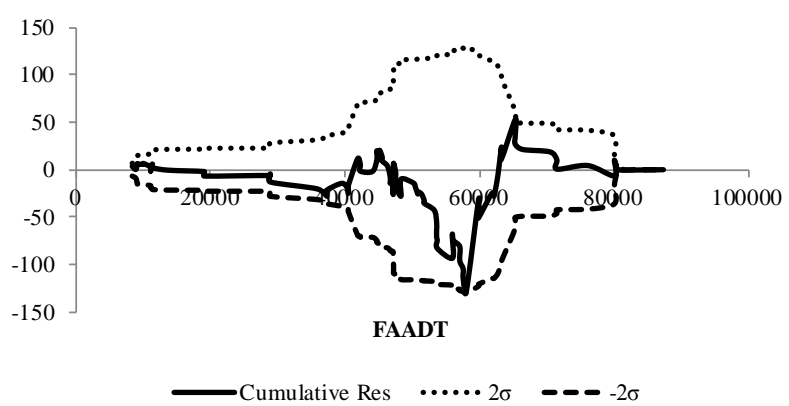

PDO Crash - ACC Length CURE Plot

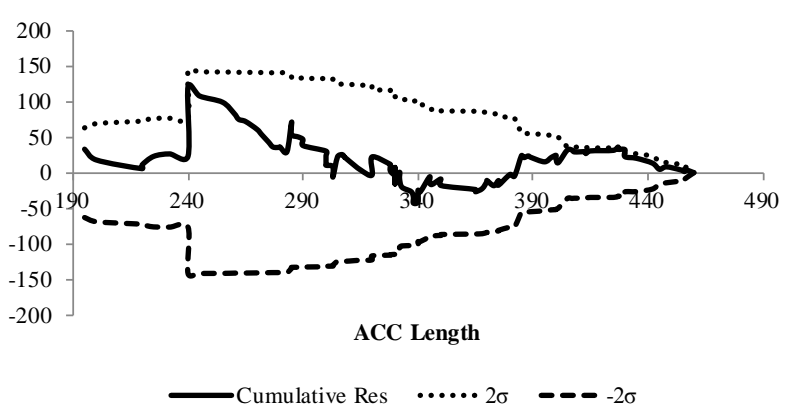

PDO Crash - RAADT CURE Plot

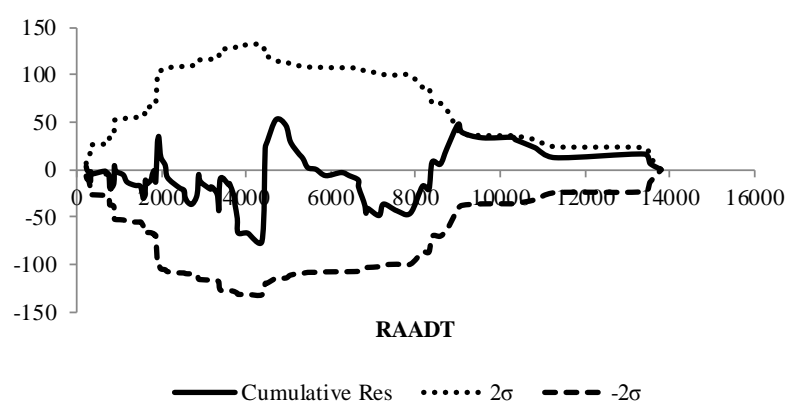

PDO Crash - Predicted PDO Crash CURE Plot

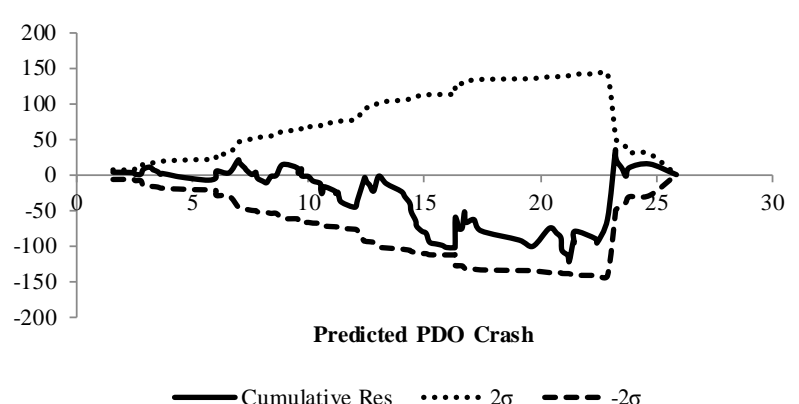

Figure 23. Crash-Merge-1,500 ft. SPFs PDO Crash CURE Plots (good CURE plots)
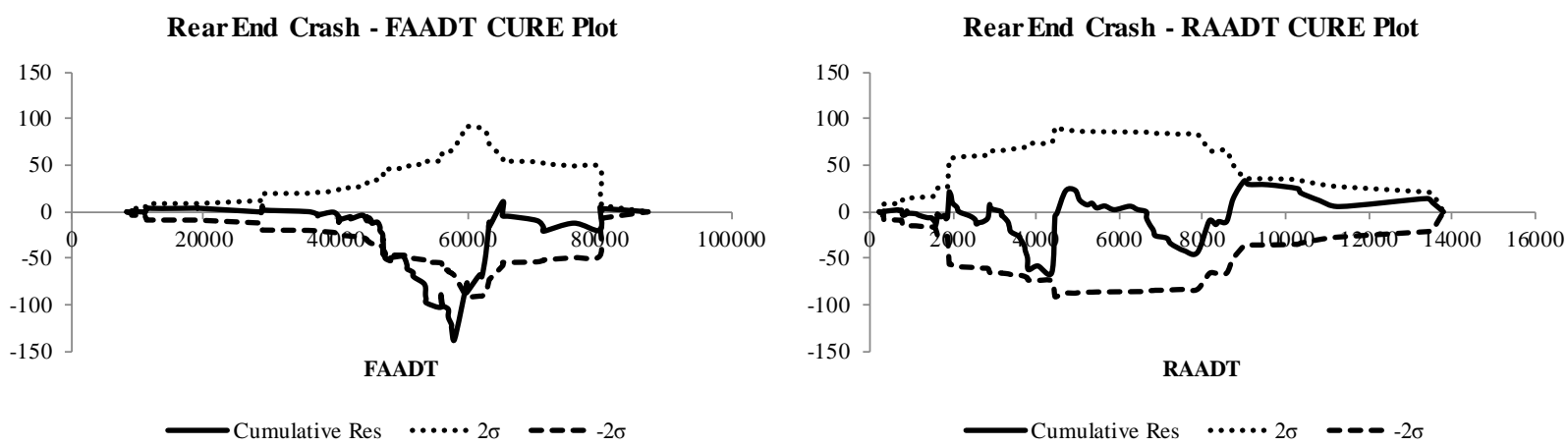

RearEnd Crash - ACC Length CURE Plot
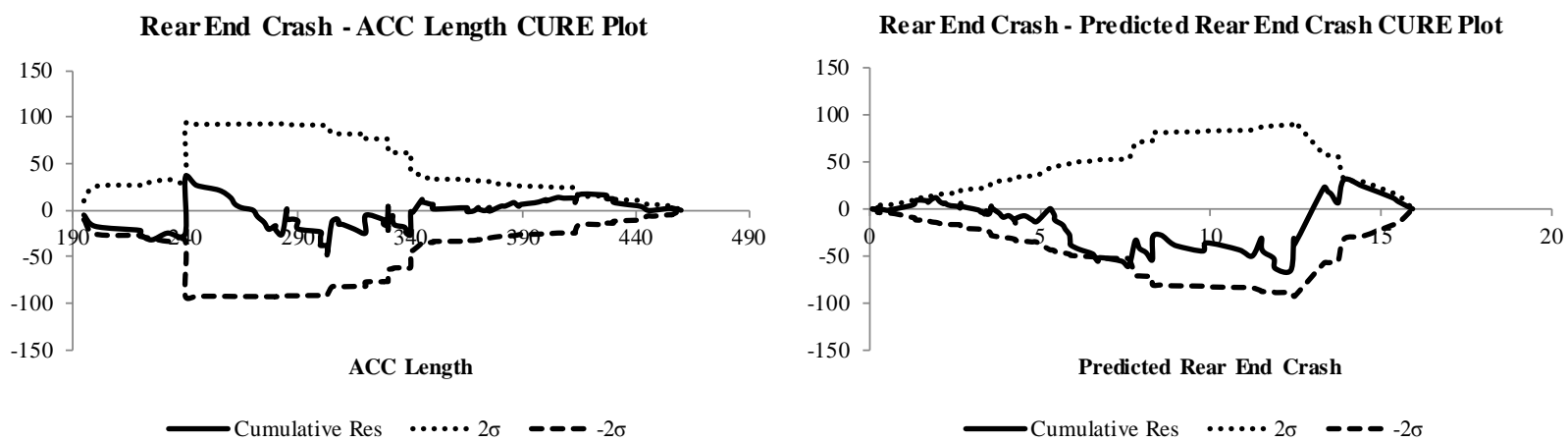

Figure 24. Crash-Merge-1,500 ft. SPFs Rear End Crash CURE Plots (CURE plots with outliers) 


\subsubsection{Model Comparison}

For merge areas, two types of influence areas were evaluated to capture the safety performance of merge areas. Both methods produced models with statistically significant parameters. Also, the obtained goodness-of-fit and CURE plots indicate good fit of the models. The coefficients for acceleration lane length are negative in both conditions with larger coefficients for 1,500 ft. influence areas. In sum, either model could be used to find the CMFs for lengthening acceleration lanes. 


\subsection{Diverge Areas}

To develop the SPFs for diverge areas, data for 78 sites were collected. Two types of influence areas were evaluated and compared. In addition to the freeway and ramp AADT, the length of the deceleration lane was considered as an independent variable in the models.

\subsubsection{Crash-Diverge-DEC SPFs}

The collision counts for Crash-Diverge-ACC SPFs were collected from the deceleration lane and the adjacent mainline. Similar to Crash-Merge-ACC SPFs, the influence area is different for each site when evaluating the safety performance of the deceleration lanes.

The model format for Crash-Diverge-ACC SPFs is shown in Equation 8. Unlike the SPFs for merge areas, freeway AADT and ramp AADT were combined to get better p-values in these models. Table 13 presents the coefficients and p-values for each model.

$$
\frac{\text { Crashes }}{\text { year }}=(F A A D T+R A A D T)^{\beta_{1}} \times e^{\left(\alpha+\beta_{2} D E C L \text { ength }\right)}
$$

Table 13. Crash-Diverge-DEC SPFs Results

\begin{tabular}{|c|c|c|c|c|c|c|c|}
\hline \multirow{2}{*}{ Crash Type } & \multicolumn{2}{|c|}{$\alpha$} & \multicolumn{2}{|c|}{$\beta_{1}$} & \multicolumn{2}{|c|}{$\beta_{2}$} & \multirow{2}{*}{$\mathrm{k}$} \\
\cline { 2 - 8 } & Est & P>ChiSq & Est & P>ChiSq & Est & P>ChiSq & \\
\hline Total & -6.5770 & 0.0003 & 0.6514 & 0.0002 & 0.0012 & 0.3921 & 0.7050 \\
\hline F\&I & -5.9463 & 0.0149 & 0.4542 & 0.0563 & 0.0002 & 0.9143 & 0.7240 \\
\hline PDO & -7.4997 & $<.0001$ & 0.7142 & 0.0001 & 0.0014 & 0.3320 & 0.7353 \\
\hline Rear End & -14.7179 & $<.0001$ & 1.2579 & $<.0001$ & 0.0022 & 0.2399 & 1.2652 \\
\hline Side Swipe & -15.3666 & $<.0001$ & 1.3225 & $<.0001$ & 0.0006 & 0.7187 & 0.6425 \\
\hline Single Vehicle & -3.0095 & 0.1233 & 0.2870 & 0.1314 & -0.0001 & 0.9339 & 0.7225 \\
\hline
\end{tabular}

According to Table 13, except for single vehicle collisions, all the p-values for intercepts and traffic volumes indicate significance at the 95\% confidence level. However, the p-values of DEC 
length in all models were not significant. Moreover, the coefficients are positive, which is not intuitive. Therefore, using the deceleration lane and adjacent mainline as an influence area may not be appropriate in capturing the safety performance of diverge areas, or evaluating the effectiveness of deceleration lanes.

The goodness-of-fit results are shown in Table 14. The CURE Plots for FAADT and RAADT, DEC Length, and predicted crashes were evaluated separately for each crash type, and examples of good and poor CURE plots are presented in Figure 25 and Figure 26. The MPB, MAD, MES, and MSPE values are close to zero, indicating that the models fit the observed data reasonably well. There is little or no bias in the CURE plots for each model.

Table 14. Crash-Diverge-DEC SPFs Goodness-of-Fit Results

\begin{tabular}{|c|c|c|c|c|c|c|}
\hline Crash Type & Total & F\&I & PDO & Rear End & Side Swipe & Single Vehicle \\
\hline Avg. Observed. Crashes/Year/Site & 0.0277 & 0.0046 & 0.0231 & 0.0088 & 0.0054 & 0.0132 \\
\hline MPB & -0.0837 & 0.0004 & -0.0622 & -0.2501 & -0.0257 & 0.0177 \\
\hline MPB/Year/Site & -0.0167 & 0.0001 & -0.0164 & -0.0661 & -0.0068 & 0.0047 \\
\hline MAD & 0.0837 & 0.0005 & 0.0821 & 0.3303 & 0.0339 & 0.0233 \\
\hline MAD/Year/Site & 0.0167 & 0.0001 & 0.0164 & 0.0661 & 0.0068 & 0.0047 \\
\hline MSPE & 201.4012 & 6.5216 & 141.3596 & 50.7898 & 7.5817 & 30.1321 \\
\hline MSPE/Year ${ }^{2} /$ Site & 8.0560 & 0.2609 & 5.6544 & 2.0316 & 0.3033 & 1.2053 \\
\hline MSE & 196.2371 & 6.3544 & 137.7350 & 49.4875 & 7.3873 & 29.3595 \\
\hline MSE/Year ${ }^{2} /$ Site & 7.8495 & 0.2542 & 5.5094 & 1.9795 & 0.2955 & 1.1744 \\
\hline
\end{tabular}



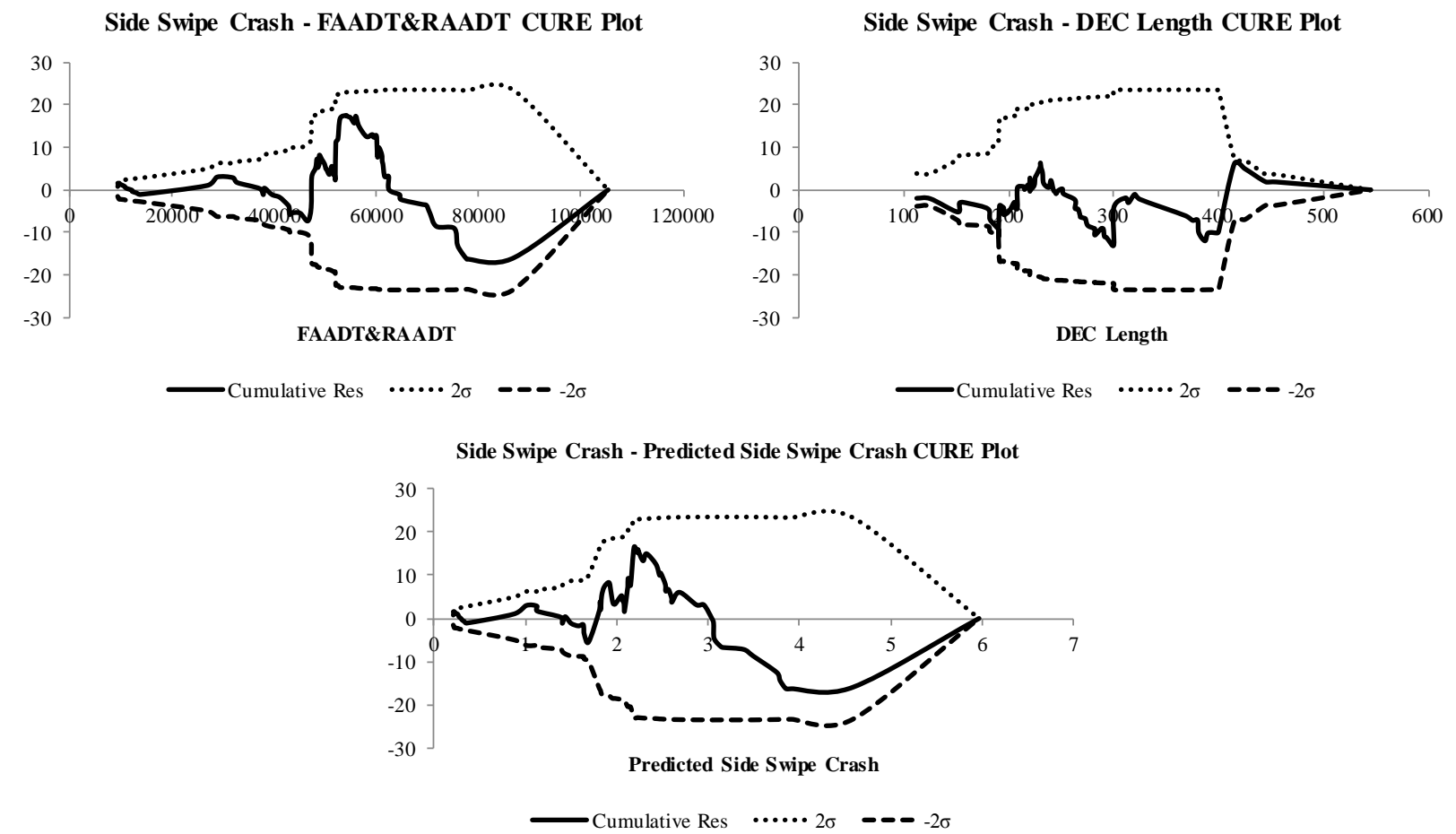

Figure 25. Crash-Diverge-DEC SPFs Side Swipe Crash CURE Plots (good CURE plots)
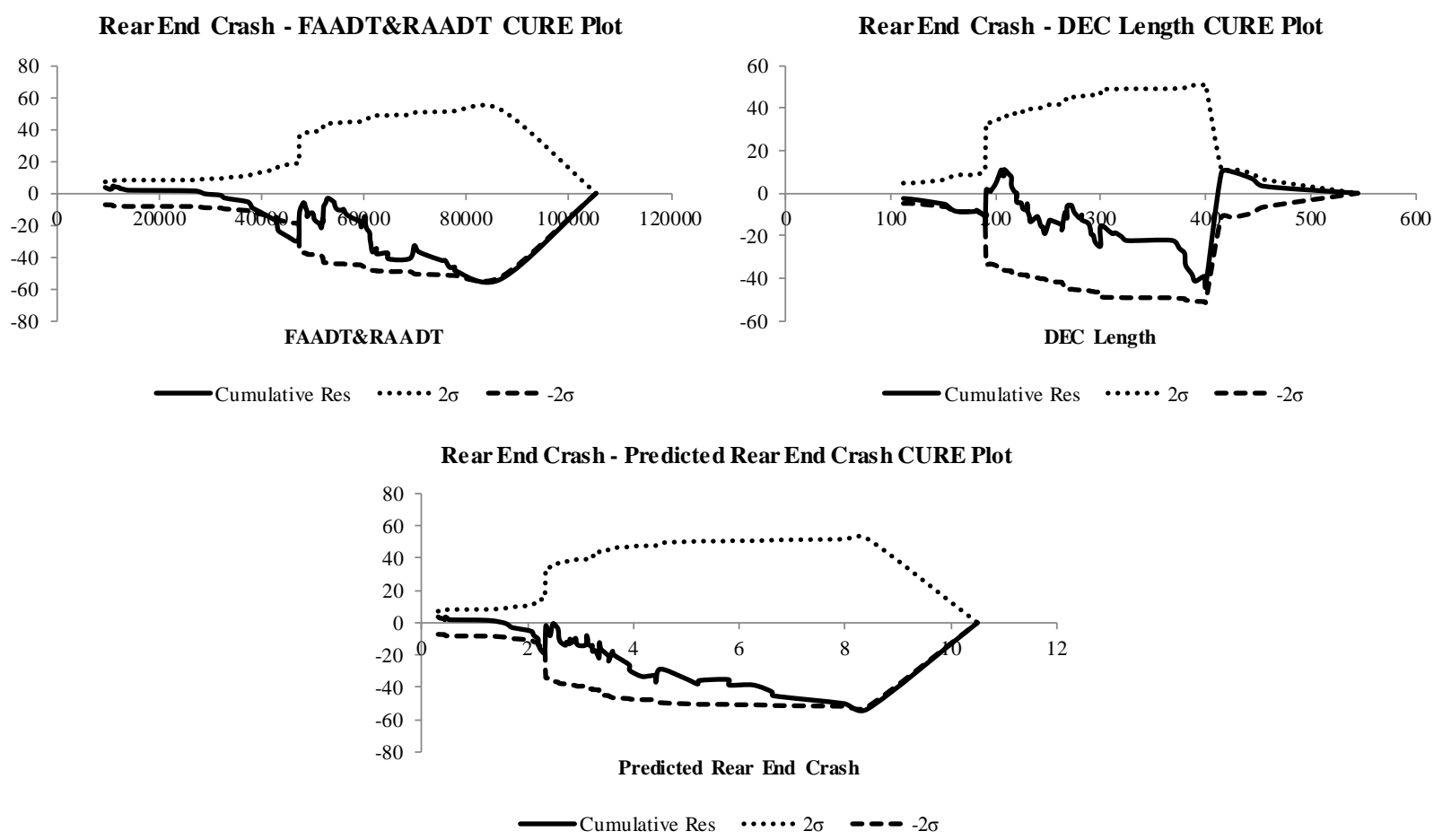

Figure 26. Crash-Diverge-DEC SPFs Rear End Crash CURE Plots (CURE plots with several outliers) 


\subsubsection{Crash-Diverge-1,500 ft. SPFs}

The collision counts for Crash-Diverge-1,500 ft. SPFs were collected from the 1,500 ft. section from the beginning of taper to the gore. Similar to Crash-Merge-1,500 $\mathrm{ft}$. SPFs, the influence area is a fixed area with same length.

The model format for Crash-Diverge-1,500 ft. SPFs is shown in Equation 9, and Table 15 presents the coefficients and p-values for each model.

$$
\frac{\text { Crashes }}{\text { year }}=(F A A D T+R A A D T)^{\beta_{1}} \times e^{\left(\alpha+\beta_{2} D E C L e n g t h\right)}
$$

(Equation 9)

Table 15. Crash-Diverge-1,500 ft. SPFs Results

\begin{tabular}{|c|c|c|c|c|c|c|c|}
\hline \multirow{2}{*}{ Crash Type } & \multicolumn{2}{|c|}{$\alpha$} & \multicolumn{2}{|c|}{$\beta_{1}$} & \multicolumn{2}{c|}{$\beta_{2}$} \\
\cline { 2 - 8 } & Est & P>ChiSq & Est & P >ChiSq & Est & P>ChiSq \\
\hline Total & -5.5235 & 0.0003 & 0.6685 & $<.0001$ & -0.0025 & 0.0170 & 0.4138 \\
\hline F\&I & -4.5003 & 0.0230 & 0.4586 & 0.0136 & -0.0046 & 0.0005 & 0.2577 \\
\hline PDO & -6.3169 & $<.0001$ & 0.7168 & $<.0001$ & -0.0021 & 0.0495 & 0.4486 \\
\hline Rear End & -13.4561 & $<.0001$ & 1.2734 & $<.0001$ & -0.0021 & 0.1603 & 0.8459 \\
\hline Side Swipe & -12.3289 & $<.0001$ & 1.1584 & $<.0001$ & -0.0029 & 0.0113 & 0.2638 \\
\hline Single Vehicle & -2.2762 & 0.1869 & 0.3161 & 0.0541 & -0.0030 & 0.0165 & 0.4899 \\
\hline
\end{tabular}

According to the results shown in Table 15, most of the p-values indicate significance at the 95\% confidence level, which is an improvement on the Crash-Diverge-DEC SPFs. Also, the coefficients for DEC length are negative, which indicates that the models can capture the safety performance of diverge areas by using 1,500 $\mathrm{ft}$. as influence areas, and can thus be used to evaluate the safety effects of changing deceleration lane length.

The goodness-of-fit results are shown in Table 16. The CURE plots for FAADT and RAADT, DEC Length, and predicted crashes were evaluated separately for each crash type, and examples 
of good and poor CURE plots are presented in Figure 27 and Figure 28. The MPB, MAD, MES, and MSPE values are close to zero, indicating that the models fit the observed data reasonably well. The CURE plots of deceleration lane for each model showed better results with little or no bias compared with other plots.

Table 16. Crash-Diverge-1,500 ft. SPFs Goodness-of-Fit Result

\begin{tabular}{|c|c|c|c|c|c|c|}
\hline Crash Type & Total & F\&I & PDO & Rear End & Side Swipe & Single Vehicle \\
\hline Avg. Observed. Crashes/Year/Site & 0.0356 & 0.0060 & 0.0296 & 0.0101 & 0.0071 & 0.0180 \\
\hline MPB & -0.1290 & 0.0169 & 0.0605 & -0.0225 & 0.0296 & -0.0271 \\
\hline MPB/Year/Site & -0.0258 & 0.0045 & 0.0160 & -0.0059 & 0.0078 & -0.0072 \\
\hline MAD & 0.1290 & 0.0223 & 0.0799 & 0.0297 & 0.0391 & 0.0358 \\
\hline MAD/Year/Site & 0.0258 & 0.0045 & 0.0160 & 0.0059 & 0.0078 & 0.0072 \\
\hline MSPE & 107.0360 & 3.5125 & 81.8474 & 21.1100 & 5.1766 & 31.3480 \\
\hline MSPE/Year ${ }^{2} /$ Site & 4.2814 & 0.1405 & 3.2739 & 0.8444 & 0.2071 & 1.2539 \\
\hline MSE & 109.8528 & 3.6049 & 84.0013 & 21.6656 & 5.3128 & 32.1729 \\
\hline MSE/Year ${ }^{2} /$ Site & 4.3941 & 0.1442 & 3.3601 & 0.8666 & 0.2125 & 1.2869 \\
\hline
\end{tabular}

F\&I Crash - FAADT\&RAADT CURE Plot

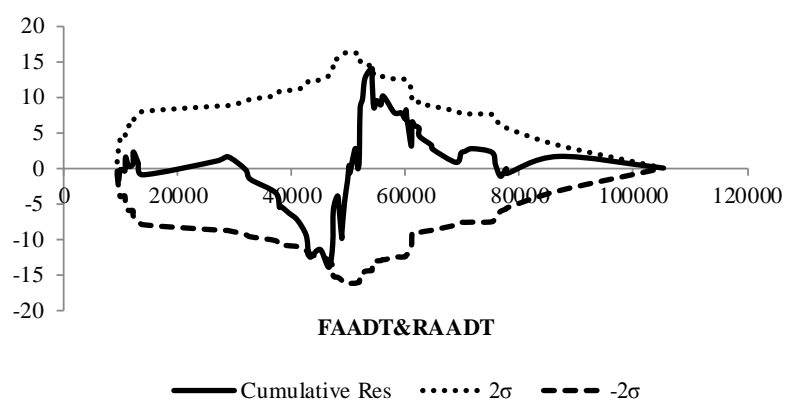

F\&I Crash - DEC Length CURE Plot

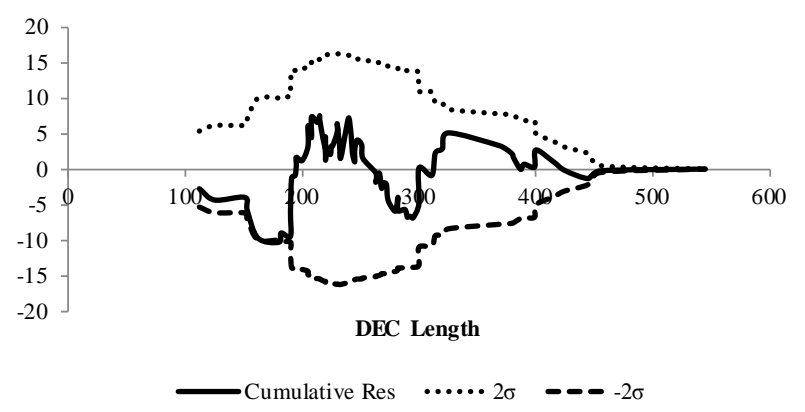

F\&I Crash - Predicted F\&I Crash CURE Plot

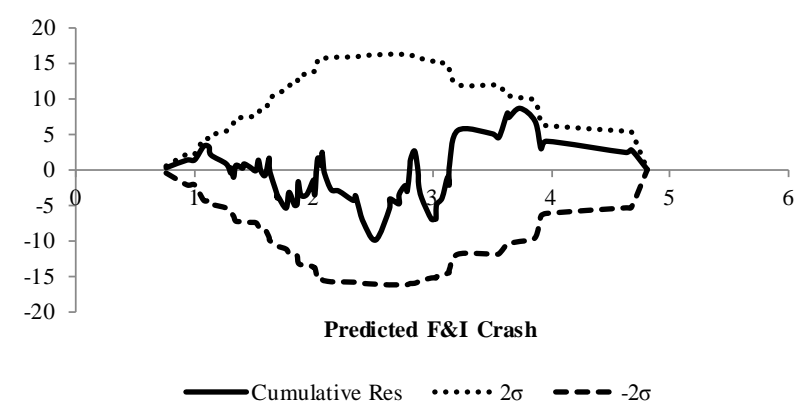

Figure 27. Crash-Diverge-1,500 ft. SPFs F\&I Crash CURE Plots (good CURE plots) 

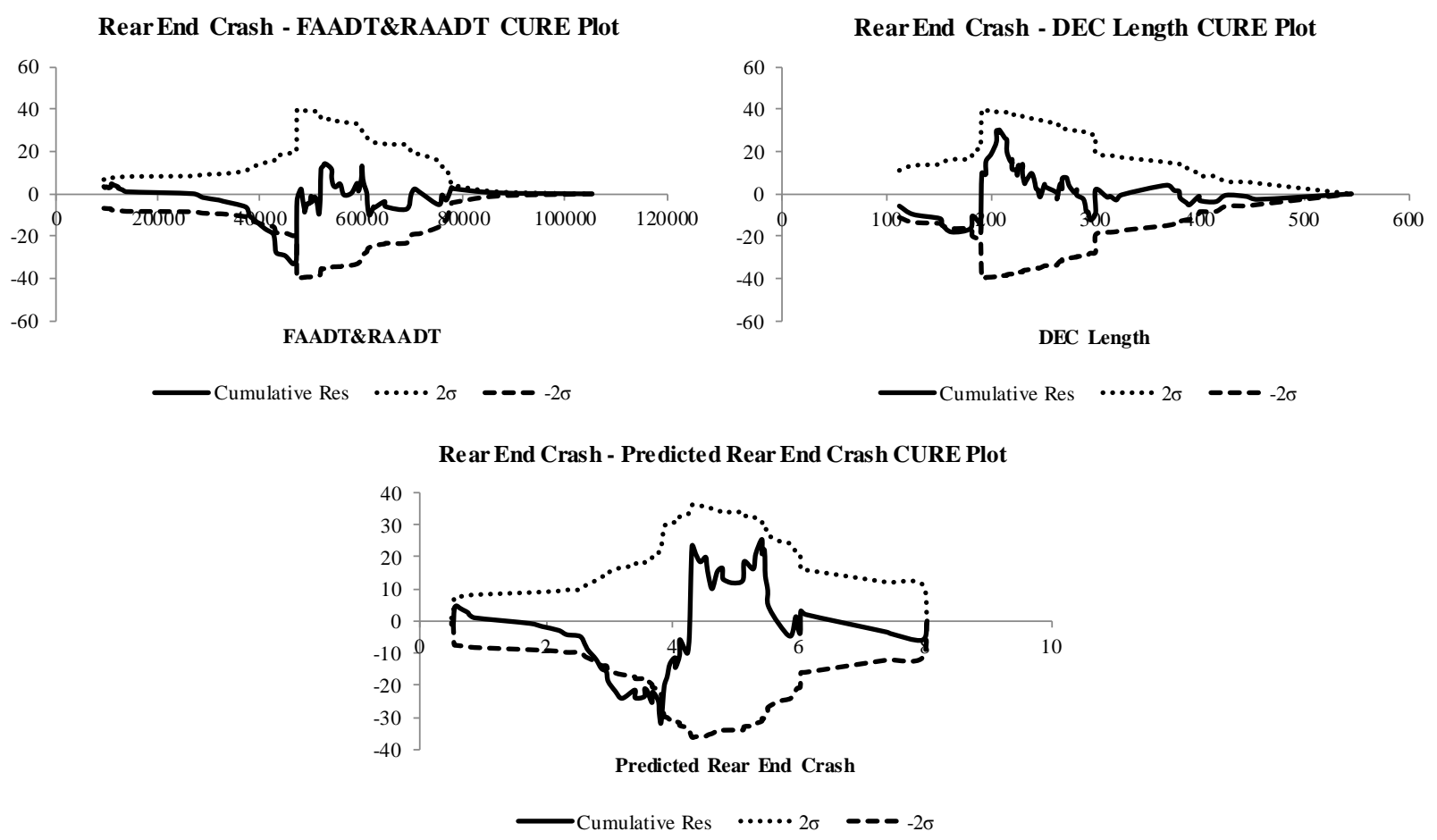

Figure 28. Crash-Diverge-1,500 ft. SPFs Rear End Crash CURE Plots (CURE plots with several outliers)

\subsubsection{Model Comparison}

For diverge areas, two approaches were pursued to develop the SPFs with different types of influence areas. However, the parameters for Crash-Diverge-DEC models are not statistically significant. The Crash-1,500 ft.-DEC SPFs show better results for p-values, goodness-of-fit, and CURE plots. The coefficients for deceleration lane length are negative. In sum, this model could be used to estimate CMFs for changing deceleration lane length.

\subsection{Weave Areas}

Collision data for 22 sites were collected from auxiliary lanes and adjacent freeway mainline to develop the SPFs for weave areas. The influence area of each site varies according to the length of the auxiliary lane. 
The model format of Crash-Weave-AUX SPFs shown in Equation 10 has two variables: FAADT (freeway $\mathrm{AADT}$ ) and the AUX length (length of the auxiliary lane). Table 17 presents the coefficients and p-values for each model.

$$
\frac{\text { Crashes }}{\text { year }}=F A A D T^{\beta_{1}} \times e^{\left(\alpha+\beta_{2} \text { AUXLength }\right)}
$$

Table 17. Crash-Weave-AUX SPFs Results

\begin{tabular}{|c|c|c|c|c|c|c|c|}
\hline \multirow{2}{*}{ Crash Type } & \multicolumn{2}{|c|}{$\alpha$} & \multicolumn{2}{|c|}{$\beta_{1}$} & \multicolumn{2}{c|}{$\beta_{2}$} \\
\cline { 2 - 8 } & Est & P>ChiSq & Est & P $>$ ChiSq & Est & P $>$ ChiSq & $k$ \\
\hline Total & -12.9051 & 0.0110 & 1.1751 & 0.0116 & 0.0015 & 0.0132 & 0.1848 \\
\hline F\&I & -8.1769 & 0.2366 & 0.6136 & 0.3356 & 0.0016 & 0.0576 & 0.1591 \\
\hline PDO & -15.5776 & 0.0038 & 1.3931 & 0.0046 & 0.0015 & 0.0169 & 0.1767 \\
\hline Rear End & -33.9467 & 0.0005 & 2.9288 & 0.0009 & 0.0023 & 0.0399 & 0.5039 \\
\hline Side Swipe & -13.5358 & 0.0607 & 1.1199 & 0.0888 & 0.0013 & 0.0990 & 0.1734 \\
\hline Single Vehicle & 0.0150 & 0.9974 & -0.0565 & 0.8931 & 0.0011 & 0.0539 & 0.0131 \\
\hline
\end{tabular}

According to the p-values, the Crash-Weave-AUX models for Total, PDO, Rear End and Side Swipe collisions have significant coefficients $(\mathrm{p}<0.10)$. Since the coefficients for AUX length are positive, the estimated collisions would be increased with increasing length of the auxiliary lane. However, the small sample size may introduce bias to the results. It is also possible that this result is reflecting the effect of increased exposure with increasing length.

The goodness-of-fit results are shown in Table 18. The CURE plots for FAADT, AUX Length, and predicted crashes were evaluated separately for each crash type. All the CURE plots show good results without outliers or large vertical drops, and one example is shown in Figure 29. The MPB, MAD, MES, and MSPE values are close to zero, indicating that the models fit the observed data reasonably well. CURE plots for each model are reasonable, with no outliers or large drops. 
Table 18. Crash-Weave-AUX SPFs Goodness-of-Fit Results

\begin{tabular}{|c|c|c|c|c|c|c|}
\hline Crash Type & Total & F\&I & PDO & Rear End & Side Swipe & Single Vehicle \\
\hline Avg. Observed. Crashes/Year/Site & 0.1306 & 0.0310 & 0.0996 & 0.0492 & 0.0326 & 0.0471 \\
\hline MPB & -0.2667 & -0.0133 & 0.0071 & 0.0110 & -0.0048 & 0.0253 \\
\hline MPB/Year/Site & -0.0533 & -0.0125 & 0.0067 & 0.0103 & -0.0045 & 0.0237 \\
\hline MAD & 0.2667 & 0.0625 & 0.0334 & 0.0516 & 0.0223 & 0.1185 \\
\hline MAD/Year/Site & 0.0533 & 0.0125 & 0.0067 & 0.0103 & 0.0045 & 0.0237 \\
\hline MSPE & 61.3497 & 5.6742 & 40.4102 & 19.8085 & 6.3043 & 5.5157 \\
\hline MSPE/Year ${ }^{2} /$ Site & 2.4540 & 0.2270 & 1.6164 & 0.7923 & 0.2522 & 0.2206 \\
\hline MSE & 67.4846 & 6.2416 & 44.4513 & 21.7893 & 6.9347 & 6.0673 \\
\hline MSE/Year ${ }^{2} /$ Site & 2.6994 & 0.2497 & 1.7781 & 0.8716 & 0.2774 & 0.2427 \\
\hline
\end{tabular}

Total Crash - FAADT CURE Plot

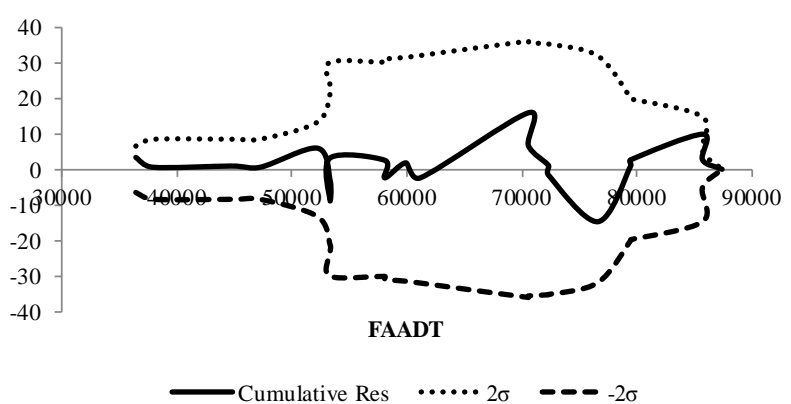

Total Crash - AUX Length CURE Plot

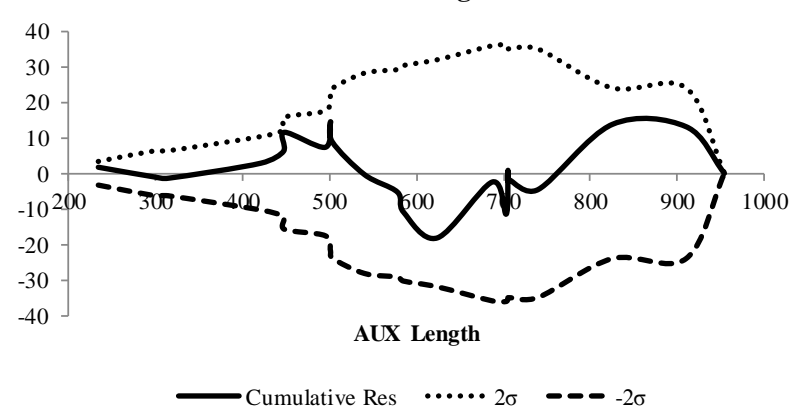

Total Crash - Predicted Total Crash CURE Plot



Figure 29. Crash-Weave-AUX SPFs Total Crash CURE Plots (good CURE plots) 


\section{Conflict Prediction Models}

Conflict Prediction Models were developed to assess the sensitivity of simulated conflicts to parameters such as length of speed change lanes, and the goodness-of-fit for each model was evaluated. Besides, to test the sensitivity of the time to collision (TTC) simulation parameter, different TTC thresholds were evaluated and compared. Following is the list of the models developed in this chapter:

- Conflict-Merge-ACC SPFs -TTC $\leq 1.5 \mathrm{~s}$ (conflict SPFs for merge areas with acceleration lane and adjacent mainline as influence areas for $\mathrm{TTC} \leq 1.5 \mathrm{~s}$ )

- Conflict-Merge-ACC SPFs -TTC $\leq 1.0$ s (conflict SPFs for merge areas with acceleration lane and adjacent mainline as influence areas for $\mathrm{TTC} \leq 1.0 \mathrm{~s}$ )

- Conflict-Merge-ACC SPFs -TTC $\leq 0.5 \mathrm{~s}$ (conflict SPFs for merge areas with acceleration lane and adjacent mainline as influence areas for $\mathrm{TTC} \leq 0.5 \mathrm{~s}$ )

\subsection{TTC $\leq 1.5 \mathrm{~s}$}

The conflict statistics for TTC $\leq 1.5 \mathrm{~s}$ are shown in Table 19 .

Table 19. Conflict Statistics for $\mathrm{TTC} \leq 1.5 \mathrm{~s}$

\begin{tabular}{|c|c|c|c|}
\hline Conflicts & Total & Rear End & Lane Change \\
\hline Sum & 5759 & 4276 & 1483 \\
\hline Maximum & 491 & 454 & 99 \\
\hline Minimum & 0 & 0 & 0 \\
\hline Mean & 55.91 & 41.51 & 14.40 \\
\hline Percentage & $100.00 \%$ & $74.25 \%$ & $25.75 \%$ \\
\hline
\end{tabular}

The model format for Conflict-Merge-ACC SPFs is shown in Equation 11. Three independent variables including FPHV (freeway peak hour volume), RPHV (ramp peak hour volume), and ACC Length (length of acceleration lane) were evaluated. Models were estimated for Total, Rear 
End, and Lane Change conflicts and the results are shown in Table 20.

$$
\text { Conflicts }=F P H V^{\beta_{1}} \times R P H V^{\beta_{2}} \times e^{\left(\alpha+\beta_{3} \text { ACCLength }\right)}
$$

Table 20. Conflict-Merge ACC SPFs Results (TTC $\leq 1.5 \mathrm{~s})$

\begin{tabular}{|c|c|c|c|c|c|c|c|c|c|}
\hline \multirow{2}{*}{ Conflict Type } & \multicolumn{2}{|c|}{$\alpha$} & \multicolumn{2}{|c|}{$\beta_{1}$} & \multicolumn{2}{|c|}{$\beta_{2}$} & \multicolumn{2}{|c|}{$\beta_{3}$} & \multirow{2}{*}{$\mathrm{k}$} \\
\cline { 2 - 11 } & Est & P>ChiSq & Est & P>ChiSq & Est & P>ChiSq & Est & P>ChiSq & \\
\hline Total & -5.9707 & 0.0003 & 0.7312 & $<.0001$ & 0.6737 & $<.0001$ & -0.0035 & 0.0372 & 0.5280 \\
\hline Rear End & -7.6821 & 0.0008 & 0.8985 & $<.0001$ & 0.7432 & $<.0001$ & -0.0065 & 0.0014 & 0.6138 \\
\hline Lane Change & -9.0257 & $<.0001$ & 0.9030 & $<.0001$ & 0.6821 & $<.0001$ & -0.0005 & 0.7628 & 0.3494 \\
\hline
\end{tabular}

According to Table 20, except Lane Change conflicts, all the p-values for intercepts, traffic volumes, and ACC length indicate the significance at the 95\% confidence level. Consistent with the Crash-Merge-ACC SPFs, the coefficients for ACC length are negative in the conflict-based SPFs.

The goodness-of-fit results are shown in Table 21. The CURE plots for FPHV and RPHV, ACC Length, and predicted conflicts were evaluated separately for each conflict type, and examples of good and poor CURE plots are presented in Figure 30 and Figure 31. The MPB and MAD values are close to zero, indicating that the models fit the observed data well. CURE plots for each model show good results expect for the freeway peak hour volume (FPHV) variable. This is probably because of the large differences in freeway volumes between rural and urban areas.

Table 21. Conflict-Merge ACC SPFs Goodness-of-Fit Results (TTC $\leq 1.5 \mathrm{~s}$ )

\begin{tabular}{|c|c|c|c|}
\hline Conflict Type & Total & Rear End & Lane Change \\
\hline Avg. Observed. Conflicts/Site & 0.2159 & 0.1098 & 0.1061 \\
\hline MPB/Site & -1.3917 & -1.1718 & 0.1139 \\
\hline MAD/Site & 1.3917 & 1.1718 & 0.1139 \\
\hline MSPE/Site & 414.9830 & 242.2882 & 90.5124 \\
\hline MSE/Site & 430.9439 & 251.6069 & 93.9936 \\
\hline
\end{tabular}


Lane Change Conflict - FPHV CURE Plot

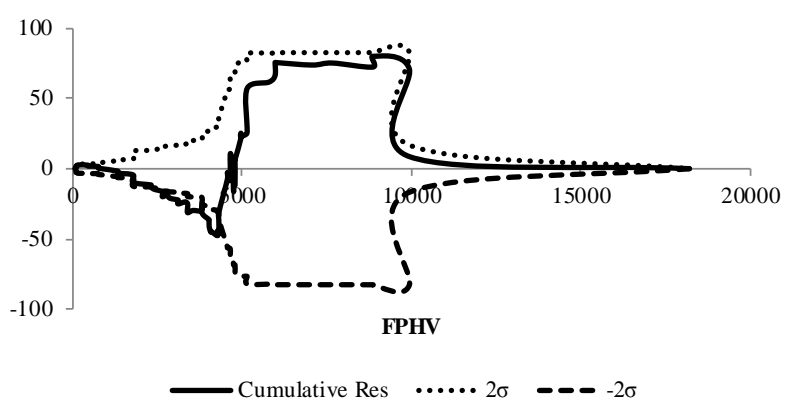

Lane Change Conflict - ACC Length CURE Plot

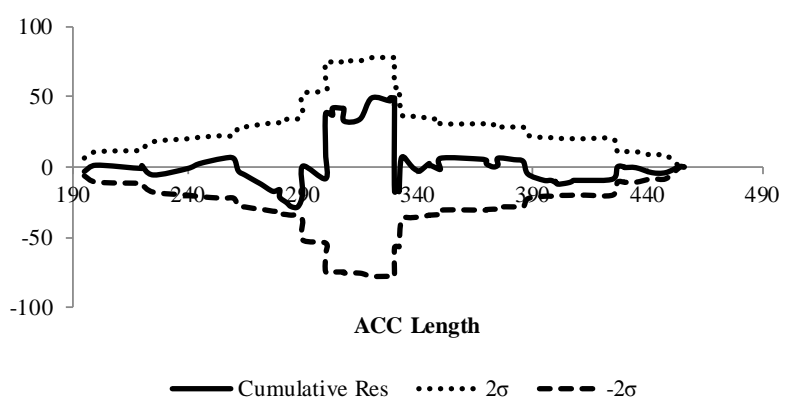

Lane Change Conflict - RPHV CURE Plot

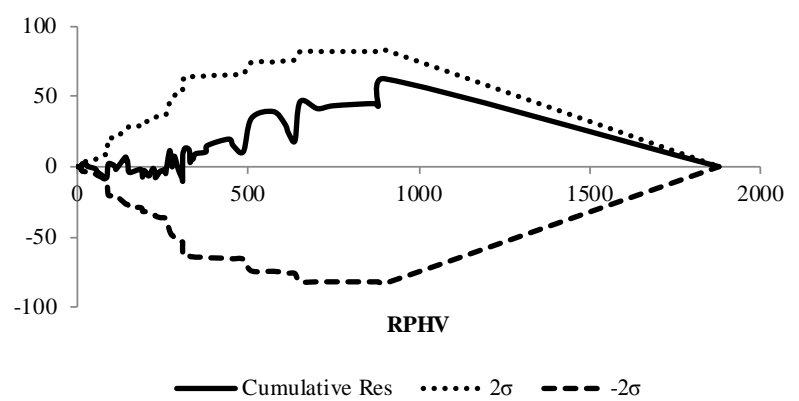

Lane Change Conflict - Predicted Lane Change Conflict CURE Plot

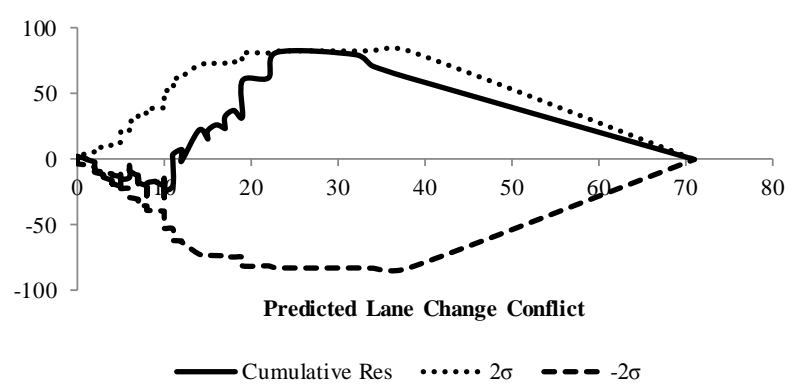

Figure 30. Conflict-Merge ACC SPFs Lane Change Conflict CURE Plots (TTC $\leq 1.5 \mathrm{~s}$ ) (good CURE plots)

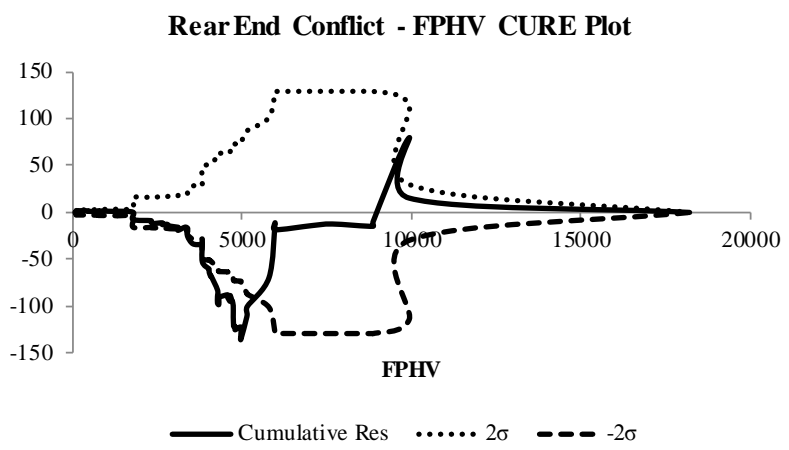

RearEnd Conflict - ACC Length CURE Plot



RearEnd Conflict - RPHV CURE Plot

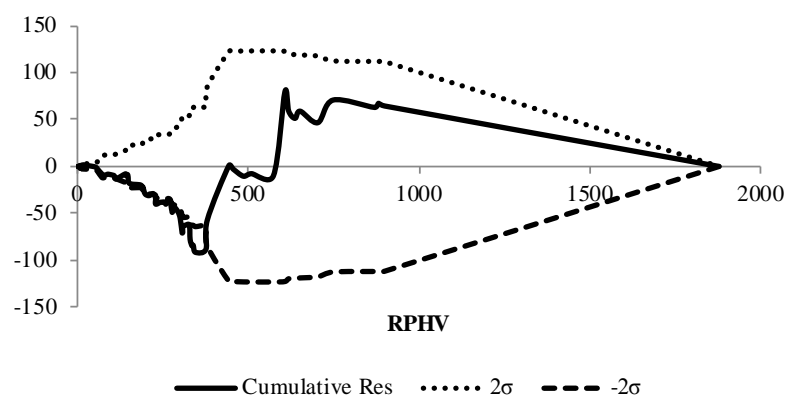

Rear End Conflict - Predicted Rear End Conflict CURE Plot

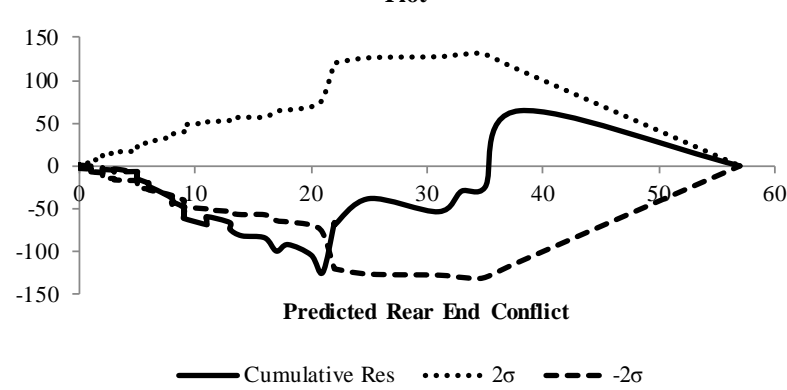

Figure 31. Conflict-Merge ACC SPFs Rear End Conflict CURE Plots (TTC $\leq 1.5 \mathrm{~s}$ ) (CURE plots with several outliers) 


\section{$7.2 \quad \mathrm{TTC} \leq 1.0 \mathrm{~s}$}

The conflict statistics for TTC $\leq 1.0$ s are shown in Table 22 .

Table 22. Conflict Statistics for TTC $\leq 1.0 \mathrm{~s}$

\begin{tabular}{|c|c|c|c|}
\hline Conflicts & Total & Rear End & Lane Change \\
\hline Sum & 2273 & 1513 & 761 \\
\hline Maximum & 162 & 148 & 53 \\
\hline Minimum & 0 & 0 & 0 \\
\hline Mean & 22.07 & 14.68 & 7.39 \\
\hline Percentage & $100.00 \%$ & $66.53 \%$ & $33.47 \%$ \\
\hline
\end{tabular}

The model format of TTC $\leq 1.0 \mathrm{~s}$ shown in Equation 12 is the same as that of $\mathrm{TTC} \leq 1.5 \mathrm{~s}$. Coefficients and p-values were estimated for Total, Rear End, and Lane Change conflicts and results are shown in Table 23.

$$
\text { Conflicts }=F P H V^{\beta_{1}} \times R P H V^{\beta_{2}} \times e^{\left(\alpha+\beta_{3} \text { ACCLength }\right)}
$$

Table 23. Conflict-Merge ACC SPFs Results (TTC $\leq 1.0 \mathrm{~s})$

\begin{tabular}{|c|c|c|c|c|c|c|c|c|c|}
\hline \multirow{2}{*}{ Conflict Type } & \multicolumn{2}{|c|}{$\alpha$} & \multicolumn{2}{|c|}{$\beta_{1}$} & \multicolumn{2}{|c|}{$\beta_{2}$} & \multicolumn{2}{|c|}{$\beta_{3}$} & \multirow{2}{*}{$\mathrm{k}$} \\
\cline { 2 - 11 } & Est & P>ChiSq & Est & P $>$ ChiSq & Est & P>ChiSq & Est & P >ChiSq & \\
\hline Total & -8.7640 & $<.0001$ & 0.9344 & $<.0001$ & 0.6787 & $<.0001$ & -0.0027 & 0.1076 & 0.4112 \\
\hline Rear End & -8.5091 & 0.0016 & 0.8343 & 0.0027 & 0.8002 & $<.0001$ & -0.0065 & 0.0049 & 0.5122 \\
\hline Lane Change & -10.7061 & $<.0001$ & 1.0752 & $<.0001$ & 0.6176 & $<.0001$ & -0.0006 & 0.7251 & 0.3652 \\
\hline
\end{tabular}

For TTC $\leq 1.0$ s, according to Table 23, except p-values for ACC length for total and lane change Conflicts, all the p-values for intercepts and traffic volumes indicate the significance at 95\% confidence level. Consistent with the previous results, the coefficients for ACC length are negative in the conflict-based SPFs.

The goodness-of-fit results are shown in Table 24. The CURE plots for FPHV and RPHV, ACC 
Length, and predict conflicts were evaluated separately for each conflict type, and examples of good and poor CURE plots are presented in Figure 32 and Figure 33. Although the values of MPB, MAD, MSPE and MSE decreased compared to the results of TTC $\leq 1.5 \mathrm{~s}$, the CURE plots show worse results, with more bias and outliers for each type of conflict.

Table 24. Conflict-Merge ACC SPFs Goodness-of-Fit Results (TTC $\leq 1.0 \mathrm{~s}$ )

\begin{tabular}{|c|c|c|c|}
\hline Conflict Type & Total & Rear End & Lane Change \\
\hline Avg. Observed. Conflicts/Site & 0.0914 & 0.0371 & 0.0543 \\
\hline MPB/Site & 0.0238 & -0.2558 & 0.3193 \\
\hline MAD/Site & 0.0238 & 0.2558 & 0.3193 \\
\hline MSPE/Site & 78.5566 & 37.0924 & 29.1996 \\
\hline MSE/Site & 81.5780 & 38.5190 & 30.3227 \\
\hline
\end{tabular}
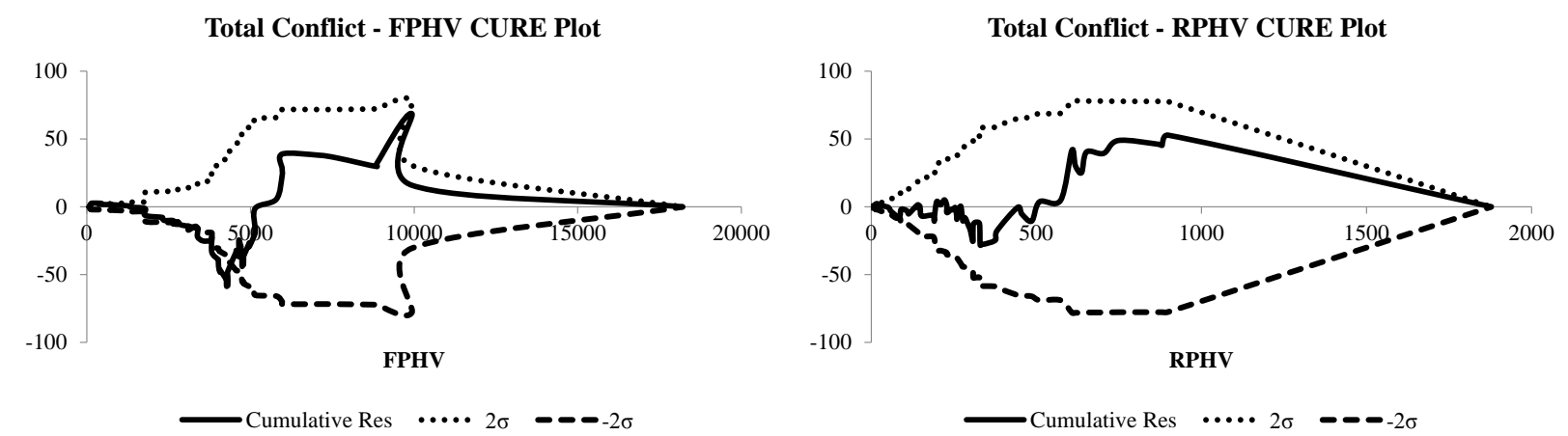

Total Conflict - ACC Length CURE Plot

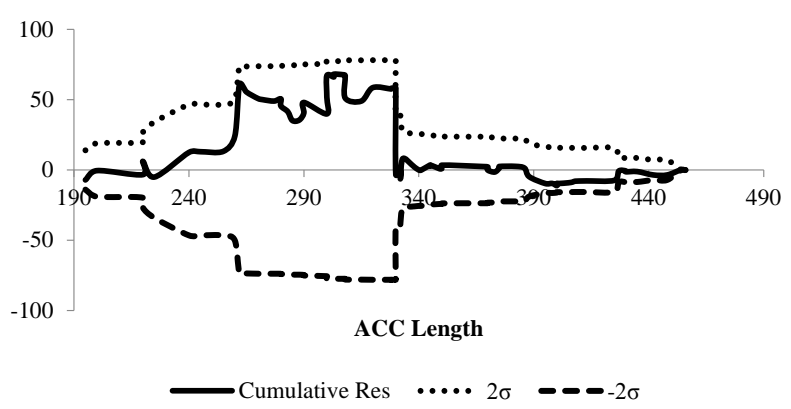

Total Conflict - Predicted Total Conflict CURE Plot

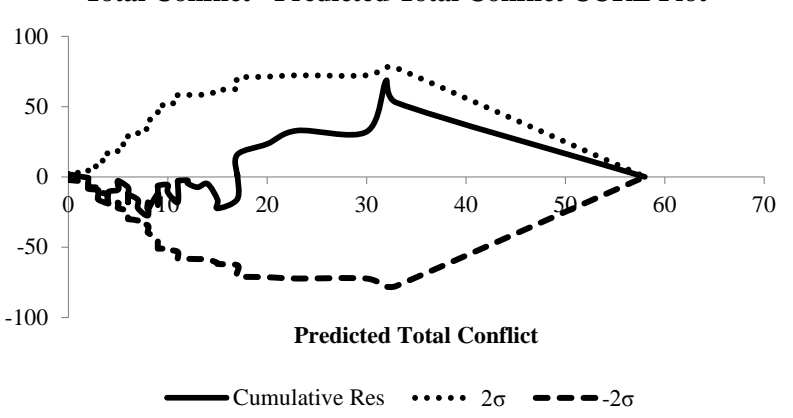

Figure 32. Conflict-Merge ACC SPFs Total Conflict CURE Plots (TTC $\leq 1.0 \mathrm{~s})$ (good CURE plots) 

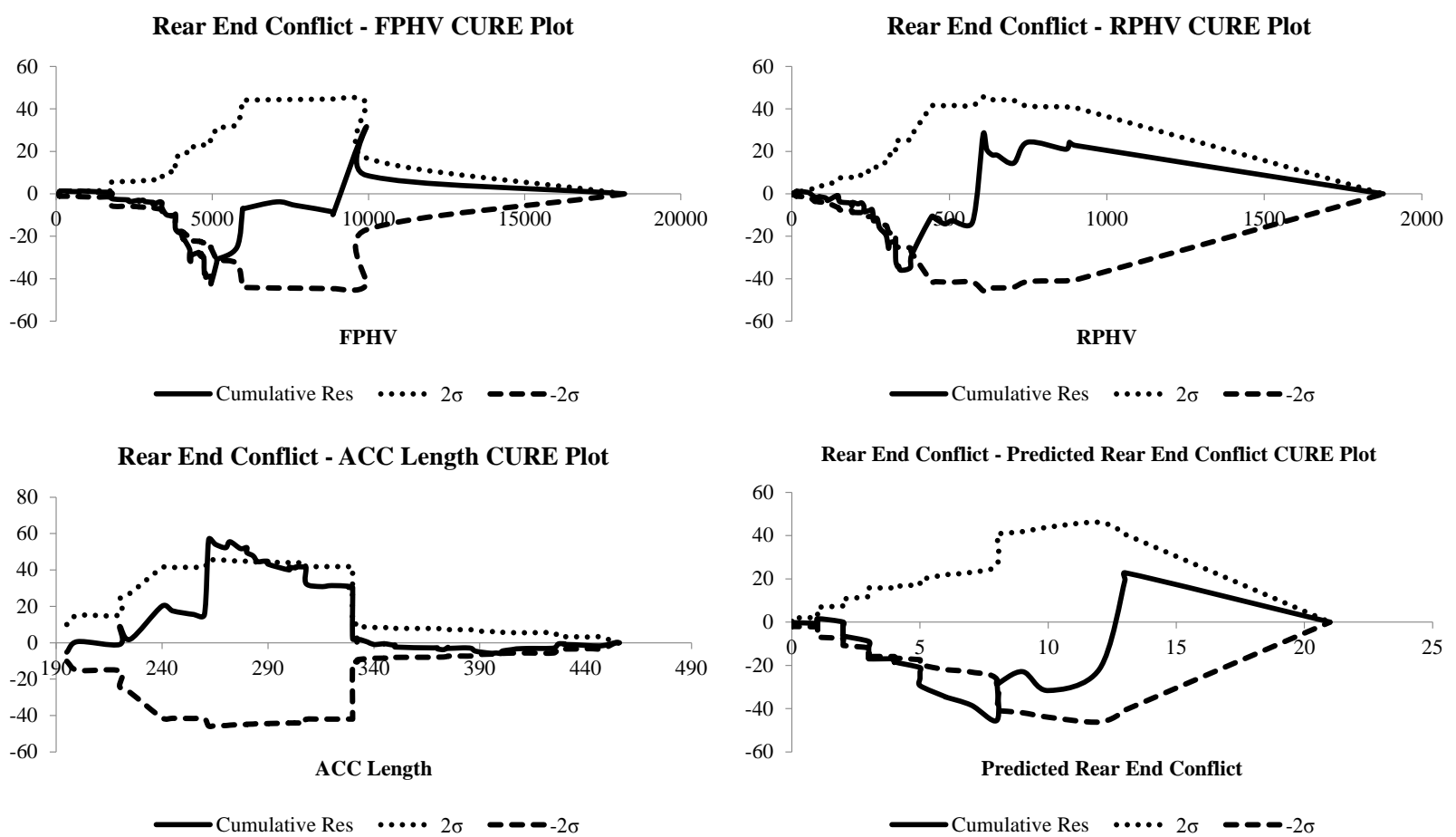

Figure 33. Conflict-Merge ACC SPFs Rear End Conflict CURE Plots (TTC $\leq 1.0 s$ ) (CURE plots with several outliers)

\subsection{TTC $\leq 0.5 \mathrm{~s}$}

The conflict statistics for TTC $\leq 0.5 \mathrm{~s}$ are shown in Table 25 .

Table 25. Conflict Statistics for TTC $\leq 0.5 \mathrm{~s}$

\begin{tabular}{|c|c|c|c|}
\hline Conflicts & Total & Rear End & Lane Change \\
\hline Sum & 337 & 100 & 238 \\
\hline Maximum & 18 & 4 & 15 \\
\hline Minimum & 0 & 0 & 0 \\
\hline Mean & 3.28 & 0.97 & 2.31 \\
\hline Percentage & $100.00 \%$ & $29.52 \%$ & $70.48 \%$ \\
\hline
\end{tabular}

The model format of TTC $\leq 0.5 \mathrm{~s}$ shown in Equation 13 is the same as that of $\mathrm{TTC} \leq 1.5 \mathrm{~s}$. Coefficients and p-values were estimated for Total, Rear End, and Lane Change conflicts and results are shown in Table 26. 
Table 26. Conflict-Merge ACC SPFs Results (TTC $\leq 0.5 \mathrm{~s}$ )

\begin{tabular}{|c|c|c|c|c|c|c|c|c|c|}
\hline \multirow{2}{*}{ Conflict Type } & \multicolumn{2}{|c|}{$\alpha$} & \multicolumn{2}{|c|}{$\beta_{1}$} & \multicolumn{2}{|c|}{$\beta_{2}$} & \multicolumn{2}{|c|}{$\beta_{3}$} & \multirow{2}{*}{$\mathrm{k}$} \\
\cline { 2 - 11 } & Est & P>ChiSq & Est & P>ChiSq & Est & P>ChiSq & Est & P>ChiSq & \\
\hline Total & -7.1858 & 0.0001 & 0.6573 & 0.0011 & 0.5341 & 0.0002 & -0.0015 & 0.4134 & 0.2015 \\
\hline Rear End & -5.0730 & 0.0201 & 0.2023 & 0.4088 & 0.6314 & 0.0011 & -0.0015 & 0.5468 & 0.0000 \\
\hline Lane Change & -9.2345 & $<.0001$ & 0.9073 & 0.0003 & 0.4670 & 0.0041 & -0.0017 & 0.4132 & 0.1871 \\
\hline
\end{tabular}

For TTC $\leq 0.5 \mathrm{~s}$, according to Table 26, all the p-values of ACC length increased, indicating very low statistical significance. Besides, the p-value for FPHV in Rear End conflicts exceeds 0.1. In sum, the models show poor results for the lowest TTC value, likely due to the much smaller sample of estimated conflicts.

The goodness-of-fit results are shown in Table 27. The CURE plots for FPHV and RPHV, ACC Length, and predicted conflicts were evaluated separately for each conflict type, and examples of good and poor CURE plots are presented in Figure 34 and Figure 35. MPB, MAD, MSPE and MSE values are lower than for TTC $\leq 1.5 \mathrm{~s}$ and $\mathrm{TTC} \leq 1.0 \mathrm{~s}$, but the CURE plots have more outliers for total, rear end, and lane change conflicts.

Table 27. Conflict-Merge ACC SPFs Goodness-of-Fit Results (TTC $\leq 0.5 \mathrm{~s}$ )

\begin{tabular}{|c|c|c|c|}
\hline Conflict Type & Total & Rear End & Lane Change \\
\hline Avg. Observed. Conflicts/Site & 0.0247 & 0.0077 & 0.0169 \\
\hline MPB/Site & 0.0248 & 0.0067 & 0.0289 \\
\hline MAD/Site & 0.0248 & 0.0067 & 0.0289 \\
\hline MSPE/Site & 4.1484 & 0.3872 & 2.4464 \\
\hline MSE/Site & 4.3080 & 0.4021 & 2.5405 \\
\hline
\end{tabular}


Rear End Conflict - FPHV CURE Plot

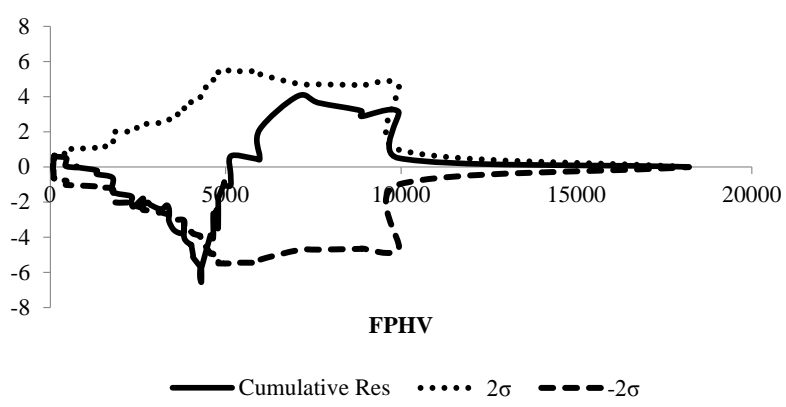

Rear End Conflict - ACC Length CURE Plot

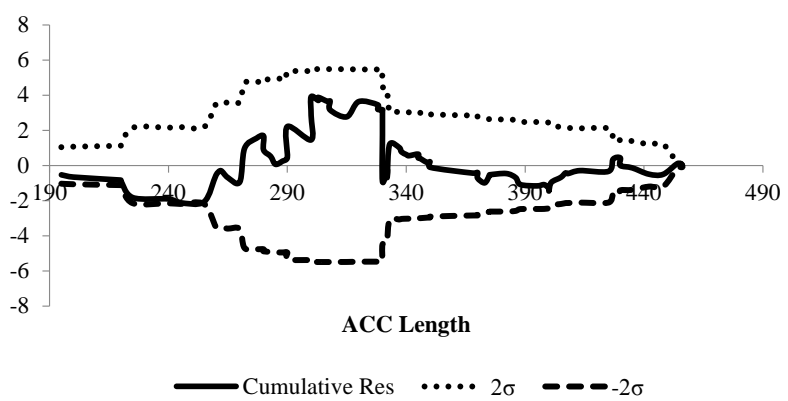

Rear End Conflict - RPHV CURE Plot

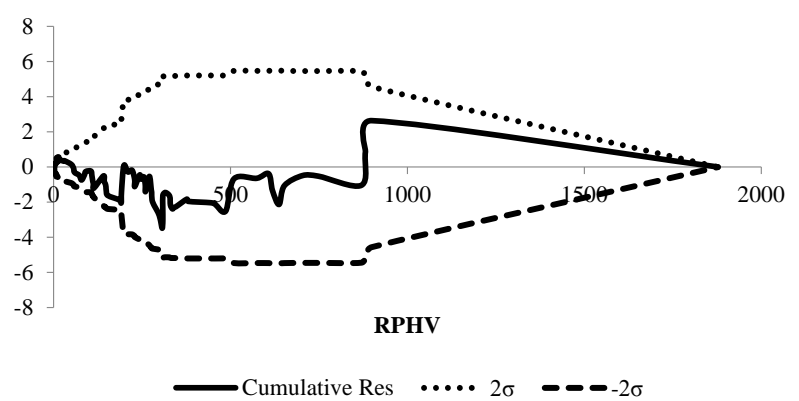

Rear End Conflict - Predicted Rear End Conflict CURE Plot

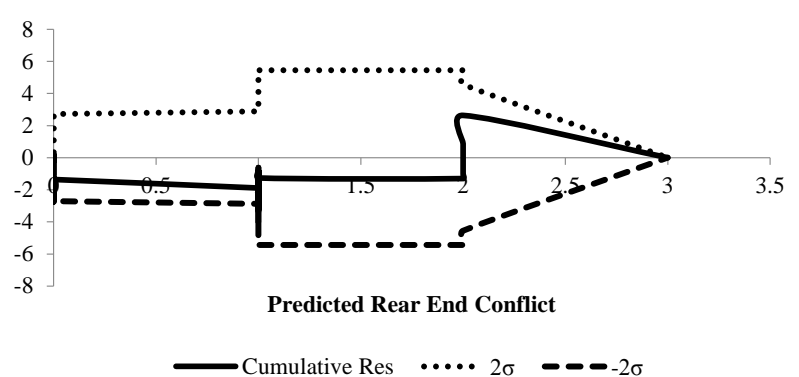

Figure 34. Conflict-Merge ACC SPFs Rear End Conflict CURE Plots (TTC $\leq 0.5 \mathrm{~s}$ ) (good CURE plots)

Total Conflict - FPHV CURE Plot

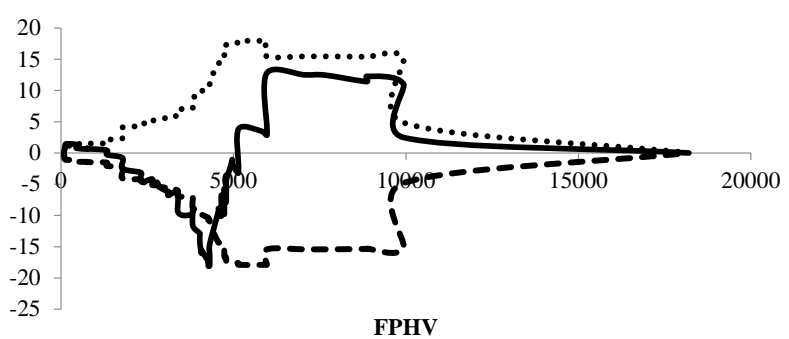

- Cumulative Res $\quad \cdots \cdots \cdot 2 \sigma \quad---2 \sigma$

Total Conflict - ACC Length CURE Plot

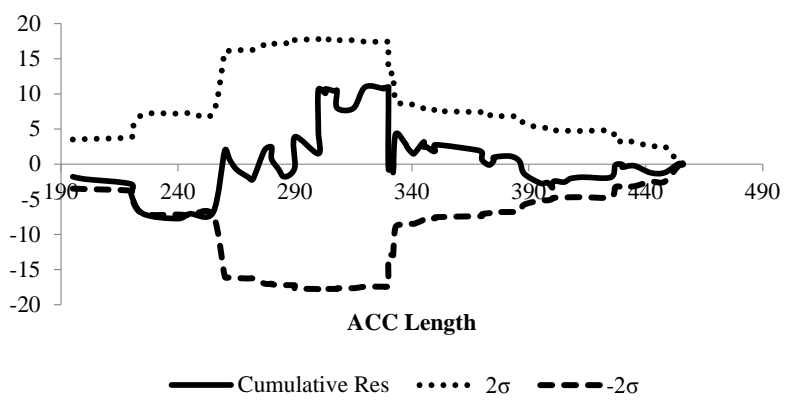

Total Conflict - RPHV CURE Plot

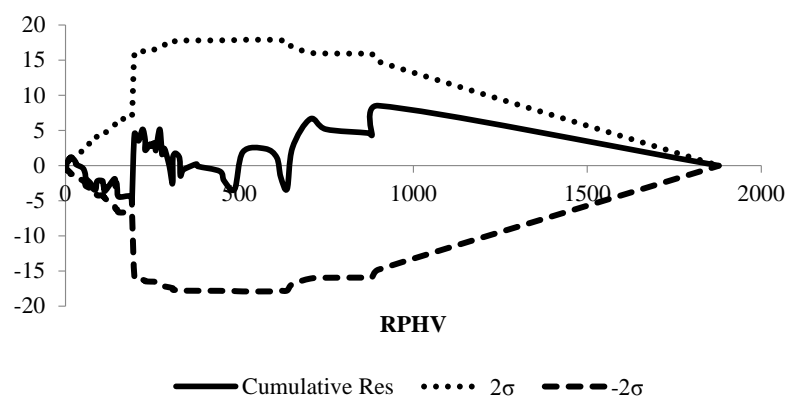

Total Conflict - Predicted Total Conflict CURE Plot

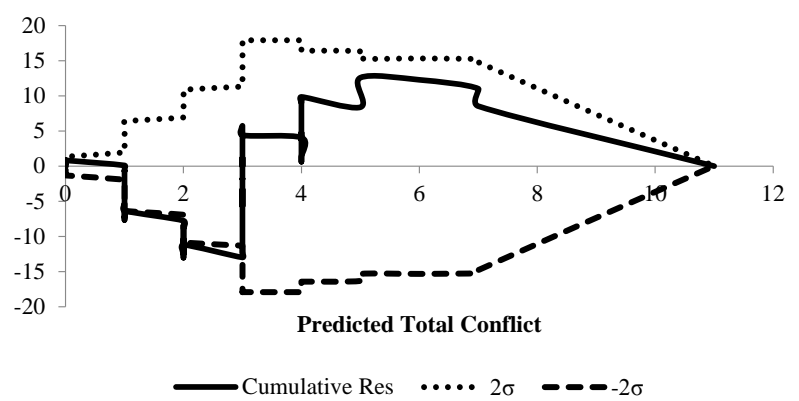

Figure 35. Conflict-Merge ACC SPFs Total Conflict CURE Plots (TTC $\leq 0.5 \mathrm{~s}$ ) (CURE plots with several outliers) 


\subsection{Model Comparison}

For conflict-based SPFs, according to the results of different TTC thresholds with statistically significant parameters, the coefficients for freeway and ramp peak hour volumes are always positive, and the coefficients for ACC length are negative, consistent with the results of crash-based SPFs. By reducing the TTC upper limit, the generated conflicts were significantly reduced, creating a sample size issue for the modeling, especially for TTC $\leq 0.5 \mathrm{~s}$. Therefore, TTC $\leq 1.5 \mathrm{~s}$ is suggested when filtering the conflicts in the SSAM software. 


\section{Crash-Conflict Integrated Crash Prediction Models}

The purpose of this chapter is to find the relationship between real crash data and simulated conflicts, and in so doing to verify that conflicts can be considered as a surrogate safety measure for predicting crashes for freeway speed-change lane influence areas. Crash-conflict integrated SPFs were developed, and the goodness-of-fit measures for each model were evaluated. Similar to conflict-based SPFs, sensitivity analysis to TTC thresholds was conducted. Following is the list of the models developed in this chapter:

- Crash-Conflict-Merge-ACC SPFs (TTC $\leq 1.5 \mathrm{~s}$ ) (crash-conflict integrated SPFs for merge areas with acceleration lane and adjacent mainline as influence areas for $\mathrm{TTC} \leq 1.5 \mathrm{~s}$ )

- Crash-Conflict-Merge-ACC SPFs (TTC $\leq 1.0 \mathrm{~s})$ (crash-conflict integrated SPFs for merge areas with acceleration lane and adjacent mainline as influence areas for $\mathrm{TTC} \leq 1.0 \mathrm{~s}$ )

- Crash-Conflict-Merge-ACC SPFs (TTC $\leq 0.5 \mathrm{~s}$ ) (crash-conflict integrated SPFs for merge areas with acceleration lane and adjacent mainline as influence areas for $\mathrm{TTC} \leq 0.5 \mathrm{~s}$ )

\subsection{TTC $\leq 1.5 \mathrm{~s}$}

The model format for Crash-Conflict-Merge-ACC SPFs is shown in Equation 14. Different types of conflicts were used as independent variables to predict different crash of the corresponding type. Total, F\&I, PDO, Single Vehicle, Rear End and Side Swipe crashes were related to Total, Rear End, and Lane Change conflicts separately. The parameter "years" was specified as an offset in the model as before. Table 28 presents the coefficients and p-values for each model.

$$
\frac{\text { Crashes }}{\text { year }}=e^{\alpha} \times \text { Conflict Type }{ }^{\beta_{1}}
$$


Table 28. Crash-Conflict-Merge ACC SPFs Results (TTC $\leq 1.5 \mathrm{~s}$ )

\begin{tabular}{|c|c|c|c|c|c|c|}
\hline Crash-Conflict & \multicolumn{2}{|c|}{ Total-Total } & \multicolumn{2}{|c|}{ Total-Rear End } & \multicolumn{2}{|c|}{ Total-Lane Change } \\
\hline Coefficient & Estimate & Pr $>$ ChiSq & Estimate & Pr $>$ ChiSq & Estimate & Pr $>$ ChiSq \\
\hline$\alpha$ & 0.1512 & 0.2211 & 0.4188 & $<.0001$ & 0.2346 & 0.0531 \\
\hline$\beta_{1}$ & 0.2573 & $<.0001$ & 0.2296 & $<.0001$ & 0.3255 & $<.0001$ \\
\hline $\mathrm{k}$ & \multicolumn{2}{|c|}{0.5275} & \multicolumn{2}{|c|}{0.5340} & \multicolumn{2}{|c|}{0.5422} \\
\hline Crash-Conflict & \multicolumn{2}{|c|}{ F\&I-Total } & \multicolumn{2}{|c|}{ F\&I-Rear End } & \multicolumn{2}{|c|}{ F\&I-Lane Change } \\
\hline Coefficient & Estimate & $\operatorname{Pr}>$ ChiSq & Estimate & $\mathrm{Pr}>\mathrm{ChiSq}$ & Estimate & $\operatorname{Pr}>$ ChiSq \\
\hline$\alpha$ & -1.6428 & $<.0001$ & -1.3209 & $<.0001$ & -1.5675 & $<.0001$ \\
\hline$\beta_{1}$ & 0.2828 & $<.0001$ & 0.2430 & $<.0001$ & 0.3629 & $<.0001$ \\
\hline $\mathrm{k}$ & \multicolumn{2}{|c|}{0.4691} & \multicolumn{2}{|c|}{0.4639} & \multicolumn{2}{|c|}{0.5385} \\
\hline Crash-Conflict & \multicolumn{2}{|c|}{ PDO-Total } & \multicolumn{2}{|c|}{ PDO-Rear End } & \multicolumn{2}{|c|}{ PDO-Lane Change } \\
\hline Coefficient & Estimate & $\operatorname{Pr}>$ ChiSq & Estimate & $\operatorname{Pr}>$ ChiSq & Estimate & $\operatorname{Pr}>$ ChiSq \\
\hline$\alpha$ & -0.0299 & 0.8190 & 0.2292 & 0.0415 & 0.0625 & 0.6257 \\
\hline$\beta_{1}$ & 0.2516 & $<.0001$ & 0.2252 & $<.0001$ & 0.3136 & $<.0001$ \\
\hline $\mathrm{k}$ & \multicolumn{2}{|c|}{0.5767} & \multicolumn{2}{|c|}{0.5780} & \multicolumn{2}{|c|}{0.5960} \\
\hline Crash-Conflict & \multicolumn{2}{|c|}{ SnglVeh-Total } & \multicolumn{2}{|c|}{ SnglVeh-Rear End } & \multicolumn{2}{|c|}{ SnglVeh-Lane Change } \\
\hline Coefficient & Estimate & Pr $>$ ChiSq & Estimate & Pr $>$ ChiSq & Estimate & Pr $>$ ChiSq \\
\hline$\alpha$ & -0.1893 & 0.1668 & 0.0429 & 0.6743 & -0.2074 & 0.1048 \\
\hline$\beta_{1}$ & 0.1049 & 0.0152 & 0.0002 & 0.8882 & 0.1557 & 0.0034 \\
\hline $\mathrm{k}$ & \multicolumn{2}{|c|}{0.5759} & \multicolumn{2}{|c|}{0.6728} & \multicolumn{2}{|c|}{0.5437} \\
\hline Crash-Conflict & \multicolumn{2}{|c|}{ Rear End-Rear End } & \multicolumn{2}{|c|}{ Side Swipe-Lane Change } & & \\
\hline Coefficient & Estimate & $\operatorname{Pr}>$ ChiSq & Estimate & Pr $>$ ChiSq & & \\
\hline$\alpha$ & -1.1795 & $<.0001$ & -1.5832 & $<.0001$ & & \\
\hline$\beta_{1}$ & 0.4121 & $<.0001$ & 0.3694 & $<.0001$ & & \\
\hline $\mathrm{k}$ & \multicolumn{2}{|c|}{0.7641} & \multicolumn{2}{|c|}{0.3921} & & \\
\hline
\end{tabular}

For TTC $\leq 1.5 \mathrm{~s}$, according to Table 28, the parameters for PDO and Single Vehicle crashes are not statistically significant. However, the crash-conflict integrated models yield more significant results $(\mathrm{p}<0.05)$ for other crash types.

The goodness-of-fit results are shown from Table 29 to Table 33. The CURE plots for Total, F\&I, PDO, Single Vehicle, Rear End, Side Swipe, and predicted conflicts were evaluated separately, and examples of good and poor CURE plots are presented in Figure 36 and Figure 37. The MPB, 
MAD, MSPE, and MSE values are close to zero, indicating that the models fit the observed data well. The lane change conflict type is not a good predictor, as the CURE plots for this variable in all models have substantial outliers. For other types of conflict, the CURE plots are reasonable.

Table 29. Crash-Conflict-Merge ACC SPFs Goodness-of-Fit Results of Total Crashes (TTC $\leq 1.5 \mathrm{~s}$ )

\begin{tabular}{|c|c|c|c|}
\hline Crash-Conflict & Total-Total & Total-Rear End & Total-Lane Change \\
\hline Avg. Observed. Crashes/Year/Site & 0.0232 & 0.0232 & 0.0232 \\
\hline MPB & -8.0432 & -8.1691 & -8.0377 \\
\hline MPB/Year & -1.6086 & -1.6338 & -1.6075 \\
\hline MAD & 8.0432 & 8.1691 & 8.0377 \\
\hline MAD/Year & 1.6086 & 1.6338 & 1.6075 \\
\hline MSPE & 111.3128 & 123.2728 & 109.1706 \\
\hline MSPE/Year ${ }^{2}$ & 4.4525 & 4.9309 & 4.3668 \\
\hline MSE & 112.4041 & 124.4813 & 110.2409 \\
\hline MSE/Year ${ }^{2}$ & 4.4962 & 4.9793 & 4.4096 \\
\hline
\end{tabular}

Table 30. Crash-Conflict-Merge ACC SPFs Goodness-of-Fit Results of F\&I Crashes (TTC $\leq 1.5 \mathrm{~s}$ )

\begin{tabular}{|c|c|c|c|}
\hline Crash-Conflict & F\&I-Total & F\&I-Rear End & F\&I-Lane Change \\
\hline Avg. Observed. Crashes/Year/Site & 0.0042 & 0.0042 & 0.0042 \\
\hline MPB & -0.8254 & -0.8404 & -0.8296 \\
\hline MPB/Year & -0.1651 & -0.1681 & -0.1659 \\
\hline MAD & 0.8254 & 0.8404 & 0.8296 \\
\hline MAD/Year & 0.1651 & 0.1681 & 0.1659 \\
\hline MSPE & 2.4934 & 2.7746 & 2.4030 \\
\hline MSPE/Year ${ }^{2}$ & 0.0997 & 0.1110 & 0.0961 \\
\hline MSE & 2.5179 & 2.8018 & 2.4265 \\
\hline MSE/Year ${ }^{2}$ & 0.1007 & 0.1121 & 0.0971 \\
\hline
\end{tabular}


Table 31. Crash-Conflict-Merge ACC SPFs Goodness-of-Fit Results of PDO Crashes (TTC $\leq 1.5 \mathrm{~s}$ )

\begin{tabular}{|c|c|c|c|}
\hline Crash-Conflict & PDO-Total & PDO-Rear End & PDO-Lane Change \\
\hline Avg. Observed. Crashes/Year/Site & 0.0189 & 0.0189 & 0.0189 \\
\hline MPB & -7.2182 & -7.3348 & -7.2238 \\
\hline MPB/Year & -1.4436 & -1.4670 & -1.4448 \\
\hline MAD & 7.2182 & 7.3348 & 7.2238 \\
\hline MAD/Year & 1.4436 & 1.4670 & 1.4448 \\
\hline MSPE & 82.1384 & 90.3679 & 80.4159 \\
\hline MSPE/Year ${ }^{2}$ & 3.2855 & 3.6147 & 3.2166 \\
\hline MSE & 82.9437 & 91.2539 & 81.2043 \\
\hline MSE/Year ${ }^{2}$ & 3.3177 & 3.6502 & 3.2482 \\
\hline
\end{tabular}

Table 32. Crash-Conflict-Merge ACC SPFs Goodness-of-Fit Results of Single Vehicle Crashes (TTC $\leq 1.5 \mathrm{~s})$

\begin{tabular}{|c|c|c|c|}
\hline Crash-Conflict & SnglVeh-Total & SnglVeh-Rear End & SnglVeh-Lane Change \\
\hline Avg. Observed. Crashes/Year/Site & 0.0102 & 0.0102 & 0.0102 \\
\hline MPB & -2.7373 & -3.1846 & -2.8127 \\
\hline MPB/Year & -0.5475 & -0.6369 & -0.5625 \\
\hline MAD & 2.7373 & 3.1846 & 2.8127 \\
\hline MAD/Year & 0.5475 & 0.6369 & 0.5625 \\
\hline MSPE & 9.7876 & 12.0943 & 11.1662 \\
\hline MSPE/Year ${ }^{2}$ & 0.3915 & 0.4838 & 0.4466 \\
\hline MSE & 9.8835 & 12.2128 & 11.2757 \\
\hline MSE/Year & 0.3953 & 0.4885 & 0.4510 \\
\hline
\end{tabular}

Table 33. Crash-Conflict-Merge ACC SPFs Goodness-of-Fit Results of RearEnd \& SideSwipe Crashes (TTC $\leq 1.5 \mathrm{~s}$ )

\begin{tabular}{|c|c|c|}
\hline Crash-Conflict & Rear End-Rear End & Side Swipe-Lane Change \\
\hline Avg. Observed. Crashes/Year/Site & 0.0085 & 0.0042 \\
\hline MPB & -1.6280 & -3.8271 \\
\hline MPB/Year & -0.3256 & -0.7654 \\
\hline MAD & 1.6280 & 3.8271 \\
\hline MAD/Year & 0.3256 & 0.7654 \\
\hline MSPE & 24.2198 & 16.4100 \\
\hline MSPE/Year ${ }^{2}$ & 0.9688 & 0.6564 \\
\hline MSE & 24.4572 & 16.5709 \\
\hline MSE/Year ${ }^{2}$ & 0.9783 & 0.6628 \\
\hline
\end{tabular}


PDO Crash - Total Conflict CURE Plot

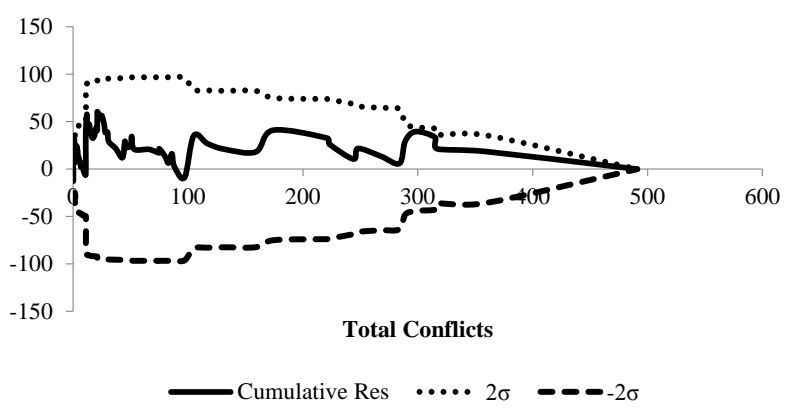

PDO Crash - Rear End Conflict CURE Plot

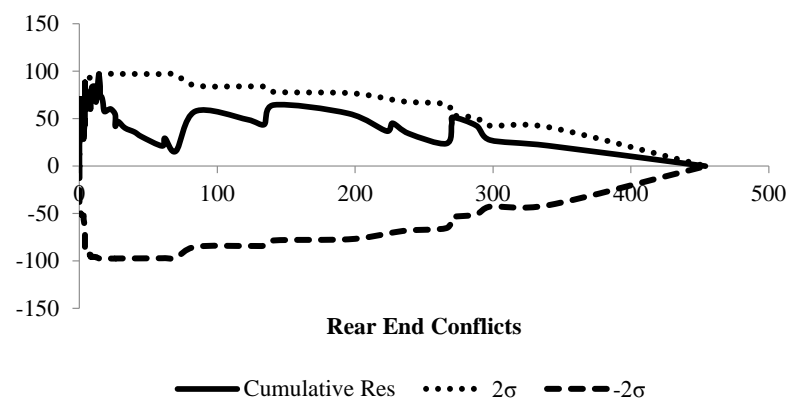

PDO Crash - Lane Change Conflict CURE Plot

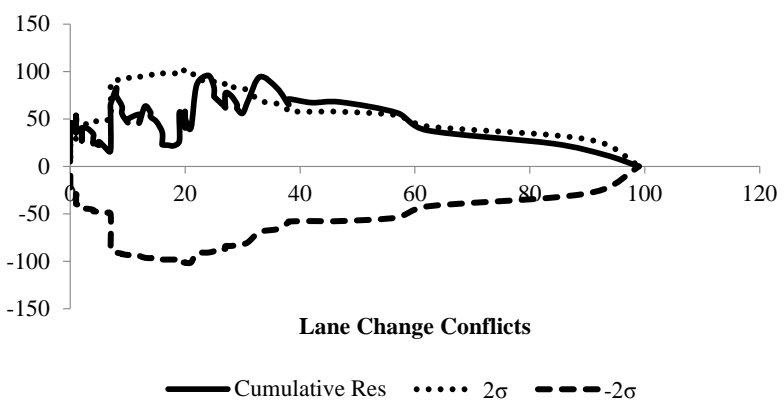

Figure 36. Merge ACC Area PDO Crash-Conflict CURE Plots (TTC $\leq 1.5 \mathrm{~s}$ ) (good CURE plots)

Singl Vehicle Crash - Total Conflict CURE Plot

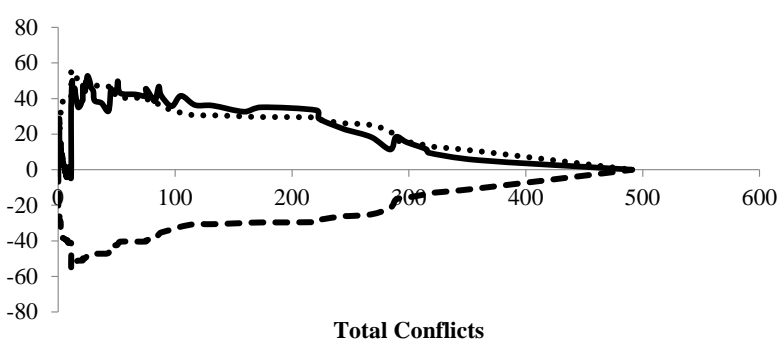

Single Vehicle Crash - Rear End Conflict CURE Plot



Single Vehicle Crash - Lane Change Conflict CURE Plot

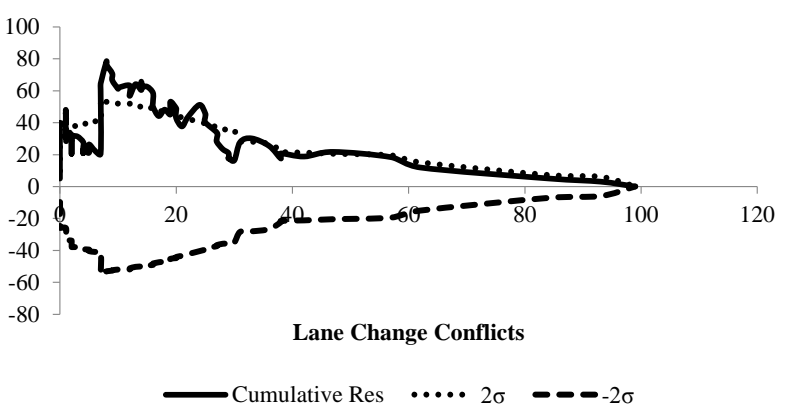

Figure 37. Merge ACC Area Single Vehicle Crash-Conflict CURE Plots (TTC $\leq 1.5 \mathrm{~s}$ ) (CURE plots with several outliers) 


\subsection{TTC $\leq 1.0 \mathrm{~s}$}

For TTC $\leq 1.0 \mathrm{~s}$, the model format shown in Equation 15 is the same as that of $\mathrm{TTC} \leq 1.5 \mathrm{~s}$. Table 34 presents the coefficients and p-values for each model.

$$
\frac{\text { Crashes }}{\text { year }}=e^{\alpha} \times \text { Conflict Type } e^{\beta 1}
$$

(Equation 15)

Table 34. Crash-Conflict-Merge ACC SPFs Results (TTC $\leq 1.0 \mathrm{~s}$ )

\begin{tabular}{|c|c|c|c|c|c|c|}
\hline Crash-Conflict & \multicolumn{2}{|c|}{ Total-Total } & \multicolumn{2}{|c|}{ Total-Rear End } & \multicolumn{2}{|c|}{ Total-Lane Change } \\
\hline Coefficient & Estimate & Pr $>$ ChiSq & Estimate & Pr>ChiSq & Estimate & $\operatorname{Pr}>$ ChiSq \\
\hline$\alpha$ & 0.3779 & 0.0006 & 0.6618 & $<.0001$ & 0.5041 & $<.0001$ \\
\hline$\beta_{1}$ & 0.2552 & $<.0001$ & 0.2338 & $<.0001$ & 0.3001 & $<.0001$ \\
\hline $\mathrm{k}$ & \multicolumn{2}{|c|}{0.5389} & \multicolumn{2}{|c|}{0.5211} & \multicolumn{2}{|c|}{0.6029} \\
\hline Crash-Conflict & \multicolumn{2}{|c|}{ F\&I-Total } & \multicolumn{2}{|c|}{ F\&I-Rear End } & \multicolumn{2}{|c|}{ F\&I-Lane } \\
\hline Coefficient & Estimate & Pr>ChiSq & Estimate & $\operatorname{Pr}>$ ChiSq & Estimate & $\operatorname{Pr}>$ ChiSq \\
\hline$\alpha$ & -1.3906 & $<.0001$ & -1.0627 & $<.0001$ & -1.3281 & $<.0001$ \\
\hline$\beta_{1}$ & 0.2809 & $<.0001$ & 0.2456 & $<.0001$ & 0.3688 & $<.0001$ \\
\hline $\mathrm{k}$ & \multicolumn{2}{|c|}{0.4768} & \multicolumn{2}{|c|}{0.4820} & \multicolumn{2}{|c|}{0.5632} \\
\hline Crash-Conflict & \multicolumn{2}{|c|}{ PDO-Total } & \multicolumn{2}{|c|}{ PDO-Rear End } & \multicolumn{2}{|c|}{ PDO-Lane Change } \\
\hline Coefficient & Estimate & Pr $>$ ChiSq & Estimate & Pr $>$ ChiSq & Estimate & Pr>ChiSq \\
\hline$\alpha$ & 0.1911 & 0.1037 & 0.4692 & $<.0001$ & 0.3368 & 0.0050 \\
\hline$\beta_{1}$ & 0.2496 & $<.0001$ & 0.2282 & $<.0001$ & 0.2806 & $<.0001$ \\
\hline $\mathrm{k}$ & \multicolumn{2}{|c|}{0.5952} & \multicolumn{2}{|c|}{0.5639} & \multicolumn{2}{|c|}{0.6690} \\
\hline Crash-Conflict & \multicolumn{2}{|c|}{ SnglVeh-Total } & \multicolumn{2}{|c|}{ SnglVeh-Rear End } & \multicolumn{2}{|c|}{ SnglVeh-Lane Change } \\
\hline Coefficient & Estimate & Pr $>$ ChiSq & Estimate & Pr $>$ ChiSq & Estimate & $\operatorname{Pr}>$ ChiSq \\
\hline$\alpha$ & -0.0670 & 0.5805 & 0.0817 & 0.4090 & -0.608 & 0.5669 \\
\hline$\beta_{1}$ & 0.0908 & 0.0553 & 0.0564 & 0.2324 & 0.1331 & 0.0302 \\
\hline $\mathrm{k}$ & \multicolumn{2}{|c|}{0.5836} & \multicolumn{2}{|c|}{0.5626} & \multicolumn{2}{|c|}{0.5898} \\
\hline Crash-Conflict & \multicolumn{2}{|c|}{ Rear End-Rear End } & \multicolumn{2}{|c|}{ Side Swipe-Lane Change } & & \\
\hline Coefficient & Estimate & Pr $>$ ChiSq & Estimate & Pr $>$ ChiSq & & \\
\hline$\alpha$ & -0.7599 & $<.0001$ & -1.2490 & $<.0001$ & & \\
\hline$\beta_{1}$ & 0.4278 & $<.0001$ & 0.3305 & $<.0001$ & & \\
\hline $\mathrm{k}$ & \multicolumn{2}{|c|}{0.7692} & \multicolumn{2}{|c|}{0.4208} & & \\
\hline
\end{tabular}

According to Table 34, except PDO and Single Vehicle crashes, all the p-values of other 
crash-conflict integrated models indicate very significant results $(\mathrm{p}<0.001)$.

The goodness-of- fit results are shown from Table 35 to Table 39. The CURE plots for Total, F\&I, PDO, Single Vehicle, Rear End, Side Swipe, and predicted conflicts were evaluated separately, and examples of good and poor CURE plots are presented in Figure 38 and Figure 39.

Table 35. Crash-Conflict-Merge ACC SPFs Goodness-of-Fit Results of Total Crashes (TTC $\leq 1.0 \mathrm{~s}$ )

\begin{tabular}{|c|c|c|c|}
\hline Crash-Conflict & Total-Total & Total-Rear End & Total-Lane Change \\
\hline Avg. Observed. Crashes/Year/Site & 0.0232 & 0.0232 & 0.0232 \\
\hline MPB & -8.2146 & -8.2858 & -8.3187 \\
\hline MPB/Year & -1.6429 & -1.6572 & -1.6637 \\
\hline MAD & 8.2146 & 8.2858 & 8.3187 \\
\hline MAD/Year & 1.6429 & 1.6572 & 1.6637 \\
\hline MSPE & 113.7988 & 130.2300 & 114.9088 \\
\hline MSPE/Year ${ }^{2}$ & 4.5520 & 5.2092 & 4.5964 \\
\hline MSE & 114.9145 & 131.5067 & 116.0353 \\
\hline MSE/Year ${ }^{2}$ & 4.5966 & 5.2603 & 4.6414 \\
\hline
\end{tabular}

Table 36. Crash-Conflict-Merge ACC SPFs Goodness-of-Fit Results of F\&I Crashes (TTC $\leq 1.0 \mathrm{~s}$ )

\begin{tabular}{|c|c|c|c|}
\hline Crash-Conflict & F\&I-Total & F\&I-Rear End & F\&I-Lane Change \\
\hline Avg. Observed. Crashes/Year/Site & 0.0042 & 0.0042 & 0.0042 \\
\hline MPB & -0.8468 & -0.8643 & -0.8667 \\
\hline MPB/Year & -0.1694 & -0.1729 & -0.1733 \\
\hline MAD & 0.8468 & 0.8643 & 0.8667 \\
\hline MAD/Year & 0.1694 & 0.1729 & 0.1733 \\
\hline MSPE & 2.4998 & 2.9549 & 2.7055 \\
\hline MSPE/Year ${ }^{2}$ & 0.1000 & 0.1182 & 0.1082 \\
\hline MSE & 2.5244 & 2.9839 & 2.7320 \\
\hline MSE/Year ${ }^{2}$ & 0.1010 & 0.1194 & 0.1093 \\
\hline
\end{tabular}


Table 37. Crash-Conflict-Merge ACC SPFs Goodness-of-Fit Results of PDO Crashes (TTC $\leq 1.0 \mathrm{~s}$ )

\begin{tabular}{|c|c|c|c|}
\hline Crash-Conflict & PDO-Total & PDO-Rear End & PDO-Lane Change \\
\hline Avg. Observed. Crashes/Year/Site & 0.0189 & 0.0189 & 0.0189 \\
\hline MPB & -7.3649 & -7.4384 & -7.4659 \\
\hline MPB/Year & -1.4730 & -1.4877 & -1.4932 \\
\hline MAD & 7.3649 & 7.4384 & 7.4659 \\
\hline MAD/Year & 1.4730 & 1.4877 & 1.4932 \\
\hline MSPE & 84.2160 & 94.8863 & 83.9768 \\
\hline MSPE/Year ${ }^{2}$ & 3.3686 & 3.7955 & 3.3591 \\
\hline MSE & 85.0417 & 95.8166 & 84.8002 \\
\hline MSE/Year ${ }^{2}$ & 3.4017 & 3.8327 & 3.3920 \\
\hline
\end{tabular}

Table 38. Crash-Conflict-Merge ACC SPFs Goodness-of-Fit Results of Single Vehicle Crashes (TTC $\leq 1.0 \mathrm{~s}$ )

\begin{tabular}{|c|c|c|c|}
\hline Crash-Conflict & SnglVeh-Total & SnglVeh-Rear End & SnglVeh-Lane Change \\
\hline Avg. Observed. Crashes/Year/Site & 0.0102 & 0.0102 & 0.0102 \\
\hline MPB & -2.8515 & -2.9459 & -5.0987 \\
\hline MPB/Year & -0.5703 & -0.5892 & -1.0197 \\
\hline MAD & 2.8515 & 2.9459 & 5.0987 \\
\hline MAD/Year & 0.5703 & 0.5892 & 1.0197 \\
\hline MSPE & 11.0109 & 12.4598 & 27.4099 \\
\hline MSPE/Year ${ }^{2}$ & 0.4404 & 0.4984 & 1.0964 \\
\hline MSE & 11.1188 & 12.5820 & 27.6786 \\
\hline MSE/Year & 0.4448 & 0.5033 & 1.1071 \\
\hline
\end{tabular}

Table 39. Crash-Conflict-Merge ACC SPFs Goodness-of-Fit Results of RearEnd \& SideSwipe Crashes (TTC $\leq 1.0$ s)

\begin{tabular}{|c|c|c|}
\hline Crash-Conflict & Rear End-Rear End & Side Swipe-Lane Change \\
\hline Avg. Observed. Crashes/Year/Site & 0.0085 & 0.0042 \\
\hline MPB & -1.5730 & -3.8571 \\
\hline MPB/Year & -0.3146 & -0.7714 \\
\hline MAD & 1.5730 & 3.8571 \\
\hline MAD/Year & 0.3146 & 0.7714 \\
\hline MSPE & 27.5645 & 16.5996 \\
\hline MSPE/Year ${ }^{2}$ & 1.1026 & 0.6640 \\
\hline MSE & 27.8347 & 16.7624 \\
\hline MSE/Year ${ }^{2}$ & 1.1134 & 0.6705 \\
\hline
\end{tabular}


F\&I Crash - Total Conflict CURE Plot

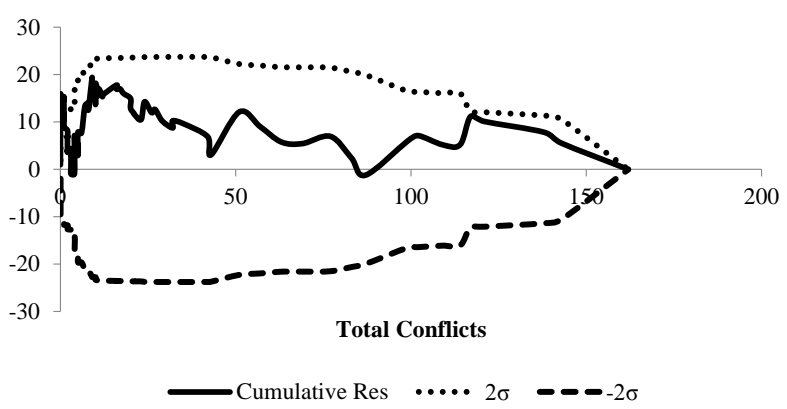

F\&I Crash - Rear End Conflict CURE Plot

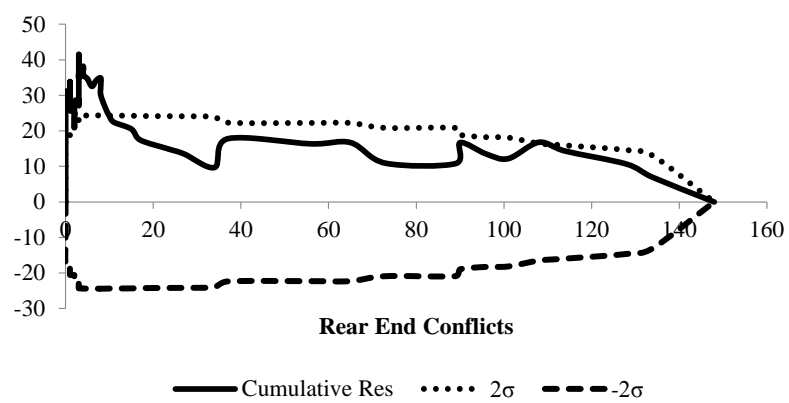

F\&I Crash - Lane Change Conflict CURE PlotTitle

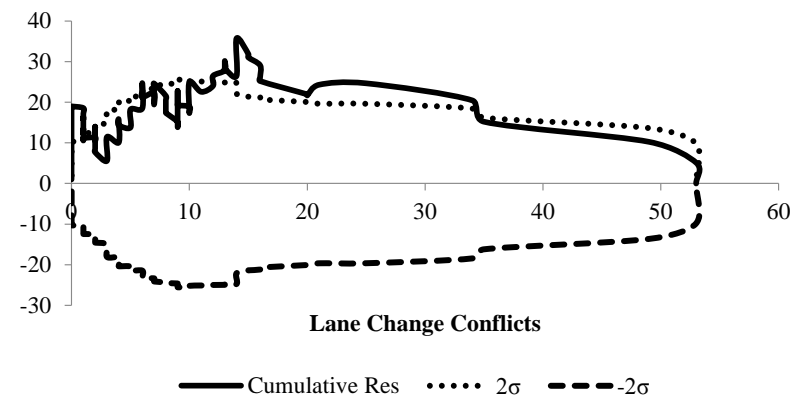

Figure 38. Merge ACC Area F\&I Crash-Conflict CURE Plots (TTC $\leq 1.0$ ) ) (good CURE plots)


Figure 39. Merge ACC Area Single Vehicle Crash-Conflict CURE Plots (TTC $\leq 1.0$ s) (CURE plots with several outliers) 


\section{$8.3 \mathrm{TTC} \leq 0.5 \mathrm{~s}$}

For TTC $\leq 1.0 \mathrm{~s}$, the model format shown in Equation 16 is the same as before, with conflict types as independent variables. Table 40 presents the coefficients and p-values for each model.

$$
\frac{\text { Crashes }}{\text { year }}=e^{\alpha} \times \text { Conflict Type } e^{\beta_{1}}
$$

(Equation 16)

Table 40. Crash-Conflict-Merge ACC SPFs Results (TTC $\leq 0.5 \mathrm{~s}$ )

\begin{tabular}{|c|c|c|c|c|c|c|}
\hline Crash-Conflict & \multicolumn{2}{|c|}{ Total-Total } & \multicolumn{2}{|c|}{ Total-Rear End } & \multicolumn{2}{|c|}{ Total-Lane Change } \\
\hline Coefficient & Estimate & $\operatorname{Pr}>$ ChiSq & Estimate & $\mathrm{Pr}>$ ChiSq & Estimate & $\operatorname{Pr}>$ ChiSq \\
\hline$\alpha$ & 0.7280 & $<.0001$ & 1.0645 & $<.0001$ & 0.8719 & $<.0001$ \\
\hline$\beta_{1}$ & 0.2930 & $<.0001$ & 0.3710 & $<.0001$ & 0.2639 & 0.0002 \\
\hline $\mathrm{k}$ & \multicolumn{2}{|c|}{0.6069} & \multicolumn{2}{|c|}{0.5938} & \multicolumn{2}{|c|}{0.6378} \\
\hline Crash-Conflict & \multicolumn{2}{|c|}{ F\&I-Total } & \multicolumn{2}{|c|}{ F\&I-Rear End } & \multicolumn{2}{|c|}{ F\&I-Lane Change } \\
\hline Coefficient & Estimate & Pr $>$ ChiSq & Estimate & $\operatorname{Pr}>$ ChiSq & Estimate & Pr $>$ ChiSq \\
\hline$\alpha$ & -1.0503 & $<.0001$ & -0.6258 & $<.0001$ & -0.9132 & $<.0001$ \\
\hline$\beta_{1}$ & 0.3679 & $<.0001$ & 0.3574 & 0.0007 & 0.3766 & $<.0001$ \\
\hline $\mathrm{k}$ & \multicolumn{2}{|c|}{0.5258} & \multicolumn{2}{|c|}{0.5609} & \multicolumn{2}{|c|}{0.5531} \\
\hline Crash-Conflict & \multicolumn{2}{|c|}{ PDO-Total } & \multicolumn{2}{|c|}{ PDO-Rear End } & \multicolumn{2}{|c|}{ PDO-Lane Change } \\
\hline Coefficient & Estimate & Pr $>$ ChiSq & Estimate & $\operatorname{Pr}>$ ChiSq & Estimate & $\operatorname{Pr}>$ ChiSq \\
\hline$\alpha$ & 0.5433 & $<.0001$ & 0.8597 & $<.0001$ & 0.6876 & $<.0001$ \\
\hline$\beta_{1}$ & 0.2752 & $<.0001$ & 0.3691 & $<.0001$ & 0.2362 & 0.0013 \\
\hline $\mathrm{k}$ & \multicolumn{2}{|c|}{0.6636} & \multicolumn{2}{|c|}{0.6415} & \multicolumn{2}{|c|}{0.7023} \\
\hline Crash-Conflict & \multicolumn{2}{|c|}{ SnglVeh-Total } & \multicolumn{2}{|c|}{ SnglVeh-Rear End } & \multicolumn{2}{|c|}{ SnglVeh-Lane Change } \\
\hline Coefficient & Estimate & Pr $>$ ChiSq & Estimate & $\operatorname{Pr}>$ ChiSq & Estimate & $\operatorname{Pr}>$ ChiSq \\
\hline$\alpha$ & 0.0737 & 0.4488 & 0.1872 & 0.0564 & 0.1284 & 0.1900 \\
\hline$\beta_{1}$ & 0.0868 & 0.1848 & 0.0812 & 0.3702 & 0.0578 & 0.4198 \\
\hline $\mathrm{k}$ & \multicolumn{2}{|c|}{0.5766} & \multicolumn{2}{|c|}{0.5709} & \multicolumn{2}{|c|}{0.6065} \\
\hline Crash-Conflict & \multicolumn{2}{|c|}{ Rear End-Rear End } & \multicolumn{2}{|c|}{ Side Swipe-Lane Change } & & \\
\hline Coefficient & Estimate & Pr $>$ ChiSq & Estimate & $\operatorname{Pr}>$ ChiSq & & \\
\hline$\alpha$ & 0.0246 & 0.8487 & -0.8263 & $<.0001$ & & \\
\hline$\beta_{1}$ & 0.7834 & $<.0001$ & 0.2849 & 0.0003 & & \\
\hline $\mathrm{k}$ & \multicolumn{2}{|c|}{1.0678} & \multicolumn{2}{|c|}{0.4248} & & \\
\hline
\end{tabular}

For TTC $\leq 0.5 \mathrm{~s}$, according to Table 40, except Single Vehicle and Rear End crashes, all the 
p-values for other crash-conflict integrated models indicate very significant results $(p<0.001)$.

The goodness-of- fit results are shown from Table 41 to Table 45. The CURE plots for Total, F\&I, PDO, Single Vehicle, Rear End, Side Swipe, and predicted conflicts were evaluated separately. The MPB, MAD, MSPE, and MSE values are reduced and close to zero, indicating that the models fit the observed data well. However, the CURE plots of models for TTC $\leq 0.5 \mathrm{~s}$ have more bias and outliers compared with the CURE plots for previous models for larger TTC values as shown in Figure 40. These results indicate that decreasing the sample size of conflicts could decrease the model predictive capabilities.

Table 41. Crash-Conflict-Merge ACC SPFs Goodness-of-Fit Results of Total Crashes (TTC $\leq 0.5 \mathrm{~s}$ )

\begin{tabular}{|c|c|c|c|}
\hline Crash-Conflict & Total-Total & Total-Rear End & Total-Lane Change \\
\hline Avg. Observed. Crashes/Year/Site & 0.0232 & 0.0232 & 0.0232 \\
\hline MPB & -8.3132 & -8.5563 & -8.6951 \\
\hline MPB/Year & -1.6626 & -1.7113 & -1.7390 \\
\hline MAD & 8.3132 & 8.5563 & 8.6951 \\
\hline MAD/Year & 1.6626 & 1.7113 & 1.7390 \\
\hline MSPE & 108.6885 & 122.5227 & 121.3387 \\
\hline MSPE/Year ${ }^{2}$ & 4.3475 & 4.9009 & 4.8535 \\
\hline MSE & 109.7540 & 123.7239 & 122.5283 \\
\hline MSE/Year ${ }^{2}$ & 4.3902 & 4.9490 & 4.9011 \\
\hline
\end{tabular}

Table 42. Crash-Conflict-Merge ACC SPFs Goodness-of-Fit Results of F\&I Crashes (TTC $\leq 0.5 \mathrm{~s}$ )

\begin{tabular}{|c|c|c|c|}
\hline Crash-Conflict & F\&I-Total & F\&I-Rear End & F\&I-Lane Change \\
\hline Avg. Observed. Crashes/Year/Site & 0.0042 & 0.0042 & 0.0042 \\
\hline MPB & -0.8519 & -0.8904 & -0.9151 \\
\hline MPB/Year & -0.1704 & -0.1781 & -0.1830 \\
\hline MAD & 0.8519 & 0.8904 & 0.9151 \\
\hline MAD/Year & 0.1704 & 0.1781 & 0.1830 \\
\hline MSPE & 2.4509 & 2.4152 & 2.9613 \\
\hline MSPE/Year ${ }^{2}$ & 0.0980 & 0.0966 & 0.1185 \\
\hline MSE & 2.4749 & 2.4389 & 2.9904 \\
\hline MSE/Year $^{2}$ & 0.0990 & 0.0976 & 0.1196 \\
\hline
\end{tabular}


Table 43. Crash-Conflict-Merge ACC SPFs Goodness-of-Fit Results of PDO Crashes (TTC $\leq 0.5 \mathrm{~s}$ )

\begin{tabular}{|c|c|c|c|}
\hline Crash-Conflict & PDO-Total & PDO-Rear End & PDO-Lane Change \\
\hline Avg. Observed. Crashes/Year/Site & 0.0189 & 0.0189 & 0.0189 \\
\hline MPB & -7.4645 & -7.6765 & -7.7856 \\
\hline MPB/Year & -1.4929 & -1.5353 & -1.5571 \\
\hline MAD & 7.4645 & 7.6765 & 7.7856 \\
\hline MAD/Year & 1.4929 & 1.5353 & 1.5571 \\
\hline MSPE & 80.4234 & 91.5136 & 88.7167 \\
\hline MSPE/Year ${ }^{2}$ & 3.2169 & 3.6605 & 3.5487 \\
\hline MSE & 81.2119 & 92.4108 & 89.5864 \\
\hline MSE/Year ${ }^{2}$ & 3.2485 & 3.6964 & 3.5835 \\
\hline
\end{tabular}

Table 44. Crash-Conflict-Merge ACC SPFs Goodness-of-Fit Results of Single Vehicle Crashes (TTC $\leq 0.5 \mathrm{~s})$

\begin{tabular}{|c|c|c|c|}
\hline Crash-Conflict & SnglVeh-Total & SnglVeh-Rear End & SnglVeh-Lane Change \\
\hline Avg. Observed. Crashes/Year/Site & 0.0102 & 0.0102 & 0.0102 \\
\hline MPB & -2.9374 & -3.0944 & -3.2211 \\
\hline MPB/Year & -0.5875 & -0.6189 & -0.6442 \\
\hline MAD & 2.9374 & 3.0944 & 3.2211 \\
\hline MAD/Year & 0.5875 & 0.6189 & 0.6442 \\
\hline MSPE & 12.1381 & 14.5602 & 15.3953 \\
\hline MSPE/Year ${ }^{2}$ & 0.4855 & 0.5824 & 0.6158 \\
\hline MSE & 12.2571 & 14.7029 & 15.5462 \\
\hline MSE/Year & 0.4903 & 0.5881 & 0.6218 \\
\hline
\end{tabular}

Table 45. Crash-Conflict-Merge ACC SPFs Goodness-of-Fit Results of RearEnd \& SideSwipe Crashes (TTC $\leq 0.5 \mathrm{~s}$ )

\begin{tabular}{|c|c|c|}
\hline Crash-Conflict & Rear End-Rear End & Side Swipe-Lane Change \\
\hline Avg. Observed. Crashes/Year/Site & 0.0085 & 0.0042 \\
\hline MPB & -1.5323 & -3.8974 \\
\hline MPB/Year & -0.3065 & -0.7795 \\
\hline MAD & 1.5323 & 3.8974 \\
\hline MAD/Year & 0.3065 & 0.7795 \\
\hline MSPE & 19.6186 & 16.8685 \\
\hline MSPE/Year ${ }^{2}$ & 0.7847 & 0.6747 \\
\hline MSE & 19.8109 & 17.0339 \\
\hline MSE/Year & & 0.6814 \\
\hline
\end{tabular}


Total Crash - Total Conflict CURE Plot

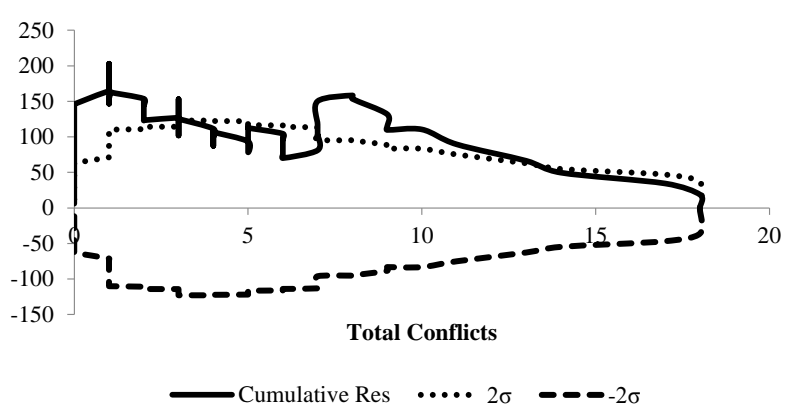

Total Crash - Rear End Conflict CURE Plot

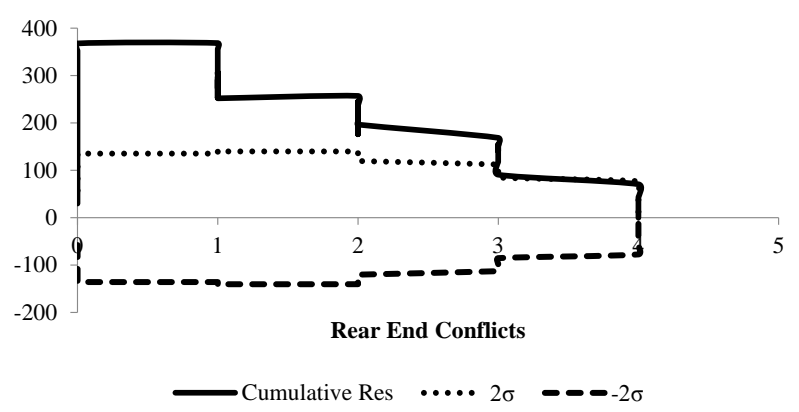

Total Crash - Lane Change Conflict CURE Plot

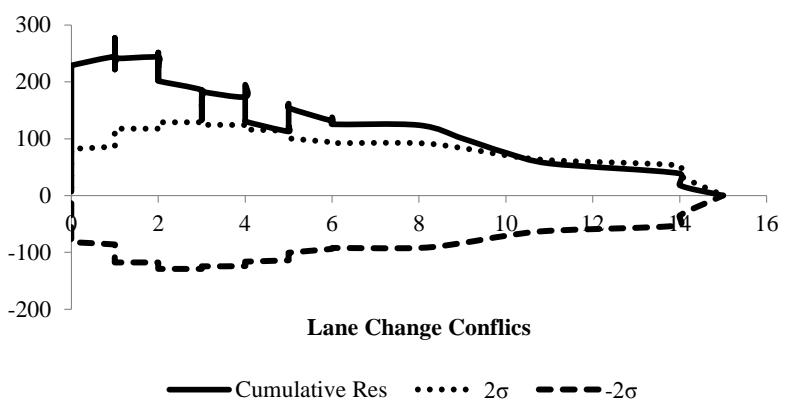

Figure 40. Merge ACC Area Total Crash-Conflict CURE Plots (TTC $\leq 0.5 s$ ) (CURE plots with several outliers)

\subsection{Model Comparison}

For the crash-conflict integrated SPFs, the p-values of most models indicate statistically significant parameters. The one notable exception is SPFs for the single vehicle crashes. According to the SPF results and goodness-of-fit for different TTC thresholds, all three TTC values were found to yield good SPFs results. Although the p-values of SPFs for TTC $\leq 0.5 \mathrm{~s}$ show more significant results compared with $\mathrm{TTC} \leq 1.0 \mathrm{~s}$ and $\mathrm{TTC} \leq 0.5 \mathrm{~s}$, the CURE plots indicate that a smaller TTC value can result in more bias and outliers. As for the conflict-based SPFs, TTC $\leq 1.5 \mathrm{~s}$ is suggested when filtering the conflicts in SSAM software to get more significant results for crash-conflict models. 


\section{Model Validation and Transferability}

\subsection{Model Validation Test}

In order to validate the crash prediction models, one example for ramp 42 on interchange 96 at freeway 400 is presented below to compare the predicted crashes from conventional crash prediction models and from surrogate safety measures (conflicts in this case). The base condition scenario is:

- Freeway AADT: 47150

- $\quad$ Ramp AADT: 6867

- Acceleration lane length: $220 \mathrm{~m}$

- Crash data: 5 years

- $\quad$ Average total conflicts: 86.2

- Average rear end conflicts: 62

- Average lane change conflicts: 24.2

Changing the length of the acceleration lane will result in a change in the crashes predicted from crash-based SPFs and crash-conflict integrated SPFs. The modified scenario with longer acceleration lane is:

- Acceleration lane length: $320 \mathrm{~m}$

- Crash data: 5 years

- Average total conflicts: 36

- $\quad$ Average rear end conflicts: 16.3

- Average lane change conflicts: 19.7

The updated average conflicts were estimated from another simulation run with an acceleration 
lane of $330 \mathrm{~m}$. In this case, models with $\mathrm{TTC} \leq 1.5 \mathrm{~s}$ were applied and evaluated. The results of two types of crash prediction models are shown in Table 46.

Table 46. Predicted Crashes Comparis on with Crash-based SPFs and Crash-Conflict Integrated SPFs

\begin{tabular}{|c|c|c|c|c|c|c|c|}
\hline Crashes & $\begin{array}{l}\text { Observed } \\
(\mathrm{ACC}=220)\end{array}$ & $\begin{array}{l}\text { Crash SPFs } \\
(\mathrm{ACC}=220)\end{array}$ & $\begin{array}{c}\text { Integrated SPFs } \\
(A C C=220)\end{array}$ & $\begin{array}{l}\text { Difference } \\
(\mathrm{ACC}=220)\end{array}$ & $\begin{array}{l}\text { Crash SPFs } \\
(\mathrm{ACC}=320)\end{array}$ & $\begin{array}{l}\text { Integrated SPFs } \\
\qquad(A C C=320)\end{array}$ & $\begin{array}{l}\text { Difference } \\
(\mathrm{ACC}=320)\end{array}$ \\
\hline Total & 27 & 22.9 & 18.3 & 4.6 & 16.8 & 14.6 & 2.18 \\
\hline F\&I & 2 & 4.0 & 3.4 & 0.6 & 3.0 & 2.7 & 0.35 \\
\hline PDO & 25 & 18.6 & 14.9 & 3.7 & 13.4 & 12.0 & 1.41 \\
\hline Rear End & 8 & 8.5 & 8.4 & 0.1 & 6.0 & 4.9 & 1.10 \\
\hline Side Swipe & 4 & 4.0 & 3.3 & 0.6 & 2.7 & 3.1 & -0.34 \\
\hline Single Vehicle & 15 & 10.2 & 6.6 & 3.6 & 7.0 & 6.0 & 1.02 \\
\hline
\end{tabular}

According to the results, the predicted crashes from two types of crash prediction models are reasonably similar to the observed counts for the existing scenario, considering the randomness of crash counts. Most important, the results of crash-based SPFs are close to that of crash-conflict integrated SPFs, especially for the scenario after the modification, indicating that the latter can reasonably be used for evaluating "what-if" scenarios using variables that may not be included in crash prediction models.

\subsection{NCHRP 17-45 Model Transferability Analysis}

In the National Cooperative Highway Research Program (NCHRP) Project 17-45 report, SPFs for speed-change lanes are given with different crash types, area types, and the number of through lanes (Bonneson et al. 2012). The SPFs were developed as an addendum to the Highway Safety Manual.

\subsubsection{Merge Areas}

Several parameters to determine the model transferability were evaluated and these parameters 
are described below (AASHTO 2014).

- Calibration factor (C) - Calibration factor is estimated by the total observed crashes divided by the total predicted crashes. a calibration factor of 1.0 indicates that there are assumed to be no difference between the local conditions and the base conditions (HSM 2009). A value larger than 1.0 indicates that the model under-predict the crashes.

- Coefficient of variation $(\mathrm{CV}(\mathrm{C}))-\mathrm{CV}(\mathrm{C})$ is estimated from standard deviation of calibration factor divided by the calibration factor. It is suggested that a reasonable upper threshold for $\mathrm{CV}$ is 0.10 or 0.15 .

- $\quad$ Modified $\mathrm{R}^{2}$ - This parameter subtracts the normal amount of random variation that would be expected if the SPF were 100 percent accurate. Larger values indicate a better fit to the data.

- Mean absolute deviation (MAD) - MAD is described in Chapter 2. Smaller values are preferred to larger values when comparing two models.

- Over-dispersion parameter $(\mathrm{k})$ - $\mathrm{k}$ is described in Chapter 2. A smaller $\mathrm{k}$ value is preferred with a SPF with less dispersion.

For merge areas, since most of the interchanges are located on the rural areas with 6 through lanes, corresponding SPFs from Bonneson et al. SPFs for the F\&I and PDO crashes shown in Equation 17 and Equation 18 were used for the transferability analysis. The calibration results are shown in Table 47.

$$
\begin{aligned}
& \text { F \& I Crashes }=\text { years } \times L_{\text {ent }} \times \exp (-4.154) \times\left(\frac{A A D T}{2000}\right)^{1.173} \quad \text { (Equation 17) } \\
& \text { PDO Crashes }=\text { years } \times L_{\text {ent }} \times \exp (-3.097) \times\left(\frac{A A D T}{2000}\right)^{1.215} \quad \text { (Equation 18) }
\end{aligned}
$$


Table 47. Calibration Results for Merge Areas

\begin{tabular}{|c|c|c|c|c|c|c|c|c|}
\hline \multirow{2}{*}{ Area } & \multicolumn{3}{|c|}{ Crashes } & \multirow{2}{*}{ C } & Modified R & \multirow{2}{*}{ MAD } & $\mathrm{k}$ & \multirow{2}{*}{ CV(C) } \\
\cline { 2 - 9 } & Type & Total Observed & Total Predict & & & & & \\
\hline \multirow{2}{*}{ Merge } & F\&I & 225 & 65.17 & 3.45 & 0.20 & 1.74 & 0.60 & 0.14 \\
\cline { 2 - 10 } & PDO & 1004 & 214.85 & 4.67 & 0.02 & 7 & 0.85 & 0.14 \\
\hline
\end{tabular}

The calibration factors for merge areas indicate that the NCHRP SPFs under-predict the F\&I and PDO crashes for Ontario freeways. The modified $R^{2}$ of 0.20 for F\&I crashes is low, but the MAD of 1.47 and the dispersion parameter of 0.60 indicate a reasonable goodness-of-fit to the data. For the PDO crashes, the small modified $\mathrm{R}^{2}$ with large MAD and $\mathrm{k}$ values indicate that the model is not very significant. Coefficient of variation of the calibration factor values for both types of crashes are less than 0.15 , indicating that the calibration factor is reasonably accurate. The CURE plots in Figure 41 and Figure 42 for both types of crashes also show that the crash prediction model for the F\&I crashes is more statistically significant than the model for the PDO crashes.
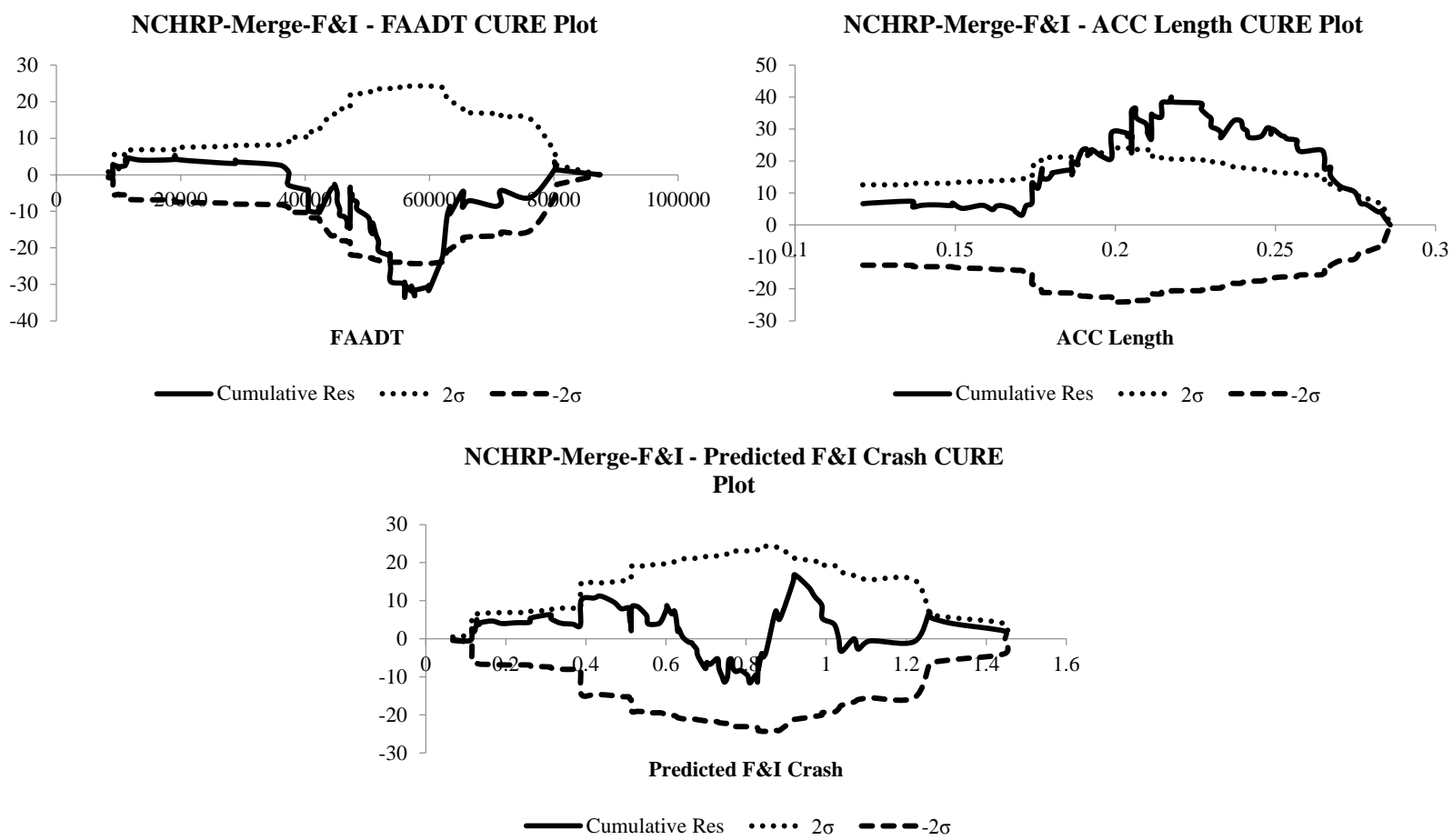

Figure 41. NCHRP-Merge ACC Area F\&I Crash CURE Plots 

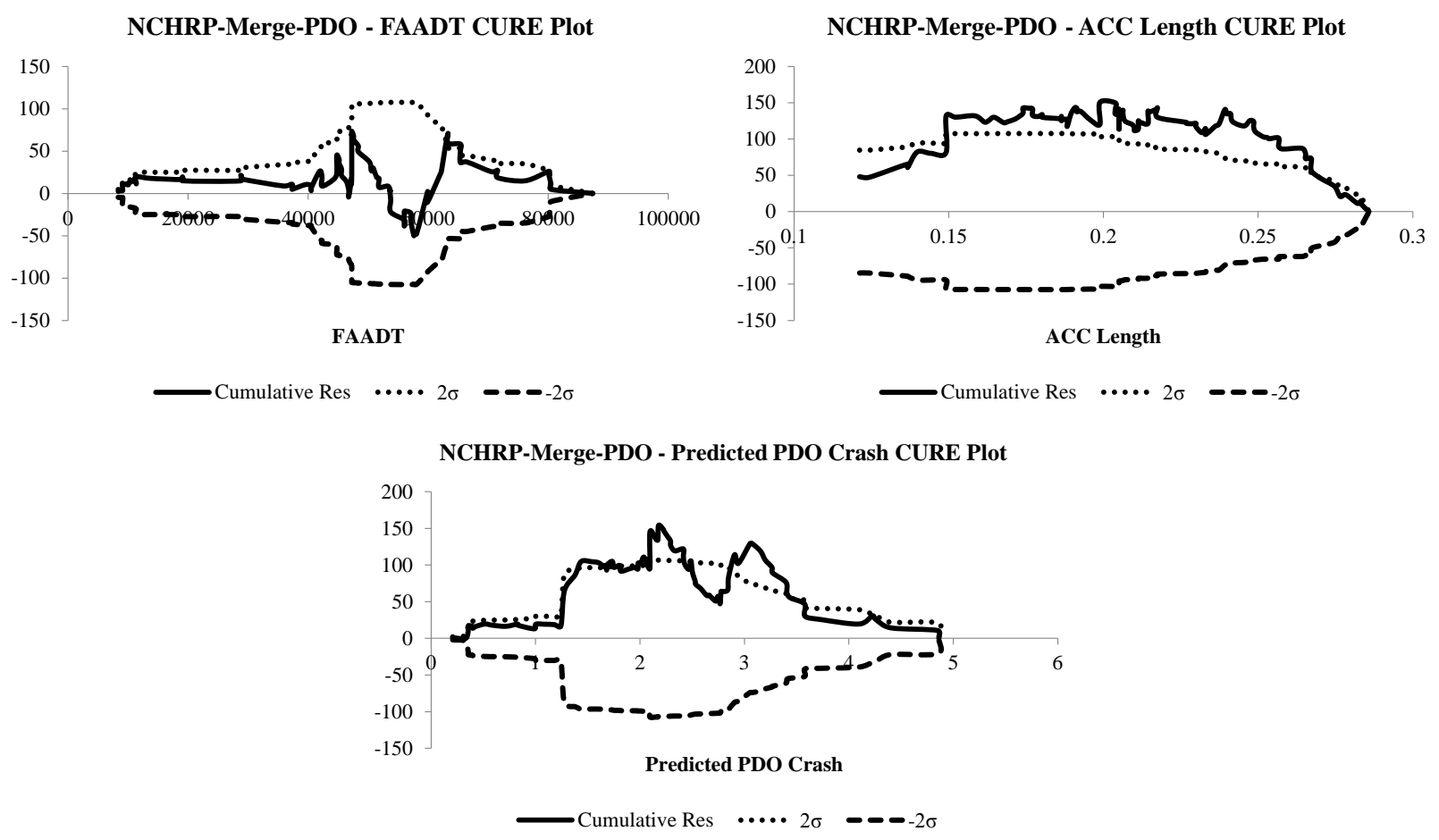

Figure 42. NCHRP-Merge ACC Area PDO Crash CURE Plots

\subsubsection{Diverge Areas}

For diverge areas, since most of the interchanges are located on the rural areas with 6 through lanes, corresponding SPFs from Bonneson at al. for the F\&I and PDO crashes shown in Equation 19 and Equation 20 were used for transferability analysis. The calibration results are shown in Table 48.

$$
\begin{aligned}
& F \& I \text { Crashes }=\text { years } \times L_{e x} \times \exp (-2.679) \times\left(\frac{A A D T}{2000}\right)^{0.903} \\
& P D O \text { Crashes }=\text { years } \times L_{e x} \times \exp (-1.798) \times\left(\frac{A A D T}{2000}\right)^{0.932}
\end{aligned}
$$


Table 48. Calibration Results for Diverge Areas

\begin{tabular}{|c|c|c|c|c|c|c|c|c|}
\hline \multirow{2}{*}{ Area } & \multicolumn{3}{|c|}{ Crashes } & \multirow{2}{*}{$\mathrm{C}$} & \multirow{2}{*}{ Modified $\mathrm{R}^{2}$} & \multirow{2}{*}{ MAD } & \multirow{2}{*}{ k } & \multirow{2}{*}{$\mathrm{CV}(\mathrm{C})$} \\
\hline & Type & Total Observed & Total Predict & & & & & \\
\hline \multirow{2}{*}{ Merge } & F\&I & 141 & 72.13 & 1.95 & 0.03 & 1.68 & 0.88 & 0.20 \\
\hline & PDO & 702 & 190.89 & 3.68 & 0.16 & 6.99 & 0.78 & 0.18 \\
\hline
\end{tabular}

The calibration factors for diverge areas indicate that the NCHRP SPFs under-predict the F\&I and PDO crashes for Ontario freeways. Compared with F\&I crashes, the calibration results for PDO crashes are better due to a larger $\mathrm{R}^{2}$ and a smaller $\mathrm{k}$ value. However, the $\mathrm{CV}(\mathrm{C})$ values for both conditions exceed the suggested upper limit of 0.15. The CURE plots in Figure 43 and Figure 44 for both types of crashes also indicate that the crash prediction model for the PDO crashes is more statistically significant than the model for F\&I crashes.


Figure 43. NCHRP-Diverge DEC Area F\&I Crash CURE Plots 

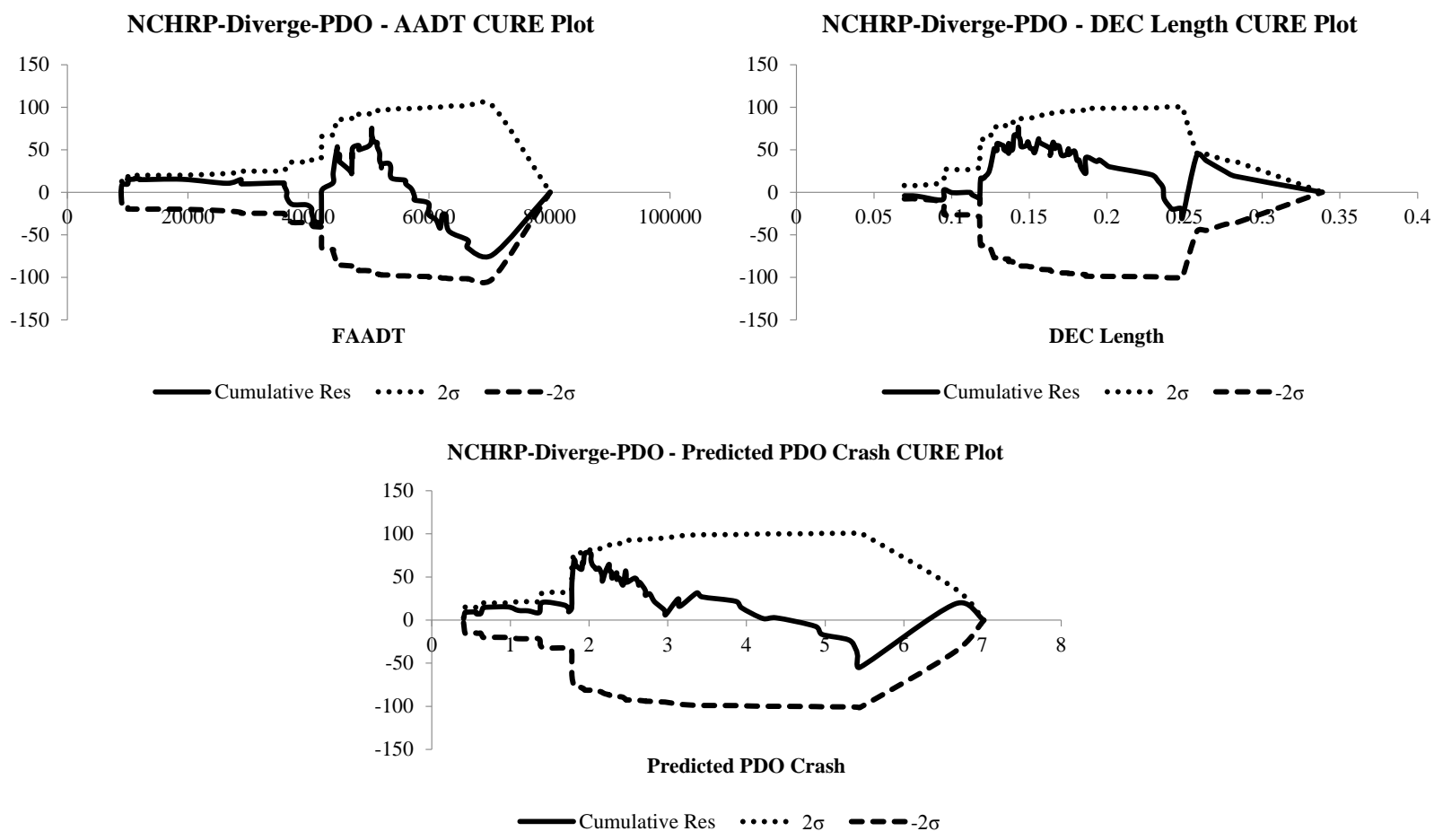

Figure 44. NCHRP-Diverge DEC Area PDO Crash CURE Plots 


\section{Summary and Conclusions}

The purpose of this study was to develop crash prediction models for the speed-change lanes on the freeways in Ontario with a view to using them to evaluate the safety effects of design and operational elements such as the length. Two approaches, including conventional crash prediction models and crash prediction models based on simulated conflicts as a surrogate safety measure, were examined.

For conventional crash prediction models, merge, diverge, and weave areas were evaluated. Two groups of SPFs, with two types of influence areas, were developed separately for 103 merge and 78 diverge areas. For Type A influence area, all of the collisions were collected from the acceleration (or deceleration) lane and adjacent mainline. For Type B influence areas, collisions were collected from 1,500 ft. around the gores of merge and diverge junctions. The SPFs for merge areas with both types of influence areas had statistically significant coefficients, for the key AADT and length variables. However, for diverge areas, only the SPFs with 1,500 $\mathrm{ft}$. influence areas show good results for p-values, goodness-of-fit, and CURE plots. In addition, the coefficients for acceleration lanes and deceleration lanes are both negative. The negative coefficients show that the expected collisions will decrease by increasing the length of speed-change lanes for those sites. For weave areas, the coefficients for length of the auxiliary lanes are positive, which is probably because of the limited sample size and increased exposure.

For crash prediction models based on simulated conflicts as a surrogate safety measure, 103 merge sites with Type A influence areas were simulated and analyzed using VISSIM and SSAM software packages. Maximum times to collision (TTC) parameter values ranging from 0.5 sec to 1.5 sec were applied to assess the influence of this parameter on the results. The results of the conflict-based SPFs are in agreement with the crash-based SPFs, with negative coefficients for 
acceleration lanes and positive coefficients for traffic volumes. The p-values for crash-conflict integrated SPFs are statistically significant for most models, except the SPFs for the single vehicle crashes. When using $\mathrm{TTC} \leq 1.5 \mathrm{~s}$, the results of both conflict-based and crash-conflict integrated SPFs are statistically more significant compared with using $\mathrm{TTC} \leq 1.0 \mathrm{~s}$ or $\mathrm{TTC} \leq 0.5 \mathrm{~s}$, likely because the sample of conflicts gets reduced with the decreasing thresholds. In sum, it is suggested to use $\mathrm{TTC} \leq 1.5 \mathrm{~s}$ when filtering the conflicts for use in crash prediction models.

The validity of the crash-conflict approach was further confirmed by evaluating the difference between the two crash prediction approaches (crash-based SPFs and crash-conflict integrated SPFs) for estimating a crash modification factor for increasing an acceleration lane length in the dataset by 100 meters. The results confirm the promise of the crash-conflict integrated SPF approach for safety evaluation of what-if scenarios for variables not included in conventional crash prediction models.

A final aspect to the research was to assess the transferability to Ontario of US models recently developed for the Highway Safety Manual. For both merge and diverge areas, the US-based SPFs for F\&I and PDO crashes were evaluated. According to the calibration results and CURE plots, the Merge-F\&I SPF and Diverge-PDO SPF transferred better than the others.

For future research, more interchanges could be introduced to enlarge the sample size and increase robustness of the results, given the promise of the approaches investigated in this research. Also, a data validation process could be applied for the developed SPFs for speed-change lanes using an independent dataset, potentially from another jurisdiction. In addition, more work could be done on VISSIM parameters calibration process for car following and lane change behaviour models. Simulation results from different microscopic simulation software packages, such as Paramics and even Synchro, could also be compared and evaluated. 
Such research efforts will increase confidence in applying the Ontario results to other jurisdictions. 


\section{Appendix A: List of Study Sites}

A.1 - List of Merge Areas

Table 49. List of Merge Areas

\begin{tabular}{|c|c|c|c|c|c|c|c|c|c|c|c|}
\hline No & HWY No & Interchange ID & Name & LHRS & Ramp No & No & HWY No & Interchange ID & Name & LHRS & Ramp No \\
\hline 1 & QEW & 51 & Seventh Street Louth & 10064 & 15 & 53 & 401 & 320 & Martin St & 47700 & 36 \\
\hline 2 & QEW & 51 & Seventh Street Louth & 10064 & 26 & 54 & 401 & 312 & Guelph Line & 47710 & 25 \\
\hline 3 & QEW & 55 & Jordan Rd & 10066 & 15 & 55 & 401 & 312 & Guelph Line & 47710 & 35 \\
\hline 4 & QEW & 55 & Jordan Rd & 10066 & 46 & 56 & 401 & 312 & Guelph Line & 47710 & 36 \\
\hline 5 & QEW & 57 & Victoria Ave & 10070 & 15 & 57 & 401 & 299 & Brock Rd S & 47720 & 15 \\
\hline 7 & QEW & 64 & Ontario St & 10074 & 26 & 59 & 401 & 286 & Townlined Rd & 47725 & 35 \\
\hline 8 & QEW & 64 & Ontario St & 10074 & 36 & 60 & 401 & 286 & Townlined Rd & 47725 & 26 \\
\hline 9 & QEW & 68 & Bartlett Ave & 10080 & 26 & 61 & 401 & 286 & Townlined Rd & 47725 & 36 \\
\hline 10 & QEW & 68 & Bartlett Ave & 10080 & 15 & 62 & 401 & 282 & Hespeler Rd & 47730 & 36 \\
\hline 11 & QEW & 71 & Christie St & 10083 & 16 & 63 & 401 & 282 & Hespeler Rd & 47730 & 35 \\
\hline 12 & 400 & 33 & Rutherford Rd & 46824 & 63 & 64 & 402 & 100 & Wonderland Rd S & 48112 & 16 \\
\hline 13 & 400 & 35 & Major MacKenzie Dr W & 46827 & 53 & 65 & 402 & 98 & Colonel Talbot Rd & 48115 & 15 \\
\hline 14 & 400 & 52 & Lloy dtown-Aurora Rd & 46836 & 61 & 66 & 402 & 98 & Colonel Talbot Rd & 48115 & 26 \\
\hline 15 & 400 & 55 & Davis Dr.W & 46840 & 53 & 67 & 402 & 98 & Colonel Talbot Rd & 48115 & 36 \\
\hline 16 & 400 & 55 & Davis Dr.W & 46840 & 63 & 68 & 402 & 86 & Longwoods Rd & 48120 & 45 \\
\hline 17 & 400 & 75 & 89 Cookstown Alliston & 46860 & 42 & 69 & 402 & 86 & Longwoods Rd & 48120 & 46 \\
\hline 18 & 400 & 85 & Innisfil Beach Rd & 46870 & 62 & 70 & 402 & 82 & Glendon Dr & 48123 & 15 \\
\hline 19 & 400 & 85 & Innisfil Beach Rd & 46870 & 63 & 71 & 402 & 82 & Glendon Dr & 48123 & 16 \\
\hline 20 & 400 & 85 & Innisfil Beach Rd & 46870 & 53 & 72 & 402 & 69 & Hickory Dr & 48127 & 16 \\
\hline 21 & 400 & 90 & Mapleview Dr W & 46875 & 42 & 73 & 402 & 69 & Hickory Dr & 48127 & 15 \\
\hline 22 & 400 & 90 & Mapleview Dr W & 46875 & 43 & 74 & 402 & 65 & Centre Rd & 48131 & 15 \\
\hline
\end{tabular}




\begin{tabular}{|c|c|c|c|c|}
\hline 23 & 400 & 96 & Dunlop St. East & 46890 \\
\hline 24 & 400 & 96 & Dunlop St. East & 46890 \\
\hline 25 & 400 & 98 & Bay field St & 46900 \\
\hline 26 & 400 & 98 & Bay field St & 46900 \\
\hline 27 & 400 & 102 & Duckworth St & 46904 \\
\hline 28 & 400 & 102 & Duckworth St & 46904 \\
\hline 29 & 400 & 102 & Duckworth St & 46904 \\
\hline 30 & 401 & 432 & Liberty St. & 47575 \\
\hline 31 & 401 & 431 & Waverley Rd & 47577 \\
\hline 32 & 401 & 431 & Waverley Rd & 47577 \\
\hline 33 & 401 & 425 & Courtice Rd & 47580 \\
\hline 34 & 401 & 419 & Harmony Road & 47584 \\
\hline 35 & 401 & 419 & Harmony Road & 47584 \\
\hline 36 & 401 & 418 & Ritson Rd S & 47587 \\
\hline 37 & 401 & 418 & Ritson Rd S & 47587 \\
\hline 38 & 401 & 417 & Simcoe St S & 47590 \\
\hline 39 & 401 & 412 & Thickson Rd S & 47596 \\
\hline 40 & 401 & 410 & Brock St S & 47598 \\
\hline 41 & 401 & 340 & Mavis Rd & 47682 \\
\hline 42 & 401 & 340 & Mavis Rd & 47682 \\
\hline 43 & 401 & 336 & Mississauga Rd & 47685 \\
\hline 44 & 401 & 336 & Mississauga Rd & 47685 \\
\hline 45 & 401 & 333 & Winston Churchill Blvd & 47688 \\
\hline 46 & 401 & 328 & Trafalgar Rd & 47690 \\
\hline 47 & 401 & 328 & Trafalgar Rd & 47690 \\
\hline 48 & 401 & 328 & Trafalgar Rd & 47690 \\
\hline 49 & 401 & 324 & James Snow Pkwy S & 47695 \\
\hline 50 & 401 & 324 & James Snow Pkwy S & 47695 \\
\hline
\end{tabular}

\begin{tabular}{|c|c|c|c|}
\hline 42 & 75 & 402 & 65 \\
\hline 43 & 76 & 402 & 56 \\
\hline 42 & 77 & 404 & 29 \\
\hline 53 & 78 & 404 & 31 \\
\hline 42 & 79 & 404 & 31 \\
\hline 63 & 80 & 404 & 31 \\
\hline 53 & 81 & 404 & 37 \\
\hline 15 & 82 & 404 & 37 \\
\hline 36 & 83 & 404 & 37 \\
\hline 15 & 84 & 404 & 37 \\
\hline 15 & 85 & 404 & 41 \\
\hline 85 & 86 & 404 & 41 \\
\hline 76 & 87 & 404 & 41 \\
\hline 15 & 88 & 404 & 41 \\
\hline 16 & 89 & 404 & 45 \\
\hline 16 & 90 & 404 & 45 \\
\hline 36 & 91 & 404 & 45 \\
\hline 36 & 92 & 404 & 45 \\
\hline 35 & 93 & 404 & 49 \\
\hline 26 & 94 & 404 & 49 \\
\hline 35 & 95 & 404 & 51 \\
\hline 36 & 96 & 404 & 51 \\
\hline 35 & 97 & 404 & 51 \\
\hline 25 & 98 & 404 & 51 \\
\hline 26 & 99 & 410 & 7 \\
\hline 36 & 100 & 410 & 7 \\
\hline 25 & 101 & 410 & 10 \\
\hline 26 & 102 & 410 & 10 \\
\hline
\end{tabular}

Centre Rd
Kerwood Rd
16th Avenue

Major MacKenzie Dr E

Major MacKenzie Dr E

Major MacKenzie Dr E

Stouffville Rd

Stouffville Rd

Stouffville Rd

Stouffville Rd

Bloomington Rd

Bloomington Rd

Bloomington Rd

Bloomington $\mathrm{Rd}$

Wellington St E

Wellington St E

Wellington St E

Wellington St E

Mulock Dr

Mulock Dr

Davis Dr

Davis Dr

Davis Dr

Davis Dr

Steeles Avenue

Steeles Avenue

Queen Street

Queen Stree 


\begin{tabular}{|c|c|c|c|c|c|c|c|c|c|c|c|}
\hline 51 & 401 & 324 & James Snow Pkwy S & 47695 & 36 & 103 & 410 & 12 & Williams Parkway & 49072 & 52 \\
\hline 52 & 401 & 320 & Martin St & 47700 & 26 & & & & & & \\
\hline
\end{tabular}

\section{A.2 - List of Diverge Areas}

Table 50. List of Diverge Areas

\begin{tabular}{|c|c|c|c|c|c|c|c|c|c|c|c|}
\hline No & HWY No & Interchange ID & Name & LHRS & Ramp No & No & HWY No & Interchange ID & Name & LHRS & Ramp No \\
\hline 1 & QEW & 51 & Seventh Street Louth & 10064 & 51 & 40 & 402 & 69 & Hickory Dr & 48127 & 61 \\
\hline 2 & QEW & 55 & Jordan Rd & 10066 & 51 & 41 & 402 & 65 & Centre Rd & 48131 & 61 \\
\hline 3 & QEW & 55 & Jordan Rd & 10066 & 61 & 42 & 402 & 56 & Kerwood Rd & 48134 & 61 \\
\hline 4 & QEW & 57 & Victoria Ave & 10070 & 51 & 43 & QEW & 68 & Bartlett Ave & 10080 & 51 \\
\hline 5 & QEW & 57 & Victoria Ave & 10070 & 61 & 44 & 401 & 275 & Homer Watson Blvd & 47745 & 51 \\
\hline 7 & QEW & 71 & Christie St & 10083 & 51 & 46 & 401 & 299 & Brock Rd S & 47720 & 51 \\
\hline 8 & QEW & 71 & Christie St & 10083 & 61 & 47 & 401 & 299 & Brock Rd S & 47720 & 61 \\
\hline 9 & QEW & 74 & Casablanca Blvd & 10085 & 51 & 48 & 401 & 312 & Guelph Line & 47710 & 61 \\
\hline 10 & QEW & 78 & Fifty Rd & 10090 & 61 & 49 & 401 & 320 & Martin St & 47700 & 51 \\
\hline 11 & QEW & 83 & Fruitland Rd & 10094 & 51 & 50 & 401 & 320 & Martin St & 47700 & 61 \\
\hline 13 & 401 & 275 & Homer Watson Blvd & 47745 & 61 & 52 & 401 & 410 & Brock St S & 47598 & 64 \\
\hline 14 & 401 & 286 & Townlined Rd & 47725 & 51 & 53 & 401 & 418 & Ritson Rd S & 47587 & 51 \\
\hline 15 & 401 & 286 & Townlined Rd & 47725 & 61 & 54 & 401 & 418 & Ritson Rd S & 47587 & 61 \\
\hline 16 & 401 & 336 & Mississauga Rd & 47685 & 51 & 55 & 401 & 419 & Harmony Road & 47584 & 58 \\
\hline 17 & 401 & 336 & Mississauga Rd & 47685 & 61 & 56 & 401 & 419 & Harmony Road & 47584 & 67 \\
\hline 18 & 401 & 412 & Thickson Rd S & 47596 & 51 & 57 & 401 & 425 & Courtice Rd & 47580 & 51 \\
\hline 19 & 401 & 412 & Thickson Rd S & 47596 & 61 & 58 & 401 & 431 & Waverley Rd & 47577 & 51 \\
\hline 20 & 401 & 417 & Simcoe St S & 47590 & 57 & 59 & 401 & 432 & Liberty St. & 47575 & 51 \\
\hline 21 & 401 & 425 & Courtice Rd & 47580 & 61 & 60 & 401 & 432 & Liberty St. & 47575 & 61 \\
\hline
\end{tabular}




\begin{tabular}{|c|c|c|c|c|c|c|c|c|c|c|c|}
\hline 22 & 401 & 428 & Holt Rd & 47578 & 51 & 61 & 401 & $435 / 6$ & Bennett Rd & 47573 & 51 \\
\hline 23 & 400 & 33 & Rutherford Rd & 46824 & 34 & 62 & 400 & 52 & Lloy dtown-Aurora Rd & 46836 & 24 \\
\hline 24 & 400 & 43 & King Rd & 46830 & 24 & 63 & 400 & 75 & 89 Cookstown Alliston & 46860 & 24 \\
\hline 25 & 400 & 52 & Lloydtown-Aurora Rd & 46836 & 34 & 64 & 400 & 85 & Innisfil Beach Rd & 46870 & 24 \\
\hline 26 & 400 & 55 & Davis Dr.W & 46840 & 24 & 65 & 400 & 85 & Innisfil Beach Rd & 46870 & 34 \\
\hline 27 & 400 & 75 & 89 Cookstown Alliston & 46860 & 34 & 66 & 400 & 96A/B & Dunlop St. East & 46890 & 25 \\
\hline 28 & 400 & 90 & Mapleview Dr W & 46875 & 24 & 67 & 400 & $96 \mathrm{~A} / \mathrm{B}$ & Dunlop St. East & 46890 & 34 \\
\hline 29 & 400 & 90 & Mapleview Dr W & 46875 & 34 & 68 & 400 & 98 & Bay field St & 46900 & 34 \\
\hline 30 & 400 & 98 & Bay field St & 46900 & 24 & 69 & 404 & 37 & Stouffville Rd & 48515 & 34 \\
\hline 31 & 400 & 102 & Duckworth St & 46904 & 24 & 70 & 404 & 41 & Bloomington Rd & 48525 & 24 \\
\hline 32 & 400 & 102 & Duckworth St & 46904 & 34 & 71 & 404 & 41 & Bloomington Rd & 48525 & 34 \\
\hline 33 & 404 & 31 & Major MacKenzie Dr E & 48506 & 24 & 72 & 404 & 45 & Wellington St E & 48530 & 34 \\
\hline 34 & 404 & 31 & Major MacKenzie Dr E & 48506 & 34 & 73 & 404 & 51 & Davis Dr & 48540 & 24 \\
\hline 35 & 404 & 37 & Stouffville Rd & 48515 & 24 & 74 & 402 & 86 & Longwoods Rd & 48120 & 54 \\
\hline 36 & 404 & 49 & Mulock Dr & 48535 & 24 & 75 & 402 & 86 & Longwoods Rd & 48120 & 64 \\
\hline 37 & 402 & 100 & Wonderland Rd S & 48112 & 51 & 76 & 402 & 82 & Glendon Dr & 48123 & 51 \\
\hline 38 & 402 & 98 & Colonel Talbot Rd & 48115 & 51 & 77 & 402 & 82 & Glendon Dr & 48123 & 61 \\
\hline 39 & 402 & 98 & Colonel Talbot Rd & 48115 & 61 & 78 & 402 & 69 & Hickory Dr & 48127 & 51 \\
\hline
\end{tabular}

\section{A.3 - List of Weave Areas}

Table 51. List of Weave Areas

\begin{tabular}{|c|c|c|c|c|c|}
\hline No & HWY No & Interchange ID & Name & LHRS & Ramp No \\
\hline 1 & QEW & 51 & Seventh Street Louth & 10063 & 61 \\
2 & QEW & 78 & Fifty Rd & 10085 & 51 \\
3 & 401 & 320 & Martin St & 47700 & 35 \\
4 & 401 & 333 & Winston Churchill Blvd & 47688 & 51 \\
5 & 401 & 333 & Winston Churchill Blvd & 47688 & 36
\end{tabular}




\begin{tabular}{|l|l|l|c|c|c|}
6 & 401 & 412 & Thickson Rd S & 47594 & 55 \\
7 & 401 & 435 & Bennett Rd & 47570 & 15 \\
8 & 401 & 435 & Bennett Rd & 47573 & 16 \\
9 & 400 & 33 & Rutherford Rd & 46822 & 24 \\
10 & 400 & 33 & Rutherford Rd & 46822 & 62 \\
11 & 400 & 33 & Rutherford Rd & 46824 & 53 \\
12 & 400 & 35 & Major MacKenzie Dr W & 46827 & 62 \\
13 & 400 & 35 & Major MacKenzie Dr W & 46827 & 34 \\
14 & 400 & 35 & Major MacKenzie Dr W & 46824 & 63 \\
15 & 400 & 37 & Teston Rd & 46827 & 34 \\
16 & 400 & 52 & Lloydtown-Aurora Rd & 46830 & 53 \\
17 & 410 & 7 & Steeles Avenue & 49063 & 24 \\
18 & 410 & 7 & Steeles Avenue & 49063 & 53 \\
19 & 410 & 10 & Queen Street & 49071 & 34 \\
20 & 410 & 12 & Williams Parkway & 49072 & 62 \\
21 & 410 & 12 & Williams Parkway & 49072 & 34 \\
22 & 404 & 29 & 16th Avenue & 48500 & 53 \\
\hline
\end{tabular}




\section{Appendix B: Additional CURE Plots for Crash-based SPFs in Chapter 6}

\section{B.1 - Crash-Merge-ACC SPFs}
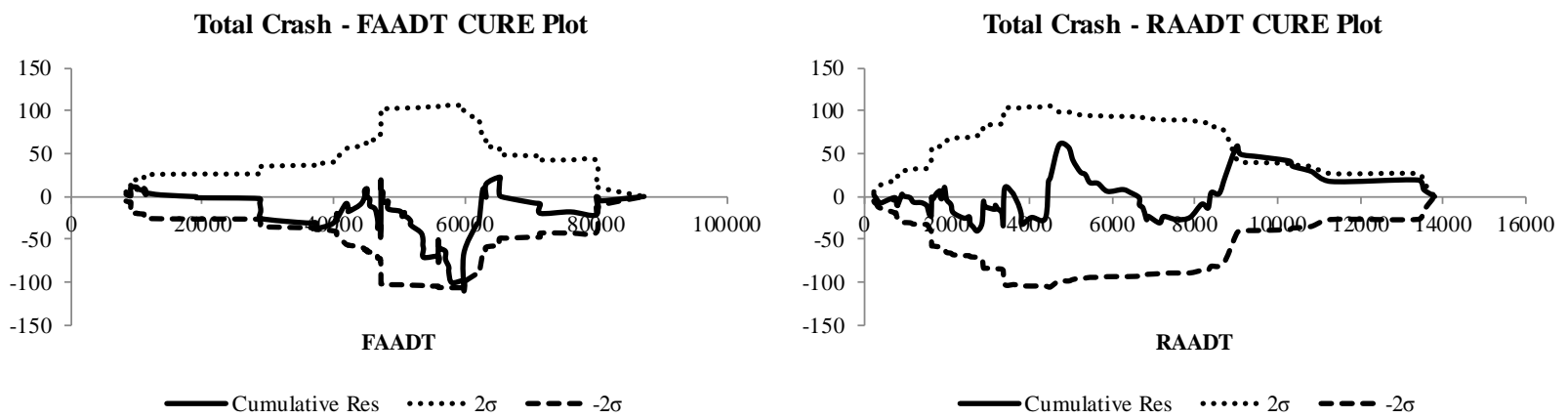

Total Crash - ACC Length CURE Plot
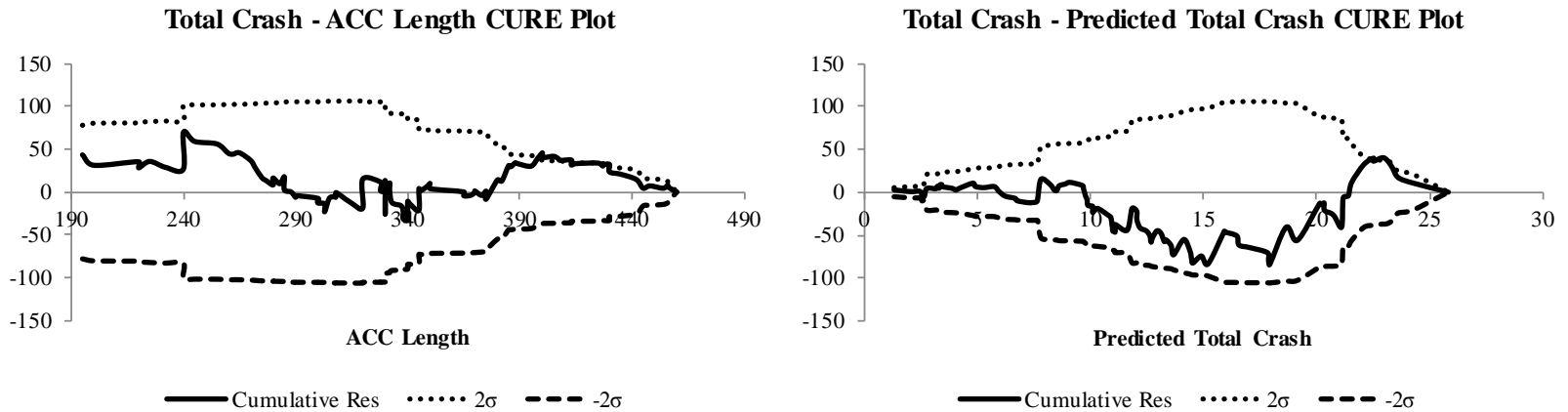

Figure 45. Crash-Merge-ACC SPFs Total Crash CURE Plots

F\&I Crash - FAADT CURE Plot

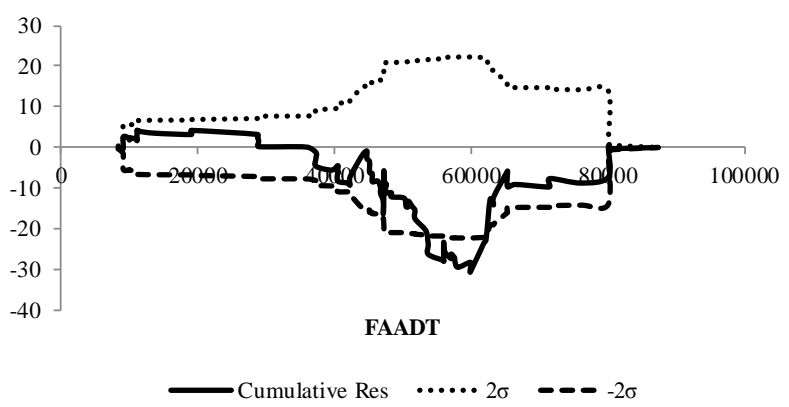

F\&I Crash - ACC Length CURE Plot

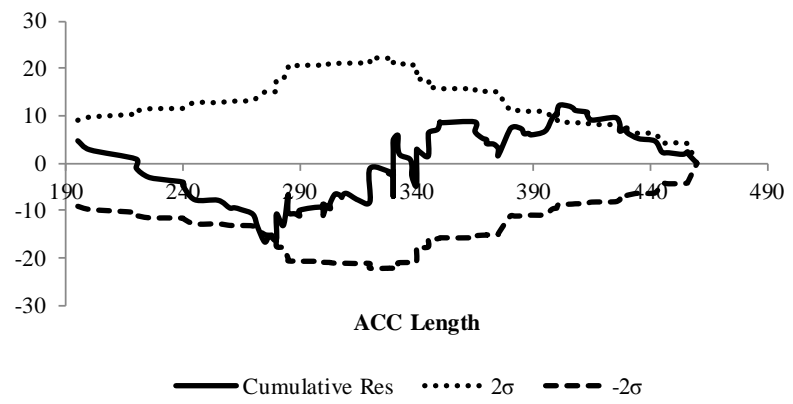

F\&I Crash - RAADT CURE Plot

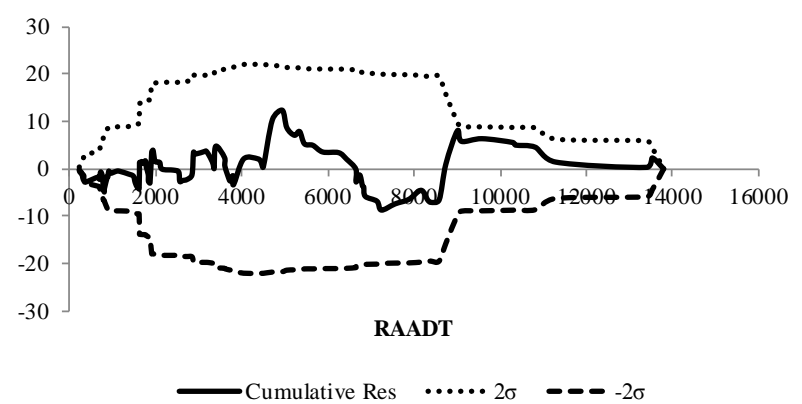

F\&I Crash - Predicted F\&I Crash CUPE Plot

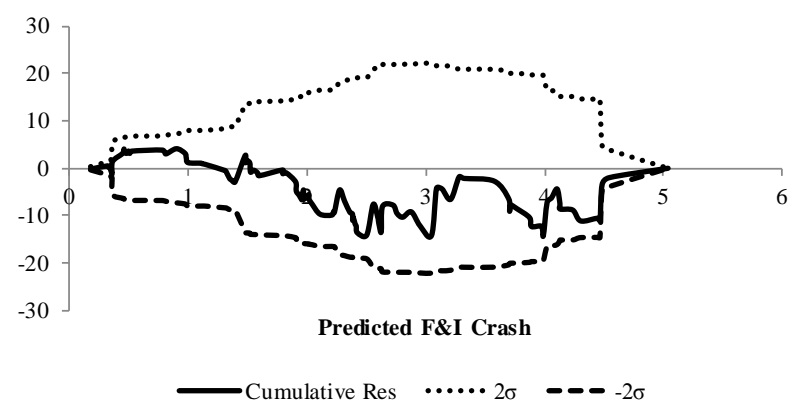

Figure 46. Crash-Merge-ACC SPFs F\&I Crash CURE Plots 
Side Swipe Crash - FAADT CURE Plot

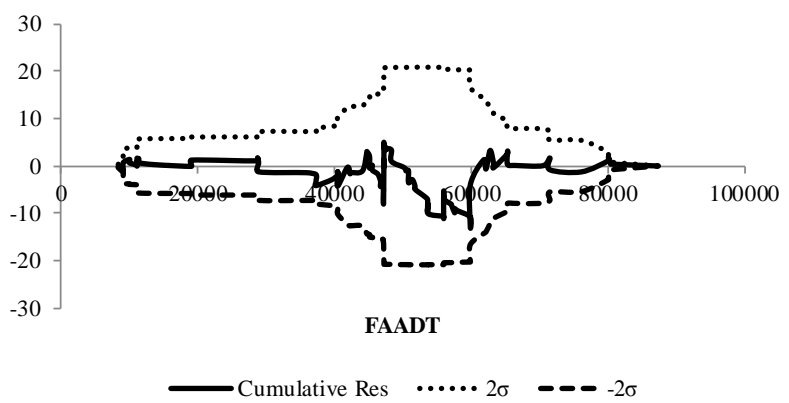

Side Swipe Crash - ACC Length CURE Plot

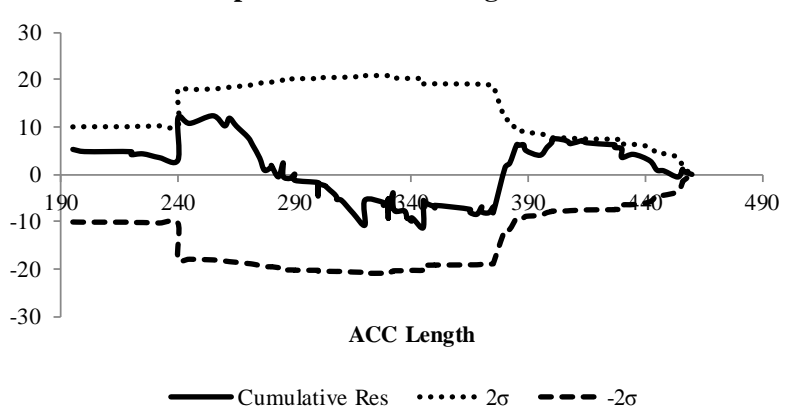

Side Swipe Crash - RAADT CURE Plot

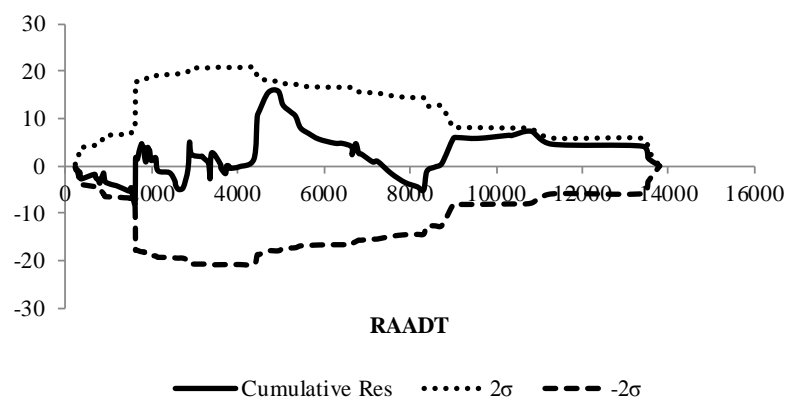

Side Swipe Crash - Predicted Side Swipe Crash CURE Plot



Figure 47. Crash-Merge-ACC SPFs Side Swipe Crash CURE Plots

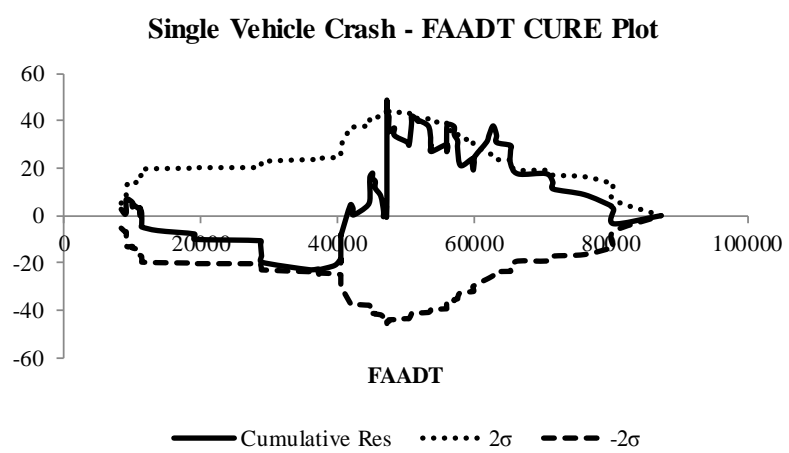

Single Vehicle Crash - ACC Length CURE Plot

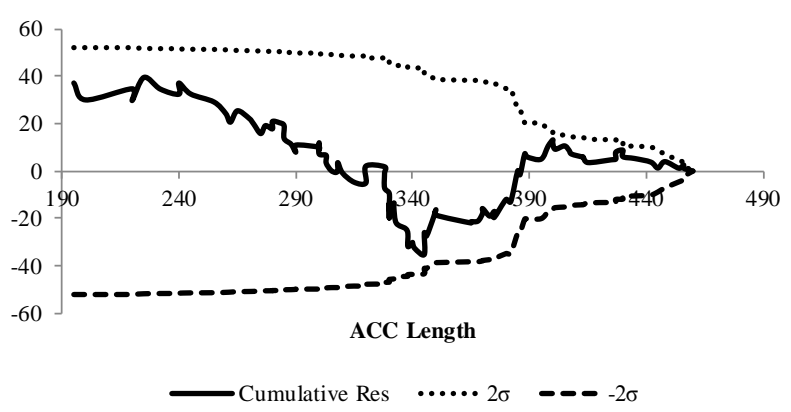

Single Vehicle Crash - RAADT CURE Plot

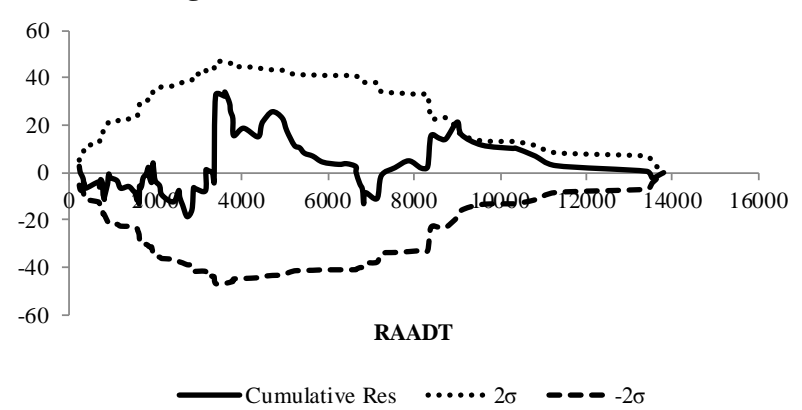

Single Vehicle Crash - Predicted Single Vehicle Crash



Figure 48. Crash-Merge-ACC SPFs Single Vehicle Crash CURE Plots 


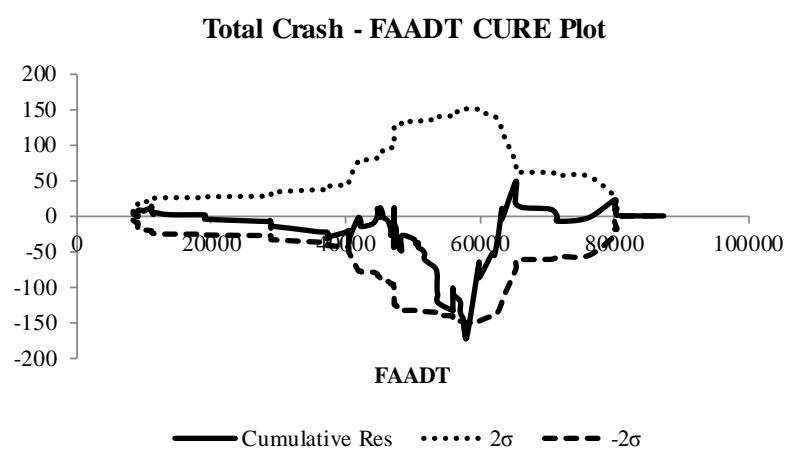

Total Crash - ACC Length CURE Plot

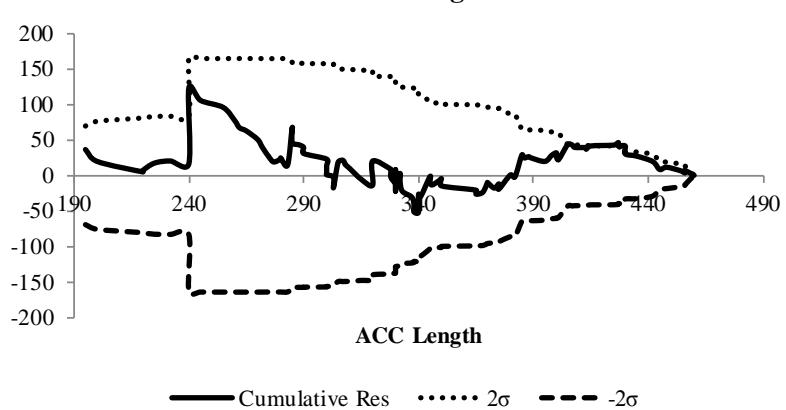

Figure 49. Crash-Merge-1,500 ft. SPFs Total Crash CURE Plots

F\&I Crash - FAADT CURE Plot

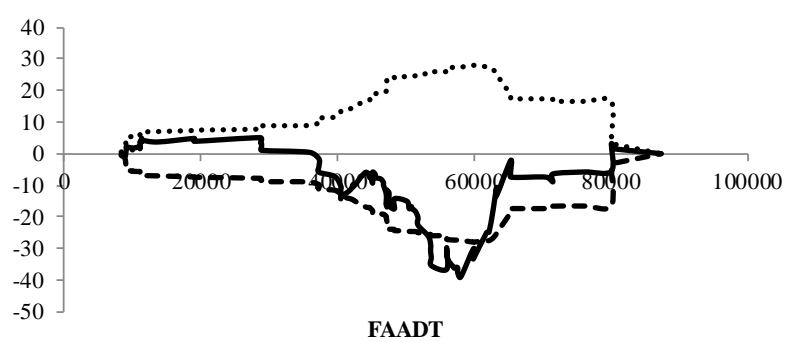

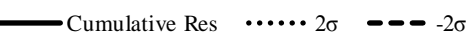

F\&I Crash - ACC Length CURE Plot

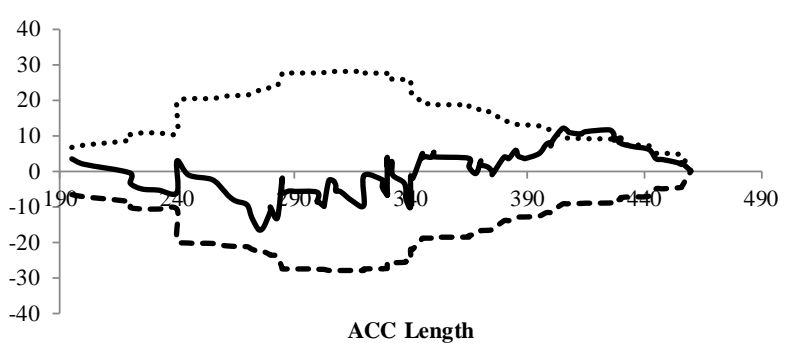

Cumulative Res $\quad \cdots \cdots \cdot 2 \sigma \quad \ldots--2 \sigma$
Total Crash - RAADT CURE Plot

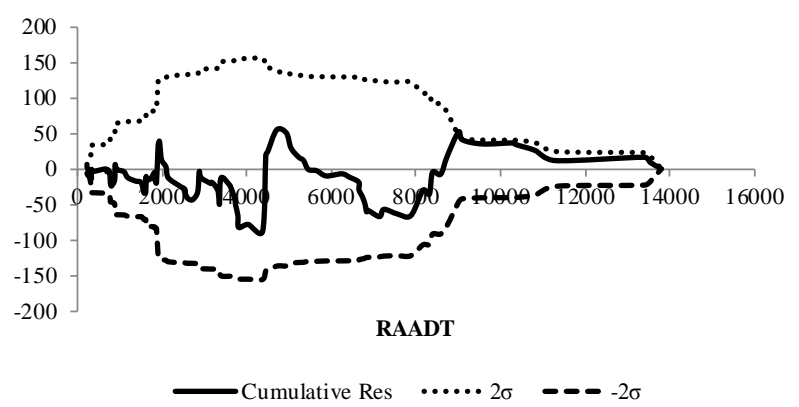

Total Crash - Predicted Total Crash CURE Plot

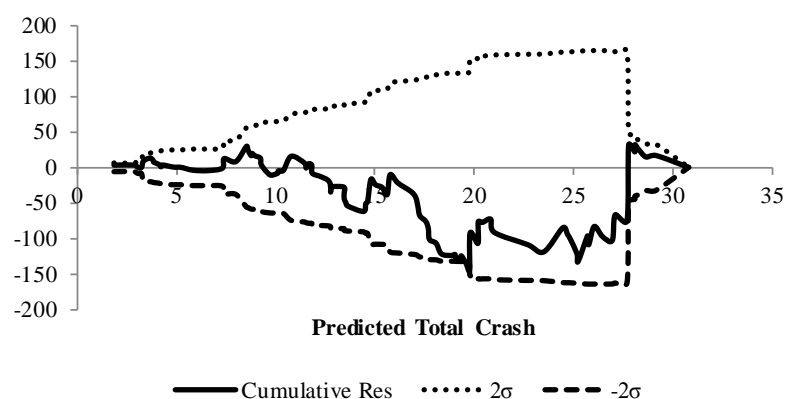


Side Swipe Crash - FAADT CURE Plot

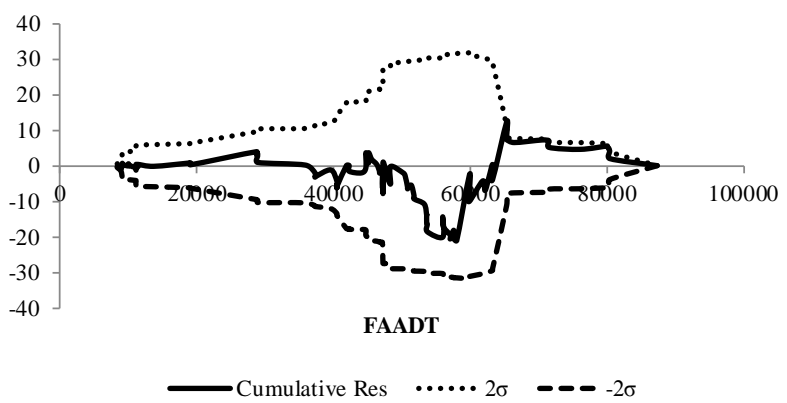

Side Swipe Crash - ACC Length CURE Plot

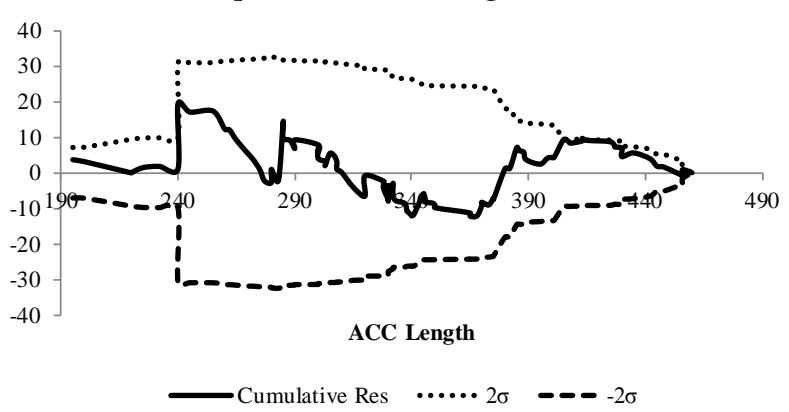

Side Swipe Crash - RAADT CURE Plot

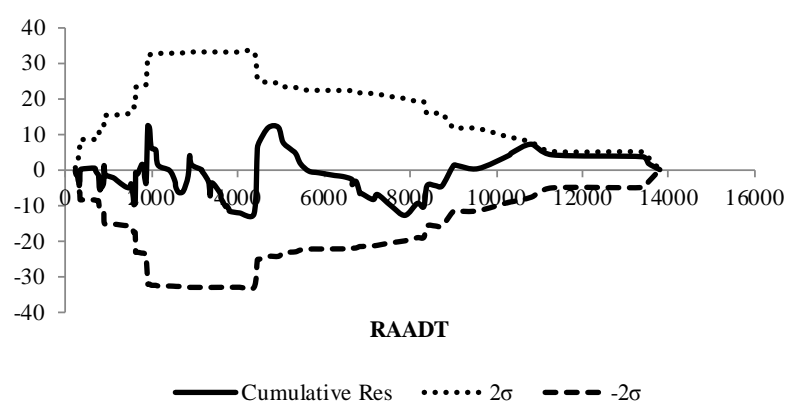

Side Swipe Crash - Predicted Side Swipe Crash CURE Plot

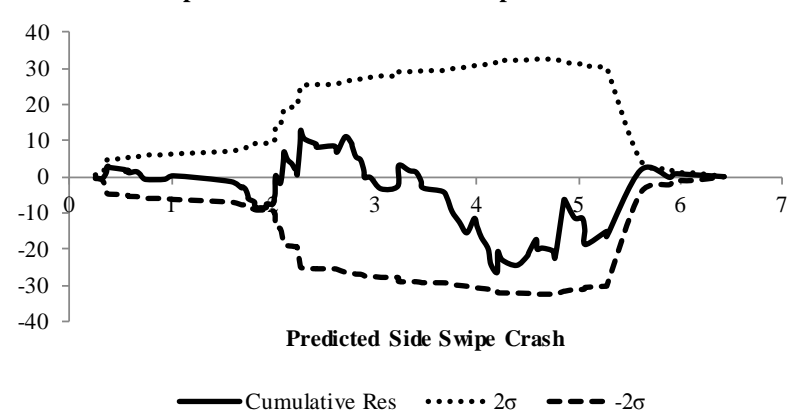

Figure 51. Crash-Merge-1,500 ft. SPFs Side Swipe Crash CURE Plots

Single Vehicle Crash - FAADT CURE Plot

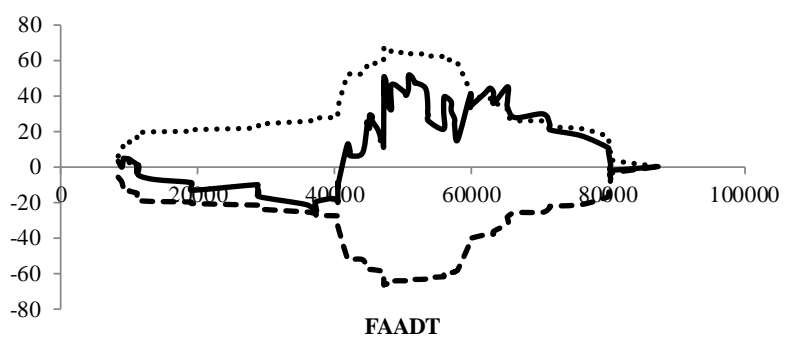

Cumulative Res $\quad \cdots \cdots 2 \sigma \quad---2 \sigma$

Single Vehicle Crash - ACC Length CURE Plot

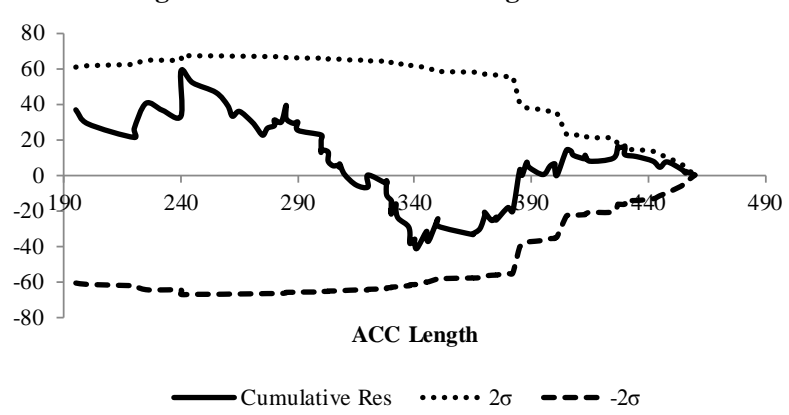

Single Vehicle Crash - RAADT CURE Plot

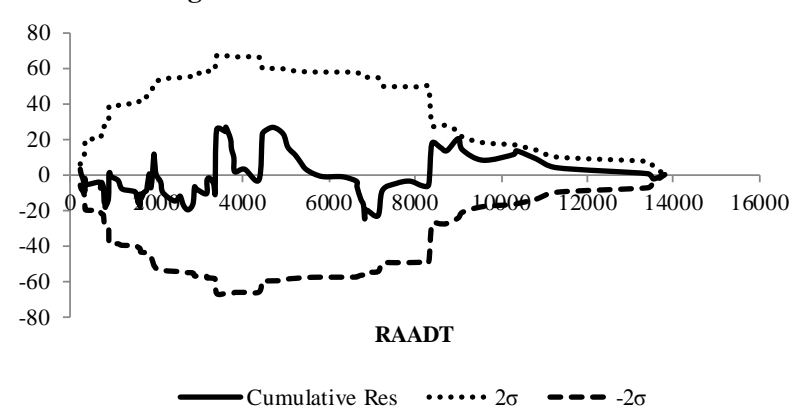

Single Vehicle Crash - PredictedSingle Vehicle Crash CURE Plot

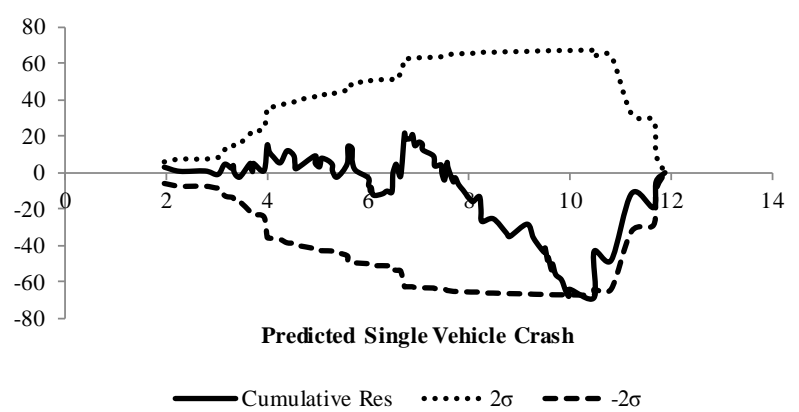

Figure 52. Crash-Merge-1,500 ft. SPFs Single Vehicle Crash CURE Plots 


\section{B.3 - Crash-Diverge-DEC SPFs}
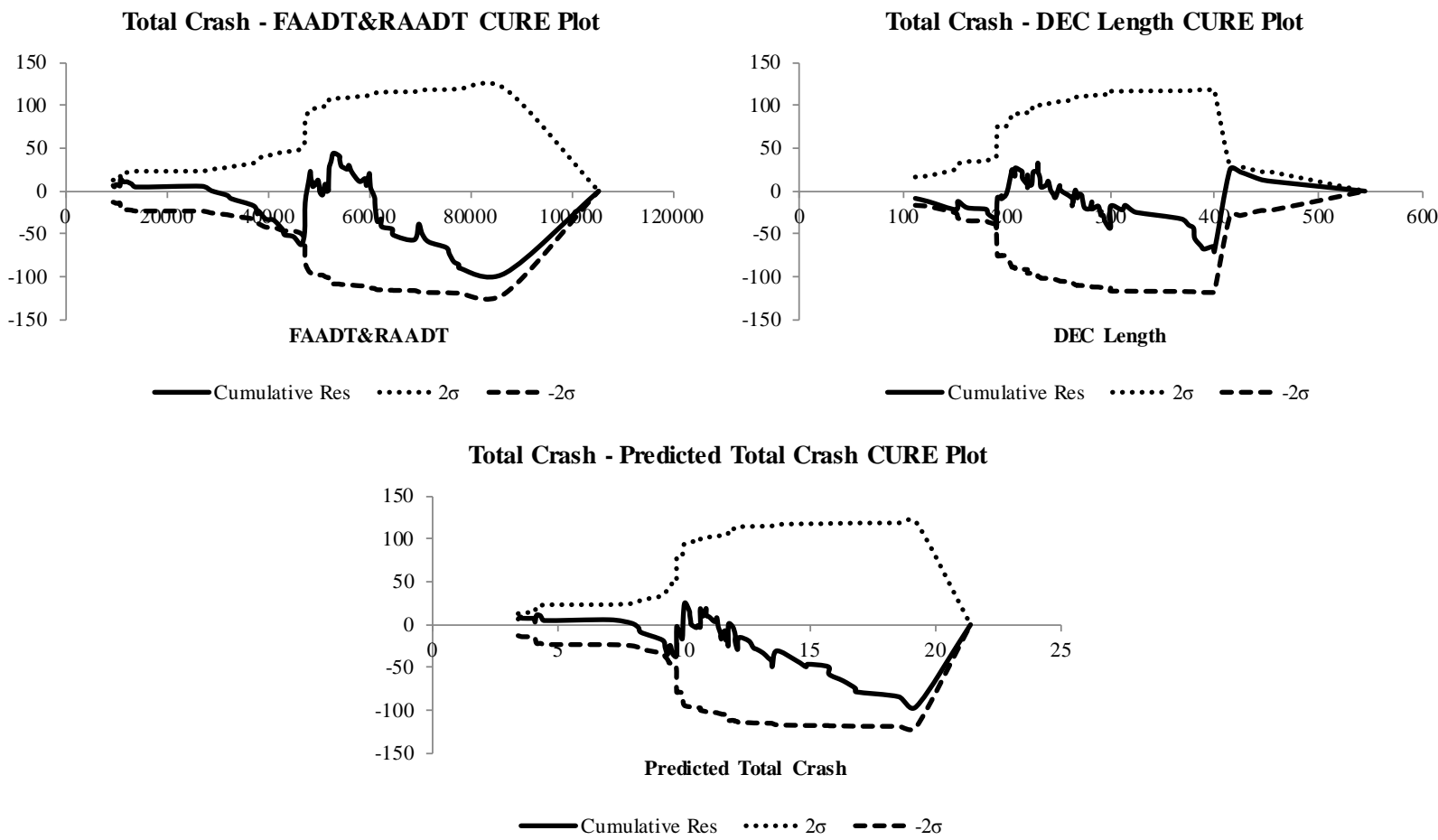

Figure 53. Crash-Diverge-DEC SPFs Total Crash CURE Plots

F\&I Crash - FAADT\&RAADT CURE Plot

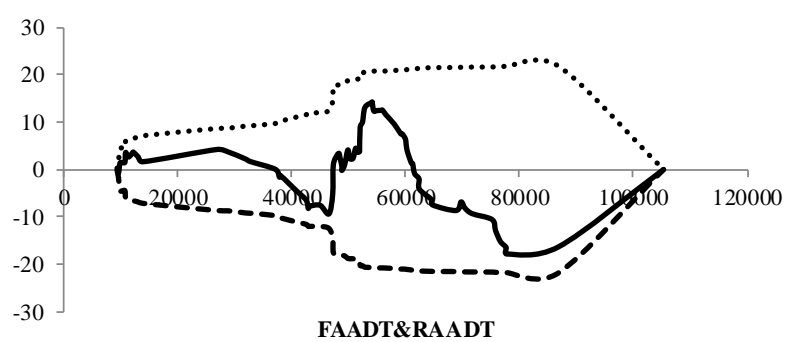

F\&I Crash - DEC Length CURE Plot

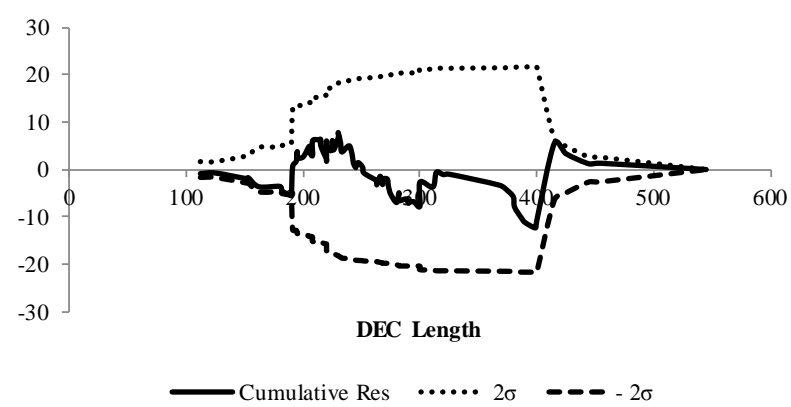

F\&I Crash - Predicted F\&I Crash CURE Plot

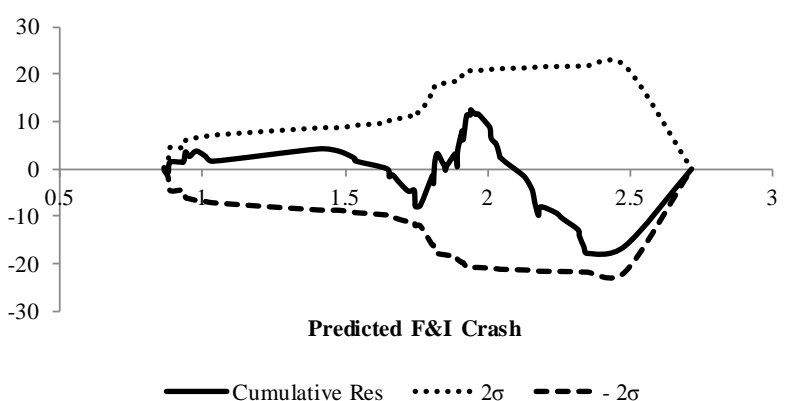

Figure 54. Crash-Diverge-DEC SPFs F\&I Crash CURE Plots 



Figure 55. Crash-Diverge-DEC SPFs PDO Crash CURE Plots

Single Vehicle Crash - FAADT\&RAADT CURE Plot

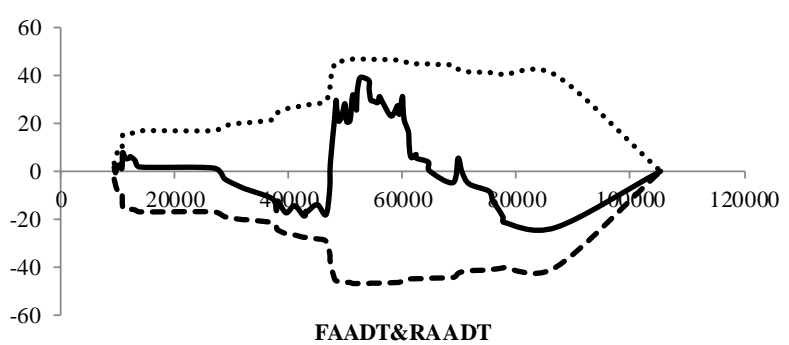

Cumulative Res $\cdots \cdots \cdot 2 \sigma \quad \boldsymbol{- \infty}-2 \sigma$
Single Vehicle Crash - DEC Length CURE Plot

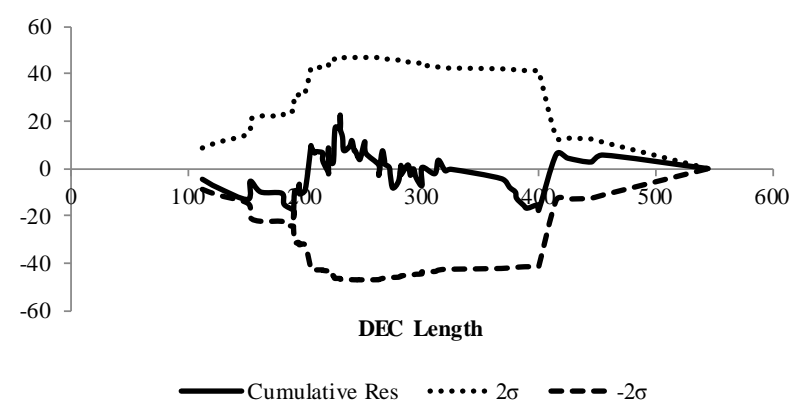

Single Vehicle Crash - PredictedSingle Vehicle Crash CURE Plot

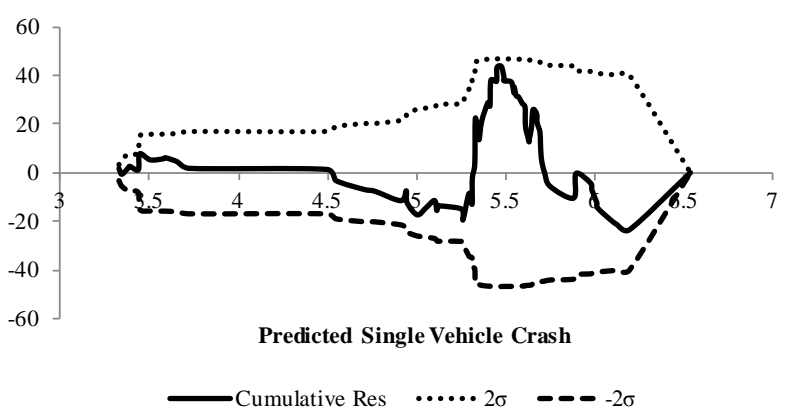

Figure 56. Crash-Diverge-DEC SPFs Single Vehicle Crash CURE Plots 
B.4 - Crash-Diverge-1,500ft. SPFs
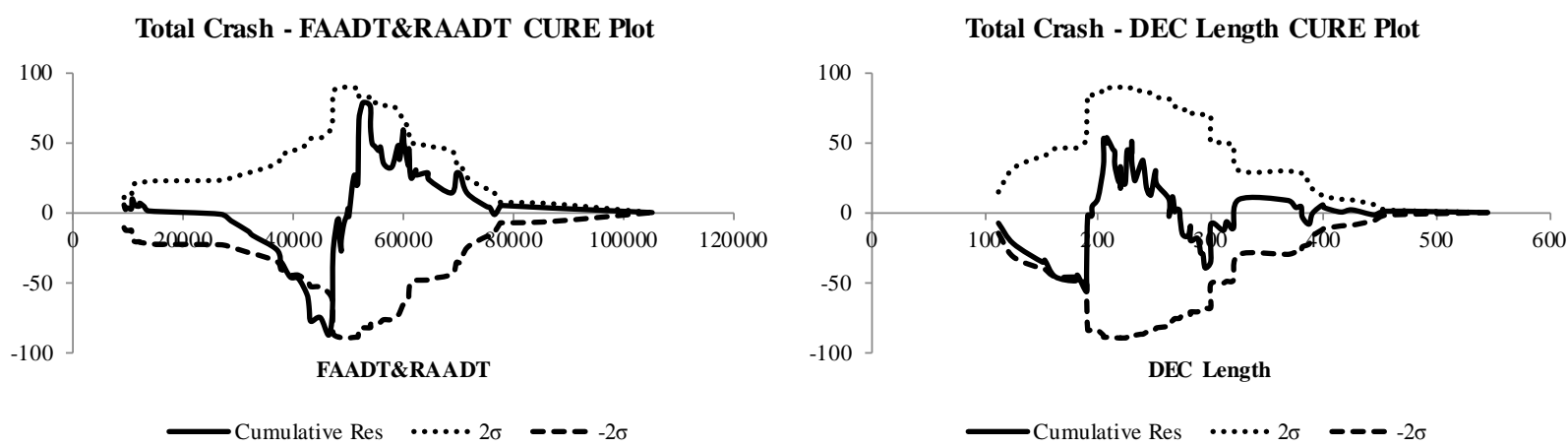

Total Crash - Predicted Total Crash CURE Plot

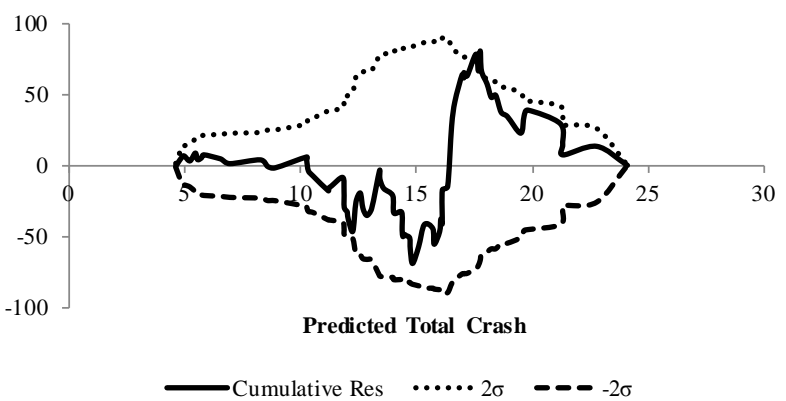

Figure 57. Crash-Diverge-1,500 ft. SPFs Total Crash CURE Plots

PDO Crash - FAADT\&RAADT CURE Plot

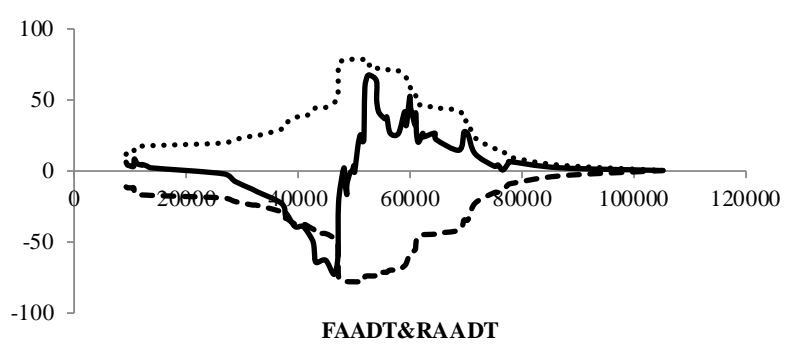

PDO Crash - DEC Length CURE Plot



PDO Crash - Predicted PDO Crash CURE Plot

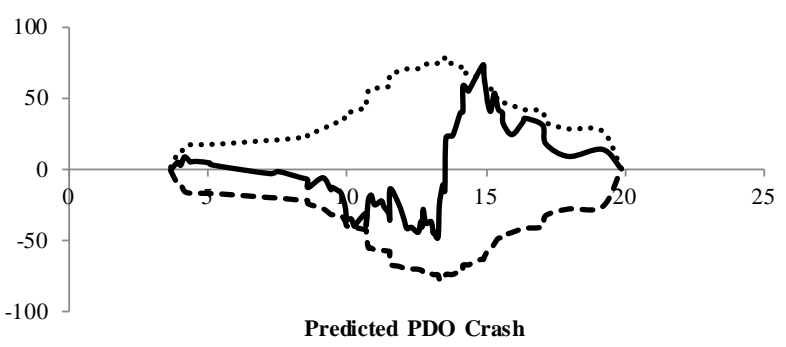

- Cumulative Res $\cdots \cdots \cdot 2 \sigma \quad-\mathbf{c}-2 \sigma$

Figure 58. Crash-Diverge-1,500 ft. SPFs PDO Crash CURE Plots 
Side Swipe Crash - FAADT\&RAADT CURE Plot
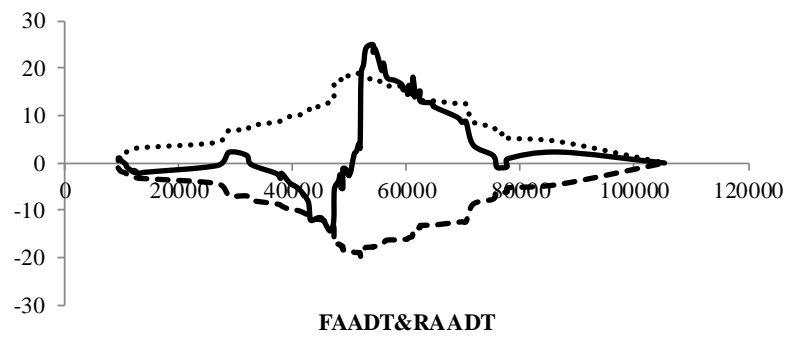

Side Swipe Crash - DEC Length CURE Plot

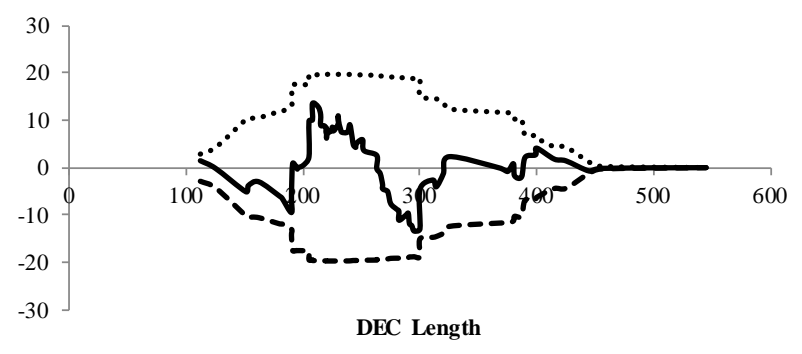

Cumulative Res $\cdots \cdots \cdot 2 \sigma \quad \boldsymbol{- \infty}-2 \sigma$

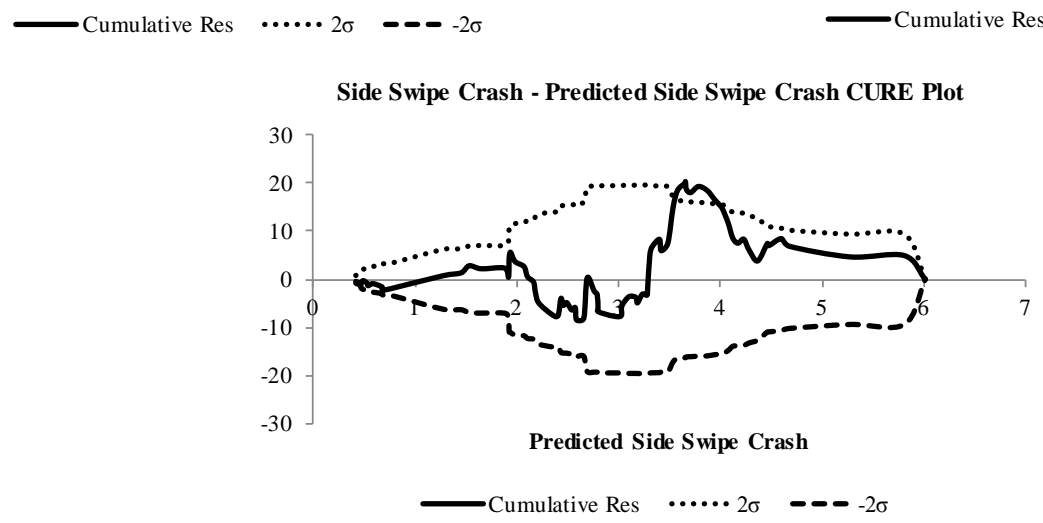

Figure 59. Crash-Diverge-1,500 ft. SPFs Side Swipe Crash CURE Plots

Single Vehicle Crash - FAADT\&RAADT CURE Plot

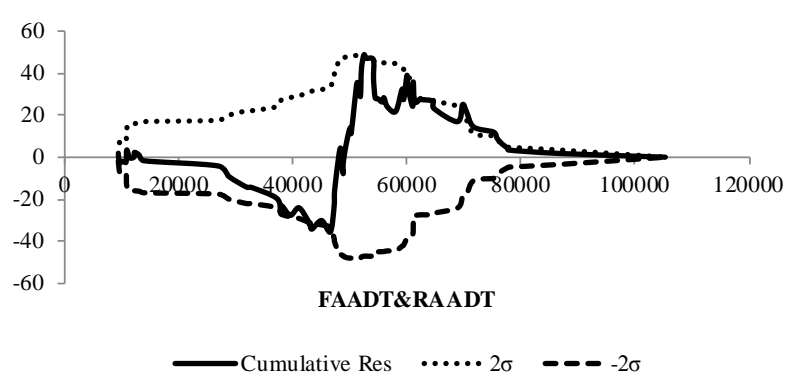

Single Vehicle Crash - Predicted Single Vehicle Crash CURE Plot

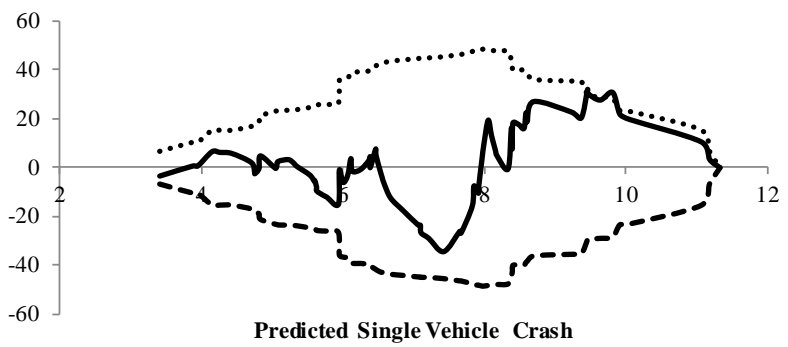

- Cumulative Res $\cdots \cdots \cdot 2 \sigma \quad-\quad-2 \sigma$

Figure 60. Crash-Diverge-1,500 ft. SPFs Single Vehicle Crash CURE Plots 
F\&I Crash - FAADT CURE Plot

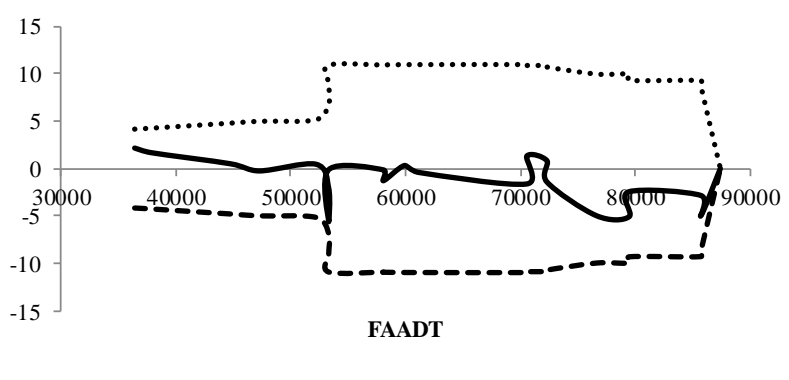

F\&I Crash - AUX Length CURE PlotTitle

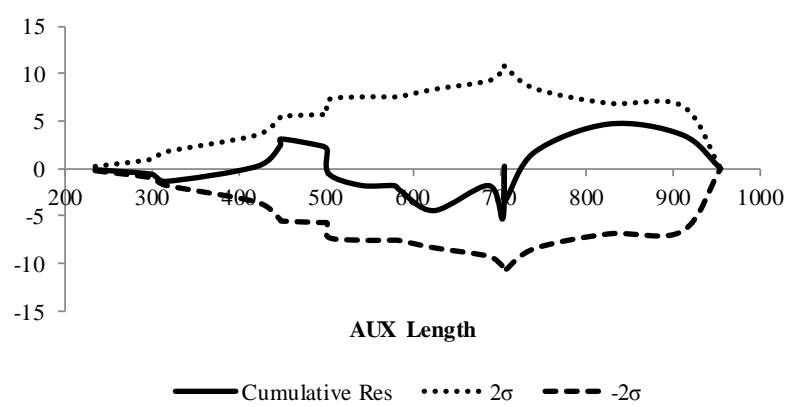

F\&I Crash - Predicted F\&I Crash CURE Plot

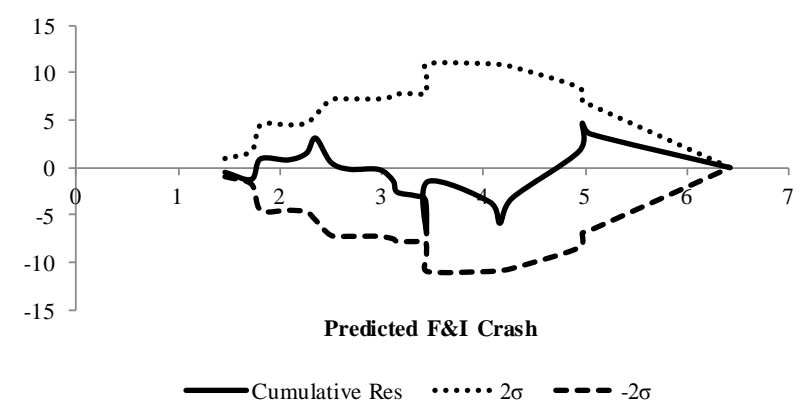

Figure 61. Crash-Weave-AUX SPFs F\&I Crash CURE Plots

PDO Crash - FAADT CURE Plot

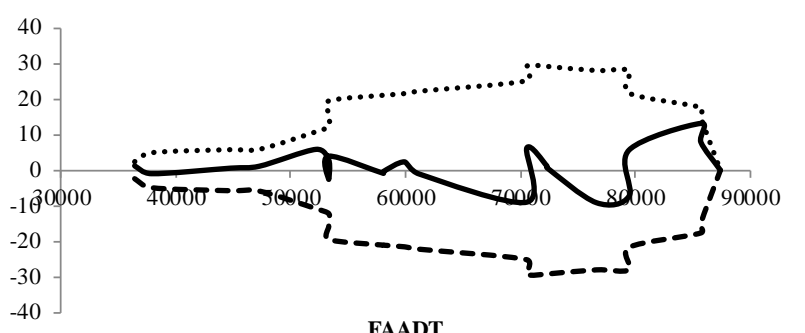

FAADT
PDO Crash - AUX Length CURE Plot

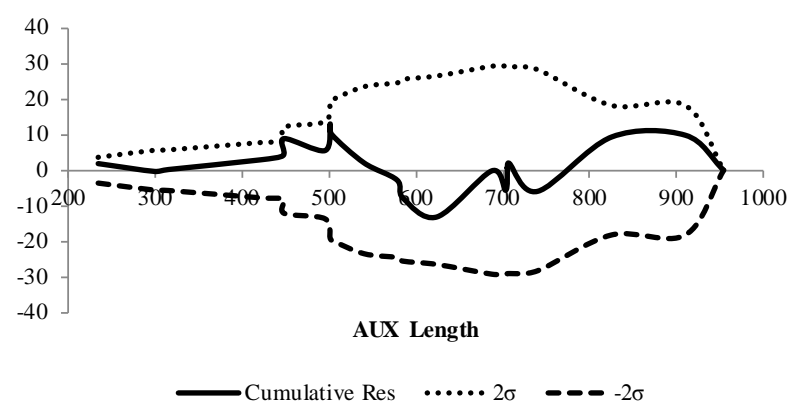

PDO Crash - Predicted PDO Crash CURE Plot

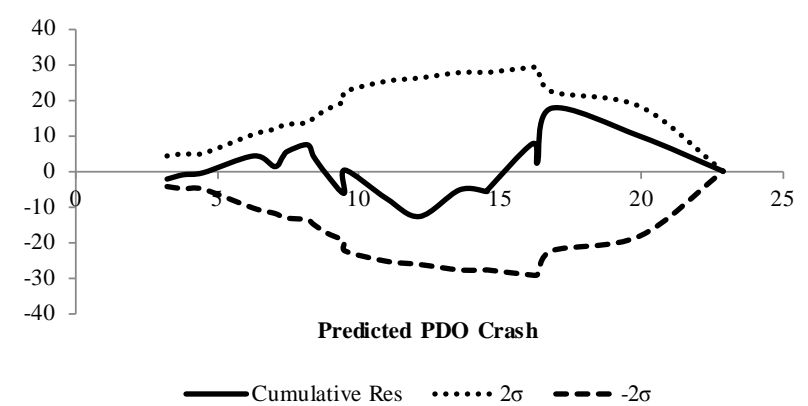

Figure 62. Crash-Weave-AUX SPFs PDO Crash CURE Plots 

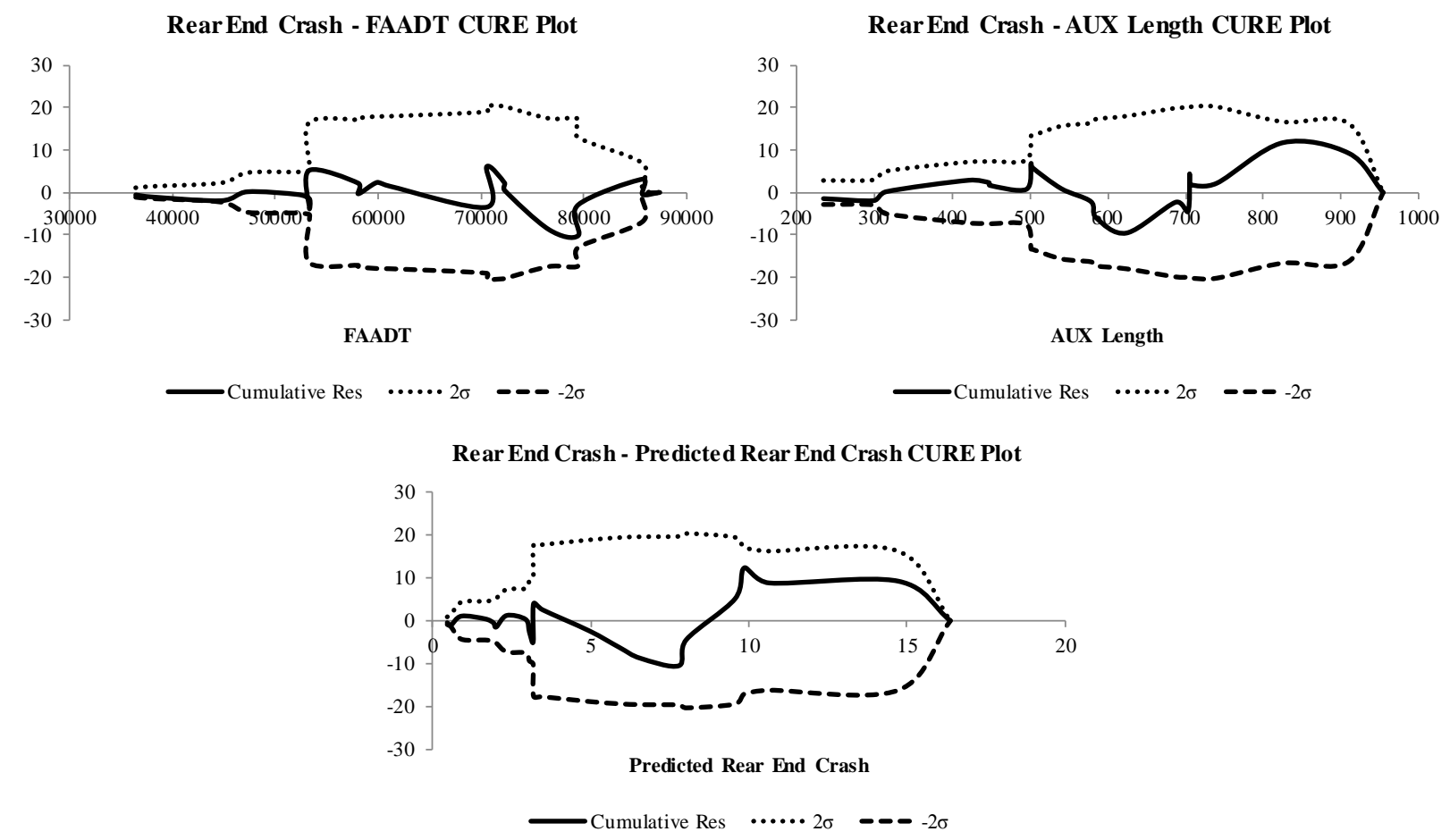

Figure 63. Crash-Weave-AUX SPFs Rear End Crash CURE Plots
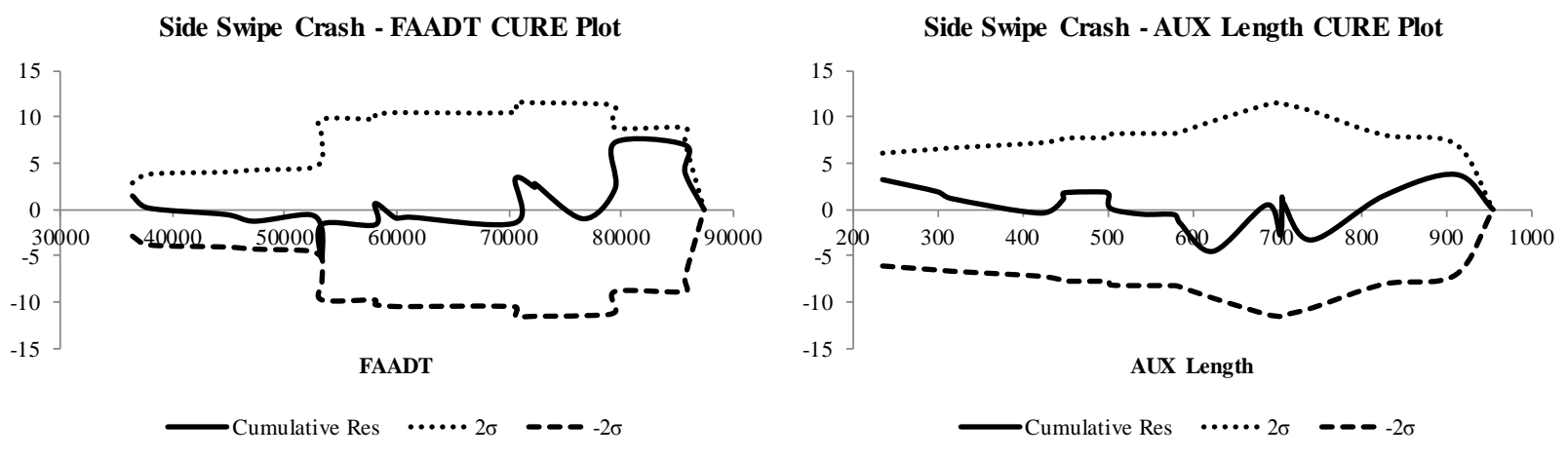

Side Swipe Crash - Predicted Side Swipe Crash CURE Plot

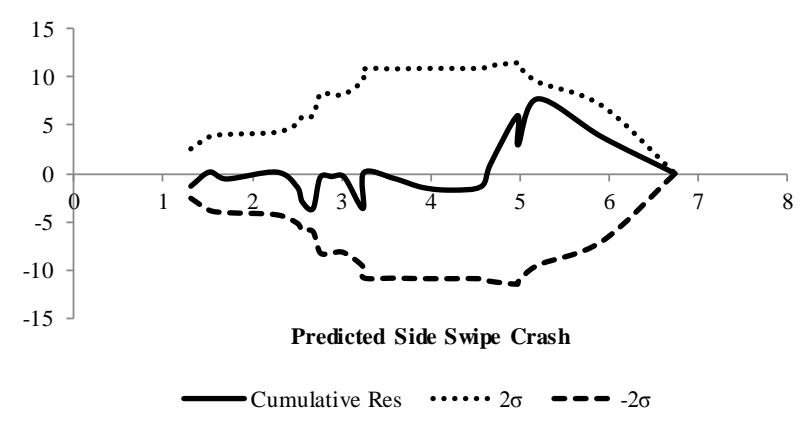

Figure 64. Crash-Weave-AUX SPFs Side Swipe Crash CURE Plots 

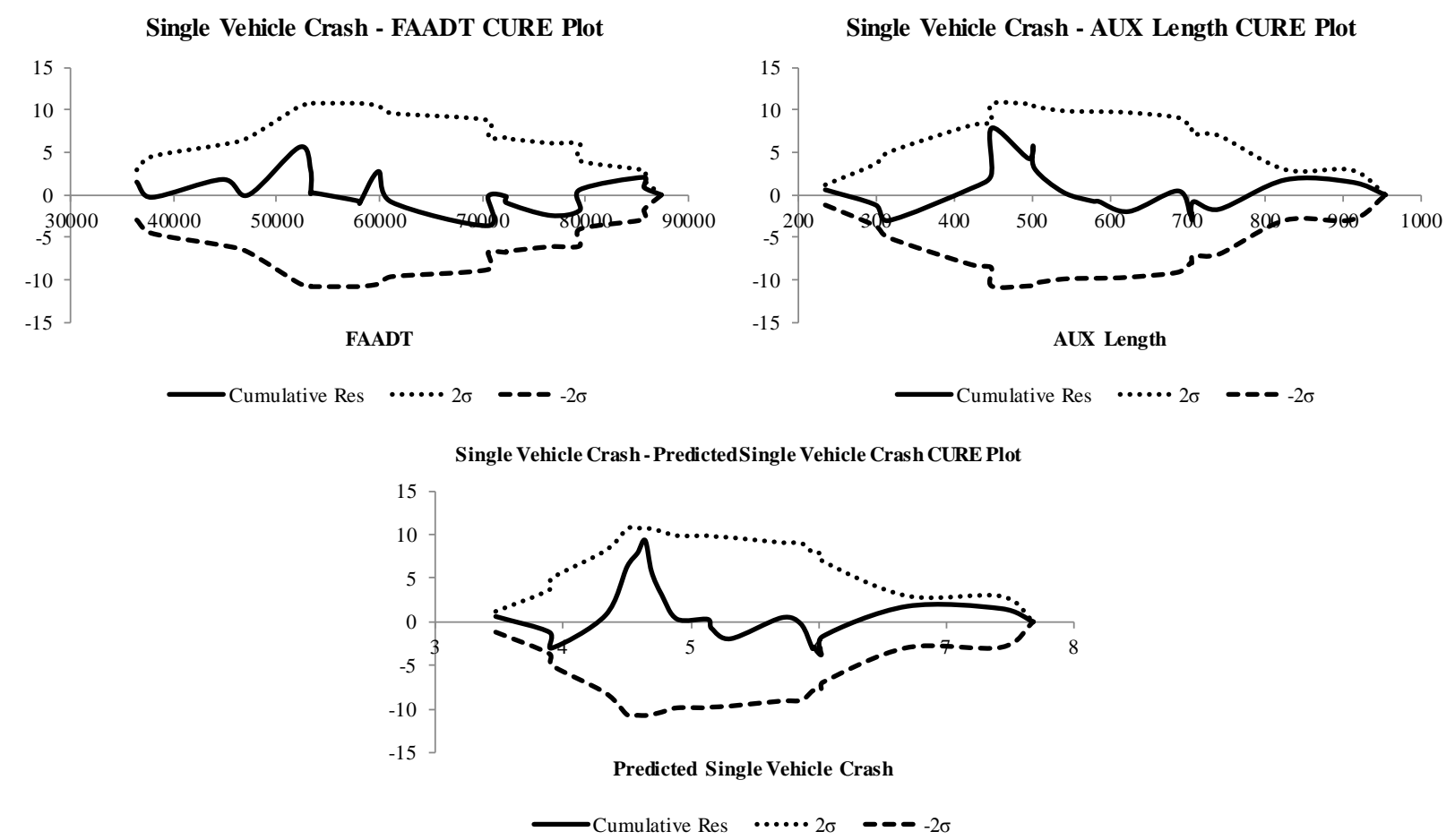

Figure 65. Crash-Weave-AUX SPFs Single Vehicle Crash CURE Plots

\section{Appendix C: Additional CURE Plots for Conflict-based SPFs in Chapter 7}

\section{C. $1-\mathrm{TTC} \leq 1.5 \mathrm{~s}$}



Total Conflict - ACC Length CURE Plot

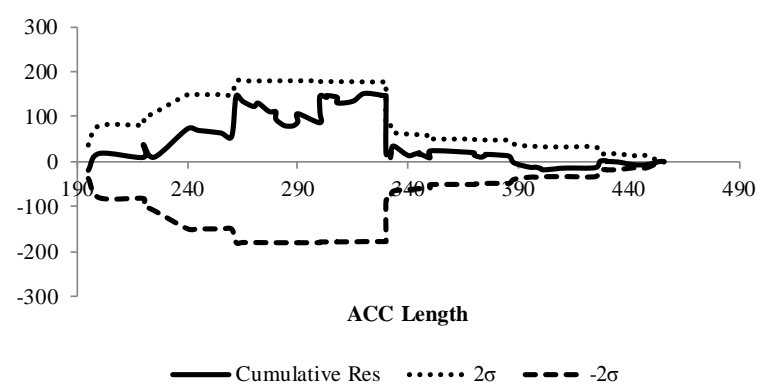

Total Conflict - RPHV CURE Plot

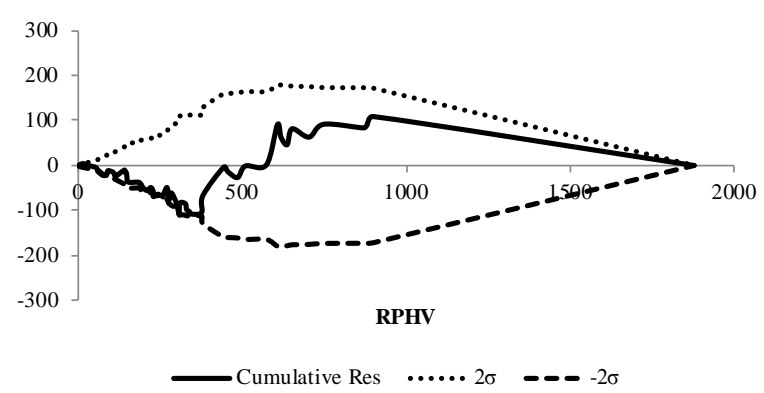

Total Conflict - Predicted Total Conflict CURE Plot

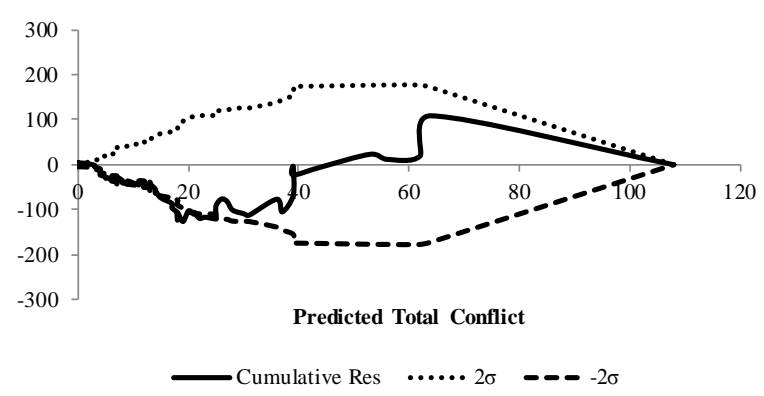

Figure 66. Conflict-Merge ACC SPFs Total Conflict CURE Plots (TTC $\leq 1.5 \mathrm{~s})$ 

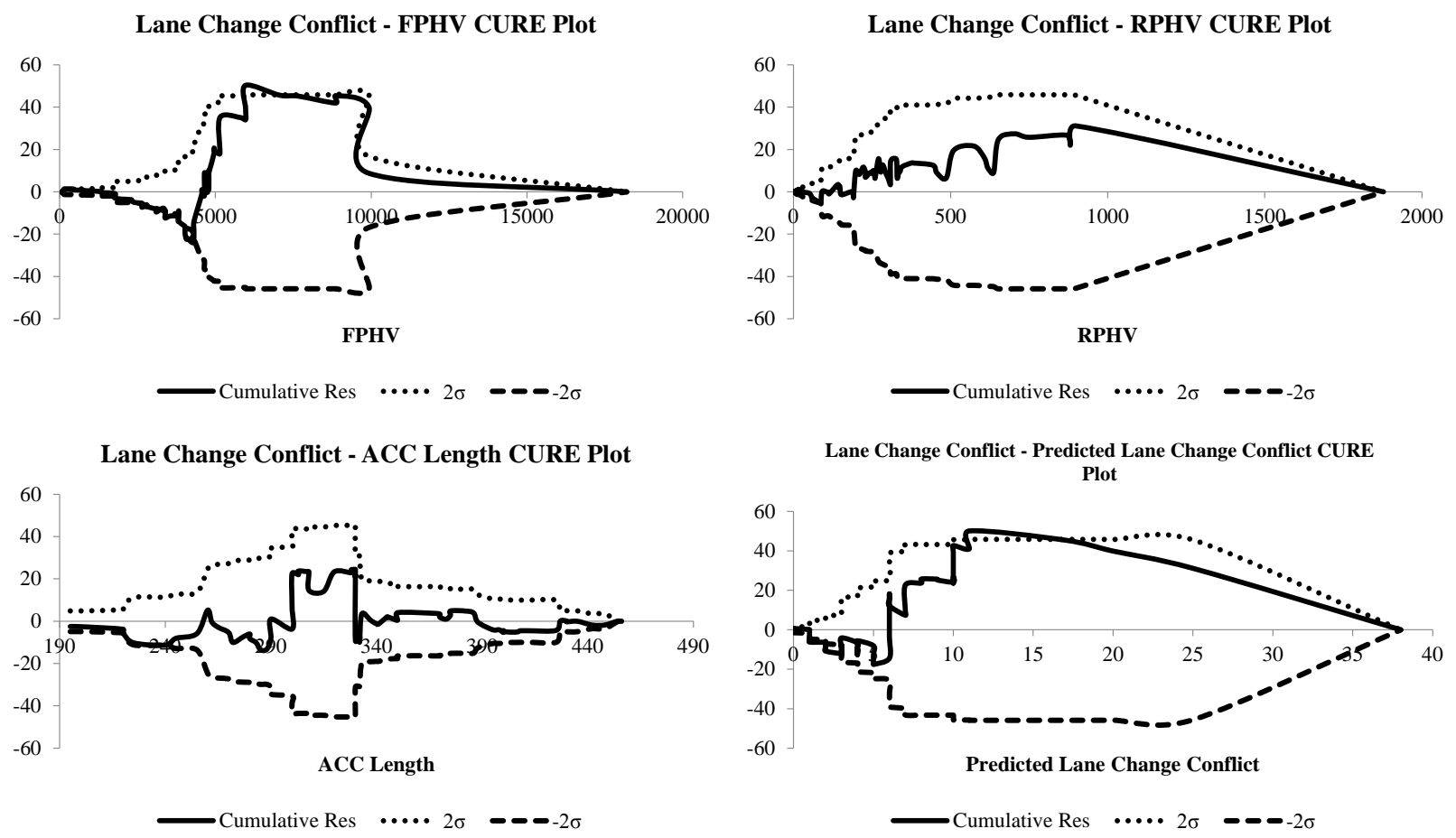

Figure 67. Conflict-Merge ACC SPFs Lane Change Conflict CURE Plots (TTC $\leq 1.0 \mathrm{~s}$ )

\section{C. $3-\mathrm{TTC} \leq 0.5 \mathrm{~s}$}
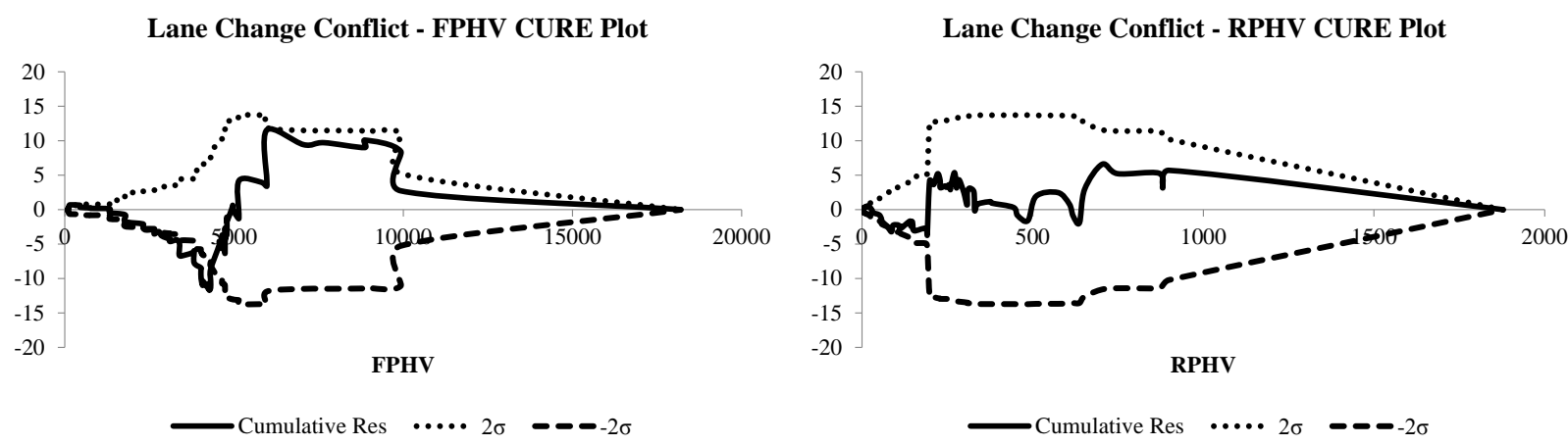

Lane Change Conflict - ACC Length CURE Plot
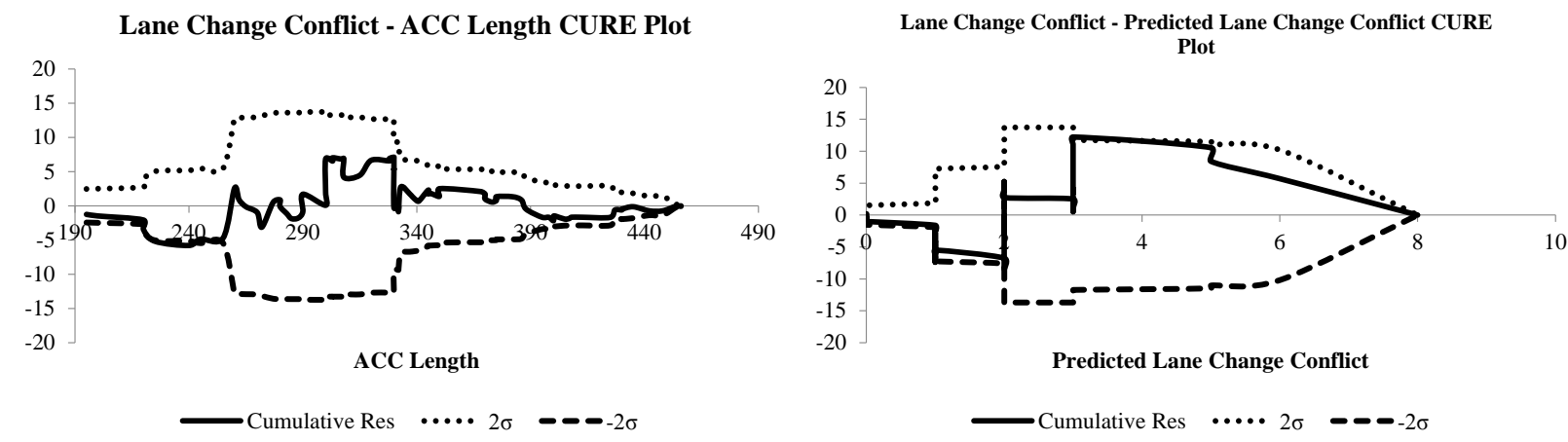

Figure 68. Conflict-Merge ACC SPFs Lane Change Conflict CURE Plots (TTC $\leq 0.5 \mathrm{~s})$ 


\section{Appendix D: Additional CURE Plots for Crash-Conflict Integrated SPFs in}

\section{Chapter 8}

D. $1-\mathrm{TTC} \leq 1.5 \mathrm{~s}$
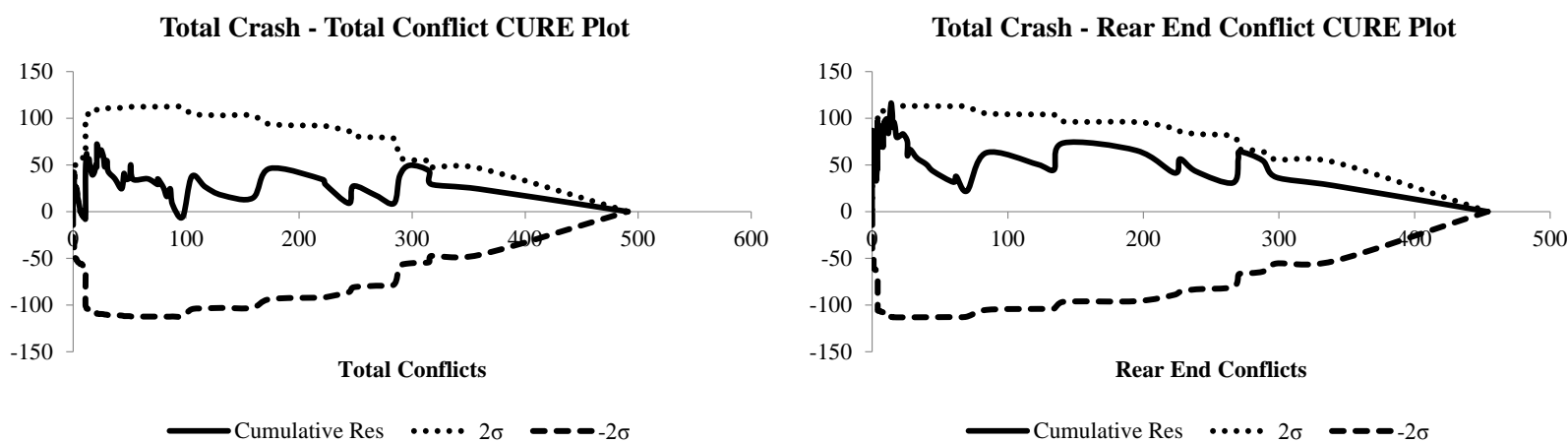

Total Crash - Lane Change Conflict CURE Plot

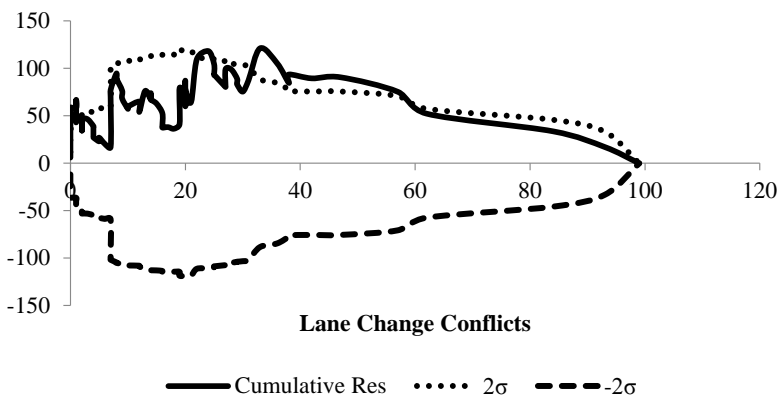

Figure 69. Merge ACC Area Total Crash-Conflict CURE Plots (TTC $\leq 1.5 \mathrm{~s}$ )
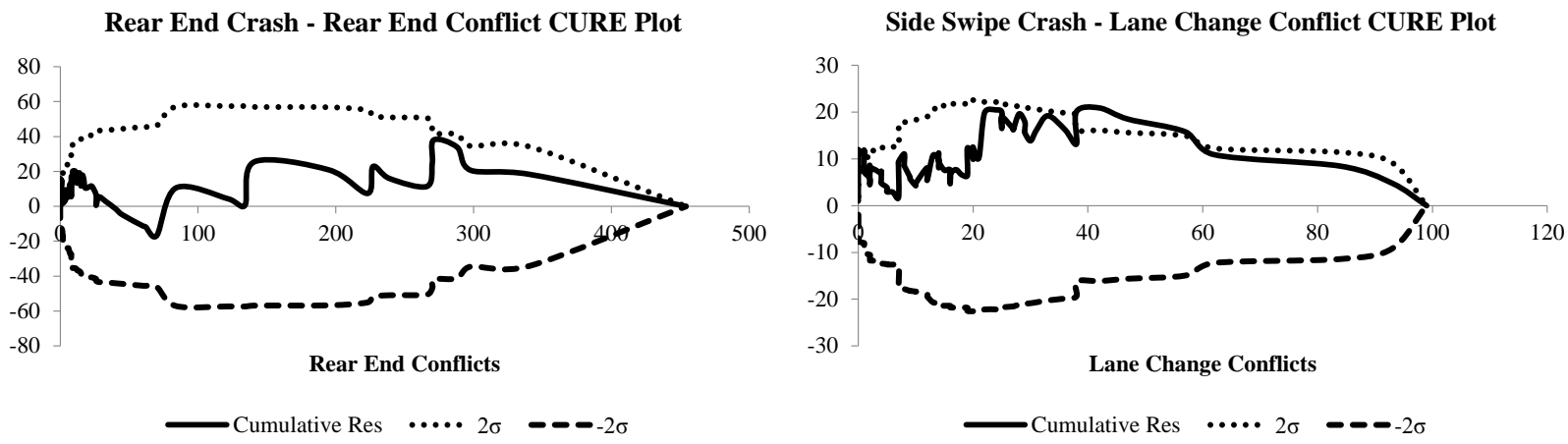

Figure 70. Merge ACC Area Rear End and Side Swipe Crash-Conflict CURE Plots (TTC $\leq 1.5 \mathrm{~s}$ ) 
FI Crash - Total Conflict CURE Plot

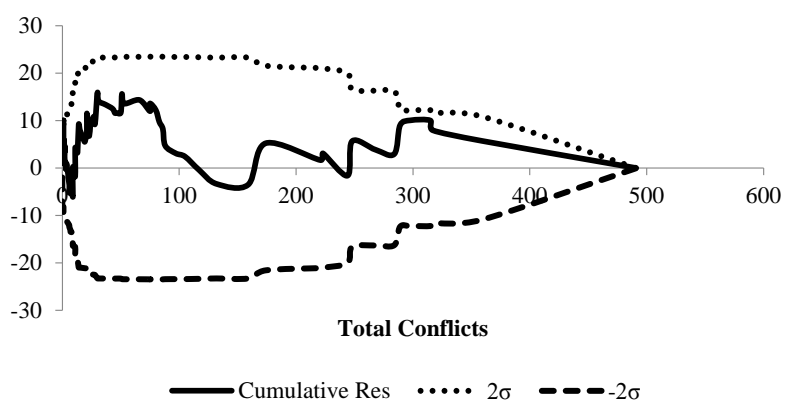

F\&I Crash - Rear End Conflict CURE Plot

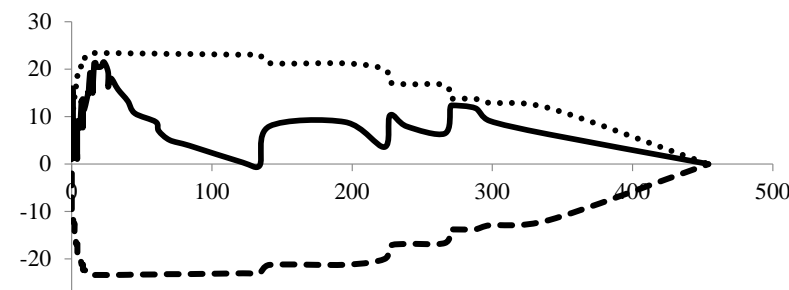

Rear End Conflicts

F\&I Crash - Lane Change Conflict CURE Plot

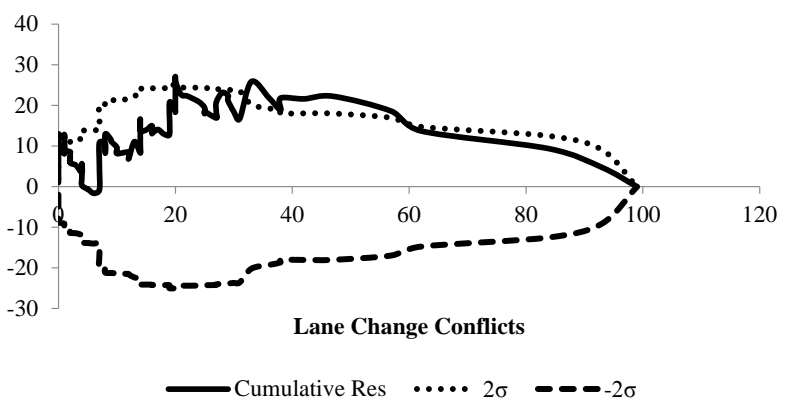

Figure 71. Merge ACC Area F\&I Crash-Conflict CURE Plots (TTC $\leq 1.5 \mathrm{~s}$ )

D. $2-\mathrm{TTC} \leq 1.0 \mathrm{~s}$
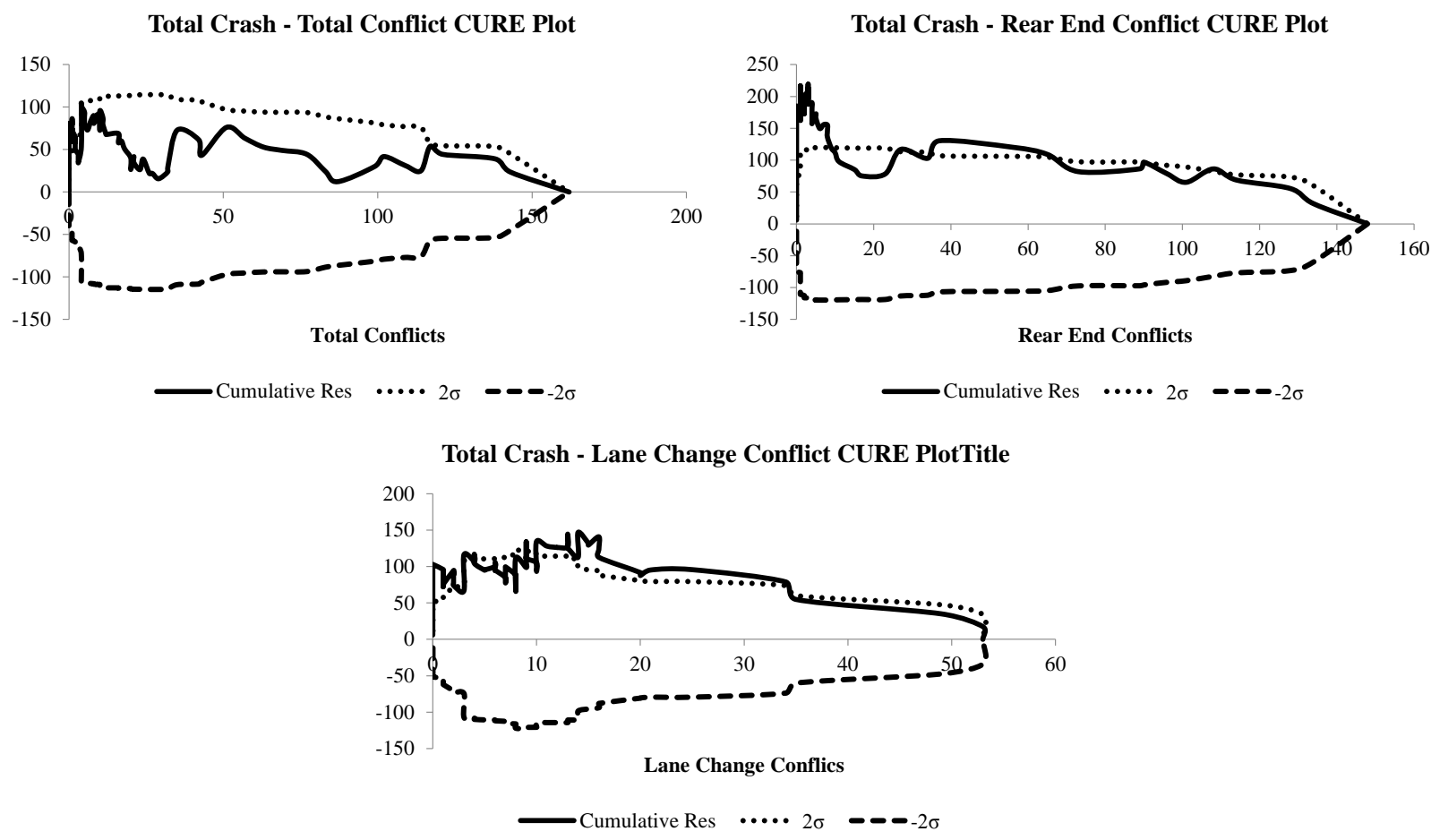

Figure 72. Merge ACC Area Total Crash-Conflict CURE Plots (TTC $\leq 1.0 \mathrm{~s})$ 
PDO Crash - Total Conflict CURE Plot

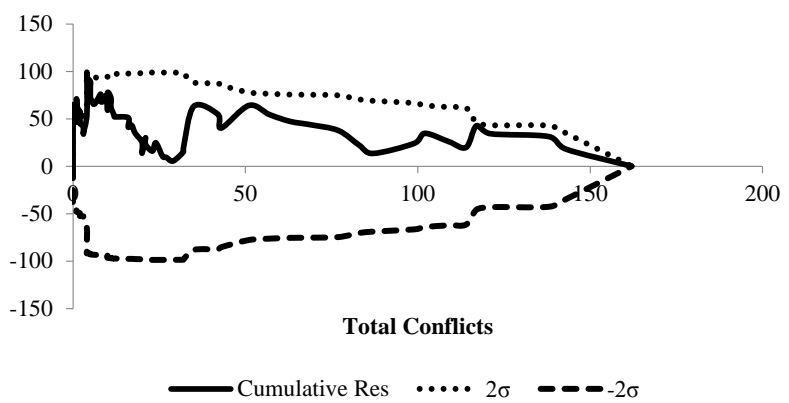

PDO Crash - Rear End Conflict CURE Plot

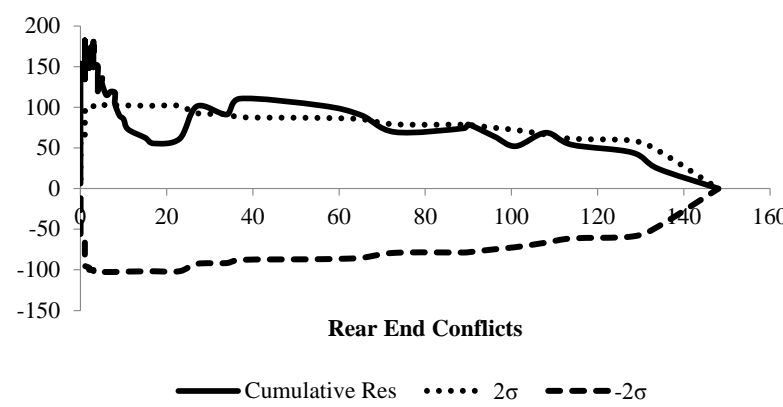

PDO Crash - Lane Change Conflict CURE Plot

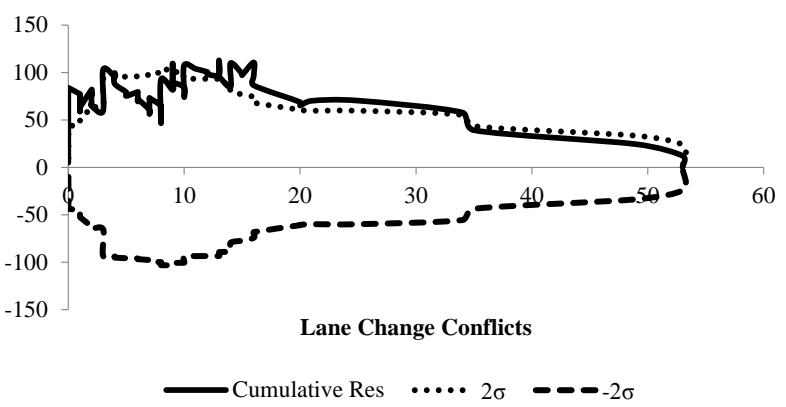

Figure 73. Merge ACC Area PDO Crash-Conflict CURE Plots (TTC $\leq 1.0 \mathrm{~s}$ )
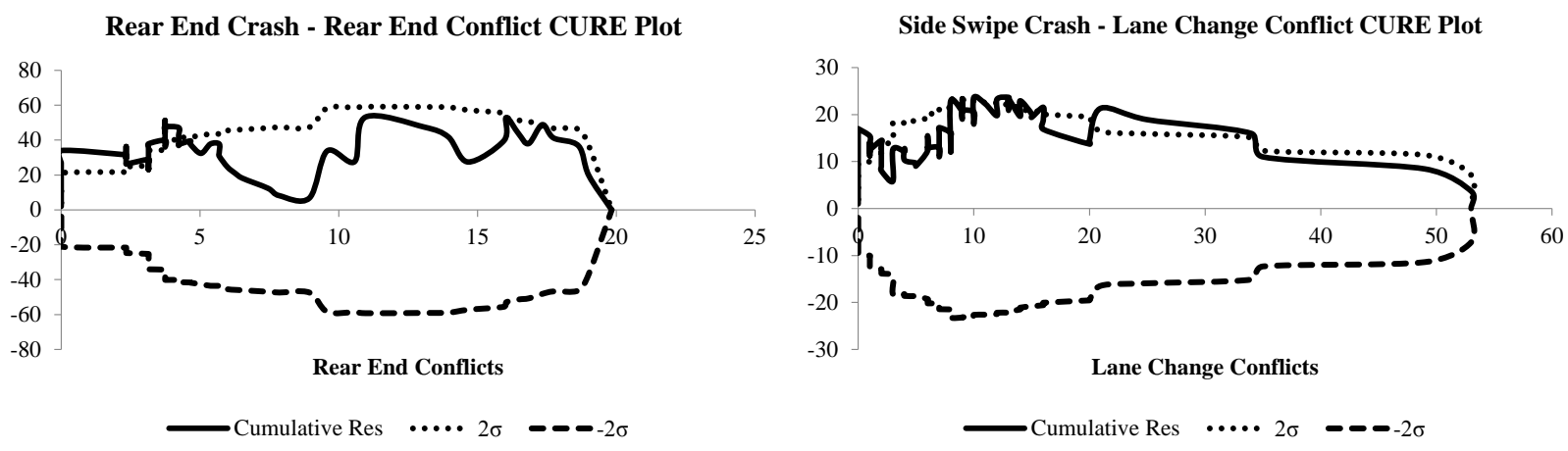

Figure 74. Merge ACC Area Rear End and Side Swipe Crash-Conflict CURE Plots (TTC $\leq 1.0 \mathrm{~s}$ ) D.3 - TTC $\leq 0.5 \mathrm{~s}$

Rear End Crash - Rear End Conflict CURE Plot

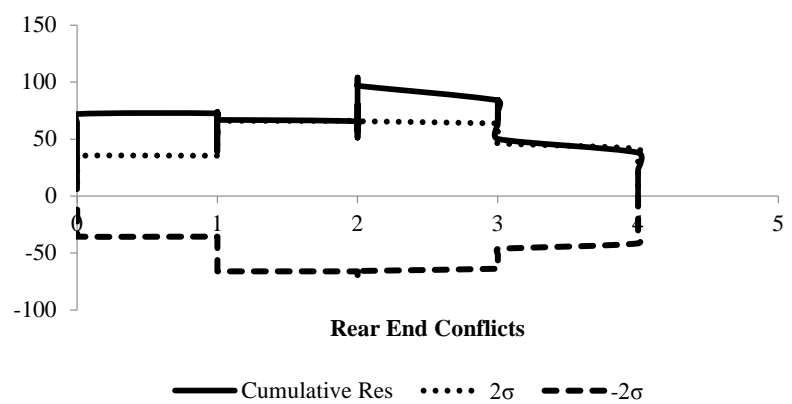

Side Swipe Crash - Lane Change Conflict CURE Plot

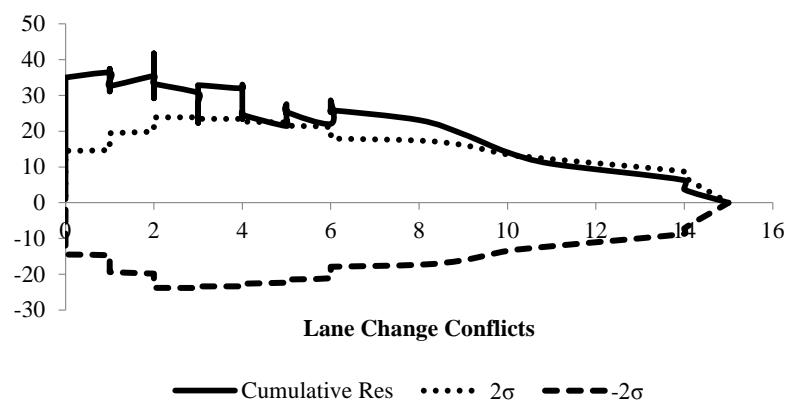

Figure 75. Merge ACC Area Rear End and Side Swipe Crash-Conflict CURE Plots (TTC $\leq 0.5 \mathrm{~s}$ ) 
F\&I Crash - Total Conflict CURE Plot



F\&I Crash - Rear End Conflict CURE Plot

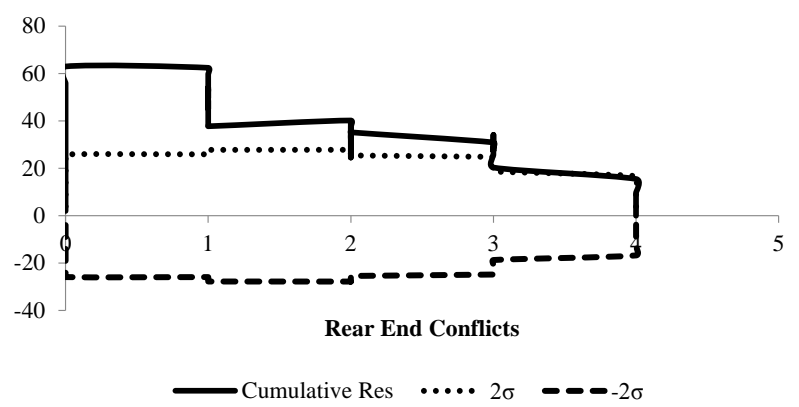

F\&I Crash - Lane Change Conflict CURE Plot

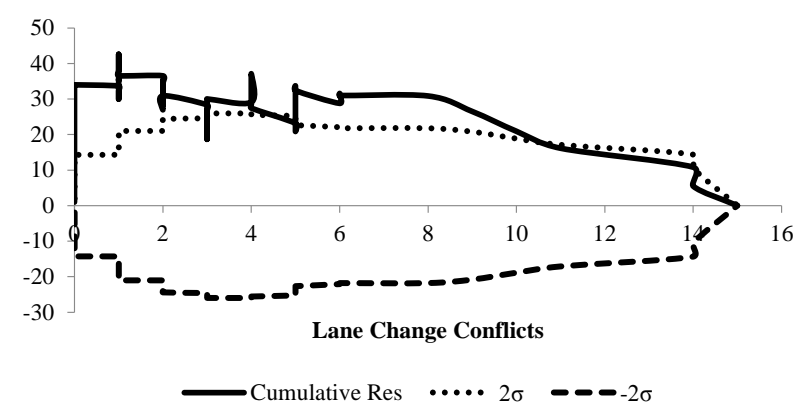

Figure 76. Merge ACC Area F\&I Crash-Conflict CURE Plots (TTC $\leq 0.5 \mathrm{~s}$ )

PDO Crash - Total Conflict CURE Plot



PDO Crash - Rear End Conflict CURE Plot

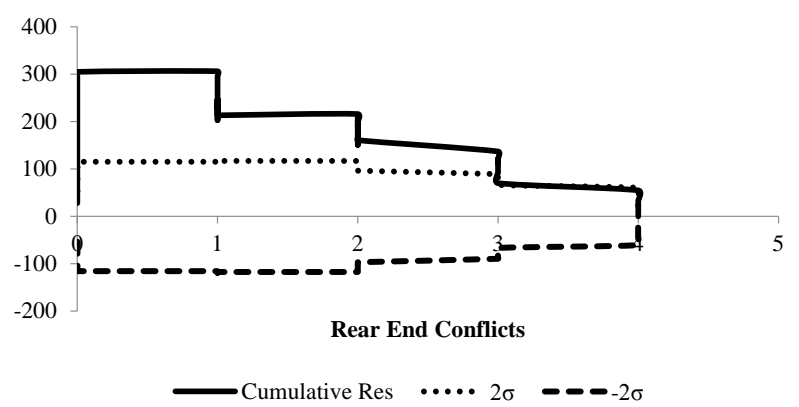

PDO Crash - Lane Change Conflict CURE Plot

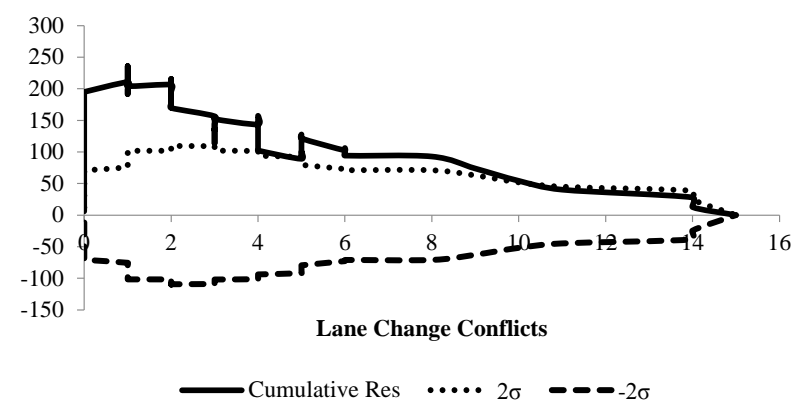

Figure 77. Merge ACC Area PDO Crash-Conflict CURE Plots (TTC $\leq 0.5 \mathrm{~s})$ 

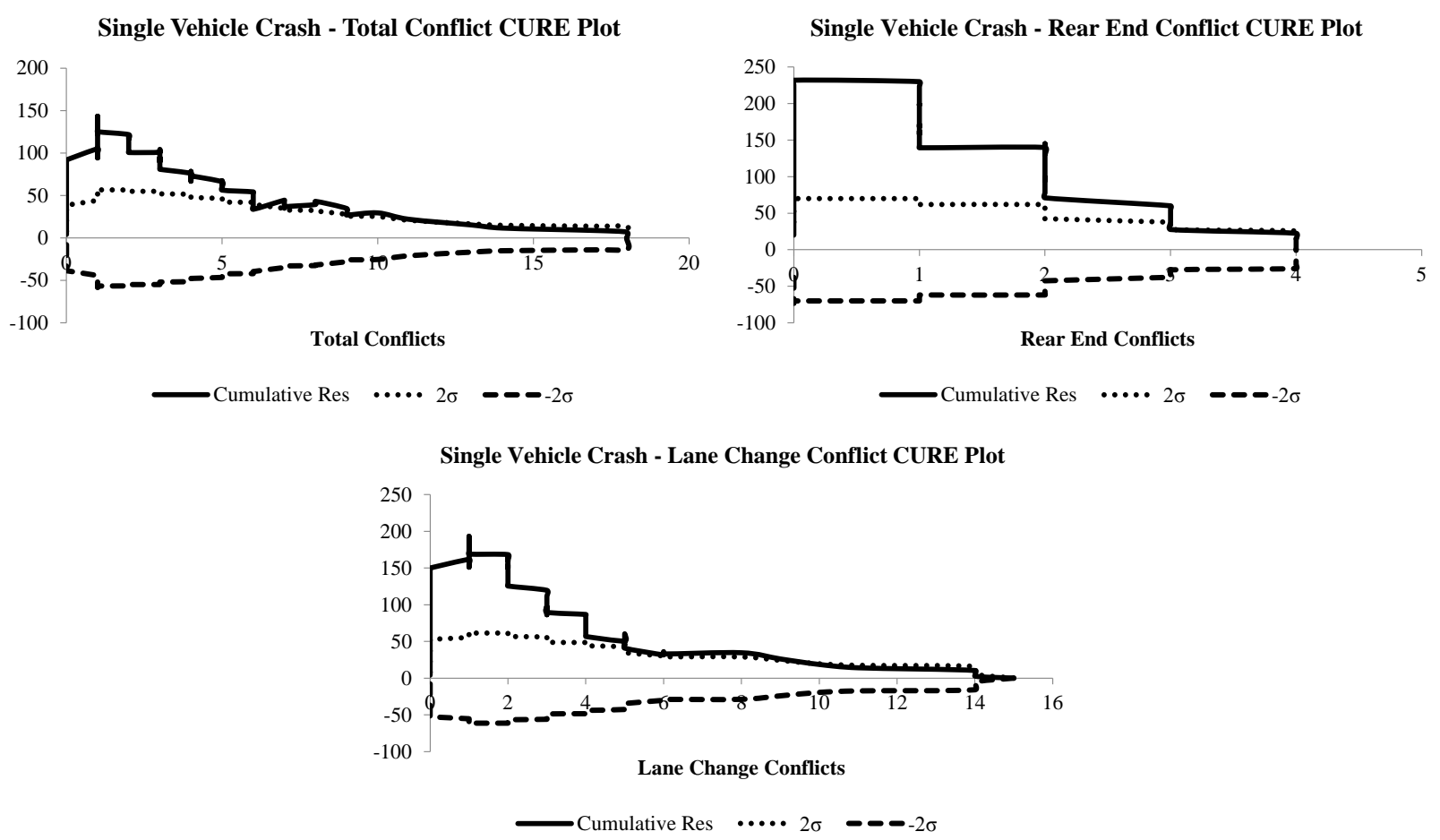

Figure 78. Merge ACC Area Single Vehicle Crash-Conflict CURE Plots (TTC $\leq 0.5 \mathrm{~s}$ ) 


\section{References}

AASHTO, 2001. Policy on geometric design of highways and streets. American Association of State Highway and Transportation Officials, Washington, DC, 1(990), p.158.

AASHTO, 2014. User's Guide to Develop Highway Safety Manual Safety Performance Function Calibration Factors, Available at: http:/onlinepubs.trb.org/onlinepubs/nchrp/docs/NCHRP20-07(332)_FinalGuide.pdf.

Allen, B.L., Shin, B.T. \& Cooper, P.J., 1978. Analysis of traffic conflicts and collisions. Transportation Research Record: Journal of the Transportation Research Board, (667), pp.67-74.

Atamo, M.A., 2012. Safety assessment of freeway merging and diverging influence areas based on conflict analysis of simulated traffic. University of Colorado Denver.

Bared, J., Giering, G.L. \& Warren, D.L., 1999. Safety evaluation of acceleration and deceleration lane lengths. Institute of Transportation Engineers. ITE Journal, 69(5), p.50.

Bauer, K.M. \& Harwood, D.W., 1998. Statistical models of accidents on interchange ramps and speed-change lanes, Available at: http//ntl.bts.gov/DOCS/97-106/index.htm.

Bonneson, J.A. et al., 2012. Safety prediction methodology and analysis tool for freeways and interchanges. National Cooperative Highway Research, 7, pp.17-45.

Caliendo, C. \& Guida, M., 2012. Microsimulation approach for predicting crashes at unsignalized intersections using traffic conflicts. Journal of Transportation Engineering, 138(12), pp.1453-1467.

Canada, T., 2013. Canadian Motor Vehicle Traffic Collision Statistics 2013, Available at: https://www.tc.gc.ca/media/documents/roadsafety/cmvtcs2013_eng.pdf.

Cirillo, J.A., 1970. The relationship of accidents to length of speed-change lanes and weaving areas on Interstate highways. Highway Research Record, (312).

Cooper, D.F. \& Ferguson, N., 1976. Traffic studies at t-junctions-a conflict simulation model. Traffic Engineering and Control, 17(7), pp.306-309.

El-Basyouny, K., 2006. Field validation for surrogate safety assessment methodology (SSAM) using a multi-purpose micro-simulation. Retrospective Theses and Dissertations, 1919-2007.

Elvik, R., 2005. Speed and road safety: synthesis of evidence from evaluation studies. Transportation Research Record: Journal of the Transportation Research Board, (1908), pp.59-69.

Evans, L., 1991. Traffic safety and the driver, Science Serving Society.

Gettman, D. et al,, 2008. Surrogate safety assessment model and validation: Final report, Available at: https:/www.fhwa.dot.gov/publications/research/safety/08051/08051.pdf.

Goldenbeld, C. \& van Schagen, I., 2005. The effects of speed enforcement with mobile radar on speed and accidents: An evaluation study on rural roads in the Dutch province Friesland. Accident Analysis \& Prevention, 37(6), pp.1135-1144. 
Gordon, R.L. et al., 1996. TRAFFIC CONTROL SYSTEMS HANDBOOK-REVISED EDITION 1996 1985th ed., Available at:

http://ops.fhwa.dot.gov/publications/fhwahop06006/fhwa_hop_06_006.pdf.

Hauer, E., 1997. Observational Before/After Studies in Road Safety. Estimating the Effect of Highway and Traffic Engineering Measures on Road Safety, Emerald Group Publishing Limited.

Hauer, E., 2001. Overdispersion in modelling accidents on road sections and in Empirical Bayes estimation. Accident Analysis \& Prevention, 33(6), pp.799-808.

Hauer, E., 2015. The Art of Regression Modeling in Road Safety, Springer.

Hauer, E. \& Bamfo, J., 1997. Two tools for finding what function links the dependent variable to the explanatory variables. In Proceedings of the ICTCT 1997 Conference, Lund, Sweden.

Hauer, E., Ng, J.C.N. \& Lovell, J., 1988. Estimation of safety at signalized intersections (with discussion and closure). Transportation Research Record: Journal of the Transportation Research Board, (1185), pp.48-61.

Hayward, J., 1971. Near misses as a measure of safety at urban intersections, Pennsylvania Transportation and Traffic Safety Center.

HCM, 2010. Transportation Research Board. National Research.

Heydari, M., 2012. A full Bayes approach to road safety: Hierarchical Poisson mixture models, variance function characterization, and prior specification. Citeseer.

HSM, 2009. AASHTO. Washington, DC, 529.

Hydén, C., 1987. The development of a method for traffic safety evaluation: The Swedish Traffic Conflicts Technique. Bulletin Lund Institute of Technology, Department, (70).

Institute, S.A.S., 2008. SAS/STAT 9.2 user's guide.

Jovanis, P.P. \& Chang, H.-L., 1986. Modeling the relationship of accidents to miles traveled. Transportation Research Record, 1068, pp.42-51.

Kononov, J. \& Allery, B., 2003. Level of service of safety: Conceptual blueprint and analytical framework. Transportation Research Record: Journal of the Transportation Research Board, (1840), pp.57-66.

Lord, D. \& Park, P.Y.-J., 2008. Investigating the effects of the fixed and varying dispersion parameters of Poisson-gamma models on empirical Bayes estimates. Accident Analysis \& Prevention, 40(4), pp.1441-1457.

Lorion, A., 2014. Investigation of Surrogate Measures for Safety Assessment of two-way stop controlled intersections. M. Sc. thesis, Ryerson University. Available from http:/digital. library. ryerson. ca/islandora/object/RULA\% 3A2678.

Lyon, C. et al, 2013. Safety Performance Functions for Freeway Merge Zones, Available at: http://www.coloradodot.in...3/spf.pdf/at_download/file.

Lyon, C. et al., 2005. Safety performance functions for signalized intersections in large urban areas: Development and application to evaluation of left-turn priority treatment. Transportation Research Record: Journal of the Transportation Research Board, (1908), 
pp.165-171.

Miaou, S.-P. \& Lum, H., 1993. Modeling vehicle accidents and highway geometric design relationships. Accident Analysis \& Prevention, 25(6), pp.689-709.

Mitra, S. \& Washington, S., 2007. On the nature of over-dispersion in motor vehicle crash prediction models. Accident Analysis \& Prevention, 39(3), pp.459-468.

Moon, J.-P. \& Hummer, J.E., 2009. Development of safety prediction models for influence areas of ramps in freeways. Journal of Transportation Safety \& Security, 1(1), pp.1-17.

Oh, J. et al., 2003. Validation of FHWA crash models for rural intersections: Lessons learned. Transportation Research Record: Journal of the Transportation Research Board, (1840), pp.41-49.

Perkins, S.R. \& Harris, J.I., 1967. Criteria for Traffic Conflict Characteristics, Signalized Intersections, Research Laboratories, General Motors Corporation.

Persaud, B. et al., 2012. Safety Performance Functions for Estimating the Safety Benefits of Proposed or Implemented Countermeasures. Draft Report for Transport Canada under Canada" s National Road Safety Research and Outreach Program.

Persaud, B. \& Lyon, C., 2007. Empirical Bayes before--after safety studies: lessons learned from two decades of experience and future directions. Accident Analysis \& Prevention, 39(3), pp.546-555.

Persaud, B., Lyon, C. \& Nguyen, T., 1999. Empirical Bayes procedure for ranking sites for safety investigation by potential for safety improvement. Transportation Research Record: Journal of the Transportation Research Board, (1665), pp.7-12.

Persaud, B.N., 2001. Statistical methods in highway safety analysis, Available at: http:/onlinepubs.trb.org/onlinepubs/nchrp/nchrp_syn_295.pdf.

PTV, A.G., 2011. VISSIM 5.40 user manual. Karlsruhe, Germany.

Pu, L. \& Joshi, R., 2008. Surrogate safety assessment model (SSAM): software user manual, Available at: http//www.fhwa.dot.gov/publications/research/safety/08050/index.cfm.

Saleem, T., 2012. Evaluation of the Predictive Capabilities of Simulated Peak Hour conflict Based Crash Prediction Models. Evaluation, 1, pp.1-2012.

Sarhan, M., Hassan, Y. \& Abd El Halim, A.O., 2008. Safety performance of freeway sections and relation to length of speed-change lanes. Canadian Journal of Civil Engineering, 35(5), pp.531-541.

Svensson, Å., 1998. A method for analysing the traffic process in a safety perspective. Lund University.

Tarko, A. et al, 2009. Surrogate measures of safety. White paper, ANB20 (3) Subcommittee on Surrogate Measures of Safety.

Team, R.C., 2014. R: A language and environment for statistical computing. R Foundation for Statistical Computing, Vienna, Austria. 2013.

Vodden, K., 2007. Analysis and estimation of the social cost of motor vehicle collisions in Ontario: final report, Transport Canada. 
Zhao, J., 2009. A Study on the Safety of Left-Side Off-Ramps on Freeways. 